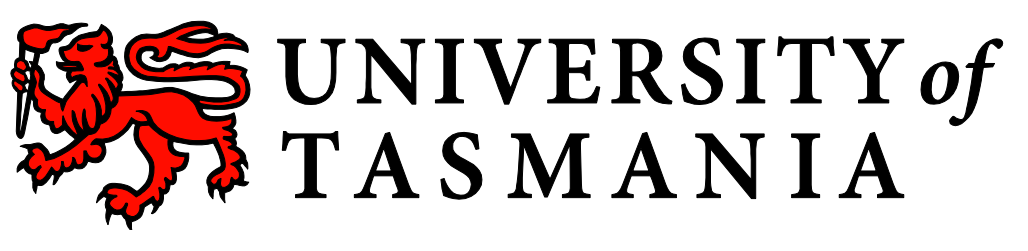

\title{
Linguistic Complexity in English Textbooks: A Functional Grammar Perspective
}

by

Vinh Thi To, B.A, M.A, GradCert Research

Submitted in fulfilment of the requirements for the degree of

Doctor of Philosophy

Faculty of Education

University of Tasmania

May 2015 


\section{Declaration of originality}

I, Vinh Thi To, am the author of the thesis titled Linguistic complexity in English textbooks: A functional grammar perspective, submitted for the degree of Doctor of Philosophy. I declare that the material is original, and to the best of my knowledge and belief, contains no material previously published or written by another person, except where due acknowledgement is made in the text of the thesis, nor does the thesis contain any material that infringes copyright. The thesis contains no material which has been accepted for a degree or diploma by the University or any other institution. 


\section{Statement of authority of access}

I, Vinh Thi To, author of the thesis title Linguistic complexity in English textbooks: A

functional grammar perspective, submitted for the degree of Doctor of Philosophy, agree that this thesis may be made available for loan and limited copying and communication in accordance with the Copyright Act 1968.

Vinh Thi To

Date: $22^{\text {nd }}$ May 2015 


\section{Abstract}

Linguistic complexity is an important concept in language and literacy education. Despite its significant contributions to the understanding of language sciences, there are no general measures towards it, as different linguistic theories lead to different perspectives on the linguistic complexity. Systemic Functional Linguistics $(\mathrm{SFL})$ is a theory of language that views language as a social semiotic and a meaningmaking resource. In other words, it looks at how people use language to construe and create meaning to fulfil their communicative purposes in social contexts. Despite the complexity of language in social contexts, SFL provides powerful principles to understand and manage complexity.

Adopting SFL as the main theoretical and methodological framework, this study investigated linguistic complexity in English textbooks used in teaching English as a foreign language (TEFL) with special reference to the Vietnamese context. The purpose of this study was to examine how the level of linguistic complexity shifted across four textbook levels and within science and non-science fields in a book series. The study also examined the relationships among linguistic features characterising complexity as well as how complexity differed according to stages of text types. The study applied Halliday's linguistic features, namely lexical density, grammatical intricacy, nominalisation, grammatical metaphor, and thematic structure to analyse 24 reading extracts in the selected textbooks on a quantitative analysis basis. Genre analysis of complexity regarding hierarchies of periodicity was conducted with four full texts.

Results of the quantitative data analysis show that overall the language of textbook texts became more complex when the levels advanced in the chosen book series. Specifically, at a higher level of textbook, a greater number of nominalisations and grammatical metaphors were employed, contributing to lexically dense written texts. However, the highest level of textbook did not display the topmost complexity among the four levels. Concerning grammatical intricacy, on average, 
texts at higher levels were slightly more intricate. Also, various theme types were used in the selected texts across levels. In addition, the differences between descriptive statistics of linguistic features employed in the science-related texts and those in the non-science ones were not significant within the same book.

With regard to the complexity according to genre analysis, the analysis of four full texts reveals that both explanatory texts demonstrated higher scores of lexical density, nominalisation, grammatical metaphor, and lower intricacy in the explanation stages in comparison with the phenomenon stages. Two information reports displayed higher density values in the description stages, but lower intricacy compared with the general statement stages. Frequencies of nominalisation and grammatical metaphor were slightly higher in the description stage than in the general statement stage in the elementary text, but the figures were lower in the description stage in the intermediate text. Additionally, grammatical metaphors, which construct the textual prominence, were employed most in New in the four chosen texts.

These findings not only give more insights into the nature of language, but also provide useful implications for English language teaching and learning, teacher education and training, textbook choice and writing, as well as curriculum design. 


\section{Acknowledgements}

This thesis has been completed thanks to the wisdom, contributions and support of a number of people for whom I am dearly indebted and would like to express my profound gratitude.

First and foremost, I would like to extend my deepest appreciation to my supervision team including Dr Thao Lê, Dr Si Fan and Dr Quynh Lê for their full commitment and support on my study. Their intellectual mentoring and insightful feedback have immensely enlightened me and broadened my views in many different ways. In their tight schedule, my supervisors still managed to offer much time to teaching me about linguistics, a number of necessary skills in doing research, and giving me timely feedback on thesis chapters. In addition to enormous academic support, Dr Thao Lê's academic expertise, enthusiasm and dedication in supervising and teaching have inspired me over years and left a significant impact on me. I am impressed by Dr Si Fan's expertise and friendly manner. Her kind words of encouragement have motivated me during the research journey. In addition to wise intellectual guidance, Dr Quynh Lê's warm care for our family when we first settled in our new lives and during our time here has brightened our lives in Australia.

I would like to express my heartfelt gratitude to other scholars and experts in SFL who are willing to give me further advice when needed. Their constructive comments and academic advice have helped me gain more useful insights into the research.

My great appreciation goes to the University of Tasmania (UTas) and the Faculty of Education for their financial support, the academic and administrative staff at UTas for their swift responses to my enquiries, the library staff for their quick service and the IT support with problems with my machines. 
I would like to send a big thank you to my research fellows at UTas, the Vietnamese community in Launceston, my friends and colleagues in Vietnam for the memorable moments on chatting, gathering, and for their huge mental and spiritual support.

To my extended family, I cannot thank them enough for their unceasing support, persistent love and belief in me. I owe my profound gratitude to my parents-in-law for looking after my little son in Vietnam in my first year of candidature.

To my beloved husband, Nguyen Thanh Vinh, I warmly thank you for your hard work in providing massive support to our family life. I am grateful for your love, company, empathy, and sharing on our journey. To my little daughter and son, Nguyen To $\mathrm{Ha}$ Binh and Nguyen To Thanh Trung, the past three years have seen you growing up together with the thesis. I am happy to see you enjoying schooling, and I also owe you both for the lack of care and time to play with during my busy study time. 


\section{Table of Contents}

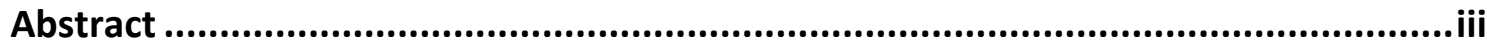

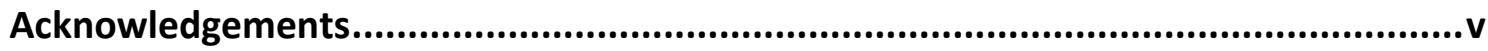

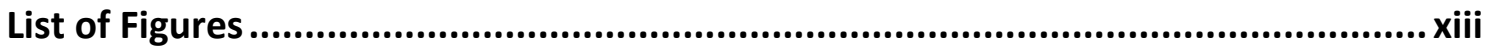

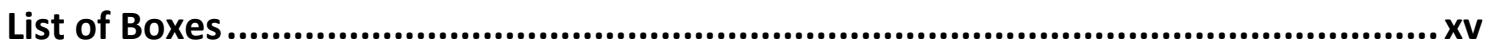

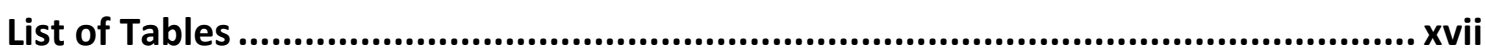

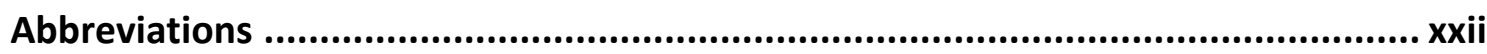

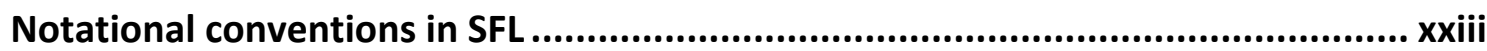

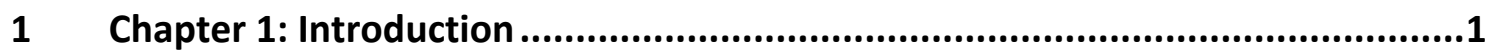

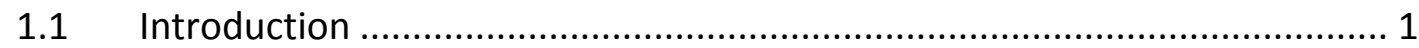

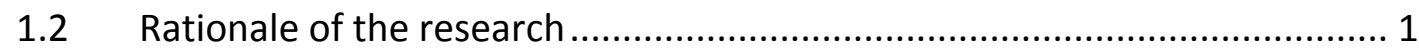

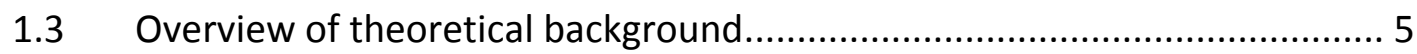

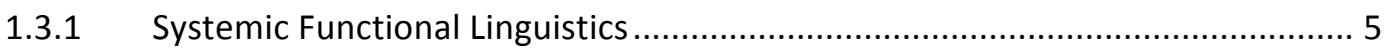

1.3.2 Systemic Functional Linguistics and linguistic complexity ................................. 6

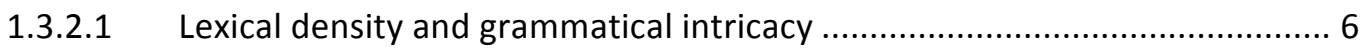

1.3.2.2 Nominalisation and grammatical metaphor ............................................ 7

1.3.2.3 Thematic structure and hierarchies of periodicity..................................... 8

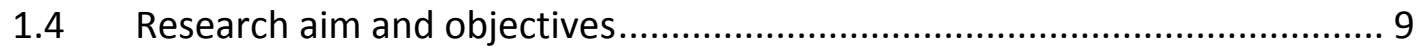

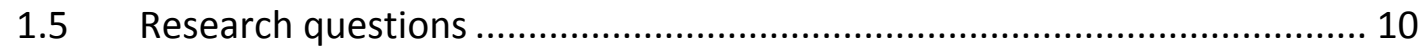

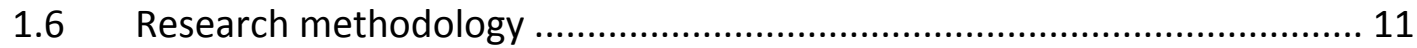

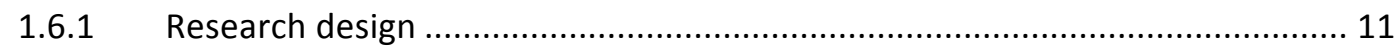

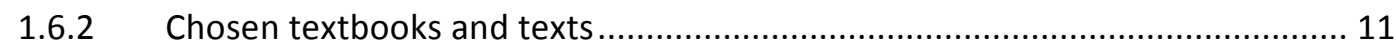

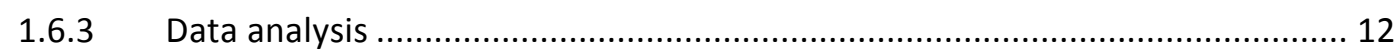

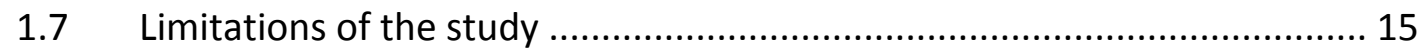

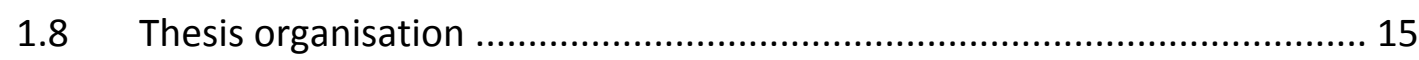

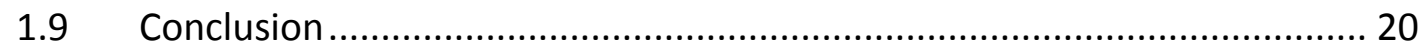




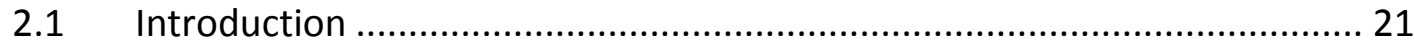

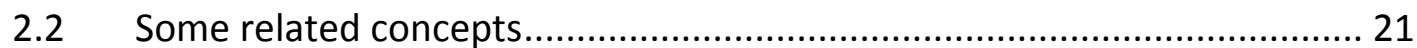

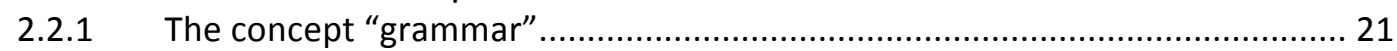

2.2.2 The concept "linguistic complexity" ........................................................... 23

2.3 Linguistic complexity from different perspectives ..................................... 25

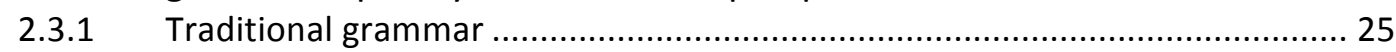

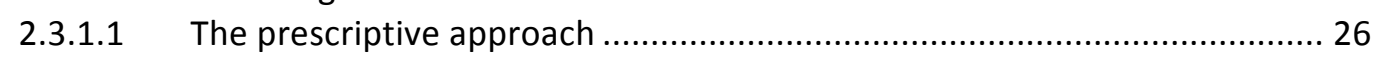

2.3.1.2 Traditional categories ........................................................................ 26

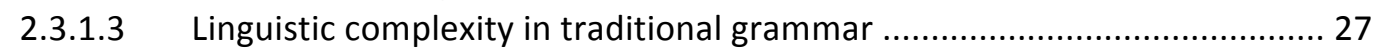

2.3.2 Transformational-generative grammar ...................................................... 30

2.3.2.1 Early development: finite state grammar and phrase structure

2.3.2.2 Later developments and linguistic complexity in deep structure................ 34

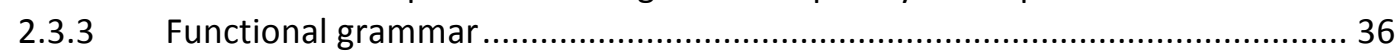

2.3.3.1 Functional grammar versus formal grammar ............................................. 37

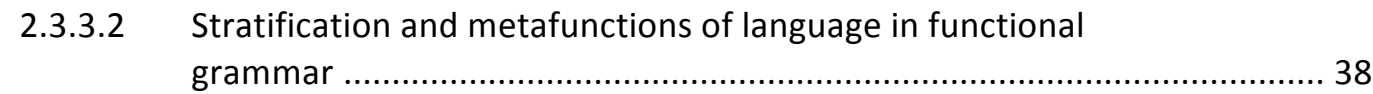

2.3.3.3 Context of situation and context of culture ............................................ 41

2.3.3.4 Linguistic complexity in Halliday's functional grammar.............................. 42

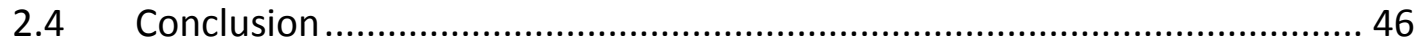

3 Chapter 3: A Hallidayan Approach on Linguistic Complexity ........................47

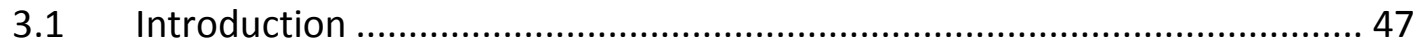

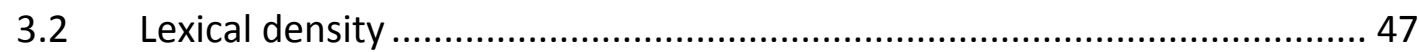

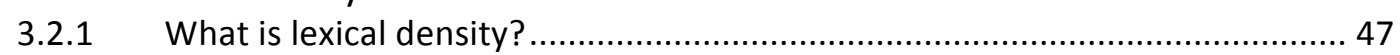

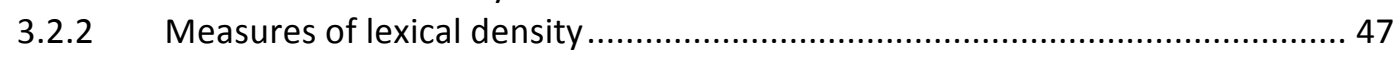

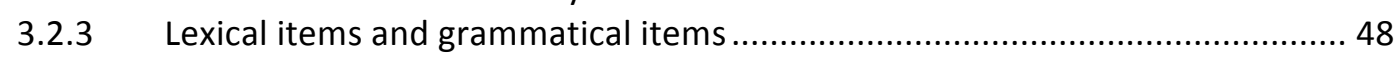

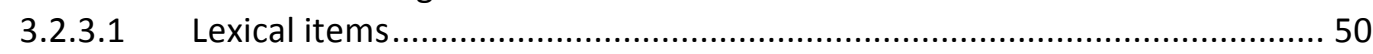

3.2.3.2 Grammatical items................................................................ 50

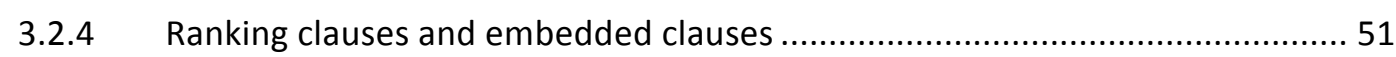

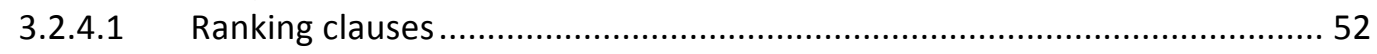

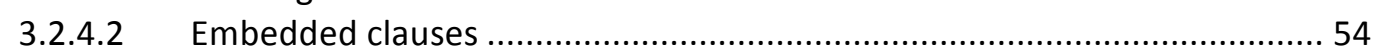

3.2.5 Lexical density in written and spoken language .......................................... 58

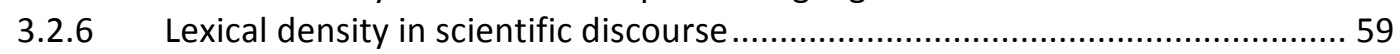

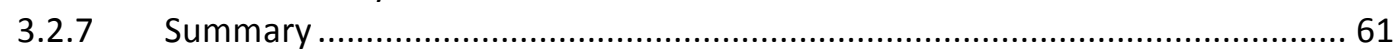

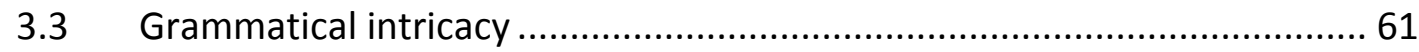

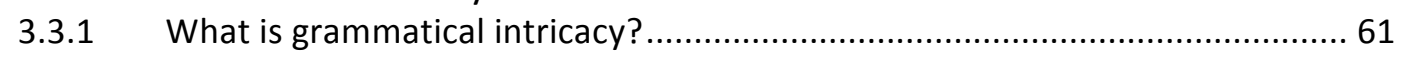

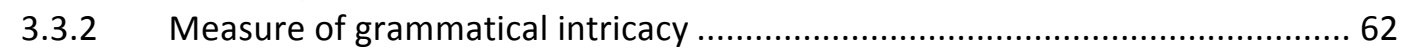

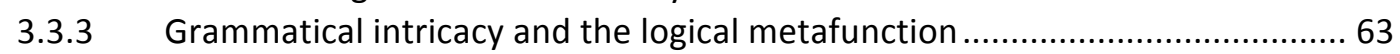

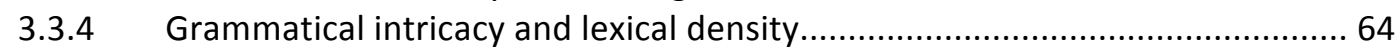

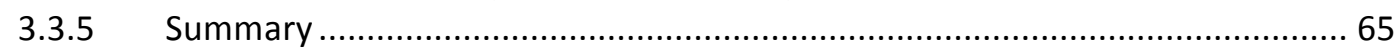

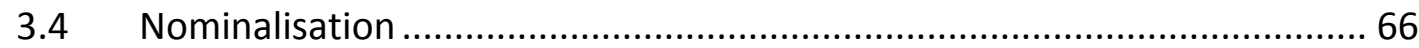

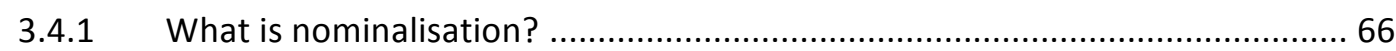

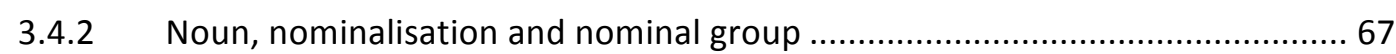




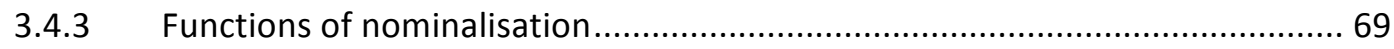

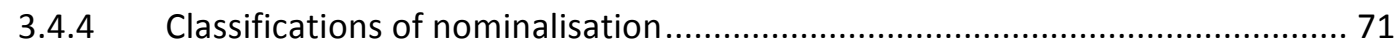

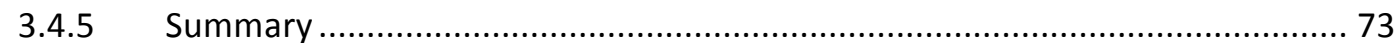

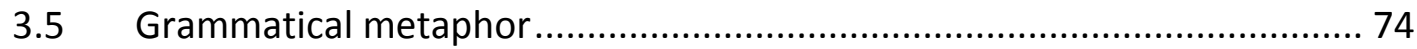

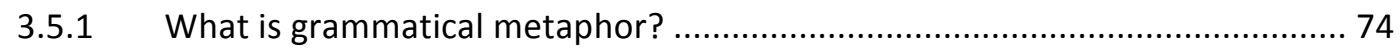

3.5.2 Grammatical metaphor versus traditional metaphor .................................... 75

3.5.3 Ideational metaphor (metaphor of transitivity)................................................ 77

3.5.4 Interpersonal metaphor (metaphor of mood and metaphor of

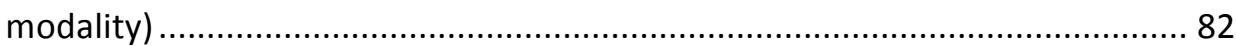

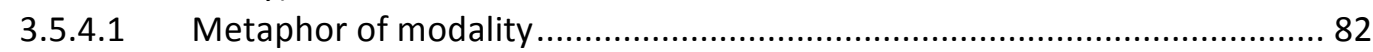

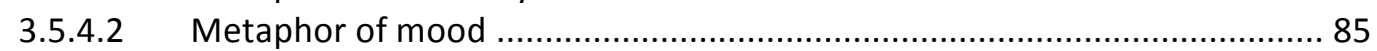

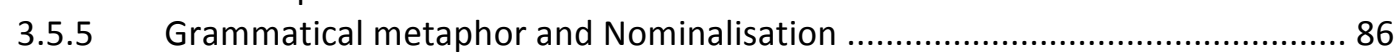

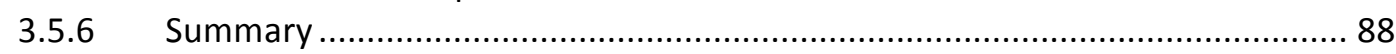

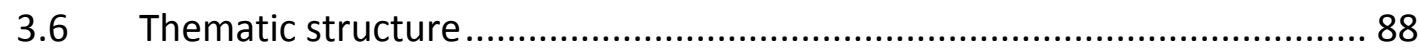

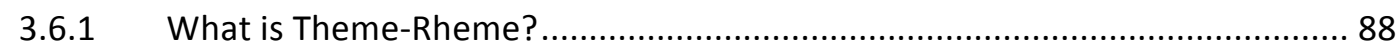

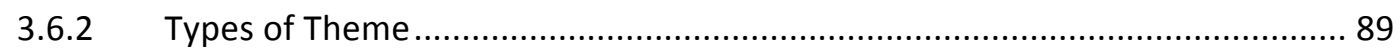

3.6.2.1 Simple Themes (topical Theme or experiential Theme) ............................ 89

3.6.2.2 Multiple Themes (textual and interpersonal Themes) ............................... 91

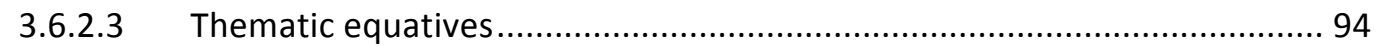

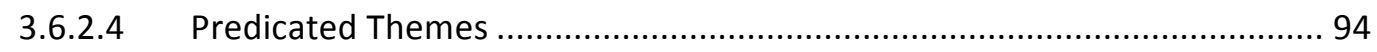

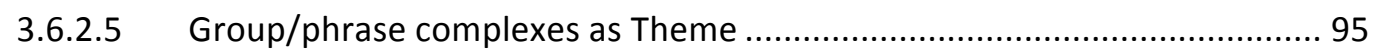

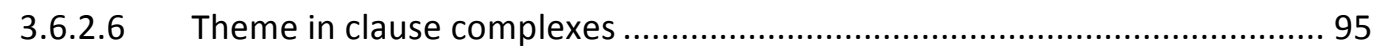

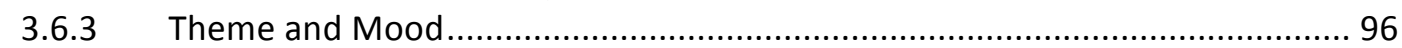

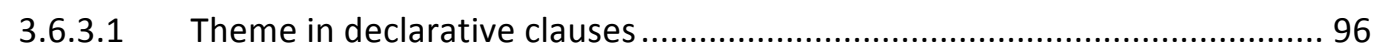

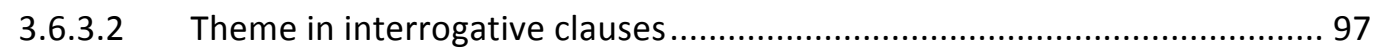

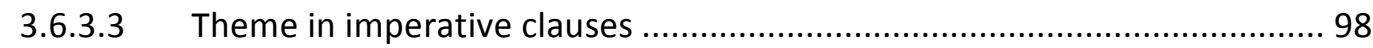

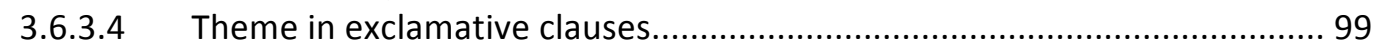

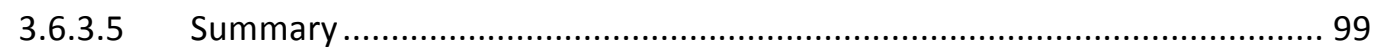

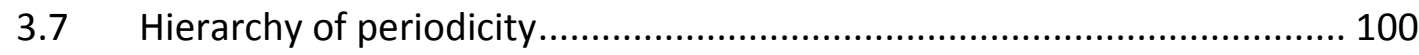

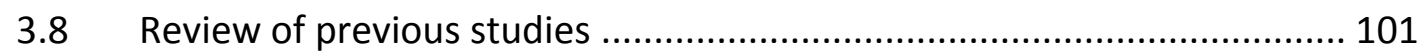

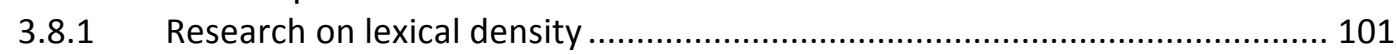

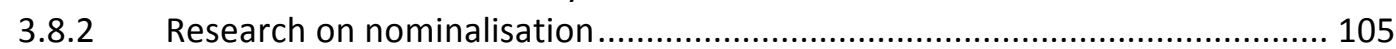

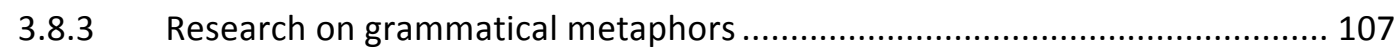

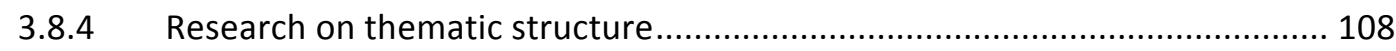

3.8.5 Research on functional grammar in Vietnam ............................................. 109

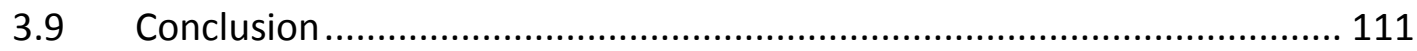

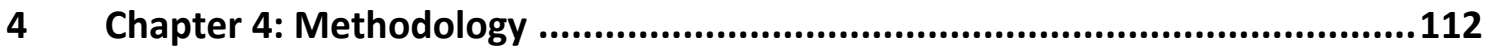

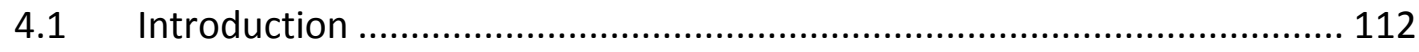

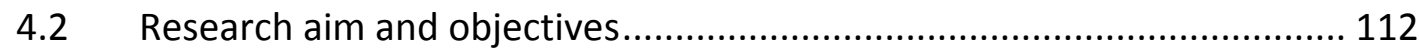

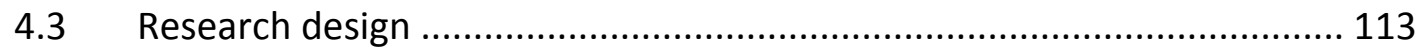

4.4 Description of the chosen textbooks and texts...................................... 116

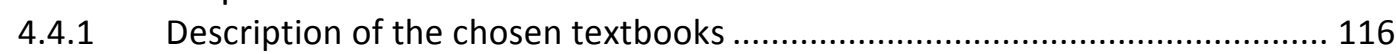

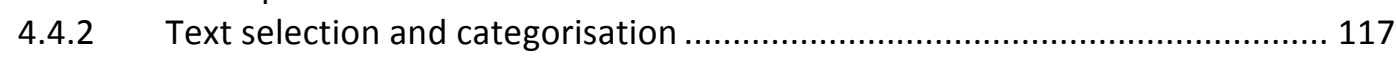

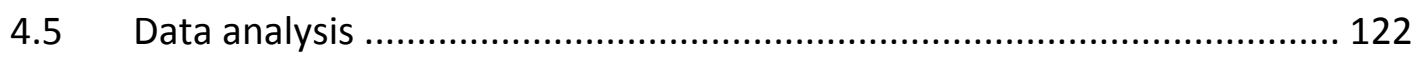




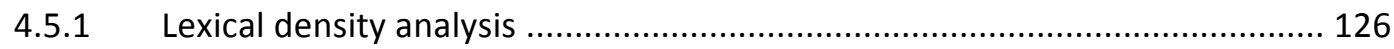

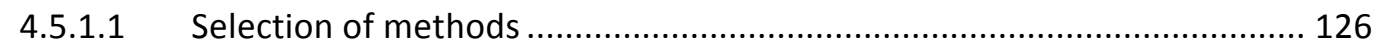

4.5.1.2 Lexical density analysis: Manual or computational? ............................... 127

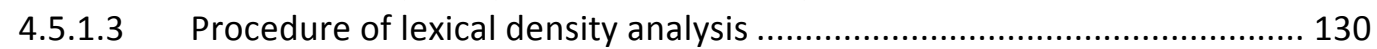

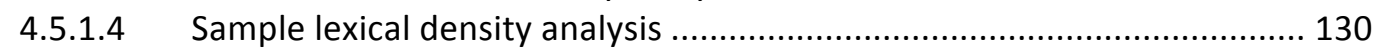

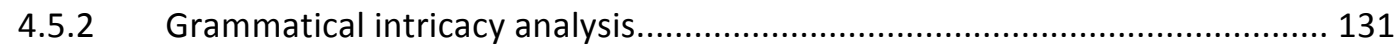

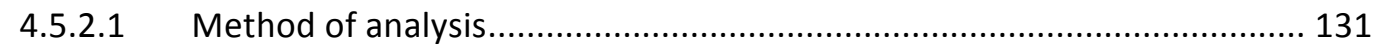

4.5.2.2 Procedure of grammatical intricacy analysis ....................................... 132

4.5.2.3 Sample grammatical intricacy analysis ................................................ 132

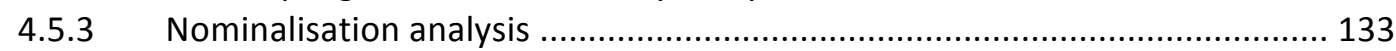

4.5.3.1 Classification of nominalisation and procedure for analysis .................... 133

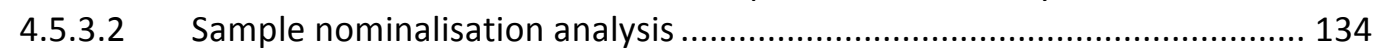

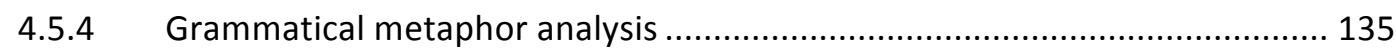

4.5.4.1 Types of grammatical metaphor investigated in this study...................... 135

4.5.4.2 Grammatical metaphor, transcategorisation and nominalisation.............. 136

4.5.4.3 Sample grammatical metaphor and nominalisation analysis ................... 137

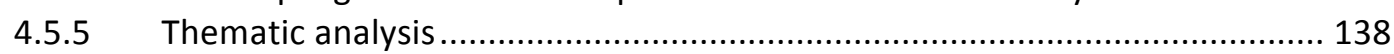

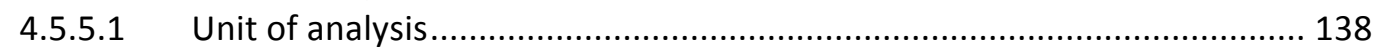

4.5.5.2 Procedure of theme analysis ........................................................... 140

4.5.5.3 Sample theme analysis ...................................................................... 140

4.6 Reliability and validity of the study .................................................. 141

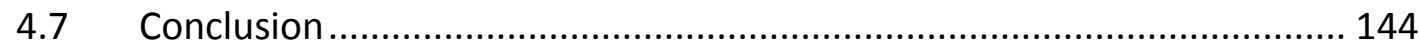

$5 \quad$ Chapter 5: Analysis of Linguistic Complexity across Levels ..........................145

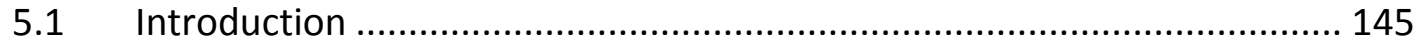

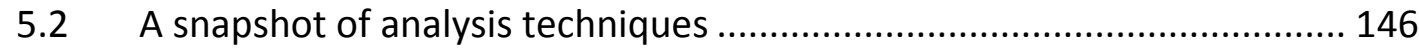

5.3 Linguistic features analysis across four levels of textbooks..................... 147

5.3.1 Lexical density in Ure's method across textbook levels................................... 147

5.3.2 Lexical density in Halliday's method across textbook levels........................... 150

5.3.3 Grammatical intricacy across textbook levels.............................................. 152

5.3.4 Nominalisation across textbook levels......................................................... 154

5.3.5 Grammatical metaphor across textbook levels ............................................ 156

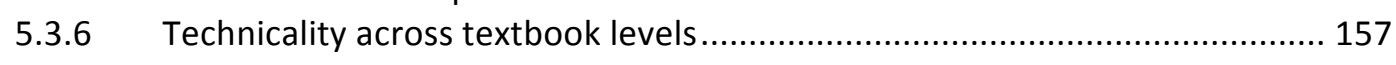

5.3.7 Thematic structure across textbook levels ................................................ 158

$5.4 \quad$ Linguistic features in scientific and non-scientific texts.......................... 159

5.4.1 Ure's lexical density in scientific and non-scientific texts .............................. 159

5.4.2 Halliday's lexical density in scientific and non-scientific texts ....................... 161

5.4.3 Grammatical intricacy in scientific and non-scientific texts........................... 162

5.4.4 Nominalisation in scientific and non-scientific texts.................................... 163

5.4.5 Grammatical metaphor in scientific and non-scientific texts ....................... 164

5.4.6 Thematic analysis in scientific and non-scientific texts ................................ 165

5.5 Correlations among linguistic features ................................................ 167

5.5.1 Grammatical metaphor and Halliday's lexical density .................................. 167

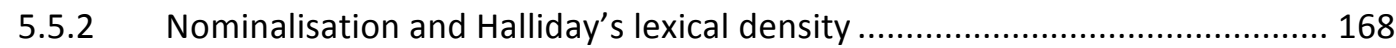

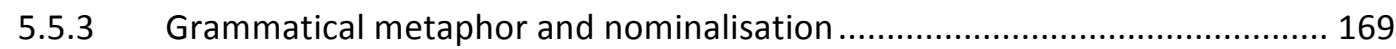

5.5.4 Grammatical intricacy and Halliday's lexical density ..................................... 170

5.5.5 Halliday's lexical density and Ure's lexical density......................................... 171 
6.1 Introduction 173

6.2 Choosing texts for the illustration ........................................................... 174

6.3 General explanation of the analysis....................................................... 174

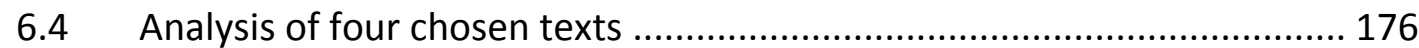

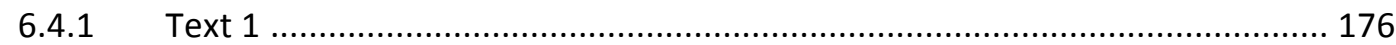

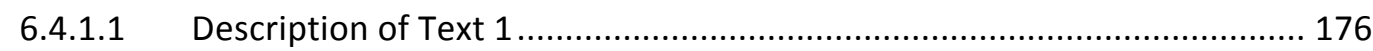

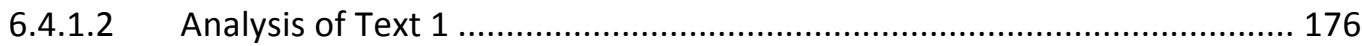

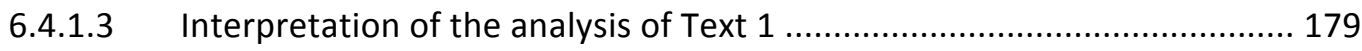

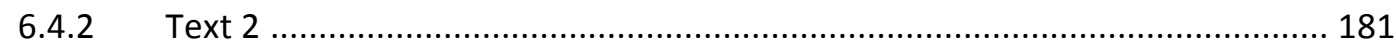

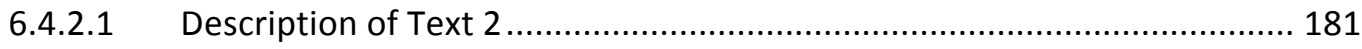

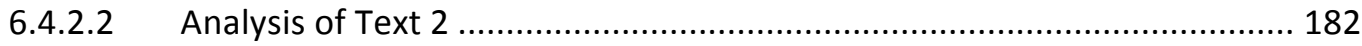

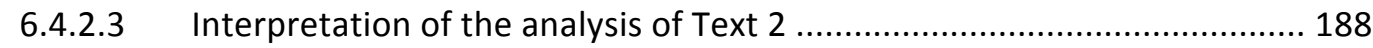

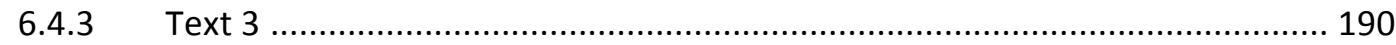

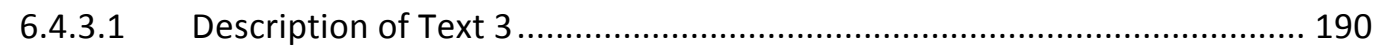

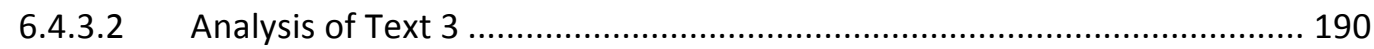

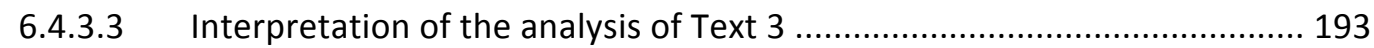

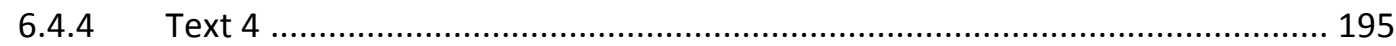

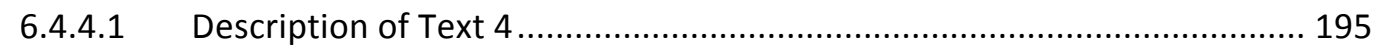

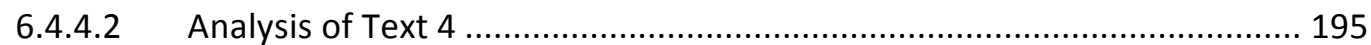

6.4.4.3 Interpretation of the analysis of Text 4 ............................................... 202

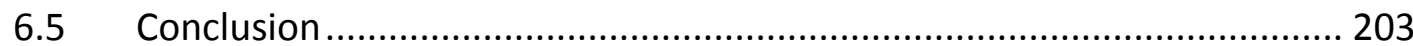

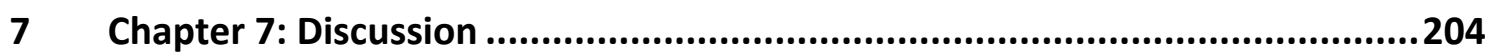

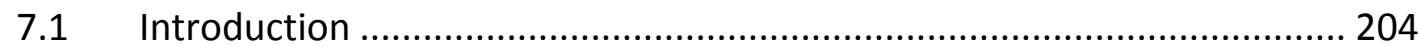

7.2 Linguistic complexity of texts across textbook levels.............................. 204

7.3 Linguistic complexity of science-related and non-science texts ............... 218

7.4 Correlations among linguistic features charactering complexity.............. 223

7.5 Linguistic features in the whole text levels ........................................... 224

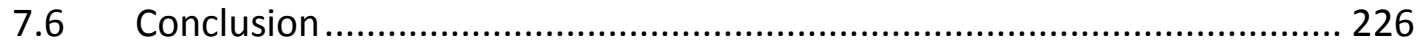

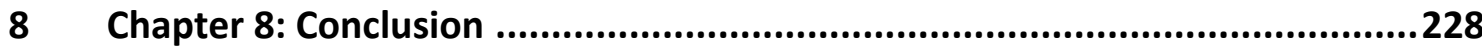

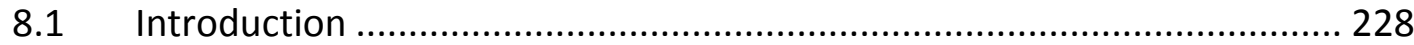

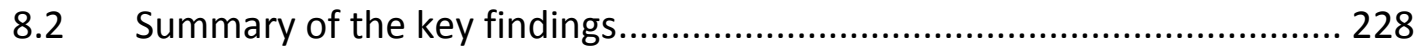

8.2.1 Linguistic complexity of texts across textbook levels .................................... 228

8.2.2 Linguistic complexity of science-related and non-science texts ..................... 229

8.2.3 Correlations among linguistic features charactering complexity.................... 230

8.2.4 Linguistic complexity according to genre analysis and hierarchies of 


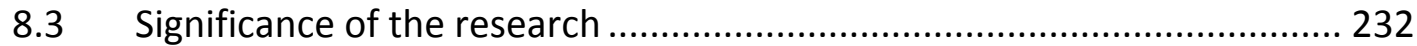

8.3.1 Theoretical significance in the area of linguistic complexity ......................... 232

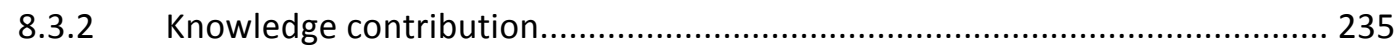

8.3.3 Educational significance in the context of Vietnam .................................... 236

8.3.3.1 Significance of the research to TEFL in the Vietnamese context ............... 237

8.3.3.2 Significance of the research to teacher training in Vietnam...................... 240

8.3.3.3 Significance of the research to textbook selection and writing in

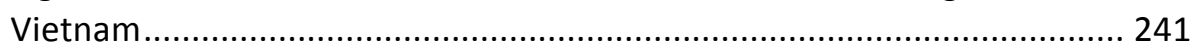

8.3.3.4 Significance of the research to English curriculum design in

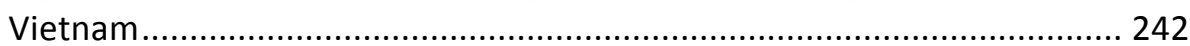

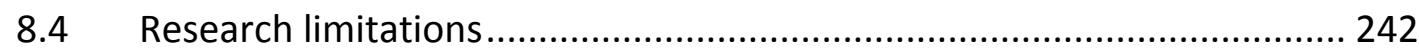

$8.5 \quad$ Recommendations for further studies .............................................. 243

8.6 Researcher's reflection on research achievements ............................... 245

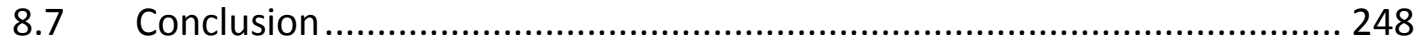

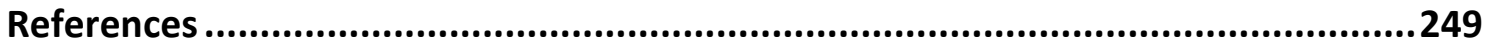

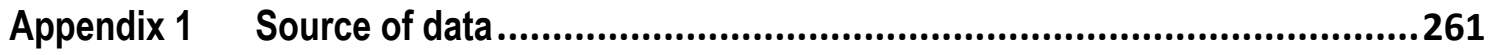

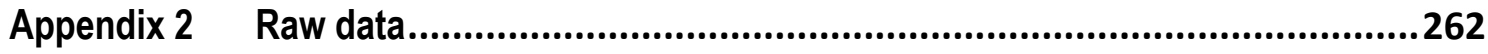

Appendix $3 \quad$ Instances and percentage of theme...............................................263

Appendix 4 One-way ANOVA test on linguistic complexity across levels ..................264

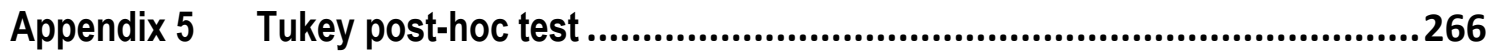

Appendix 6 One-way ANOVA test on linguistic complexity in science-related and non-science texts

Appendix $7 \quad$ Pearson correlations test .............................................................271

Appendix 8 Components of a multiple Theme...................................................2272

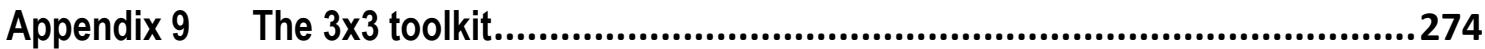




\section{List of Figures}

Figure 2.1. Phrase structure presented by phrase marker

Figure 2.2. Tree diagram .34

Figure 2.3. Stratification of language (Halliday and Matthiessen, 2014, p.26) .40

Figure 2.4. Dimension of the SFL language model (Rose, 2006, p.74) .40

Figure 2.5. Parameters of context of situation and text in context (Butt et al., 2000, p.12)

Figure 3.1. Types of relationship between clauses in the clause complex (Adapted from Halliday \& Matthiessen, 2004, p. 373) .64

Figure 3.2. Types of nouns in English (Thomson \& Droga, 2012, p. 14) 67

Figure 3.3. Two perspectives on metaphor (Adapted from Halliday, 1994, p. 342) 75

Figure 3.4. Layers of Themes and News in discourse (Martin \& Rose, 2003, p.186). 101

Figure 4.1. Maps of genre in school (adapted from Rose \& Martin, 2012, p.128). 120

Figure 4.2. Research design of the study 124

Figure 4.3. Theoretical concept maps of the study. 125

Figure 4.4. Thematic structure investigated in this study (Halliday, 1985a, 1994). 
Figure 7.1. Three dimensional model of language variation (Mahboob, 2014, p.5) .220 


\section{List of Boxes}

Box 4.1. Sample analysis of lexical density

Box 7.1. Illustration of lexical density in an elementary text

Box 7.2. Illustration of lexical density in an upper-intermediate text 208

Box 7.3. Illustration of grammatical intricacy in an elementary text 209

Box 7.4. Illustration of grammatical intricacy in an upper-intermediate text 209

Box 7.5. Illustration of the unemployment of nominalisation in an elementary text 210

Box 7.6. Illustration of nominalisation in an intermediate text 210

Box 7.7. Illustration of grammatical metaphor in an elementary text. 211

Box 7.8. Illustration of grammatical metaphor in an intermediate text. 212

Box 7.9. Illustration of technicality in an elementary text 213

Box 7.10. Illustration of technicality in an intermediate text 213

Box 7.11. Types of theme in an elementary text 215

Box 7.12. Types of theme in a pre-elementary text 215

Box 7.13. Types of theme in an intermediate text 216

Box 7.14. Types of theme in an upper-intermediate text. 216 
Box 7.15. Examples of science-related texts employing global everyday language

Box 7.16. Scientific text at the intermediate level

222

Box 7.17. Non-scientific text at the intermediate level

.222 


\section{List of Tables}

Table 2.1. Markedness status of clause-types ( Givón, 1995, p. 33)

Table 2.2. Five orientations in functional grammar and formal grammar .38

Table 3.1. Characteristics of content words and function words (Haspelmath, 2001, p. 16540)

Table 3.2. Lexical density and grammatical intricacy in spoken and written language (Eggins, 1994, p. 61)

Table 3.3. Analysis of nominalisation group .68

Table 3.4. Classification of nominalisations investigated in the study .72

Table 3.5. Nominal endings for verbs, adjectives and nouns (Cited in Ravelli, 1999, p. 64) .73

Table 3.6. Two perspectives on metaphorical variation (Taverniers, 2003, $p$.

8) .76

Table 3.7. Analysis of metaphor of transitivity .77

Table 3.8. Analysis of metaphorical form. .79

Table 3.9. Analysis of non-metaphorical form .79

Table 3.10. Two analyses combined (Halliday, 1994, p.346). .79

Table 3.11. Process types in English .80

Table 3.12. Process types and nuclear participants .80 
Table 3.13. Process types, their meanings and typical verbs .81

Table 3.14. Modality types and modal items .84

Table 3.15. Distinction between Theme and Rheme (Martin, Matthiessen \& Painter, 1997, p.22) .89

Table 3.16. Examples of Theme choice (Adapted from Thompson, 1996, pp.118-119) 89

Table 3.17. Unmarked Theme and marked Theme in declarative clauses .91

Table 3.18. Analysis of multiple Themes .94

Table 3.19. Mood type and unmarked Theme selection (Halliday \& Mathiessen, 2014, p.104)

Table 4.1. Texts in science and non-science domains 119

Table 4.2. Genre in science and non-science domains 119

Table 4.3. Total number, codes, genre and domain of texts chosen for the analysis

Table 4.4. Sample analysis of grammatical metaphor and nominalisation 138

Table 4.5. Sample analysis of thematic structure 141

Table 5.1. Descriptive statistics on lexical density measured by Ure's method across levels

Table 5.2. Comparisons of lexical density measured by Ure's method between levels 150

Table 5.3. Descriptive statistics on lexical density measured by Halliday's method across levels 
Table 5.4. Comparisons of lexical density measured by Halliday's method between levels

Table 5.5. Tukey HSD test on multiple comparisons of Halliday's lexical density

Table 5.6. Descriptive statistics on grammatical intricacy across levels 153

Table 5.7. Comparisons of grammatical intricacy between levels 154

Table 5.8. Descriptive statistics on nominalisation across levels 154

Table 5.9. Comparisons of nominalisation between levels 155

Table 5.10. Tukey HSD test on multiple comparisons of nominalisation between levels 156

Table 5.11. Descriptive statistics on grammatical metaphor across levels 157

Table 5.12. Comparisons of grammatical metaphor between levels 157

Table 5.13. Technicality in scientific texts across levels 158

Table 5.14. Percentage of theme types across textbook levels ( $n=6$ per book) 158

Table 5.15. Descriptive statistics on Ure's lexical density in scientific and nonscientific texts 160

Table 5.16. Comparisons of ULD between scientific and non-scientific texts 160

Table 5.17. Descriptive statistics on lexical density measured by Halliday's method in scientific and non-scientific texts 161

Table 5.18. Comparisons of HLD between scientific and non-scientific texts 161

Table 5.19. Descriptive statistics on grammatical intricacy measured in scientific and non-scientific texts 
Table 5.20. Comparisons of grammatical intricacy between scientific and non-scientific texts

Table 5.21. Descriptive statistics on nominalisation in scientific and nonscientific texts

Table 5.22. Comparison of nominalisation scores in scientific and nonscientific texts

Table 5.23. Descriptive statistics on grammatical metaphor in scientific and non-scientific texts 164

Table 5.24. Comparison of grammatical metaphor in scientific and nonscientific texts 165

Table 5.25. Theme in scientific and non-scientific texts 166

Table 5.26. Pearson correlations among linguistic features 167

Table 6.1. Numbers of texts chosen for periodicity analysis 174

Table 6.2. Linguistic complexity analysis of Text 1 176

Table 6.3. Theme and New analysis of Text 1 178

Table 6.4. Result of linguistic analysis according to stages of Text 1 181

Table 6.5. Linguistic complexity analysis of Text 2 182

Table 6.6. Theme and New analysis of Text 2 185

Table 6.7. Result of linguistic analysis according to stages of Text 2 190

Table 6.8. Linguistic complexity analysis of Text 3 190

Table 6.9. Analysis of Theme and New in Text 3 192 
Table 6.10. Result of linguistic analysis according to stages of Text 3

Table 6.11. Linguistic complexity analysis of Text 4 195

Table 6.12. Analysis of Theme and New of Text 4 198

Table 6.13. Result of linguistic analysis of Text 4 203

Table 7.1. Domains of language variation (Mahboob, 2014, p.5) 221 


\section{Abbreviations}

\begin{tabular}{ll} 
CL & Clause complex \\
EFL & English as a Foreign Language \\
ELT & English Language Teaching \\
ESOL & English for Speakers of Other Languages \\
L2Ls & Second Language Learners \\
LI & Lexical item \\
GI & Grammatical intricacy \\
GM & Grammatical metaphor \\
HLD & Halliday's lexical density \\
N & Nominalisation \\
SFL & Systemic Functional Linguistics \\
SLL & Second Language Learning \\
TEFL & Teaching of English as a Foreign Language \\
TESOL & Teaching of English to Speakers of Other Languages \\
ULD & Transformational-Generative Grammar \\
\hline
\end{tabular}




\section{Notational conventions in SFL}

\begin{tabular}{|c|c|}
\hline || & clause complex boundary \\
\hline || & ranking clause boundary \\
\hline [[ ] ] & embedded clause boundary \\
\hline$\alpha, \beta, \gamma \ldots$ & hypotactic structure \\
\hline $1,2,3 \ldots$ & paratactic structure \\
\hline$=$ & expansion: elaboration \\
\hline+ & expansion: extension \\
\hline$x$ & expansion: enhancement \\
\hline & projection: locution \\
\hline & projection: idea \\
\hline
\end{tabular}




\section{Chapter 1:Introduction}

\subsection{Introduction}

This introductory chapter initially states the rationale of the research which is followed by the purpose and research questions examined in the study. A brief overview of the theoretical background regarding the SFL theory and how complexity is measured from this theory's point of view is introduced. Research methodology in terms of research design, texts selection and analysis is then presented. Limitations of the research are also discussed. The chapter ends with an overview of the thesis organisation and the conclusion of the chapter.

\subsection{Rationale of the research}

"Complexity is itself a complex notion, and complexity in language is particularly so" (Halliday, 2008). In fact, although complexity is an important concept in the language sciences, its accurate notion and general measures have long been a matter of debate (see Dahl, 2004; Dahl, 2008; Dahl, 2009; Juola, 2008; Kusters, 2008; Miestamo, 2008; Miestamo, 2009; Nichols, 2009). As Halliday (2008) mentions there are a variety of factors contributing to the complexity of text, and obviously, linguistic complexity can be seen in the number of words in written sentences, the number of verbs in passive voice or sentence length. Linguistic complexity can also be measured by the markedness status of clause types (Givón, 1995); for instance, subordination and negation are considered structurally more complex than coordination and affirmation respectively (Givón, 1995). Linguistic complexity can also be seen in recursive rules of phase finite grammar and deep structure (Chomsky, 1957). As it can be seen, there are no unified and consistent measures of linguistic complexity as different theories of language result in different perspectives on complexity. Thus, from a linguistic point of view, it is argued in this study that complexity should be examined from the perspective of a particular linguistic theory (To, 2014a, 2014b). 
SFL is a linguistic theory that views language as a social semiotic and a meaningmaking resource (Halliday \& Matthiessen, 2004). This means it looks at how people use language to construe and create meaning to fulfil their communicative purposes in social contexts. It provides simple principles to understand and manage complexity. Investigating complexity from the SFL point of view helps understand complexity: (1) at three levels or strata of language including the level of wording (lexicogrammar), the level of meaning (discourse semantics) and the level of social context (register and genre); and (2) at its three social metafunctions known as the ideational, the interpersonal and the textual (Martin \& Rose, 2003). Borrowing these principles and well-established linguistic measures from SFL, this study aimed to explore the complexity of language in reading texts in EFL textbooks across four levels, which has still been under-investigated in second language learning (SLL). The focus of the research was to investigate six linguistic features which are considered interrelated in contributing to the complexity of language, specifically: lexical density (Halliday, 1985b; Halliday, 1993d, 2008), grammatical intricacy (Halliday, 1985b; Halliday, 2008), nominalisation (Banks, 2005; Halliday, 1993d, 1998, 2004; Halliday \& Martin, 1993; Halliday \& Matthiessen, 2004; Martin, 1993a, 1993d, 2008), grammatical metaphor (Banks, 2003; Derewianka, 2003; Halliday, 1985a; Halliday, 1993a, 1994; Halliday, 1995; Halliday, 1998, 2008; Halliday \& Martin, 1993; Halliday \& Matthiessen, 1999a; Halliday \& Matthiessen, 1999b; Halliday \& Matthiessen, 2004; Martin, 1992a, 1993a, 1993d, 2008; Ravelli, 1999), thematic structure (Halliday, 1985a; Halliday, 1994; Halliday \& Matthiessen, 2004) and hierarchies of periodicity (Martin, 1993a; Martin \& Rose, 2003). These concepts will be discussed in detail in Chapter 3.

The main motivation for the choice of investigating linguistic complexity of EFL textbooks is that while extensive research in light of SFL has been carried out to investigate the language of government-approved English textbooks in schools in Australia and worldwide; little attention has been paid to the language of international textbooks designed and chosen for teaching specific English skills in universities and language centres in developing countries. With the availability of various EFL textbooks in the book market, a question raised is that: what criteria do 
English language educators and teachers in the developing world based on to choose textbooks for their students and language teaching curriculum, and how appropriate they are? As textbooks are considered the backbone of education, they serve as the main teaching tool in the curriculum and effectively contribute to the improvement of educational quality as well as have vast impact on teaching and learning (Besser, Stone, \& Luan, 1999). Thus, choosing appropriate teaching materials for the curriculum is crucial to a language education program. However, choosing an appropriate textbook for a course in the diversified EFL textbook markets has become harder (Minoo \& Nikan, 2012). It is supposed that there are a number of factors that educators and teachers can rely on when choosing EFL textbooks to teach general English to second language learners (L2Ls) such as content orientation, pedagogical principles, text types and linguistic complexity. However, with reference to the context of TEFL in Vietnam, it seems that there are no unified and consistent criteria for education policy makers and educators to choose EFL textbooks for the language teaching curriculum in universities or language centres.

It is not uncommon to see that Vietnamese educators and teachers of English choose texts and textbooks for their students based on the book levels proposed by textbook writers. For instance, after students sit in a placement test, depending on the results, they will be placed in classes of different levels including elementary, low-intermediate, intermediate, and upper-intermediate. Then, educators will choose a series of book consisting of four equivalent levels proposed by the writer as the course textbooks. As a result, students who sit in the elementary class will study the textbook written for elementary level in general. Likewise, the students who sit in intermediate class will study the textbook written for overall intermediate students. One of the reasons for this practice is due to a general assumption that the textbook texts grow more complex when their levels advance; thus, educators assume that a textbook level proposed by the textbook writer will suit the level of English class which students are supposed to learn.

This is problematic as there is no guarantee that the chosen textbooks are appropriate, especially in the context that a number of universities and language 
centres in Vietnam are not internationally recognised and that evaluation of the effectiveness of the chosen EFL textbooks in the language education curriculum in Vietnam is still under-investigated. In addition, whether there is a gradual shift in the use of EFL textbook texts in a book series has not been statistically proved in literature. One may question that whether the texts in the upper-intermediate book can be used for learners who are placed in the intermediate class and vice versus? This research clarifies these questions by examining the language of reading texts in four books in a book series which are set for elementary, low-intermediate, intermediate and upper-intermediate levels.

Central to the study of complexity of text in this research is the investigation of reading extracts in relation to science-related topics and non-science ones across textbook levels in a book series. The choice of examining reading textbooks with a focus on textbook levels in this research was motivated by three main reasons. Firstly, as the heart of the research was to investigate the complexity of written language in EFL textbooks, reading passages were the best choice for data analysis to achieve the research aim. Secondly, the study focused on textbook levels as from the researchers' literature review, no previous research has been done to find out the relationship between linguistic complexity and textbook levels from Halliday's functional grammar perspective. Thirdly, Active Skills for Reading books were chosen for the analysis not only because as they are commonly used in teaching reading skills to L2Ls in universities and language centres in Vietnam, but they also consist of a variety of reading texts relating to science and non-science fields across four levels. The science field includes topics on space, astronomy, robotic surgeons, numerology, astrology, psychology, computer, etc. The non-science field consists of topics on education, culture, marriage, travelling, leisure activities, sport, etc. Therefore, investigating these textbooks will help achieve the purpose of the research in terms of the exploration of linguistic complexity in scientific and nonscientific texts in EFL textbooks.

In addition, while extensive research on complexity of written language in general and in scientific discourse in particular from the functional grammar perspective has been conducted by Halliday - the father of SFL theory (Halliday, 1985b; Halliday, 
1993a, 1993b, 1993c; Halliday, 1995; Halliday, 2004, 2008) and well-known functional and educational linguists (Banks, 2003, 2005; Martin, 1993a; Martin, 1993b; Martin, 1993d), how complexity is realised in international textbooks has not yet been examined in the literature of SLL up to now (see Benedikt \& Bernd, 2009, 2012; Dahl, 2008; Fred, 2009; Hendrikse \& Van Zweel, 2010; Juola, 2008; Kuiken \& Vedder, 2007; Miestamo, 2009; Ortega, 2003). Although there is a general assumption that textbooks grow more complex when their levels advance, no statistical study has been done to prove this. Besides, how scientific and nonscientific texts vary in EFL textbooks in terms of complexity has not yet been investigated in SLL. This raises a question on how to measure and evaluate complexity of the language of textbook to provide good implications for text and textbook design and use, and curriculum design in the area of TEFL in the developing world. This creates a strong and justified motivation for the present research to be conducted to fill this gap.

\subsection{Overview of theoretical background}

\subsubsection{Systemic Functional Linguistics}

As mentioned earlier, SFL views language as a linguistic resource used for making meaning in social contexts. In SFL, language is realised in four levels of abstraction known as four strata of language: phonetics and phonology, lexico-grammar, discourse semantic and context. Phonetics and phonology which belong to the expression plane are the most basic linguistic resources for making meaning. Lexicogrammar and discourse semantics belong to the content plane. At the lexicogrammar stratum, meaning is realised by means of wording through three levels of rank: word, group and clause (Halliday \& Matthiessen, 2004). At the discourse semantic stratum, meanings are realised within and beyond clause (Martin \& Rose, 2003). Three meanings known as three metafunctions of language at the discourse semantic level are the ideational meaning, the interpersonal meaning and the textual meaning. The ideational meaning represents human experience about the world, including the experiential meaning and logical meaning. The experiential meaning is grammatically realised by the transitivity systems, and the logical 
meaning realised by the logico-semantic types. The second metafunction, the interpersonal meaning, enacts the interactions between the writer/speaker and the reader/ listener, realised by Mood, Modality and evaluative language. Finally, the textual meaning is concerned with the text organisation realised by thematic and information structure (Halliday \& Matthiessen, 2004) and the text periodicity (Martin \& Rose, 2003). At the stratum of context, two contexts are realised: context of situation and context of culture. Register is "the immediate situational context in which the text was produced" (Eggins, 1994, p. 16). Three register variables are field, tenor and mode which determine the experiential meaning, interpersonal meaning and textual meaning respectively. Genre which is "register plus purpose" (Thompson, 1996, p. 36) is "a staged, goal-oriented, purposeful activity in which speakers engage as members of our culture" (Martin, 2001, p. 155). Overall, register refers to the context of situation, and genre refers to the context of culture.

\subsubsection{Systemic Functional Linguistics and linguistic complexity}

\subsubsection{Lexical density and grammatical intricacy}

"Lexical density and grammatical intricacy are two ways of managing complexity" (Halliday, 2008, p. 161). While lexical density is a typical feature of written language, grammatical intricacy is considered as a distinctive characteristic of spoken language. Thus, none of the two modes of communication is more complex than the other; rather, each is complex in its own way. Written language is static and dense, while spoken language is dynamic and intricate (Halliday, 1985b; Halliday, 2008). Lexical density refers to the density of information of text "according to how tightly the lexical items (content words) have been packed into the grammatical structure" (Halliday, 1993d, p. 76); therefore, it is measured by the ratio of lexical items per ranking clauses (Halliday, 1985b). Grammatical intricacy, by contrast, refers to how lexical items are scattered in strings of clauses in clause complex; as a result, it is measured by the proportion of ranking clauses per total number of clause complexes (Halliday, 2008). "The highly information-packed lexically dense passages of writing often tend to be extremely simple in their grammatical structure, as far as the organisation of the sentence (clause complex is concerned)" (Halliday, 1985b, p. 
87). Therefore, the complexity of written language can be seen in the density of strings of lexical items packed in ranking clauses and the simplicity of sentence structure packing those lexical items.

\subsubsection{Nominalisation and grammatical metaphor}

Another two linguistic concepts that are regarded as typical complexity in academic and scientific discourse are nominalisation (Banks, 2005; Halliday, 1993d, 1998, 2004; Halliday \& Martin, 1993; Halliday \& Matthiessen, 2004; Martin, 1993a, 1993d, 2008), and grammatical metaphor (Banks, 2003; Derewianka, 2003; Halliday, 1985a; Halliday, 1993a, 1994; Halliday, 1995; Halliday, 1998, 2008; Halliday \& Martin, 1993; Halliday \& Matthiessen, 1999a; Halliday \& Matthiessen, 1999b; Halliday \& Matthiessen, 2004; Martin, 1992b, 1993a, 1993d, 2008; Ravelli, 1988, 1999, 2003).

Nominalisation defined by functional linguists is the process of deriving nouns from other word classes (Eggins, 1994; Martin, 2008; Thomson \& Droga, 2012), for instance, education for educate or importance for important. Nominalisation includes two common types: verbal and adjectival nominalisations, which can be formed by adding a derivational suffix to a verb or an adjective (e.g., master/mastery); or by changing the verb internally (e.g., to plan/plan). Two main functions of nominalisation in scientific discourse are building knowledge and organising text (Halliday, 1993a; Martin, 2008). With regard to building knowledge, nominalisation helps build the field of discourse related to the ideational metafunction. Concerning the text organisation, nominalisation helps condense meaning by shortening explanations, making generalisations and connecting ideas. Thus, nominalisation is realised as cohesive tool to create coherent texts (Halliday, 1993a; Humphrey et al., 2012; Martin, 2008). This function of nominalisation is known as the textual metafunction of language which is concerned with register variable of mode with reference to the written mode.

The fourth linguistic concept that is considered to have interrelated relationship with lexical density and nominalisation is grammatical metaphor. Grammatical metaphor originally proposed by Halliday is "a substitution of one grammatical 
class, or one grammatical structure by another" (Halliday, 1994, p. 79). As stated by Halliday (1994), congruent forms are the natural ways that language encodes the meanings they express. The non-congruent ways of encoding language are viewed as metaphorical expressions or grammatical metaphors. There are two kinds of grammatical metaphor: ideational metaphor and interpersonal metaphor. Ideational metaphor is the metaphor of transitivity realised by six process types, which involves nominalisation. The transformations made between the processes and the alterations of participants and circumstances or transitivity functions are what Halliday means by the term 'grammatical metaphor' (Halliday, 1994). Ideational metaphor is divided into two sub-types: experiential metaphor and logical metaphor (Martin, 1992b). Experiential metaphor is realised by construing processes as things (explode-explosion) or qualities as things (free-freedom). Logical metaphor is realised by construing causal relationship by a verb (cause) instead of a conjunction (because) (Martin, 1992b). Interpersonal metaphor expresses the interpersonal relationships between the speaker/writer and the listener/reader. The interpersonal meaning can be seen by means of evaluative words, modality and mood. Therefore, interpersonal metaphor consists of metaphor of mood and metaphor of modality (Halliday, 1994).

\subsubsection{Thematic structure and hierarchies of periodicity}

The fifth aspect of linguistic complexity is Theme. As far as the three metafunctions are concerned, Theme relates to the textual metafunction which is concerned with the organisation of a text (Eggins, 1994; Thompson, 1996). It gives the clause the character as a message. Theme is "the starting point for the message; it is what the clause is going about" (Halliday, 1985a, p. 39) and Rheme is the remainder of the message in which Theme is developed (Halliday, 1985a). Similarly, Thompson (1996) points out that "The Theme of a clause is simply the first constituent of the clause" (p.118) known as thematisation, and "all the rest of the clause is simply labelled the Rheme" (p.119). Therefore, the different choice of Theme results in a different meaning of the clause (Thompson, 1996). The Theme may be a nominal group, an adverbial group or prepositional phrase. When the Theme packs many lexical items in it, it has high lexical density value (Halliday, 1985a; Halliday, 1994). 
In SFL, the term wave in physics is adopted by functional linguists (Halliday, 1985a; Halliday, 1994; Martin, 1993a; Martin \& Rose, 2003) and sociologist (Malton, 2014) to compare information flow and semantic unfolding of discourse with semantic waves within the clause itself (Halliday, 1985a; Halliday, 1994) and beyond the clause (Martin, 1993a; Martin \& Rose, 2003). Periodicity which is a common feature of written mode is concerned with information flow in a text known as the rhythm of discourse. Hierarchy of periodicity refers to different layers of Theme and New in a text. At the clausal level, information flow is concerned with little waves realised in Themes and News. As mentioned earlier, Theme is the starting point of the message concerned with the peak of prominence, predicting what will happen next in the rest of the clause. New is the other end of the clause recognised through tonic prominence, expanding information when text unfolds. Theme and New are both concerned with the textual metafunction of language (Martin \& Rose, 2003). At the discourse level, waves of Theme and New are displayed by larger phases of discourse: bigger waves realised in hyperThemes and hyperNews at the paragraph level and tidal waves realised in macroThemes and macroNews at the whole text level. HyperThemes refers to the topic sentences of paragraphs, predicting what each paragraph of the text will be about. New information is often distilled in final sentences of phases, functioning as hyperNews to those phases. At the whole text level, macroThemes which refer to introductions of texts, predicting hyperThemes, and macroNews referring to the text conclusions. Wave patterns demonstrated by layers of Themes in relation to hyperThemes and macroThemes construct the text's organisation or the text's periodicity (Martin, 1993a; Martin \& Rose, 2003).

\subsection{Research aim and objectives}

This study aims to investigate the complexity of language in reading comprehension texts in English textbooks adopted in teaching reading skills for L2Ls. To achieve the main aim of the research, five objectives are developed as follows.

- Objective 1: Critically examining linguistic complexity in terms of Halliday's concepts of lexical density, grammatical intricacy, nominalisation, grammatical metaphor, and thematic structure. 
- Objective 2: Investigating how the complexity of language differs across various levels in the chosen English textbooks.

- Objective 3: Examining how the complexity of language differs in science and non-science fields in the chosen English textbooks.

- Objective 4: Identifying the relationships among linguistic features charactering the complexity of the investigated textbook texts.

- Objective 5: Determining how the complexity of language differs according to stages of text types and what effects they have on the text periodicity.

\subsection{Research questions}

To achieve the five objectives above, this study attempts to answer the following research questions:

- Research question 1: How is linguistic complexity manifested in terms of Halliday's concepts of lexical density, grammatical intricacy, nominalisation, grammatical metaphor, and thematic structure?

- Research question 2: How do linguistic features charactering complexity including lexical density, grammatical intricacy, nominalisation, grammatical metaphor and thematic structure differ across levels in the chosen English textbooks?

- Research question 3: How do linguistic features charactering complexity including lexical density, grammatical intricacy, nominalisation, grammatical metaphor and thematic structure differs in science and non-science fields in the chosen English textbooks?

- Research question 4: What are the relationships between lexical density, grammatical intricacy, nominalisation, and grammatical metaphor?

- Research question 5: How do linguistic features including lexical density, grammatical intricacy, nominalisation, and grammatical metaphor differ 
according to stages of text types and what effects do they have on the text periodicity?

\subsection{Research methodology}

\subsubsection{Research design}

This research used quantitative research design to examine the complexity of 24 reading extracts in four textbooks at four different levels. Complexity according to genre analysis and the text periodicity was conducted with four full texts employing a mixed research methods approach. Regarding quantitative data, descriptive statistics used in this study described values of lexical density, grammatical intricacy, nominalisation, grammatical metaphor and thematic structure in the data across textbook levels and in science and non-science fields. The descriptive statistics of lexical density, grammatical intricacy, nominalisation, grammatical metaphor were displayed as mean \pm standard deviation plus minimum and maximum values. Percentage of theme types was determined by each type of theme per clause complex. Also, inferential statistics conducted by one-way ANOVA test was presented to examine if there was a significant difference in terms of statistics between textbook levels. When there was a difference between textbook levels $(p<=0.05$ ) displayed by ANOVA test, Tukey post hoc test was presented to find out which group was statistically different. Employing Pearson correlations test, the study examined the relationships among the selected linguistic featured. All raw data of five linguistic features including lexical density, grammatical intricacy, nominalisation, grammatical metaphor and theme were analysed using the Statistical Package for the Social Sciences (SPSS) Version 22.

\subsubsection{Chosen textbooks and texts}

This study examined linguistic complexity of four international textbooks at four different levels from low to high, named Active Skills for Reading (Anderson, 2003a, 2003b, 2003c, 2003d). These textbooks were compiled by a world-known TESOL expert and published by a highly recognised publisher. The chosen textbooks have been widely used as the main English reading textbooks in the language education 
programs in universities and language centres in Vietnam for a number of years. The book series includes four books 1, 2, 3, and 4 and are classified into four levels: elementary, pre-intermediate, intermediate and upper-intermediate respectively. Each book level consists of 32 reading passages covering various genres and belongs to both science and non-science domains.

The texts chosen for data analysis were based on genre analysis (Humphrey et al., 2012; Martin \& Rose, 2008; Rose \& Martin, 2012) and the text fields: non-science and science (Banks, 2003, 2005; Halliday, 1993b, 1993c, 2004; Martin, 1993a; Martin, 1993b; Martin, 1993d). In other words, the study investigated the dominant genre in each field. The result of genre analysis in the four textbooks shows that the explanation genre was central in the science field; whereas, reports, historical recounts, interviews and conversations were common in the non-science field. However, historical recounts were not found in Book 4, and interviews and conversations concerning with the spoken mode were not aligned with the purpose of this study; thus, both of these genres were exclusive from the analysis. Accordingly, three reports in the non-scientific field and the same number of explanations in the scientific one in each book were chosen for the investigation. The corpus included 24 texts in total.

Twenty-four chosen texts are classified into four groups: Elementary $(n=6)$, Preintermediate $(n=6)$, Intermediate $(n=6)$ and Upper intermediate $(n=6)$. These twenty-four texts are also divided into two fields: Science $(n=12)$ and Non-science ( $n=12$ ). Text coding is described in Table 4.4 (see Section 4.4.2) as follows: Elementary (Science: E1, E2, E3; Non-science: E4, E5, E6), Pre-intermediate (Science: P1, P2, P3; Non-science: P4, P5, P6), Intermediate (Science: I1, 12, 13; Non-science: 14, 15, 16), Upper-intermediate (Science: U1, U2, U3; Non-science: U4, U5, U6).

\subsubsection{Data analysis}

Firstly, regarding lexical density analysis, this research employed two formulas of lexical density. The first method which is originally proposed by (Ure, 1971b) is identical to Halliday's (1985b) first approximation. In the first method, lexical 
density which is measured by the proportion of lexical items to total words was initially proposed Ure (1971) Halliday (1985b). In the second formula, lexical density is calculated by the ratio of lexical items per ranking clauses (Halliday, 1985b). The purpose of the employment of both measures of lexical density was to determine if they were consistent in measuring density and if the results obtained were reliable.

Secondly, for grammatical intricacy analysis, Halliday's (2008) measure was adopted. According to this measure, grammatical intricacy is calculated by the ratio of ranking clauses per clause complexes. Only ranking clauses comprising parataxis (or independent clause in traditional term) and hypotaxis (or dependent clauses in traditional grammar) were counted, embedded or rankshifted clauses were not included in the analysis. As embedded clauses are at a lower rank than clauses, and therefore, do not have the full status as a ranking clause (Halliday, 1985a; Ravelli, 1999). For this reason, embedded clauses are excluded from the analysis of density and intricacy.

Thirdly, for nominalisation analysis, the study focused on two main common types: nominalisation of verbs and nominalisation of adjectives (Halliday, 1994) (Halliday, 1994). Verbal nominalisation can be recognised by three ways: (1) verbs and nouns have the same stems (e.g., to visit - a visit), (2) verbs change their stems to become nouns (e.g., to live - a life), (3) verbs are added suffixes to become nouns (e.g., to explore - an exploration). Adjectival nominalisation can be formed by adding suffixes to adjectives (e.g., dense - density). These classifications of nominalisation are informed by a number of studies on nominalisation (Halliday, 1993a, 1998, 2004; Halliday \& Martin, 1993; Hartnett, 2004; Humphrey et al., 2012; Martin, 2008). In addition to these two typical types of nominalisation, nominalisation that derive from conjunction (e.g., because - reason), and nouns added suffixes to become compound noun (e.g., friend - friendship) are also included into the nominalisation analysis. Frequency of nominalisation was calculated by the ratio of instances of nominalisation to ranking clauses.

Fourthly, concerning grammatical metaphor, Halliday (1985a, 1994) divides it into two types: the ideational metaphors and the interpersonal metaphors. At the 
lexico-grammar level, they are realised by metaphors of transitivity and metaphors of mood (including modality) respectively. Metaphors of transitivity are realised by the six typical processes namely, material process, mental process, relational process, verbal process, existential process and behavioural process. As this study investigated linguistic features of written language, its purpose was to focus on the ideational metaphors only. As the study looked at the relationship between nominalisation and grammatical metaphor, it just examined ideational metaphor with the involvement of nominalisation. Interpersonal metaphor was not taken into consideration at this stage. Therefore, the term grammatical metaphor used in this research refers to the ideational metaphor.

Fifthly, with regard to thematic analysis, Themes are classified into three major types: simple themes, multiple themes and clausal themes. Simple themes are also known as topical or ideational themes which include unmarked themes and marked themes. A multiple theme may consist of a combination of two or three themes together including textual theme, interpersonal theme and ideational themes. A clause complex which contains one dependent clause followed by one independent clause, dependent clause is treated as an adverbial clause and functions as the Theme of that clause complex which is known as clausal Theme (Halliday, 1985a; Halliday, 1994).

Finally, the illustrations of linguistic complexity were conducted at two levels: elementary and intermediate as the results of quantitative data analysis show that these two textbook levels were statistically significant different in terms of the employment of lexical items, and nominalisation. Four texts chosen for the analysis were analysed according to stages of genre to see whether different stages of genre leaded to different values of lexical density, grammatical complexity, nominalisation and grammatical metaphor. Furthermore, the effect of grammatical metaphor may have on the text periodicity was also investigated. 


\subsection{Limitations of the study}

This research has some limitations. Firstly, it can be said that the data for this investigation is relatively small. In this research, six reading passages in each textbook were chosen for data analysis. The samples concluded 24 texts which comprised of 6,293 words in total. It can be said that this is not a large amount of quantitative data. A great advantage of this is that the analysis of linguistic features was done carefully, which leads to reliable statistics and high quality of research. However, it investigated one set of textbooks comprising of four levels. Further research can be done at a wider scale, examining many sets of EFL textbooks to see if there are similar patterns among different sets, then the conclusion between linguistic complexity and textbook levels could be strongly confirmed with large quantitative data.

Moreover, the study chose a small proportion of the data to conduct text analysis to provide some illustration of complexity at two significant levels: elementary and intermediate with reference to two language domains. Illustration for complexity was done with four texts including two in science field and the same number in the non-science one. Although some trends have been identified regarding complexity according to stages of text types in each field, further analysis with larger amount of texts would be helpful to draw a firm conclusion about the text periodicity.

Finally, there are many factors contributing to the text complexity, and this study has examined six linguistic features from the SFL perspective to provide an overall view on linguistic complexity. Further research in SLL could be based on the results of this study to examine each linguistic feature in depth. Looking at different aspects of each feature mentioned in this study might provide a much broader picture of complexity. Regardless, further studies can be expanded from this small but meaningful study.

\subsection{Thesis organisation}

This thesis comprises eight chapters including Introduction, Different perspectives on linguistic complexity, A Hallidayan approach on linguistic complexity, 
Methodology, Analysis of linguistic complexity across levels, Analysis of linguistic complexity at the full text level, Discussion, and Conclusion. The content of each chapter is described in details in the following sections which capture the whole picture of the research journey.

\section{Chapter 1: Introduction (this chapter)}

This chapter provides an introduction to this research. It states the rationale of the project which was drawn on the brief overview of studies on linguistic complexity and points out the gap in research in this area. This chapter also explains the purpose of the study based on the gap of investigating linguistic complexity in English textbooks used in TEFL in developing countries, followed by four research questions. The chapter also presents a general introduction to Halliday's SFL theory and briefly discusses how linguistic complexity is measured from this point of view. In particular, five linguistic concepts namely lexical density, grammatical intricacy, nominalisation, grammatical metaphor, thematic structure, and periodicity are introduced. The chapter also describes the research design employed in the study, the chosen textbooks and texts, and methods of analysing data. In the next sections, limitations of the research are discussed, which is followed by the structure of the thesis and its concluding remarks.

\section{Chapter 2: Different perspectives on linguistic complexity}

This is a comprehensive chapter with a broad literature review on the study of linguistic complexity from three linguistic perspectives. It starts with an introduction of the chapter and then examines some concepts in relation to grammar and linguistic complexity. Following that, linguistic complexity is discussed from traditional grammar, Chomsky's transformational-generative, and Halliday's functional grammar perspectives. In traditional grammar, linguistic complexity is measured in terms of markedness status of clause type. From Chomskyan point of view, complexity can be seen in discursive rules and phase structure. In Halliday's functional grammar, complexity is characterised by lexical density, grammatical intricacy, nominalisation, grammatical metaphor, thematic structure and 
periodicity. How linguistic complexity is measured from Halliday's functional grammar perspective is discussed in depth in Chapter 3.

\section{Chapter 3: A Hallidayan approach on linguistic complexity}

With a focus on objective 1 about critically examining linguistic complexity in terms of Halliday's concepts of lexical density, grammatical intricacy, nominalisation, grammatical metaphor, and thematic structure, this chapter critically examines linguistic complexity from Hallidayan functional grammar. In particular, lexical density, grammatical intricacy, nominalisation, grammatical metaphor, thematic structure and hierarchies of periodicity are discussed in depth. Two measures of lexical density, and the distinction between lexical items and grammatical items are stated. Also, how lexical density varies in written and spoken modes and how lexical density is realised in scientific discourse is included. Regarding intricacy, measure of grammatical complexity and the classification of ranking clauses and embedded clauses are proposed. This classification is also considered relevant to density measure. Concerning nominalisation, this chapter presents some definitions of this concept, distinguishes nominalisation from nouns and nominal groups, as well as discusses the functions and classifications of nominalisation. This theoretical framework chapter also discusses different types of grammatical metaphors consisting of ideational and interpersonal metaphors, and proposes the relationship between grammatical metaphor and nominalisation. Finally, the chapter introduces various theme types, how themes are recognised in different moods, and hierarchies of the text periodicity before providing a literature review on prior studies on linguistic complexity and pointing out the gap in research in this area. This chapter ends with a concluding remark of what has been previously presented.

\section{Chapter 4: Methodology}

This chapter introduces the methodological and analytical framework of the research. It begins by stating the aim and objectives of the project, and then mentions the research approach chosen for the study. This study employed quantitative research approach to quantify complexity; thus, quantitative data 
analysis was concerned with descriptive and inferential statistics of linguistic complexity. Quantitative research design was then supported by analysis of four texts to identify some trends regarding the text periodicity. Selections of textbooks and texts for the analysis are described, which is followed by detail of data analysis methods. The chapter also discusses the research reliability and validity of the study.

\section{Chapter 5: Analysis of linguistic complexity across textbook levels}

This chapter reports on findings of quantitative data analysis of linguistic complexity of 24 reading extracts in EFL textbooks in relation to research questions 2, 3 and 4. In general, the results in this chapter were presented as follows. Firstly, statistics on linguistic features of four textbooks across levels was presented. Specifically, this section reports on results of analysis of lexical density, grammatical intricacy, nominalisation, grammatical metaphor, and thematic structure. Secondly, the chapter reveals findings on linguistic features of texts in science and non-science fields across levels. The third section looks at the relationship among linguistic features investigated in characterising complexity.

\section{Chapter 6: Analysis of linguistic complexity at the full text level}

In this chapter, quantitative and qualitative analysis of four full texts was conducted to find out how linguistic features differ according to stages of genre, and what effects they have on the text periodicity. Two texts in the science field and the same number in the non-science field at the elementary and intermediate levels were chosen. Science-related texts are explanation genre, while non-scientific texts are reports. This analysis gives further explanations to the complexity of language according to genre analysis in the chosen texts and identifies some general trends regarding the measure of linguistic complexity according to stages of genres, and the effects that grammatical metaphor has on the text periodicity. 


\section{Chapter 7: Discussion}

The two data analysis chapters are followed by a discussion of the results addressing the four main research objectives and respective four latter research questions. In response to each research question, this chapter discusses the extent to which this research supports and expands the literature or challenges with previous studies. It also points out which results are expected and which ones are unforeseen but interesting. In specific, at first, the discussion focuses on how linguistic features characterising complexity differed across four levels of textbook. Secondly, this chapter discusses how these linguistic features realised in science and non-science texts according to the findings. The relationship among linguistic features is discussed to point out what supports and expands previous research. Finally, some general trends drawn on genre analysis and the text periodicity are explained based on the language variation framework (Mahboob, 2014a) and characteristics of genre (Martin \& Rose, 2008).

\section{Chapter 8: Conclusion}

This chapter firstly summarise the main results of the research which are the followed by its theoretical and educational contributions. Theoretically, the research emphasises the contribution of Halliday's linguistic theory in the understanding and managing complexity among different linguistic approaches. Educational significance of the study in the Vietnamese context is discussed in depth with reference to TEFL in Vietnam, teacher training, textbook selection and writing, and curriculum design. Knowledge contribution of this research, limitations of the study, and recommendations for further studies are also highlighted. Finally, the researcher's personal reflections on personal and academic achievement and final thoughts during the research journey give a conclusion to the whole thesis. 


\subsection{Conclusion}

This introductory chapter has provided an overview of the whole research project and the study organisation. Initially, it stated the rationale for conducting this research which has been drawn on the important concept of linguistic complexity in language and literacy education, and the gap in research of this concept in EFL textbooks in the developing world with particular reference to the Vietnam context. Following that, the overall aim and specific objectives of the study were stated, following by four research questions. Next, an introduction of the theoretical model of the study which is based on the principles of SFL was proposed, which was then followed by the discussion of how complexity is measured in this linguistic theory's point of view. Based on these principles, measures adopted for data analysis were discussed together with the research design and textbook and text choice. Followed by the methodology section, the limitations of the study were stated. This chapter ended by proposing the overall structure of the thesis.

The next chapter, Different perspective on linguistic complexity, reviews linguistic complexity from three linguistic approaches. This chapter starts by examining various definitions of complexity and grammar, and proposes which concepts are adopted in this study. Three theories of language namely traditional grammar, Chomsky's transformational-generative grammar, and Halliday's functional grammar are reviewed in terms of its overall principles and specific measures of linguistic complexity. Specifically, complexity measured by markedness status of clause types in traditional grammar is discussed. Finite phase structure grammar and deep structure in light of transformational-generative grammar is presented. Lexical density, grammatical intricacy, nominalisation, grammatical metaphor, thematic structure, and the text periodicity in light of SFL are introduced. 


\section{Chapter 2: Different Perspectives on Linguistic Complexity}

\subsection{Introduction}

This chapter firstly examines concepts related to grammar and linguistic complexity. It then provides an overview of linguistic complexity from different approaches with particular reference to traditional grammar, Chomsky's transformational generative grammar and Halliday's functional grammar. Particularly, the characteristics of each linguistic theory and how complexity is measured from the point of view of each approach is explored. With regard to SFL, the differences between functional grammar and formal grammar are discussed. General introduction of SFL in relation to its three metafunctions and strata of language is presented. Following that, six linguistic features characterising linguistic complexity in light of SFL are briefly introduced.

\subsection{Some related concepts}

\subsubsection{The concept "grammar"}

Grammar has been a familiar component in the teaching of languages for many centuries. Its notion is understood and defined in various ways according to different linguistic perspectives. Traditionally, grammar is considered as a system or a set of syntactic rules for language use (Crystal, 1971; Weaver \& Weaver, 1998). The rules of "traditional grammar" are descriptive rules of syntactic structure and prescriptive rules of actual usage of language. Generative grammar, on the contrary, is not prescriptions of language usage, nor is it the descriptions of actual speech events, they are concerned with formulations which present syntactic structure in an abstract way (Crystal, 1971). An early notion of grammar which relates to the rules is that grammar is "a device which generates all and only the grammatical sentences of a language" (Crystal, 1971, p. 221). There are several 
limitations with this approach. Firstly, it just focuses on the sentence, while other concepts such as "clause" and "utterance" are not addressed. Secondly, it focuses on all and only the grammatical sentences, but sometimes it is not absolutely explicit to make a clear distinction between grammatical and ungrammatical sentences.

It is argued that native speakers do not need to be taught grammar at all since they will gradually acquire grammatical construction of mature syntax from childhood to adulthood (Hudson, 1971; Weaver \& Weaver, 1998). This refers to the notion which indicates grammar as the implicit knowledge that a native speaker has. In other words, there is so-called "unconscious command of syntax" (Weaver \& Weaver, 1998, p. 2) that enables native speakers to use the language. Thus, another view of grammar is that "the native speaker's knowledge of his language's grammar is stored in his brain" (Hudson, 1971, p. 4). It is also true for non-native speakers who have similar opportunities to hear, read, write and speak the language (Weaver \& Weaver, 1998). As such, the meanings of grammar can be interpreted according to the following four central domains with regard to the formal approach (Weaver \& Weaver, 1998, p. 2).

- Grammar as a description of syntactic structure;

- Grammar as prescriptions for how to use structures and words;

- Grammar as rhetorically effective use of syntactic structures;

- Grammar as the functional command of sentence structure that enables us to comprehend and produce language.

However, for language and literacy teachers and educators, it is necessary to have the explicit knowledge of grammar to be able to understand and explain how the language works and makes meaning. The linguistic approach known as Systemic Functional Linguistics sees grammar "not a set of rules but a set of resources for describing, interpreting and making meaning" (Butt, Rhondda, Sue, \& Collin, 2000, p. 11). In this approach, language is treated as "a system of communication" (Lock, 1996, p. 1) in which grammar "is organised to allow speakers and writers to make and exchange meanings" (Lock, 1996, p. 1). Thus, from the functional point of view, 
there are no distinctions between grammatical and ungrammatical forms; rather, it focuses on the appropriateness of linguistic choice for a particular communicative purpose in a specific context (Lock, 1996). Therefore, from the point of view of this linguistic theory, "grammar is a way of describing how a language works to make meaning." (Derewianka, 1998, p. 1)

\subsubsection{The concept "linguistic complexity"}

Although linguistic complexity is fundamental in language education, its nature has still been a matter of debate. This section examines several notions of linguistic complexity in terms of objective and subjective complexity, global and local complexity, absolute and relative complexity as well as the relation between linguistic complexity, readability and text levels.

With regard to objective complexity and subjective complexity, Hendrikse and Van Zweel ( 2010) state that complexity expresses an objective property of an entity, event or system as well as a subjective conception of the nature of such an entity, event or system. Complexity in the objective sense alludes to the innate structure of a phenomenon. This is its multipart or multifaceted composition, as well as complicated relationships between the different components or aspects. The subjective sense of complexity refers to the difficulty in the cognitive processing or unravelling of the objective complexity of a phenomenon. Similarly, according to Miestamo (2008), the objective complexity of a phenomenon could be determined by "the amount of information needed to describe or reconstruct it" (p.2), while subjective complexity could presumably be measured by the quantity and the nature of the cognitive processing involved in the representation of a complex phenomenon.

Miestamo's terms of linguistic complexity refers to another aspect of the current discussion. Miestamo (2008) divided complexity of language into two categories: global complexity and local complexity. Global complexity is the complete language complexity which demands a comprehensive and detailed grammar such as complexity of a language, dialect, etc. As we do not have satisfactory linguistic tools, 
this is a challenging task. What we might achieve is a study of the complexity of discrete aspects of grammar across languages known as local complexity. In other words, local linguistic complexity refers to domain-specific linguistic complexity which pertains to subdomains such as phonological complexity, morphological complexity, syntactic complexity, semantic-lexical complexity and pragmatic complexity (Benedikt \& Bernd, 2012).

A number of methods have been used by analysts and grammarians to assess linguistic complexity. One of the methods is to evaluate linguistic complexity in terms of absolute complexity and relative complexity (Dahl, 2009; Kusters, 2008). In other terminology, Siegel (2012) names them componential complexity for an absolute quantitative notion and structural complexity for a relative notion. Relative complexity means the length of the extra description which is essential to characterise several entities in a given theory. The theory delivers certain information about the object and its description does not necessarily cover this information. However, if no assumption on background information is made, the absolute complexity would be the length of the full description of the entity (Relja, 2007).

In this study, the concept linguistic complexity can be understood in four distinct ways. Firstly, in Chomskyan terms, it is simplicity or complexity (Chomsky, 1965a). Secondly, complexity means "difficulty to learn" (Crystal, 1971, p. 71). However, the standards of difficulty are relative as "a thing is more difficult to do depending on how much practice we have had at doing it, and how used we are to doing similar things" (Crystal, 1971, p. 71). Complexity also refers to readability as Droop and Verhoeven (1998) believe that linguistic features have a considerable effect on the readability of a given text, which deals with the quantity and quality of transformations employed in a specific statement (Distefano \& Valencia, 1980). Hunt (1970) states that the more transformations are used in a sentence, the more complex it is; thus, the more difficult it is to process for comprehension. Finally, linguistic complexity is used in the sense that it involves text levels, so it can be understood by those with low or high levels of language skills (Hudson, 1971). 


\subsection{Linguistic complexity from different perspectives}

Linguistic complexity has momentous implications in examining children's language development, language disorders and language and literacy education. Therefore, in order to have better understanding of linguistic complexity, an overview of different linguistic theories is essential since complexity should be evaluated from the point of view of a particular linguistic theory (Kusters, 2008; To, 2014a, 2014b). Furthermore, a historical perspective in linguistics is particularly important to general readers since it explains why the modern subject has developed in the way it has, and relates to the subject to other areas which may be more familiar. As for researchers, it is crucial for them to be aware of what has already been done, or at least attempted. It also helps the researcher or teacher avoid unreal generalisations about a certain theory (Crystal, 1971). The following sections discuss linguistic complexity from various perspectives including traditional grammar, Chomsky's transformational generative grammar and Halliday's functional grammar. Following that, six central concepts charactering linguistic complexity in the systemic functional view are discussed in detail.

\subsubsection{Traditional grammar}

Traditional grammar known as school grammar has played a dominant role in school language education for the past centuries. It is a phrase which sums up "a state of mind, a spectrum of methods and principles which appear in various combinations and emphasis over the years, associated with many schools of thought" (Crystal, 1971, p. 40). Plato, Aristotle, and the Stoics are considered the first traditional grammarians and Plato is believed to be "the first to discover the potentialities of grammar" (Crystal, 1971, p. 51). Traditional grammar can be tracked back to Greece of the fifth century B.C. with the descriptions of Classical Latin and Greek languages (Crystal, 1971; Lyons, 1970). It was believed that it was appropriate to employ grammatical descriptions of those languages to the analysis of English language as "Latin and Greek were the languages of scholarship, religion, philosophy, and knowledge, grammar of these languages was taken to be the best grammar." (Yule, 1996) 


\subsubsection{The prescriptive approach}

Traditional grammar is concerned with the prescriptive approach that emphasises the correctness of language. Some prescriptive rules are: must not split an infinitive, must not end a sentence with a preposition or must not begin a sentence with and. According to this approach, the sentence "Mary runs faster than I" is correct, while the sentence "Mary runs faster than me" is incorrect. Similarly, "whom did you see?" is encouraged to use instead of "who did you see?" (Yule, 1996, p. 91). In the same way, "It was good that he left" is grammatically correct, whilst "That he left was good" is ungrammatical (Elgin, 1973, p.55). It is a social expectation that who obeys these rules is well-educated, whereas who does not is considered the poorly educated one (Yule, 1996). This leads to two main purposes in the traditional school grammar: "(a) disciplining and training the mind (and sometimes the soul); and (b) teaching grammar forms and usages that were considered correct or socially prestigious." (Weaver \& Weaver, 1998, p. 3)

\subsubsection{Traditional categories}

Traditional grammar uses traditional categories such as parts of speech, number, person, tense, voice and gender. These categories can be examined in isolation or in terms of agreement. For instance, the verb likes "agrees with" the noun girl in the sentence "The girl likes her doll." This is known as the agreement between the subject (the noun) and the verb, whether the subject is singular or plural, which belongs to the category of number. It is also based on the category of person including first person, second person or third person. In this sentence, the girl is the third singular. Besides, the verb is always described in terms of tense. The verb "likes" in this sentence is in the present tense, which is different from other tenses such as the past tense "liked". The verb is also described in terms of voice: active or passive. In this case, it is in active voice, with the girl doing the liking. The final category is gender which defines the agreement between the girl and her in the example mentioned. It is worth noting that in English, natural gender which is based on the biological distinction between male (he, his) and female (she, her) is described, whilst grammatical gender which can be found in many European 
languages such as Spanish, German, French might be inappropriate in applying to the description of gender in English (Yule, 1996).

\subsubsection{Linguistic complexity in traditional grammar}

From a traditional point of view, linguistic complexity which is grounded on the prescriptive approach and traditional categories involves the concept of markedness is similar to complexity model later proposed by the west coast functionalist Givón (1995). "The marked is structurally more complex and the unmarked more simple" (Givón, 1995, p. 25). "The main, declarative, affirmative, active clauses have been tacitly assumed, in grammatical description ever since the Greeks, to be the privileged, unmarked clause type" (Givón, 1995, p. 32). Therefore, they are simple while subordination, interrogatives, imperative, negatives and passives are more complex. Givón (1995) also proposes that the marked can be distinguished from the unmarked category in terms of three major criteria namely, structural complexity, frequency distribution and cognitive complexity. The marked type tends to be structurally complex, less frequent and demands more mental effort, attention and time to process than the unmarked. Table 2.1 describes the markedness status of the five categories mentioned.

Table 2.1. Markedness status of clause-types ( Givón, 1995, p. 33)

\begin{tabular}{|c|c|}
\hline Unmarked & Marked \\
\hline Main/conjoined & Subordinate \\
\hline Declarative & Manipulative \\
\hline Affirmative & Negative \\
\hline Active & Passive \\
\hline Continuative & Disruptive \\
\hline
\end{tabular}

Illustrations of linguistic complexity in terms of markedness status are given in the following examples.

- Conjoined main and dependent clauses 
"The grammatical structure of conjoined chain-medial clauses is clearly reduced and simplified." (Givón, 1995, p. 35)

Dependent clauses:

Example 2.1

Coming out,

stopping to check the mailbox,

taking a look at the driveway,

and pausing to adjust his hat,

Conjoined main:

\section{Example 2.2}

He turned and walked to his car. (Givón, 1995)

- Coordination and subordination

There is a general assumption that subordination is more complex than coordination (Carter \& MacCarthy, 2006; Huddleston, 1984). It has been suggested that syntactic complexity deals with subordination and levels of embeddedness (Givón, 1991).

Coordination:

\section{Example 2.3}

My kids eat some ice-cream and they want some more.

Subordination:

\section{Example 2.4}

Although they have enough food, they still want some more.

Nonetheless, it has been debated by Beaman (1984) that it is naive to treat subordination as a way of evaluating complexity without considering its varying forms. Taking finite relative clauses as an example for subordinate clause types, Beaman (1984) found that it happens more repeatedly in speech while non-finite formation with to-infinitives or -ing forms are more frequent in writing. Non-finite clauses are marked cases so they are more complex while finite clauses are unmarked which are simpler. 
Finite:

Example 2.5

He left in a hurry.

Non-finite:

Example 2.6

Leaving in a hurry, he then proceeded...

- Mood

"Of the two main non-declarative speech-acts, questions are clearly more complex." (Givón, 1995, p. 40)

Affirmative:

Example 2.7

The soup is hot.

Interrogative:

Example 2.8

Is the soup hot?

- Affirmative and negation

"In many languages, negative clauses are historically embedded (dependent) with the accompanying syntactic complexity." (Givón, 1995, p. 42)

Affirmative:

Example 2.9

She has signed the lease.

Negation:

Example 2.10

She hasn't signed the lease.

- Voice

Passive is considered to be more complex than active.

Active:

Example 2.11 
John kicked the ball.

Passive:

\section{Example 2.12}

The ball was kicked by John.

\subsubsection{Transformational-generative grammar}

Transformational-generative grammar (hereafter TGG) is a linguistic theory proposed by Noam Chomsky $(1957,1965)$. He is considered "master of modern thought" (Lyons, 1970, p. 9) and his work is described as the present-day "state of the art" (Robins, 1989, p. 280). Chomsky's TGG can be examined in two separate periods: early formulation in the 1950s which is concerned with finite state grammar and phrase structure grammar; and later development in the 1960s which proposes surface structure and deep structure (Robins, 1989). Chomsky's theories focus heavily on syntactic structure and less on semantics. It is a mentalist view of grammar as it attempts to make a special link between language and mind.

\subsubsection{Early development: finite state grammar and phrase structure grammar}

\subsection{Linguistic complexity in finite state grammar}

In 1957, Chomsky's first work named Syntactic Structures was published and immediately called transformational or transformational-generative grammar. This approach treats grammar as a set of explicit rules that generate all the well-formed syntactic structures (Robins, 1989). These rules are explained in a way that can be found in mathematics. From a mathematical point of view, with reference to an algebraic formula like $2 x+3 y$, we can give $x$ and $y$ the value of any number, then we can produce endless results which are generated by the operation of the explicitly formalised rules. If the sentences of language can be seen as comparable set; similarly, an indefinite number of grammatical structures can be generated by a finite number of rules which is called a generative grammar (Robins, 1989; Yule, 1996). 
The rules of this grammar involve the concept of recursion which is concerned with the syntactic complexity of language. Recursion is the "indefinite extensibility in syntax" (Robins, 1989, p. 285) or "the continued repetition of the same rule to the output of a prior rule" (Robins, 1989, p. 285). The capability of generating an indefinite set of sentences by means of a finite recursive rules is known as finite state grammar in Chomskyan term (Lyons, 1970). That is to say, we can produce very much longer sentences by means of a series of choice made "from left to right" (Lyons, 1970, p. 51); and the longer the sentences are, the more complex they become. Thus, linguistic complexity in this view lies on the length of sentences. Coordination, subordination or embedding are covered by various transformational rules allowing for the indefinitely continued coordinations, the nested subordinations or further embedding (Robins, 1989). Some examples of recursion can be seen in the sentences given below.

\section{Example 2.13}

a. The book was on the table.

b. The book was on the table near the window.

c. The book was on the table near the window in the hallway beside the... (Yule, 1996, p. 102)

\section{Example 2.14}

a. This is the dog.

b. This is the dog that chased the cat.

c. This is the dog that chased the cat that killed the rat...

(Yule, 1996, p. 102)

\section{Example 2.15}

a. Jack says that Mary is beautiful.

b. Jack says that Bill knows that Mary is beautiful.

c. Jack says that Bill knows that Martha thinks that Mary is beautiful.

d. Jack says that Bill knows that Martha thinks that Phil agrees that is beautiful. (Elgin, 1973, p. 33) 


\section{Example 2.16}

a. This is the farmer sowing his corn,

b. That kept the cock that crowned in the morn,

c. That waked the priest all shaven and shorn,

d. That married the man all tattered and torn,

e. That kissed the maiden all forlorn,

$f$. That milked the cow with the crumpled horn,

h. That tossed the dog,

i. That cashed the cat,

j. That worried the rat,

k. That ate the malt,

I. That lay in the house that Jack built. (Robins, 1989, pp. 275-276)

As far as the examples above are concerned, we can generate ever-longer versions of those sentences and there is, in principle, no end to the recursion. However, finite state grammar fails to handle some of the constructions in English "where there is a relationship of compatibility or dependency between the outermost constituents ( $a$ and $z$ ), between the next outermost ( $b$ and $y$ ) and so on" (Lyons, 1970, p.54) in a sentence of a form $a+b+c \ldots x+y+z$ such as "Anyone who says that is lying or Anyone who says that people who deny that ... are wrong is foolish." (Lyons, 1970, p. 54)

\subsection{Linguistic complexity in phrase structure grammar}

The second model of Chomsky's "three models for the description of language" known as phrase structure grammar is more powerful and satisfactory than finite state grammar as Lyons (1970) states that:

Any set of sentences that can be generated by a finite state grammar can be generated by a phrase structure grammar. But the converse does not hold: there are sets of sentences that can be generated by a phrase structure grammar, but not by a finite state grammar. (p.56) 
Phrase structure grammar or constituent structure is a context-free grammar which has been seen from a purely mathematical point of view relating to the notion of "bracketing" or "immediate constituent structure" (Lyons, 1970, p. 65). We have different results towards the different operations in the expressions of the two forms: $x(y+z)$ or $x y+z$. For example, with $x=2, y=3, z=4$, we have: $x(y+z)=14$, whilst $x y+z=10$. In the same way, we can find the English language ambiguous in its syntactic structure which is comparable with the mentioned mathematic formula. A classic example is old men and women which can be interpreted in two following ways (Lyons, 1970, p. 58).

$$
\text { old (men and women) }=\text { (old men) and (old women), } \mathrm{cf} . \mathrm{x}(\mathrm{y}+\mathrm{z})=\mathrm{xy}+\mathrm{xz}
$$

or

(old men) and women , cf. $x y+z$

Thus, linguistic complexity can be seen in the syntactic ambiguity in phrase structure grammar. Phrase structure can be represented using a phrase marker (labelled bracketing assigned to strings of elements) or a tree diagram (Lyons, 1970; Robins, 1989). For instance, John kicked the ball can be illustrated in Figures 2.1 and 2.2. However, this grammar has some limitations as "there are sentences of English that cannot be generated by a phrase structure grammar" (Lyons, 1970, p. 62). Phase structure and tree diagram are illustrated in Figure 2.1 and Figure 2.2 respectively.

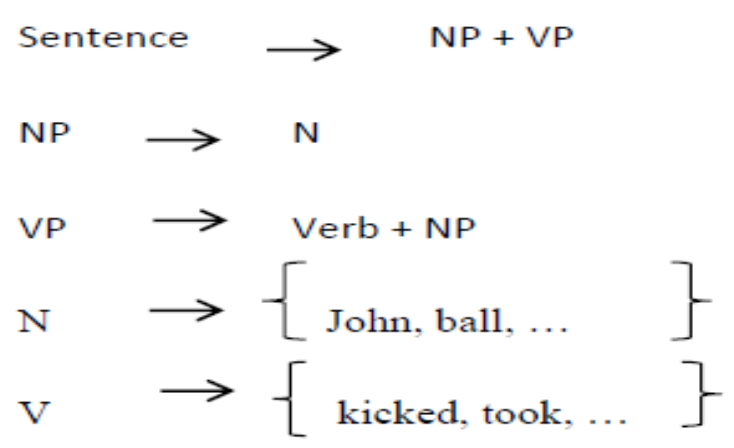

Figure 2.1. Phrase structure presented by phrase marker 


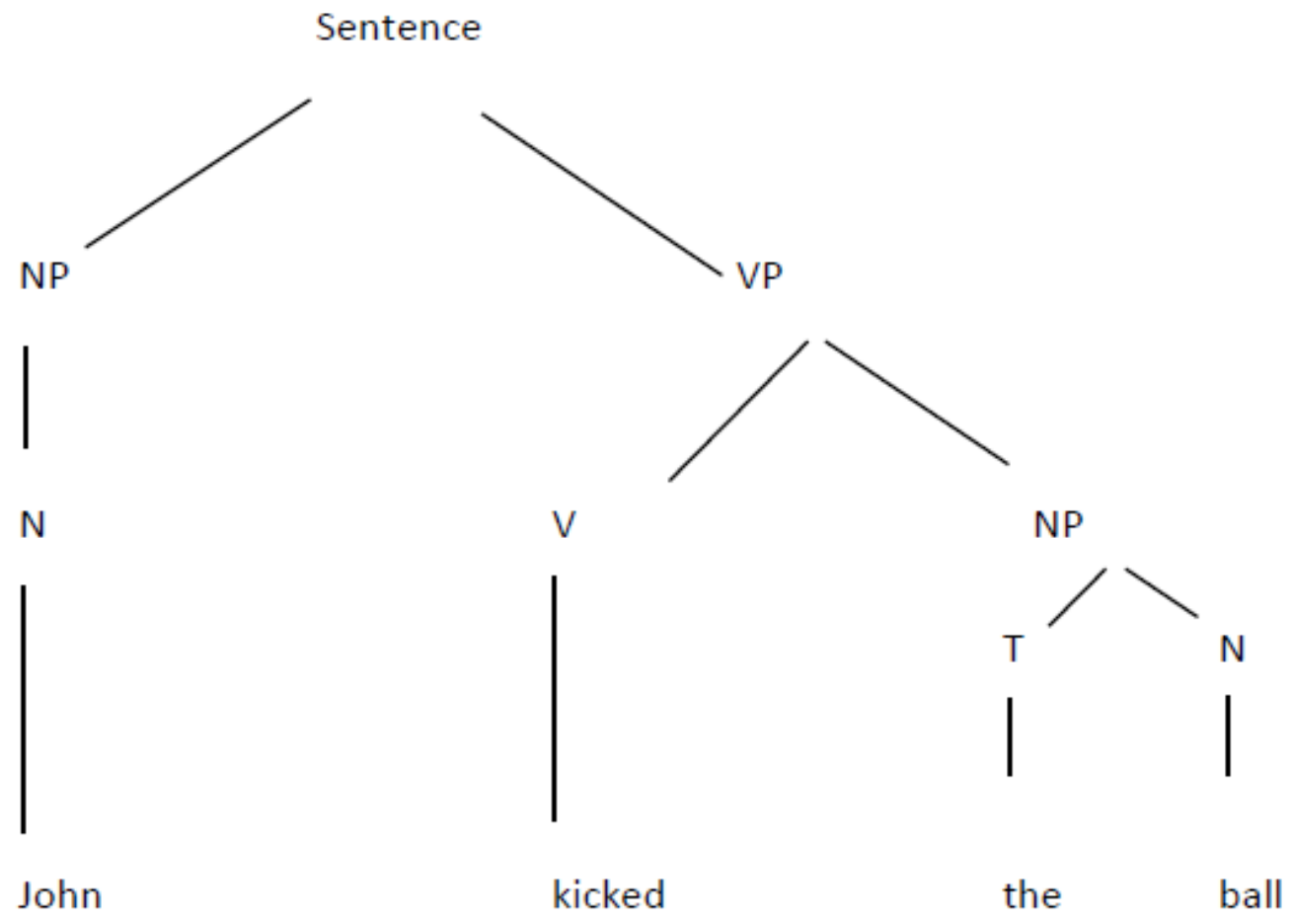

Figure 2.2. Tree diagram

\subsubsection{Later developments and linguistic complexity in deep structure}

In 1965, in the second work Aspects of the Theory of Syntax, Chomsky introduced a more comprehensive theory of transformational grammar which differed from the earlier theory proposed in Syntactic Structures. The salient difference is the semantic component that led to the distinction between deep structure and surface structure, which involves in the more complexity of transformational rules (Chomsky, 1965b; Robins, 1989; Yule, 1996). McCabe (2011) states transformations are "to show how sentences with similar surface structures have different deep structures" (p.197). Chomsky (1965) puts forward that a deep structure determines semantic interpretation and a surface structure determines phonetic interpretation. Chomsky's examples about the two sentences (17a) and (17b) below suggested very clearly that any grammatical analysis would have to be carried out on two levels, the superficial or apparent structure of sentences (surface structure) and the underlying structure (deep structure). 


\section{Example 2.17}

a. John is eager to please.

b. John is easy to please.

The pair of sentences above has identical surface structures but different deep structures. In sentence 2.17 a, John is the subject of the pleasing while in sentence $2.17 \mathrm{~b}$, John is the subject of the pleasing as well as the implied object of the pleasing as well because sentence $2.17 \mathrm{~b}$ can be interpreted in two ways: It is easy to please John or To please John is easy. Similarly, sentence $2.18 \mathrm{a}$ and $2.18 \mathrm{~b}$ has the same surface structures but has different interpretations in meaning in the deep structure.

\section{Example 2.18}

a. Atoms are too small to see by any possible technique.

b. They are too much in love to see clearly.

"See" is used in the two sentences $18 \mathrm{a}$ and $18 \mathrm{~b}$ but it conveys different meanings. See in Example 2.18a is one of five physical senses, hearing, seeing, touching, smelling, tasting. Thus, sentence 2.18a means You can't see Atoms. In sentence $2.18 \mathrm{~b}$, it is not that they cannot see each other rather than They can't distinguish what is right or wrong when they are in love.

Linguistic complexity can be seen in different interpretations of meaning in deep structure in terms of syntactic ambiguity. (Crystal, 1971) states that syntactic ambiguity (also grammatical ambiguity or transformational ambiguity) is present only in written language, since in speech, the context and the stress-pattern can tell us how to interpret the utterance. For example:

\section{Example 2.19}

I only saw John. (Crystal, 1971, p. 58)

This sentence is ambiguous in its surface structure in writing. However, in speaking, it can be interpreted in the following ways:

a. I only saw John. (It was John alone whom I saw)

b. I only saw John. (I didn't speak to him) 
In the same way, syntactic ambiguity can be found in Example 2.20.

\section{Example 2.20}

The woman hit the man with an umbrella.

The sentence is structurally ambiguous but it has two different underlying interpretations which would be represented differently in the deep structure.

a. The woman hit the man with an umbrella. (The woman hit the man by using an umbrella)

b. The woman hit the man with an umbrella. (The woman hit the man who is holding an umbrella)

Similarly, Example 2.21 can be understood in two different ways according to its deep structures.

\section{Example 2.21}

Flying planes can be dangerous (Lyons, 1970, p. 77)

Example 2.21 means To fly planes can be dangerous or Planes which are flying are dangerous.

\subsubsection{Functional grammar}

Functional grammar (also known as Systemic Functional Grammar) is a theory of language developed by Michael Halliday, a key pioneer of SFL which has been very influential linguistic approach in Australia and worldwide for the past three decades. Halliday's linguistic theory was officially introduced in his series of books entitled An Introduction to Functional Grammar (Halliday, 1985a; Halliday, 1994; Halliday \& Matthiessen, 2004) and Halliday's Introduction to Functional Grammar (Halliday \& Matthiessen, 2014). According to Halliday (1985a), functional grammar can be understood in three ways. Firstly, it is functional in the sense that it provides an explanation of how language is used. It means that every piece of text can be justified in the context of use. Moreover, it is designed to gratify human needs. Hence, a functional grammar is basically a natural grammar in the sense that everything in it can be clarified with regard to how language is used. The second 
meaning of functional grammar is that the central components of meaning in language are functional components. Language is structured with two types of meaning, "the ideational or reflective", and "the interpersonal or active". They are, in the terminology of the current theory, "metafunctions". The ideational meaning refers to language used to construe meaning or human experience about the world while the interpersonal meaning refers to the relationship between the speaker/writer and the listener/reader. The combination of these two meanings is a third metafunction known as the textual meaning. Finally, Halliday (1985a) states that functional grammar can be recognised in the sense that each element in a language is explained concerning its function in the total linguistic system. That is to say, each single unit of language such as clause or phrase, is interpreted as functional with reference to the whole. In a word, functional grammar is "the interpretation of texts, of the system and of the elements of linguistic structures" (Halliday, 1985a, p. xiii).

\subsubsection{Functional grammar versus formal grammar}

Martin, Matthiessen, and Painter (1997) mentioned that "functional grammar is a way of looking at grammar in terms of how grammar is used" (p.1). In other words, "it is not grammar of etiquette, rather, it provides you with tools for understanding why the text is the way it is" (p.3). Functional grammar is, at first, different from transformational-generative approach developed by Chomsky $(1957,1965)$ in which that it does not consider language to be a set of rules or a system of semantic, syntactic, morphological and phonological rules (Siewierska, 1991). On the contrary, for language is a system of meaning (Halliday \& Matthiessen, 2004). In other words, SFL sees language first and foremost as a system of communication, allowing speakers and writers to interact with their audience by making and exchanging meanings which refers to meaning potential based on a system of choices rather than what they can and cannot say (Halliday \& Martin, 1993; Lock \& Jones, 2011; Martin et al., 1997). This leads to the difference in teaching language towards the two approaches. Functional grammar deals with texts as a fundamental unit through which meaning is conveyed. This means it focuses on semantics of the text rather than autonomous syntax of the text itself. Furthermore, functional 
grammar is concerned with language in social contexts. It deals with the relationships between texts and contexts (Halliday \& Martin, 1993). Formal grammar is, on the contrary, concerned with sentence in decontextualized situation (Halliday \& Martin, 1993). Last but not least, functional grammar is "oriented to extravagance, rather than parsimony" (Halliday \& Martin, 1993, p. 23). A brief description of functional grammar and formal grammar in terms of five orientations are presented in Table 2.2.

Table 2.2. Five orientations in functional grammar and formal grammar (Adapted from Halliday \& Martin, 1993, pp.22-23)

\begin{tabular}{|l|l|l|}
\hline Orientations & Functional grammar & \multicolumn{2}{l|}{ Formal grammar } \\
\hline Rule/resource & $\begin{array}{l}\text { Language as a resource for } \\
\text { meaning }\end{array}$ & $\begin{array}{l}\text { Language as a system of } \\
\text { rules }\end{array}$ \\
\hline Sentence/Text & Texts & Sentences \\
\hline Text/Context & Social contexts & $\begin{array}{l}\text { Decontextualized } \\
\text { sentence }\end{array}$ \\
\hline Expressing/construing & meaning-making resource & A meaning-expressing \\
meaning & system & system \\
\hline Parsimony/extravagance & Extravagance-oriented & Parsimony-oriented \\
\hline
\end{tabular}

\subsubsection{Stratification and metafunctions of language in functional grammar}

From a functional perspective, language is organised into four strata: phonetics and phonology, lexicogrammar and semantics. "These four strata are grouped into two stratal planes, the content plane and the expression plane" (Halliday \& Matthiessen, 2004, p. 26). The content includes semantics dealing with meaning and lexicogrammar dealing wording. The expression splits into phonology and phonetics. The relationship between the two planes and between the two sets in each planes are described by Halliday and Matthiessen (2004) as follows.

The realizational relationship between content and expression, more specifically between lexicogrammar and phonology is largely conventional, or 'arbitrary'. ... However, the realisational relationship 
between the two sets of content strata (semantics and lexicogrammar) and the two sets of expression strata (phonology and phonetics) is natural rather than conventional. Patterns of wording reflect patterns of meaning. Part of the task of a functional theory of grammar is to bring out this natural relationship between wording and meaning (p.27).

Within the content strata, lexicogrammar refers to the concept of rank at three levels: word, group and clause. Unlike traditional linguists' treatment in the direction of grammar as sentence, the dominant concept for functional grammar is based on clause. There are three metafunctions of clause at the semantic level: the ideational, the interpersonal and the textual meanings. The ideational meaning which is the representation of the world includes the experiential meaning and logical meaning. The experiential meaning realised by transitivity systems expresses experiences about the world. The logical meaning is realised by the logico-semantic types. The second meta-function, the interpersonal meaning, is realised by Mood, Modality, and evaluative language which enacts the interactions between the speaker/writer and the listener/reader. Finally, the textual meaning which is about the text organisation is realised by the system of Theme and Rheme choice (Halliday, 1985a; Halliday, 1994; Halliday \& Matthiessen, 2004; Halliday \& Matthiessen, 2014), and hierarchies of periodicity (Halliday \& Martin, 1993; Martin, 1993a). Stratification of language and three metafunctions in functional grammar are presented in Figures 2.3 and Figure 2.4 respectively. 


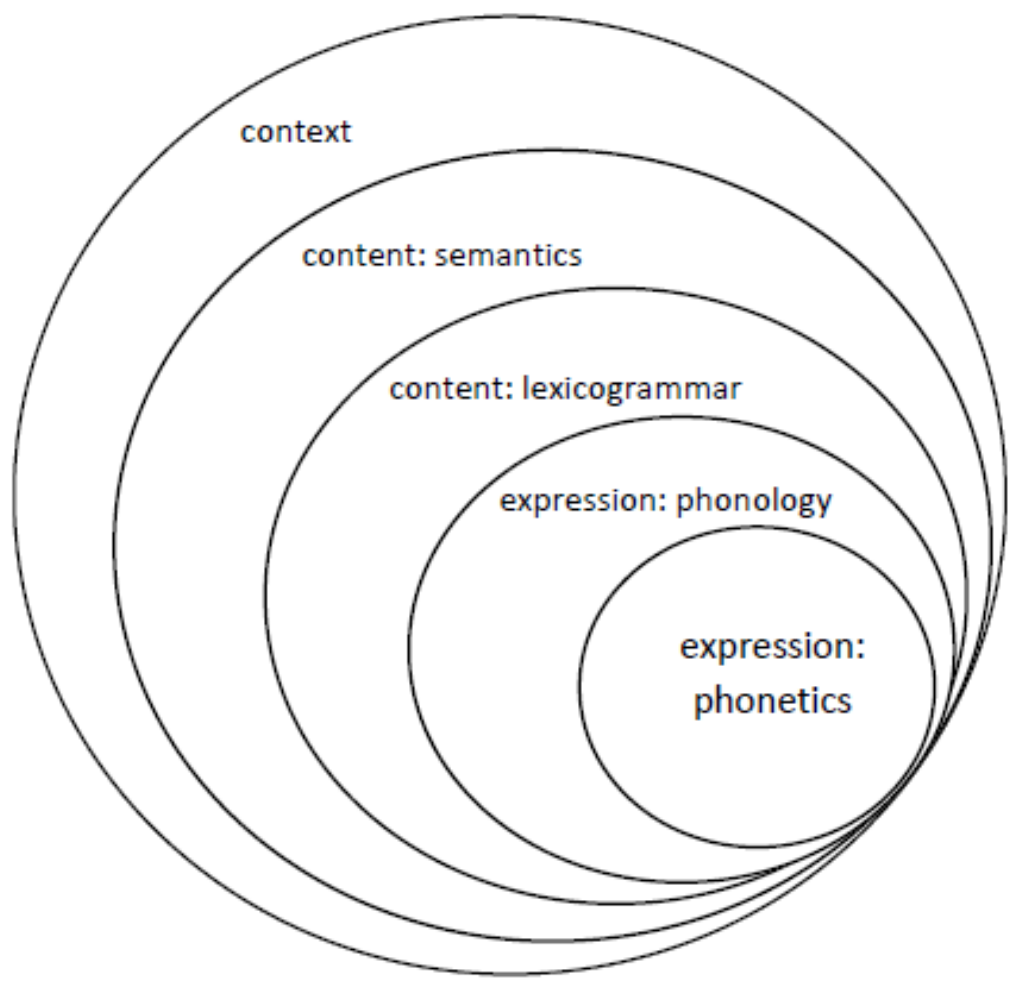

Figure 2.3. Stratification of language (Halliday and Matthiessen, 2014, p.26)

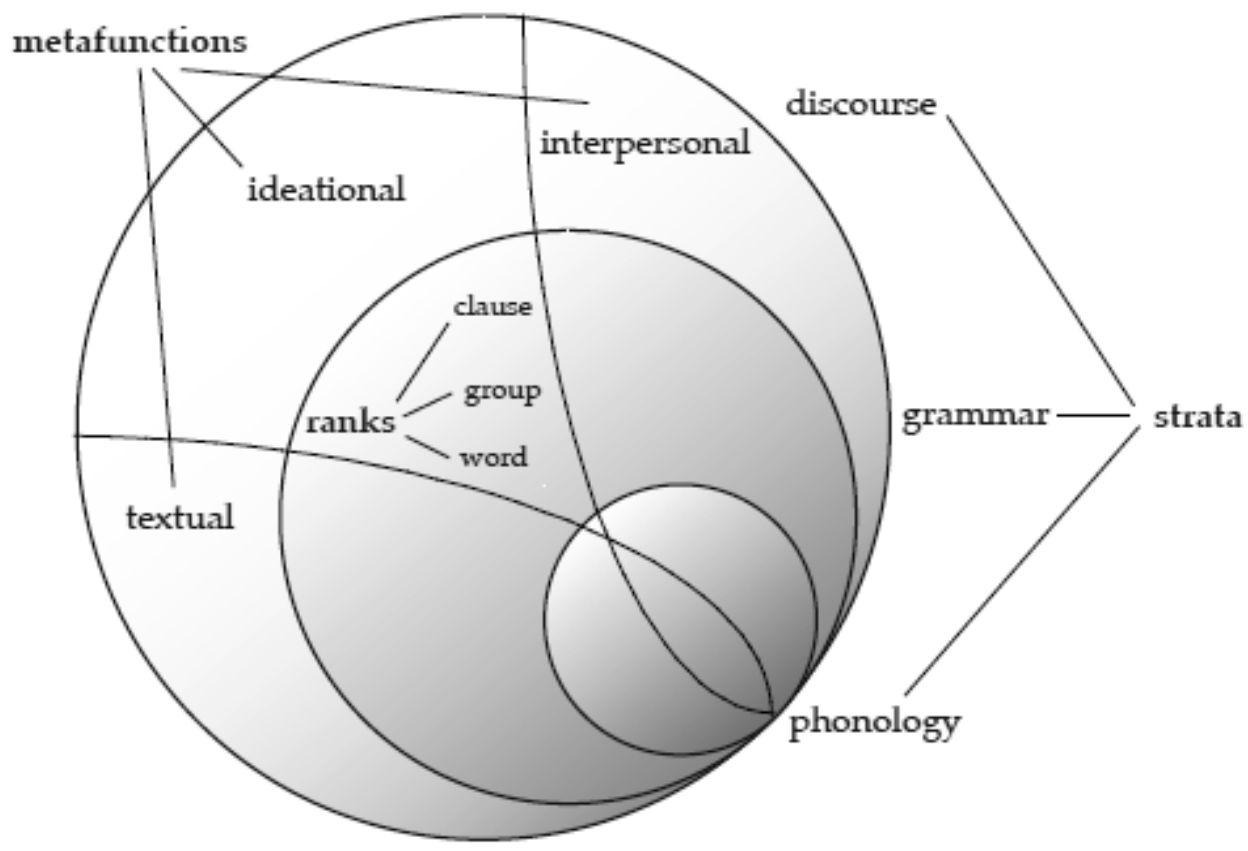

Figure 2.4. Dimension of the SFL language model (Rose, 2006, p.74) 


\subsubsection{Context of situation and context of culture}

In a functional viewpoint, language and context are interdependent. It means that language can be seen as dependent on context (Thompson, 1996) and there are two types of context: context of situation and context of culture (Butt et al., 2000). Since text is a piece of language in use, it is necessary to examine in the context of culture which involves in forms of address, ceremonies, politeness and social activities to shape how meaning is made (Butt et al., 2000). Halliday (1978) states further that language is a social semiotics; thus, SFL is a socio-linguistically and contextuallyoriented framework and is viewed as being embedded in culture, where meanings can be accurately understood in connection with the cultural environment in which language is realised. Within the context of culture, language can be used in more specific contexts or context of situation which comprises field, mode and tenor.

Eggins (1994) defines register as "the immediate situational context in which the text was produced" (p.26). Register includes field, tenor and mode which determine the experiential meaning, interpersonal meaning and textual meaning respectively. Genre which is "register plus purpose" (Thompson, 1996, p. 36) is "a staged, goaloriented, purposeful activity in which speakers engage as members of our culture" (Martin, 2001, p. 155). Overall, register refers to the context of situation, and genre refers to the context of culture (Martin, 2001). The culture is interpreted by systems of linguistic choice while the situation is interpreted by patterns of language use (Halliday, 1978). The three parameters of context of situation mentioned definitely affect language choices are presented in Figure 2.5. 


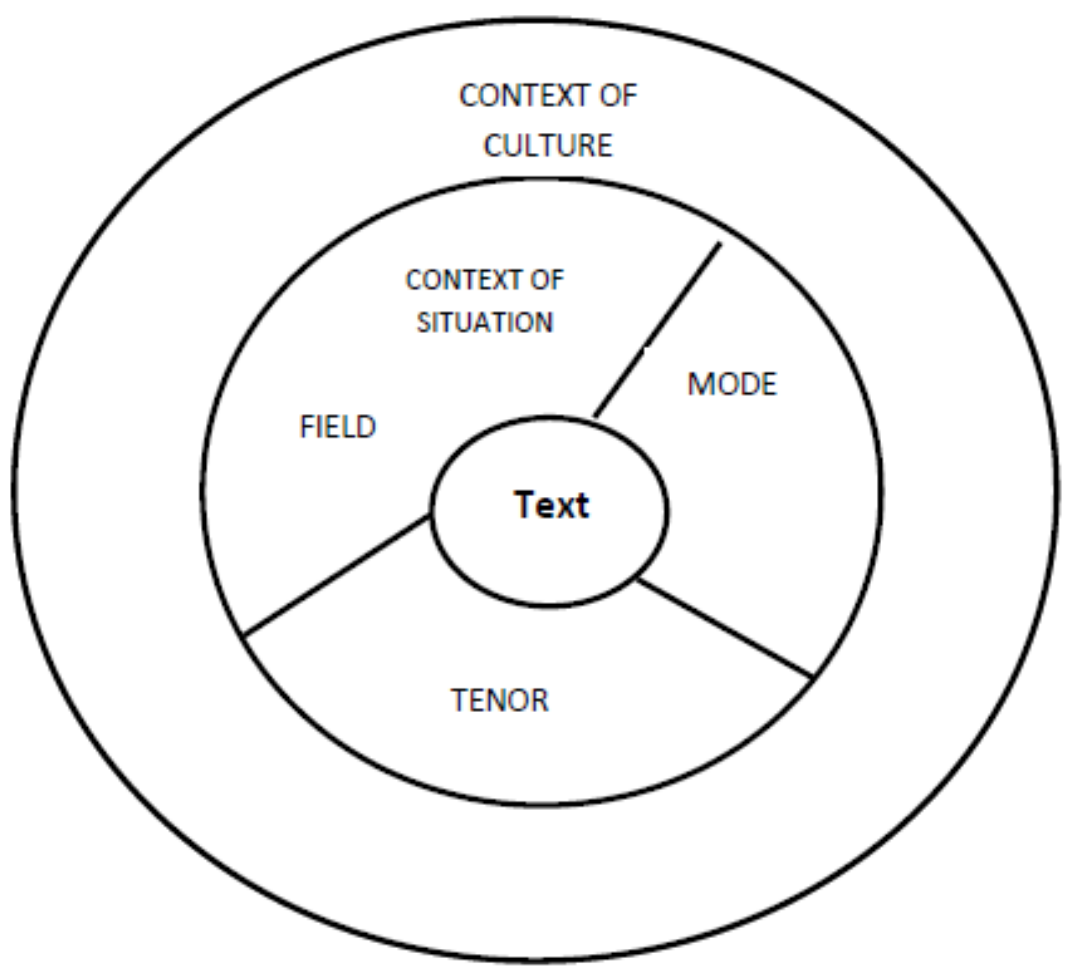

Figure 2.5. Parameters of context of situation and text in context (Butt et al., 2000, p.12)

\subsubsection{Linguistic complexity in Halliday's functional grammar}

Linguistic complexity is an important concept in the study of language and literacy. From a Hallidayan functional perspective, typical complexity of language emphasises six central concepts namely lexical density (Halliday, 1985b; Halliday, 1993d, 2008), grammatical intricacy (Halliday, 1985b; Halliday, 2008), nominalisation (Halliday, 1993a, 1998, 2004; Halliday \& Martin, 1993; Halliday \& Matthiessen, 2004; Martin, 1993a, 2008), grammatical metaphor (Banks, 2003; Derewianka, 2003; Halliday, 1985a; Halliday, 1993c, 1994, 1998, 2004, 2008; Halliday \& Martin, 1993; Halliday \& Matthiessen, 1999a, 2004; Martin, 1992a; Martin, 1993b; Ravelli, 1999), thematic structure (Halliday, 1985a; Halliday, 1994; Halliday \& Matthiessen, 2004) and the text periodicity ((Martin, 1993a; Martin \& Rose, 2003). In the book Spoken and Written Language (1985b), Halliday states that the kind of complexity that is typical of written language is lexical density. However, he also mentions that speech and writing has different kind of complexity. The 
complexity of written language is lexical, while that of spoken language is grammatical.

The complexity of written language is a lexical complexity; written language attains a high lexical density (that is, it has a greater number of lexical items per clause, and the lexical items have a higher information content), often accompanied by a relatively simple grammatical structure. The complexity of spoken language is a grammatical complexity; spoken language constructs complex dependency structures (that is, elaborate edifices of parataxis and hypotaxis, out of both clauses and phrases), often accompanied by a relatively simple choice of words. Metaphorical complexity is typically that of written language (Halliday, 1985b, p. 330).

Lexical density is measured by the proportion of lexical items (content words) per total words (Halliday, 1985b; Ure, 1971b) or by the ratio of lexical items per total clauses (Halliday, 1985b). Grammatical intricacy is calculated by the proportion of ranking clauses per clause complex (Halliday, 2008). In lexical density measure, the distinction between content words and grammatical words is momentous. Also, in calculating density and intricacy, the classification between hypotactic and embedded clauses has a great effect on lexical density and grammatical intricacy values. As stated by Halliday (1985b), it does not matter where the distinction is between those items and categories; the most important thing is to do the analysis consistently.

The third linguistic feature characterising the complexity of written language is nominalisation. Nominalisation is considered the common feature of academic and scientific discourse (Halliday, 1993a, 1998, 2004, 2008; Halliday \& Martin, 1993; Halliday \& Matthiessen, 2004; Martin, 1993a, 2008). Nominalisation as defined by functional linguists is the process of deriving nouns from other word classes (Eggins, 1994; Martin, 2008; Thomson \& Droga, 2012). Put simply, nominalisation is the process of turning things which are not normally nouns into nouns (Eggins, 1994). Thus, nominalisation itself functions as a participant in another process (Thompson, 
1996). Nominalisation can be involved in a nominal group functioning as Theme or a head noun in a nominal group. It has been shown by Halliday $(1985 b, 2004)$ that lexical meaning is largely carried in the nouns and nominal group is the primary source for packing lexical items to achieve high density. Nominalisation is the typical complexity in science discourse, academic and formal writing in general, as it allows processes to be objectified and to be expressed without the human doer (Thompson, 1996). Nominalisation is also the most powerful tool for creating grammatical metaphor (Halliday, 1985a; Halliday, 1994; Halliday \& Matthiessen, 2004; Halliday \& Matthiessen, 2014).

The fourth linguistic concept that involves the written kind of complexity and has the interrelated relations with lexical density and nominalisation is grammatical metaphor. Halliday $(1985,1994)$ defines that grammatical metaphor is the variations in expression of a given meaning. This is different from traditional metaphor called lexical metaphor in a way that lexical metaphor relates to different ways of expressing meaning of the same lexico-grammatical form. However, (Thompson, 1996) claims that there is no difference between the two kinds, and lexical metaphor can be seen as a sub-category of grammatical metaphor. As this study is grounded on Halliday's theory, the distinction between the two types of metaphor is necessary to make clear. It is agreed by the researcher that the expression of meaning is metaphorical in lexical metaphor, whilst the expression of lexico-grammar form is metaphorical in grammatical metaphor. Thus, there is a difference between the two kinds of metaphor. Grammatical metaphor includes ideational metaphor and interpersonal metaphor, which is discussed in detail in Chapter 3. It is worth noting that high lexical density involves grammatical metaphor and nominalisation is the important component of ideational metaphor (Halliday, 1985a; Halliday, 1994; Halliday \& Matthiessen, 2004; Halliday \& Matthiessen, 2014).

The fifth aspect of linguistic complexity which is one of the main investigated objectives of this study is Theme. As far as the three metafunctions are concerned, Theme relates to the textual metafunction which involves the organisation of a text (Eggins, 1994; Thompson, 1996). It gives the clause the character as a message. 
Theme is "the starting point for the message; it is what the clause is going about" (Halliday, 1985a, p. 39) and Rheme is the remainder of the message in which Theme is developed (Halliday, 1985a). Similarly, Thompson (1996) points out that "The Theme of a clause is simply the first constituent of the clause" (p.118) known as thematisation, and "all the rest of the clause is simply labelled the Rheme" (p.119). Therefore, the different choice of Theme results in a different meaning of the clause (Thompson, 1996). The Theme may be a nominal group, an adverbial group or a prepositional phrase. When the Theme packs many lexical items in it, it has high lexical density value (Halliday, 1985a, 1994).

However, while Theme is just realised at the clausal level, hierarchy of periodicity which is concerned with the information flow of the text realised at both clausal and discourse level. Thus, complexity should also be examined according to the text hierarchy of periodicity. The term hierarchy of periodicity refers to different layers of Theme and New in a text. Information flow is realised in Themes and News at the clausal level. As mentioned earlier in the previous section on thematic structure, Theme is the departure of the message predicting what the rest of the clause will be about. New is the other end of the clause, expanding information when the text unfolds. Theme and New are displayed by larger phases of discourse: hyperThemes and hyperNews at the paragraph level and macroThemes and macroNews at the whole text level. The topic sentence of each body paragraph is known as HyperThemes. New information is often distilled in final sentences of each paragraph, functioning as hyperNews to those phases. At the whole text level, the introductions of texts are known as macroThemes which predicte hyperThemes. The text conclusion is known as macroNews. Generally, layers of Themes in relation to macroThemes, hyperThemes, Themes, New, hyperNews and macroNews construct the text's organisation or the text's periodicity (Martin, 1993a; Martin \& Rose, 2003).

In summary, six important concepts characterising complexity of written language from the functional approach in terms of lexical density, grammatical complexity, nominalisation, grammatical metaphor, thematic structure, and hierarchy of periodicity have been briefly introduced. These concepts have interrelated relations 
with each other. Detail of each linguistic feature is examined in Chapter 3. In Halliday's view, language is "meaning-making resources" (Halliday \& Matthiessen, 2004, p. 4); hence, learning language is learning how to make meanings. Therefore, understanding the basic concepts indicated above not only expose learners to useful insights into language, understand the nature of language, but also help them to construe meaning effectively by using appropriate linguistic resources to achieve communicative purposes in social contexts.

\subsection{Conclusion}

This chapter introduced some related concepts of grammar and linguistic complexity. It gave an overview of linguistic complexity in the traditional point of view with respect to the concept of markedness. Complexity measured by finite phase grammar and deep structure from Chomsky's TGG was discussed. Following that, an introduction of SFL theory, its stratification, metafunctions, registers and genre were presented. Finally, six linguistic features characterising linguistic complexity from the functional perspective, specifically lexical density, grammatical intricacy, nominalisation, grammatical metaphor, thematic structure and hierarchy of periodicity were briefly stated. 


\section{Chapter 3: A Hallidayan Approach on Linguistic Complexity}

\subsection{Introduction}

This chapter critically examines linguistic complexity from Halliday's functional grammar perspective. Therefore, it responds to the first theoretical-oriented research question of the study. Six linguistic concepts namely lexical density, grammatical intricacy, nominalisation, grammatical metaphor, thematic structure, and hierarchy of periodicity are the main focus of the chapter and presented in each separate section. In each section, each concept is first explored, which is followed by the measure, classification or function of the linguistic feature mentioned. This chapter ends by reviewing prior studies adopted these linguistic concepts in the study of texts and pointing out the gap in research in the study of complexity of EFL textbooks.

\subsection{Lexical density}

\subsubsection{What is lexical density?}

Halliday (1993d) defines lexical density as "a measure of the density of information in any passage of text, according to how tightly the lexical items have been packed into the grammatical structure." (p. 76)

\subsubsection{Measures of lexical density}

There are two methods to calculate lexical density proposed by (Ure, 1971) and Halliday (1985b). Firstly, lexical density is measured by the percentage of lexical items per total words in a text (Halliday, 1985b; Ure, 1971). According to this measure, if the lexical density number surpasses $40 \%$, it accounts for higher reading difficulty. Secondly, lexical density is calculated by the ratio of lexical items per ranking clauses (Halliday, 1985b). In this study, the first formula is named Ure's 
method as it is originally proposed by (Ure, 1971) ; and the second formula is named Halliday's method as it is originally stated by Halliday (1985b). How lexical density calculated is illustrated in Example 3.1.

\section{Example 3.1}

Without this invention our lives would be very different. (Anderson, 2003a, p. 12)

In Example 3.1, there are 3 lexical items (lexical items are in bold face and italic), 6 grammatical items (grammatical items are italic), 9 words in total and 1 ranking clause. Thus, applying Ure's method, the lexical density value is 33\%, while it is 3 if calculated by Halliday's method.

Research has shown that written texts are lexically more dense compared with spoken texts (Christine \& Derewianka, 2008; Halliday, 1985b; Ure, 1971). Halliday (1985b) mentions that lexical density in spoken English text is between 1.5 and 2, while it is between 3 and 6 in written text given that lexical density measured by the ratio of lexical items per ranking clauses. Ure (1971) reveals that lexical density of spoken English is less than $40 \%$ (ranging from $24 \%$ to $43 \%$ ) and in written text, it is greater than $40 \%$ (ranging from $36 \%$ to $57 \%$ ) given that lexical density measured by the proportion of lexical items to total running words.

\subsubsection{Lexical items and grammatical items}

In calculating lexical density, the distinction between grammatical items and lexical items is vital. Grammatical items or function words come in a closed system consisting of determiners such as articles, pronouns, most prepositions, conjunctions, some classes of adverb and finite verbs (Halliday, 1985b; Lyons, 1968; Palmer, 1974; Robins, 1964). For instance, the personal pronoun him contrasts with he, his on one dimension, with me, you, her, it, is, them, one on another dimension but this is all. We cannot add any more items in these classes. In contrast, lexical items or content words are named lexical as they function in lexical sets; that is to say, they enter into an open system not a closed system. For example, the word door contrasts with gate and screen, also with window, wall, floor and ceiling, with knob, handle, panel, and sill; with room, house, hall; with entrance, opening, portal. 
We cannot close its class of items that it is related to and new items can be continually added into the sets (Halliday, 1985b). The differences between content words and function words are proposed in Table 3.1.

Table 3.1. Characteristics of content words and function words (Haspelmath, 2001, p. 16540)

\begin{tabular}{|l|l|l|}
\hline Word classes & \multicolumn{1}{c}{ Content words } & \multicolumn{1}{c}{ Function words } \\
& $\begin{array}{l}\text { nouns, verbs, } \\
\text { adjectives, adverbs }\end{array}$ & adpositions, conjunctions, \\
Class membership & apen & closed \\
Class size & large & small \\
Meaning & concrete, specific & abstract, general (or none) \\
Text frequency & low & high \\
\hline
\end{tabular}

However, the distinction between lexical items and grammatical items is not always clear-cut and they are determined differently in literature (To \& Lê, 2013). For example, phrasal verbs such as stand up, take over, or call off are treated as a lexical item by Halliday (1985b) and O'Loughlin (1994). On the contrary, Ure (1971) considers them as separate words, one being the lexical word stand, take, or call, and the other being the grammatical items up, over, or off respectively. Be and have are considered grammatical items by Halliday (1985b), Ure (1971) and O'Loughlin (1994); however, they are regarded as lexical items by Quirk, Greenbaum, Leech, and Svartvik (1972). Behind, already, therefore, always and perhaps fall somewhere in the middle, between lexical and grammatical items (Halliday, 1985b). As for contractions like haven't, don't, they're, it's, Ure (1971) and Halliday (1985b) treat them as one separate grammatical item, whilst O'Loughlin (1994) discusses that haven't consists of two grammatical items have and not.

For the purpose of analysis, Halliday (1985b) suggests that it is important to be consistent in determining lexical items and grammatical items. Another way is by classifying lexical items into two groups: high-frequency lexical items and lowfrequency lexical items. High-frequency lexical items include ten common words 
consisting of thing, people, way, do, make, get, have, go, good, many. These highfrequency lexical items make the texts less dense while low-frequency lexical items contribute to higher lexical density index. In this paper, we adopt the term "item" from Halliday's point of view to define lexical items and grammatical items as an item may contain more than one word (Halliday, 1985b). Therefore, based on the distinction of lexical items and grammatical items by linguists and researchers in literature (Castello, 2008; Halliday, 1985b; Lyons, 1968; O'Loughlin, 1994; Palmer, 1974; Quirk et al., 1972; Ure, 1971b), lexical items and grammatical items in this research are defined and described in Sections 3.2.3.1 and 3.2.3.2.

\subsubsection{Lexical items}

In this research, lexical items include the following word classes.

- All nouns consisting of common nouns (e.g., university, education) and proper nouns (e.g., David, Apple). A compound noun with a hyphen (e.g., check-out) is considered one lexical item; a compound noun without a hyphen (e.g., sales department) is treated as two separate lexical items;

- All lexical verbs except the verb be. A phrasal verb (e.g., account for) is treated as one lexical item account plus one grammatical item for;

- All adjectives. A compound adjective (e.g., warm-hearted) is treated as one lexical item; and

- Some kind of adverbs: adverbs of manner (e.g., quickly, beautifully) and sentence adverbs (e.g., honestly, fortunately).

\subsubsection{Grammatical items}

In this research, grammatical items consist of the following word classes.

- All pronouns consisting of personal pronouns (e.g., she, me, them), demonstrative pronouns (e.g., this, that, these, those), possessive pronouns (e.g., mine, yours), reflexive pronouns (e.g., myself, herself), and indefinite pronouns (e.g., no one, nothing, whatever); 
- All determiners consisting of articles (e.g., a, an, the), possessive adjectives (e.g., my, your), quantifiers (e.g., some, any, plenty of), and numerals (e.g., one, two, first, second);

- All finite verbs consisting of be, do, have and modal verbs. When the verbs do, have function as main verbs, they are treated as lexical items; but when they functions auxiliaries, they are considered as grammatical items. All forms of the verb be are treated as grammatical items. A contraction (e.g., haven't) is considered as one grammatical item;

- Some kind of adverbs: setting adverbs (e.g., here, there, now, then), degree adverbs (e.g., very, too, extremely), negative and interrogative adverbs (e.g., not, never, what, when);

- All conjunctions (e.g., and, or, however); and

- All prepositions (e.g., in, at, between).

\subsubsection{Ranking clauses and embedded clauses}

It is important to note that another method on lexical density measurement developed by Halliday (1985b) is based on clause complex. Halliday (1985b) states that

A word of low probability carries more information. But words are not packed inside other words; they are packaged in larger grammatical units - sentences, and their component parts. It is this packaging into larger grammatical structures that really determines the informational density of a passage of text. (p.66)

However, Halliday (1985b) uses the term 'clause complex' instead of 'sentence' used in traditional grammars since it allows us to refer both to written and spoken languages. For that reason, Halliday proposes that lexical density can be measured by the number of lexical items as a ratio of the total number of ranking clauses. By ranking clauses, Halliday (2004) means "those that are not embedded and hence have their full status as clause in the discourse" (p.195). Embedded clauses mean 
those that are embedded into something else, and thus, do not have equal status as ranking clauses (Lukin, 2013). Halliday (1985b) also proposes that "It is not always easy, however, to recognise what a clause is. Again, for comparative purposes, the main requirement is consistency" (p.67). Therefore, in this study, lexical density is determined by the proportion of lexical items per ranking clauses which differentiate from embedded clauses which are embedded in other groups (Butt et al., 2000; Halliday, 1985b; Halliday, 1994; Halliday \& Matthiessen, 2004; Halliday \& Matthiessen, 2014; Humphrey et al., 2012; Lukin, 2013; Thompson, 1996).

Furthermore, ranking clauses and embedded clauses are determined and described in Sections 3.2.4.1 and 3.2.4.2.

\subsubsection{Ranking clauses}

Ranking clauses consist of paratactic clauses (independent clauses), and hypotactic clauses (dependent clauses) (Butt et al., 2000; Halliday, 1985b; Halliday, 1994; Halliday \& Matthiessen, 2004; Halliday \& Matthiessen, 2014; Humphrey et al., 2012; Lukin, 2013; Thompson, 1996) as shown in the illustrations in Section 3.2.4.1.1 and 3.2.4.1.2 respectively.

\subsection{Paratactic clauses}

Paratactic clauses are finite clauses which can be a simple clause itself or a number of simple clauses joined by coordinating conjunctions such as and, so, therefore, however, etc. which are of equal status (Thompson, 1996). As can be observed in Example 22, the first clause "people dressed in costumes" is independent with the action process involved "dressed". Other clauses involving other processes such as "wore colourful masks, ate, drank, and danced" are also independent. Overall, there are 5 ranking clauses in Example 3.2. Main verbs indicating processes in these clauses in Example 3.2 are in bold face.

\section{Example 3.2}

People dressed in costumes, wore colourful masks, ate, drank, and danced all night on the Tuesday before the start of Lent. (Anderson, 2003a, p. 122) 


\subsection{Hypotactic clauses}

Hypotactic clauses are finite or non-finite clauses which have unequal relations with the paratactic clauses in the logical dependency (Thompson, 1996). Hypotactic clauses also include non-defining relative clauses.

- Finite hypotactic clauses can be connected by subordinating conjunctions (Examples 3.3 and 3.4) or by mean of idea projection (Example 3.5). In the Examples 3.3, 3.4, and 3.5, finite hypotactic clauses are underlined, and conjunctions are in bold face and underlined.

Subordinating conjunctions:

\section{Example 3.3}

If the person in the dream was yelling, for example, maybe you are angry (Anderson, 2003a, p. 157).

\section{Example 3.4}

When we read books, magazines, and newspapers, we rarely stop and think about the paper used to make it. (Anderson, 2003a, p. 12)

- Projecting idea:

\section{Example 3.5}

Dream researchers think that people in our dreams can tell us something about ourselves. (Anderson, 2003a, p. 157)

- Non-finite hypotactic clauses can be joined with the main clauses by subordinating conjunctions (Example 3.6); or clauses of purpose (Examples 3.7); or serve as hypotactic elaborations (Example 3.8). In Examples 3.6, 3.7 and 3.8, non-finite hypotactic clauses are underlined.

\section{Example 3.6}

By learning more about our dreams, we may learn more about ourselves. (Anderson, 2003a, p. 157) 


\section{Example 3.7}

In order to impress King Louis XIV, the officers paraded in front of him wearing brightly colored silk handkerchiefs around their necks. (Anderson, 2003a, p. 157)

\section{Example 3.8}

Astronauts can be exposed to intense radiation from the sun and other galactic bodies, leaving them at risk of cancer. (Anderson, 2003c, p. 111)

- Non-defining relative clauses are hypotactic clauses. In Examples 3.9 and 3.10 , non-defining relative clauses are underlined.

\section{Example 3.9}

The only Asian country to adopt it at that time, though, was the Philippines, which the Spanish invaded in the sixteenth century. (Anderson, 2003b, p. 3)

\section{Example 3.10}

Karaoke, which ranked fourth, was more popular than watching videos, which came sixth. (Anderson, 2003b, p. 83)

\subsubsection{Embedded clauses}

Bloor and Bloor (1995) define that embedded clause is "the clause which is inside another clause" (p.153). Butt et al. (2000) explains that "embedded clause do not have the same status, i.e. are not at the same rank, as independent or dependent clauses. They are doing service within a group, which is why they are described as embedded" (p.114). Embedded clauses are also called rankshifted or downranked clauses (Bloor \& Bloor, 1995; Halliday, 1985a). Based on the explanations of embedded clauses of previous linguists (Butt et al., 2000; Halliday, 1985b; Halliday, 1994; Halliday \& Matthiessen, 2004; Halliday \& Matthiessen, 2014; Humphrey et al., 2012; Lukin, 2013; Thompson, 1996), embedded clauses in this research are described as follows. Embedded clauses in all examples in Sections 3.2.4.2.1, Section 3.2.4.2.2 and Section 3.2.4.2.3 are in the bracket []. 


\subsection{Types of embedded clauses}

- An embedded clause is a nominal group itself.

\section{Example 3.11}

[[What I like most about Australia]] is its climate.

\section{Example 3.12}

The climate in Australia is [[what I like most]].

- An embedded clause is a nominal group of a defining relative clause.

\section{Example 3.13}

Numerologists believe that people with this number are peaceful, affectionate people [[who can also be very reserved]]. (Anderson, 2003b, p. 57)

- An embedded clause is nominal group of a prepositional phrase.

\section{Example 3.14}

It is an example of [[how the structure of language is significant in understanding how the written language works]]. (Thompson, 1996, p. 179)

- An embedded clause is a non-finite clause.

\section{Example 3.15}

[[Escalating classroom violence] has also motivated some parents [to remove their children from school]]. (Anderson, 2003c, p. 135)

- An embedded clause is an adverbial group.

\section{Example 3.16}

He walked so fast [[that I couldn't keep up him]].

\subsection{Functions of embedded clauses}

- An embedded clause function as Participant in the clause structure 


\section{Example 3.17}

[[Catching a bus]], [[getting to work or school on time]], and even [[meeting friends]] requires [[managing time]]. (Anderson, 2003c, p. 7)

\section{Example 3.18}

Decide [[how hard you can work]] and [[what you can do]]. (Anderson, 2003c, p. 8)

- An embedded clause functions as Post-modification (Qualifier) in a nominal group

\section{Example 3.19}

Parents [[who homeschool]] argue that they can monitor their children's education and give them the attention [[that is lacking in a traditional school setting]]. (Anderson, 2003c, p. 135)

There are two embedded clauses (defining relative clauses) in Example 38. In the first clause of Example 38, the embedded clause "who homeschool" functions as Qualifier in the nominal group "parents who homeschool". Similarly, the second embedded clause "that is lacking in a traditional school setting" is Qualifier in the nominal group "the attention that is lacking in a traditional school setting".

- An Embedded clause functions as the nominal group constituent of a prepositional phrase

\section{Example 3.20}

The level of our dams is considerably below [[where we would like them to be]]. (Butt et al., 2000, p. 114)

\subsection{Finite and non-finite embedded clauses}

- Finite embedded clauses

\section{Example 3.21}

Of course, [[where you live]] and [[how long you live]] will influence [[how much a million dollars can buy]]. (Anderson, 2003c, p. 64)

\section{Example 3.22}

The man [[who is living in the house over there]] is an American. 
There are three finite embedded clauses functioning as participants in Example 3.21 and one finite embedded clause functioning as qualifier in the nominal group in Example 3.22.

- Non-finite embedded clauses

Non-finite embedded clauses include verb groups in the forms of ing (Examples 3.23-3.26), to infinitive (Examples 3.27-3.29) and past participle (Example 3.30).

\section{Example 3.23}

The man [[living in the house over there]] is an American.

\section{Example 3.24}

You should avoid [[drinking too much coffee at night]].

\section{Example 3.25}

[[Following a schedule]] and [[doing things on time]] is extremely important in today's busy world. (Anderson, 2003c, p. 7)

\section{Example 3.26}

[[Trying to do everything]] perfectly can often cause these students [[to put off doing any work at all]]. (Anderson, 2003c, p. 8)

\section{Example 3.27}

The arguments [[to support their views]] are not convincing.

\section{Example 3.28}

One of the easiest ways [[to offend somebody]] is [[to give the wrong gift]]. (Anderson, 2003c, p. 56)

\section{Example 3.29}

For the chronic procrastinator, often the only way to solve this problem is [[to quick school]]. (Anderson, 2003c, p. 7)

\section{Example $\mathbf{3 . 3 0}$}

Some goods [[bought online]] is low quality. 


\subsubsection{Lexical density in written and spoken language}

Halliday (1985b) made a comparison of lexical density in written and spoken text. Since then, many researches on this topic have been carried out for the past decades (Belinda, 2007, Christie \& Derewianka, 2008; Eggins, 1994; Hilary, 2001; John \& Paul, 2002; Ravelli, 1999; Yu, 2007). Irrespective of what is examined, it is generally agreed that in English, written language has a higher rate of lexical density compared with that of spoken language. Christie and Derewianka (2008) explain that:

In conversation, we tend to use fewer lexical items - generally because there is no need to name something if we can see it in the surroundings. In writing, however, we need to build up the information through the language itself, so we tend to include more lexical items. Writing is therefore more lexically dense. (p.27)

Examples 3.31, 3.32 and 3.33 are illustrations of the difference between lexical density in written and spoken text taken from (Halliday, 1985b, p. 79). In these three examples, lexical items are in bold face.

- Written form

\section{Example 3.31}

|| The use of this method of control unquestionably leads to safer and faster training running in the most adverse weather conditions. || |

In Example 3.31, there are 12 lexical items, 22 words in total, and 1 ranking clause. Thus, lexical density regarding Ure and Halliday's methods (see Section 3.2.2) is 55\% and 12 respectively.

- Spoken form

\section{Example 3.32}

|| If this method of control is used, // trains will unquestionably (be able to) run more safely and faster (even) // when the weather conditions are most adverse. || | 
There are the same number of lexical items in Example 3.32 (12 lexical items) distributed in 3 ranking clauses, giving lexical density value is $41 \%$ and 4 respectively regarding Ure and Halliday's methods (see Section 3.2.2).

\section{Example 3.33}

I|| You can control the trains this way || and if you do that |/ you can be quite sure / that they'll be able to run more safely and more quickly than they would otherwise || no matter how bad the weather gets III

The lexical density keeps going down when more clauses are used in speaking in more natural speaking context as seen in Example 3.33. The same number of lexical items per total words of 44 and 5 clauses make the lexical density decrease to $27 \%$ and 2.4 .

Halliday (1985b) states that the complexity of written language is lexical, while that of spoken language is grammatical. A summary of the features of the two versions in terms of lexical density, grammatical intricacy, lexical items and clauses are presented in the table below.

Table 3.2. Lexical density and grammatical intricacy in spoken and written language (Eggins, 1994, p. 61)

\begin{tabular}{|l|l|}
\hline Spoken language & Written language \\
\hline $\begin{array}{l}\text { Low lexical density } \\
\text { proportion of all words }\end{array}$ & High lexical density \\
High grammatical intricacy & Many content-carrying words as a \\
Many clauses per sentence & proportion of all words \\
\hline
\end{tabular}

\subsubsection{Lexical density in scientific discourse}

In scientific English, there are some problems of its own that make scientific texts difficult for both learners of English as a second language and for those of English as 
a first language (Halliday, 1993d). Generally, scientific texts are found to be difficult to read because of their jargons or technical terms which make the learner feel excluded and alternated from the subject-matter. However, Halliday (1993d) argues that learning science is learning about the language of science and "the problems with technical terminology usually arise not from the technical terms themselves but from the complex relationships they have with one another" (Halliday, 1993d, p. 71). Based on the analysis of scientific documents including Australian school science and mathematics textbooks, recorded science lecturers in England, writings from the Scientific American, and historical survey and works, Halliday (1993d) suggests seven characteristics of scientific English to help understand why the science text is written in the way it is: (1) interlocking definitions, (2) technical taxonomies, (3) special expressions, (4) lexical density, (5) syntactic ambiguity, (6) grammatical metaphor, and (7) semantic discontinuity.

As such, lexical density is one of the grammatical factors that cause the scientific text difficult. It is found that the lexical density goes up higher in scientific texts as many lexical items are packed in nominal groups which build up strings of lexical words and make the text difficult to read. Illustrations are found in Examples 3.34, 3.35 and 3.36 taken from Scientific American (Halliday, 1993d, p. 76).

\section{Example 3.34}

Griffith's energy balance approach to strength and fracture also suggested the importance of surface chemistry in the mechanical behaviour of brittle materials.

\section{Example 3.35}

The conical space rendering of cosmic strings' gravitational properties applies only to straight strings.

\section{Example 3.36}

The model rests on the localised gravitational attraction exerted by rapidly oscillating and extremely massive closed loops of cosmic string. 
There is one ranking clause in Examples 3.34, 3.35 and 3.36. However, the lexical items in these examples are 13,10 and 13 respectively. Thus, lexical density value in these three examples ranges from 10 to 13 given that lexical density calculated by Halliday's measure. It is crucial to note that nominal groups that pack lexical items without any grammatical words in between or with a few grammatical items produce lexically dense texts as can be seen in the following nominal groups: Griffith's energy balance approach, cosmic strings' gravitational properties, extremely massive closed loops of cosmic string, the mechanical behaviour of brittle materials. Also, it is nominalisation that makes scientific texts more dense in those examples: the localised gravitational attraction, the importance of surface chemistry (Note: Nominalisation is in bold face).

\subsubsection{Summary}

In this section, definition of lexical density, methods of calculating lexical density, ways of determining lexical items, grammatical items, ranking clauses and embedded clauses have been discussed and examined in detail. In addition, lexical density in written and spoken texts and in scientific discourse has also been introduced. To conclude, it is suggested that in measuring lexical density, consistency is the key. It has been shown in literature that written language is lexically dense while spoken language is sparser. Scientific texts have a high rate of lexical density due to nominalised process and strings of lexical items packed in nominal groups.

\subsection{Grammatical intricacy}

\subsubsection{What is grammatical intricacy?}

Grammatical intricacy refers to how simple clauses in a clause complex are connected by means of logico-semantic types at the clausal level. As such, grammatical intricacy help construe the logical metafunction of language (Halliday, 2008). 


\subsubsection{Measure of grammatical intricacy}

Grammatical intricacy is measured by the ratio of ranking clauses per clause complex. In other words, this is calculated by the proportion of the number of ranking clauses including paratactic and hypotactic clauses (length) and the number of clause complexes in a text (depth) (Halliday, 2008). As far as the measure of grammatical intricacy is concerned, if there are a number of simple ranking clauses in a clause complex, giving the high score of grammatical intricacy, the text is more intricate.

\section{Example 3.37}

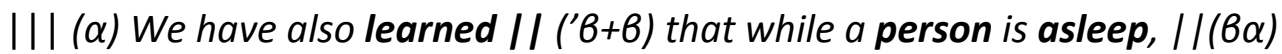
the brain is very active. III (TextE3)

In Example 3.37, there are three ranking clauses connected by means of hypotactic projection and hypotactic extension in the clause complex, giving the grammatical intricacy score at 3.

Regarding the measure of intricacy in spoken language, Halliday (2008) mentions that this could be not an easy task, and not always useful. He states as follows.

Grammatical intricacy can be measured as the number of ranking clauses in the clause complex. But this is more problematic: partly because it requires criteria for identifying the limits of a clause complex in spoken discourse, and partly because it makes no sense to calculate it as a mean. The reasons for this have nothing to do with the way spoken language construes experience; they are not ideational but interpersonal. Spoken language is inherently dialogic in nature, with very many short turns guiding the interaction; whereas intricate clause complex structures can only occur in the more monologic interludes in the dialogue. Thus the mean figure for intricacy would be essentially meaningless. (p. 161) 


\subsubsection{Grammatical intricacy and the logical metafunction}

While lexical density is concerned with the experiential metafunction, grammatical intricacy deals with the logical metafunction. Both of these linguistic features are two ways of managing complexity and construe the ideational metafunction of language. Halliday (2008) states that

The intricacy that is characteristic of spoken language is a different manner of deploying grammatical energy, exploiting the "logical" way of looking at phenomena (note that "logical" here always refers to grammatical logic, not to formal logic - which is a designed extension of it). The principle of setting up a logical-semantic relationship between two figures is extended recursively, so that it can be extended to construe complex sequences of figures that are related systemically: in grammatical terms, a "nexus" can initiate a "complex" of any length. [...] It is a powerful resource; it suits the "choreographic" spoken language, which unfold in time and builds up its own discursive momentum. (p163)

The relationship between clauses in clause complex is determined by taxis and logico-semantics systems. Firstly, taxis refers to two degrees of interdependency between clauses including parataxis (equal status) and hypotaxis (unequal status) (Halliday \& Matthiessen, 2004). They are independent and dependent clauses in the traditional terms respectively. Parataxis is "the relation between two like elements of equal status, one initiating and the other continuing" (Halliday \& Matthiessen, 2004, pp. 374-375). Hypotaxis is "the relation between a dependent element and its dominant, the element on which it is dependent" (Halliday \& Matthiessen, 2004, p. 374). Hypotactic structures are often presented by Greek letters (e.g. $\alpha, \beta$ ), while paratactic structure by numerical notation (e.g., 1, 2). Secondly, a clause complex can be formed through a range of different logico-semantic relations which "holds between a primary and a secondary member of a clause nexus" (Halliday \& Matthiessen, 2004, p. 377). Two kinds of logico-semantic relations are expansion and projection. Expansion is the secondary clause expanding the primary clause, by (a) elaborating it, (b) extending it or (c) enhancing it. Projection is the secondary 
clause projected through the primary clause, which instates it as (a) a locution or (b) an idea, as can be summarised in Figure 3.1 below.

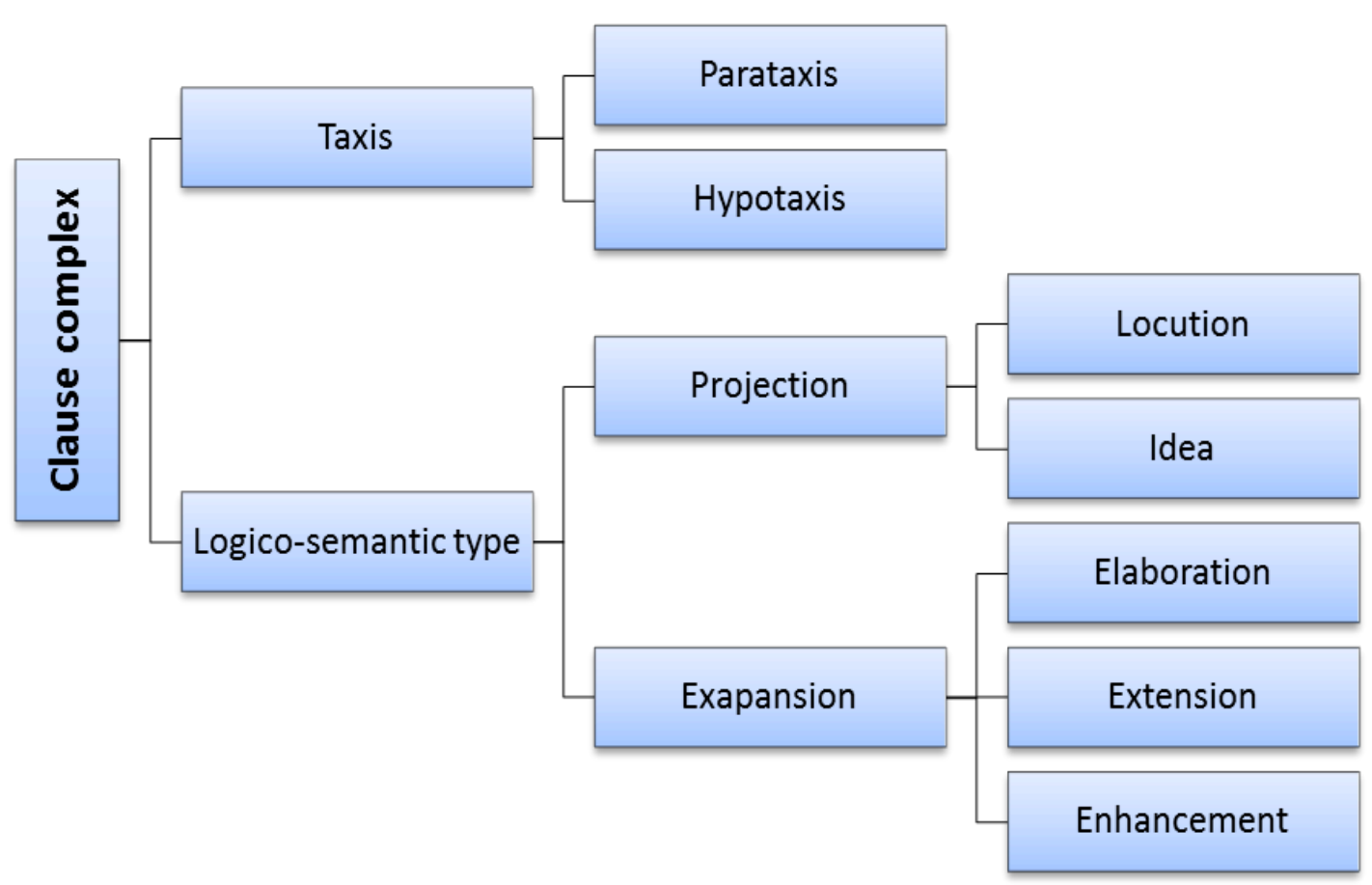

Figure 3.1. Types of relationship between clauses in the clause complex (Adapted from Halliday \& Matthiessen, 2004, p. 373)

For instance, in Example 3.38, two ranking clauses "Scientists think" and "that every dolphin has its own whistle" are connected by hypotactic relationship and logicosemantic relations of idea projection in the clause complex, giving the intricacy score of 2 .

\section{Example 3.38}

// / ( $\alpha$ ) Scientists think / / (' 6$)$ that every dolphin has its own whistle // / (Text E2).

\subsubsection{Grammatical intricacy and lexical density}

As mentioned earlier, while complexity of written language is characterised by lexical density that of spoken language is grammatical intricacy (Halliday, 1985b). Thus, none of the two modes of communication is more complex than the other; 
rather, it is complex in its own way. Written language is static and dense, while spoken language is dynamic and intricate (Halliday, 1985a; Halliday, 2008). Halliday (2008) states that:

Grammatical intricacy [logical metafunction] and lexical density [experiential metafunction] are two ways of managing complexity: different strategies for transforming complex phenomena into edifices of meaning [ideational metafunction]. They are not intrinsically tied to the speech / writing complementarity; they derive from two variants both of which evolved in spoken language as a typological variable in the construal of complex processes. (p.161)

Research has shown that written texts have high density and low intricacy; spoken texts, in constrast, have high intricacy and low density values (Eggins, 1994; Halliday, 1985b; Ravelli, 1999). Thus, the variation in lexical density and grammatical intricacy reflects the organisation of the message which relates to register variable of mode concerning the textual metafunction (Halliday, 1985b; Ravelli, 1999). It is worth noting that in density and intricacy analysis, the classification of ranking clauses and embedded clauses is momentous, which has been already discussed in Section 3.2.4. In measuring intricacy, the way of determining clause complex need to be clearly defined as well. The methodology section in Chapter 4 will discuss this concept further.

\subsubsection{Summary}

This section introduces the concept "grammatical intricacy", its measure, and relationship with lexical density and logical metafunction of language. In general, grammatical intricacy deals with the relationship between ranking clauses in clause complex, construing the logical metafunction by means of taxis and logico-semantic types. Grammatical intricacy is realised as the typical linguistic feature of spoken language, while density is considered the common feature of written texts.

Research has shown that lexically dense texts tend to result in low intricacy, and vice versa. 


\subsection{Nominalisation}

\subsubsection{What is nominalisation?}

Apart from lexical density, nominalisation is another concept contributing to the complexity of written language. Nominalisation is also a distinctive feature of academic writing and scientific writing (Banks, 2005; Halliday, 1993d, 1998, 2004; Halliday \& Martin, 1993; Halliday \& Matthiessen, 2004; Martin, 1993a, 1993d, 2008). There are several definitions of nominalisation proposed by functional linguists. Martin (2008) defines that nominalisation is "a grammatical resource for deriving nouns from other word classes" (p.82). Similarly, Thomson and Droga (2012) states that "the nouns that name processes are derived from other classes of words and are called nominalisations" (p.15). Eggins (1994) mentions nominalisation is the process of "turning things that are not normally nouns into nouns" (p.58). For example: "A bomb exploded" can be expressed by " $a$ bomb explosion". In other words, the action "explode" becomes a thing "explosion". Similarly, "She is feeling free" can be expressed by "She is feeling a sense of freedom" and the adjective "free" is turned into the noun "freedom".

Another notion of nominalisation is that it allows a process, more specifically, as a verb being realised as a noun and becomes a participant in a further process (Bloor \& Bloor, 1995). Take Example 3.39 for illustration:

\section{Example 3.39}

\section{Excessive consumption of alcohol is a major cause of motor vehicle} accidents. (Butt et al., 2000, p. 60)

In Example 3.39, nominal groups are in bold italic face and underlined. This clause complex is structured as something is something. All of the events are packaged not as processes but as participants. The process of drinking is a participant, consumption and the process of causing is packaged as major cause, another participant. The above sentence might be rewording into the congruent forms like Example 3.40 (a, b, c). 


\section{Example 3.40}

a. People who drink too much alcohol and drive often cause motor vehicle accidents.

b. If you drink too much alcohol when you drive your car, you are likely to have an accident.

c. Motor vehicle drivers often have accidents because they have been drinking too much alcohol. (Butt et al., p.60)

\subsubsection{Noun, nominalisation and nominal group}

As far as the definitions of nominalisation are concerned, nominalisation is realised by nouns, but not all nouns are nominalisations. Therefore, making a clear distinction between nouns and nominalisation is essential. Thomson and Droga (2012) distinguish concrete nouns from abstract nouns. Concrete nouns include animate nouns (teacher, doctor) and inanimate nouns (school, hospital), while abstract nouns comprise of general nouns (problem, issue) and specific nouns (organisation, education). Abstract nouns that name processes are nominalised from other classes of words (verbs, adjectives) are called nominalisations. Below is the summary of types of nouns in English.

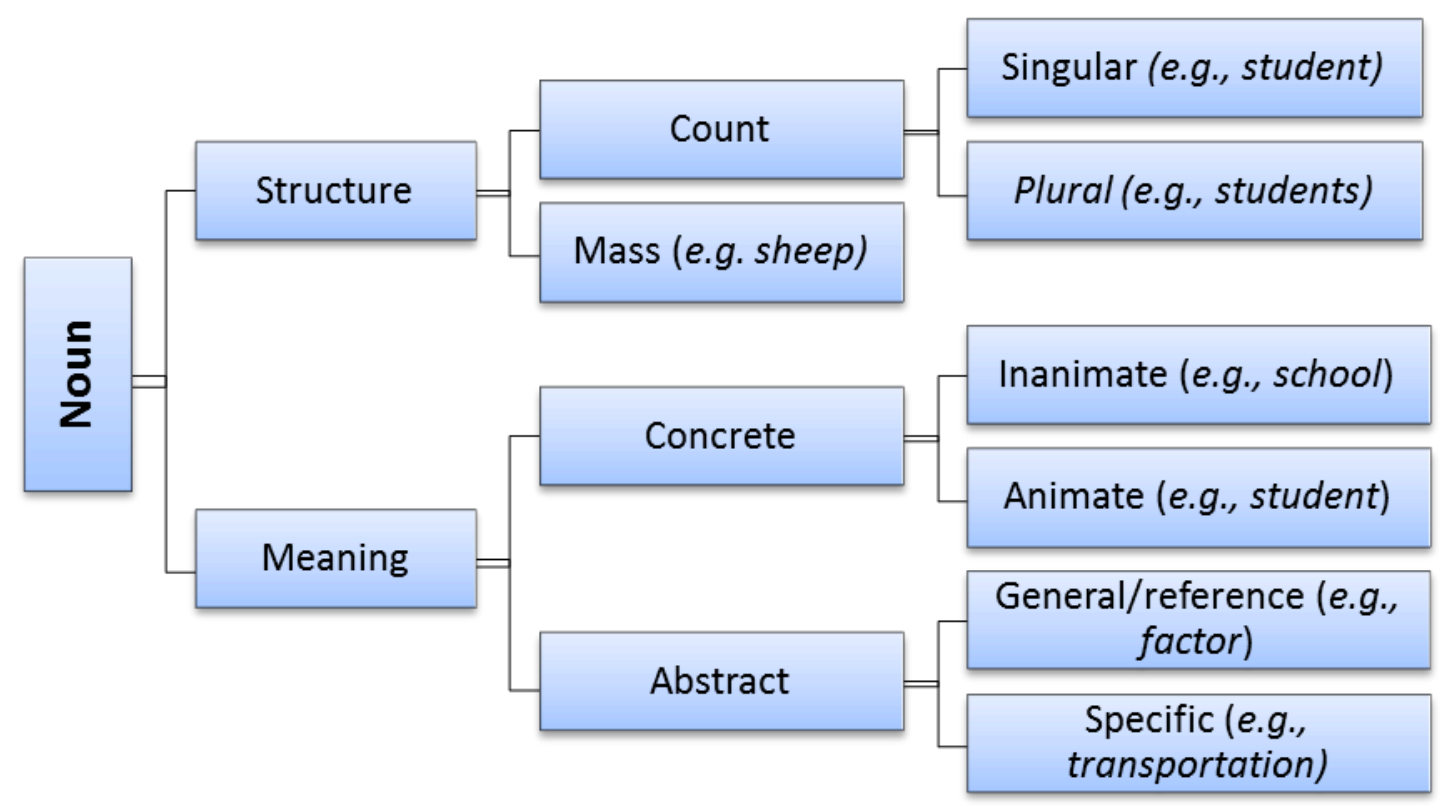

Figure 3.2. Types of nouns in English (Thomson \& Droga, 2012, p. 14) 
As far as Figure 3.2 is concerned, the specific abstract noun transportation is nominalisation because they do not refer to the concrete thing in the world but to processes or qualities of the world. Specifically, the noun transportation names the process of moving things (Thomson \& Droga, 2012).

Nominalisation is a feature of lexical density in formal writing. It results in high lexical density of the text (Eggins, 1994). The lexically dense style can also be found in the nominal group because it has the ability of packing a great number of lexical items and build long noun phrases by means of pre-modifiers, post-modifiers, or both (Lê, Yue, \& Lê, 2010). Nominal group is the grammatical unit which allows the widest range of meanings to be expressed. A nominal group includes three components: pre-modifiers, head noun and post-modifiers (also called qualifiers) (Halliday \& Matthiessen, 2004). For example:

\section{Example 3.41}

a popular nesting ground for the giant leatherback turtles. (Bloor \& Bloor, 1995, p. 141)

Table 3.3. Analysis of nominalisation group

\begin{tabular}{|l|l|l|l|l|}
\hline a & popular & nesting & ground & for the giant leatherback \\
turtles
\end{tabular}

As shown in Example 3.41, the pre-modifying elements consist of one or more functional elements including Deictic, Numerative, Epithet and Classifier, corresponding to word classes: determiner, numeral, adjective and noun respectively as in Example 3.41. Pre-modifiers have the function of specifying (i) a class of things, and (ii) some category of membership within this class (Halliday \& Matthiessen, 2004). The head is a noun which is about thing. The post-modifier may be a prepositional phrase as can be seen in Example 3.41, a defining relative clause or a non-finite clause (Thomson \& Droga, 2012). 


\subsubsection{Functions of nominalisation}

Nominalisation "is the single most powerful resource for creating grammatical metaphor" (Halliday \& Matthiessen, 2004, p. 656). It is most frequent in formal writing, less common in standard speech, and least often in non-standard varieties. It is a powerful device in English with reference to its wide range of morphological types and typical functions. Nominalisation makes the whole text a solid block of information. In others words, due to a great deal of nominalisation, the text is very dense as the information is compacted and difficult to process (Wenyan, 2012). Eggins (1994) states that "although heavily nominalised language can sound pretentious and may make the meaning obscure, the real motivation for this grammatical process is a functional one: by nominalising we are able to do things with the text that we cannot do in unnominalised text" (p.59). According to her, nominalisation has two textual advantages: first, it helps organise the text rhetorically; second, it helps pack more lexical content per sentence. Informed by the discussion of characteristics of nominalisation (Halliday, 1985b; Halliday, 1993a; Lê \& Wang, 2008) and Lê and Wang (2008), main characteristics and functions of nominalisation are summarised as follows. In Sentences 61-65, instances of nominalisation are in bold italic face.

- Nominalisations name processes, making actions (verbs) in a process become things or concepts (nouns) in other processes.

\section{Example 3.42}

The weather is constantly changing; but its changes have a definite pattern.

- A single nominalised clause packs in several complex abstract ideas.

\section{Example 3.43}

a. Every day shops lose thousands of dollars worth of valuable items. And this affects us all because prices increase and we have to pay extra.

b. The daily loss of thousands of dollars worth of valuable stock ultimately affects us all through increases in prices.

- Nominalisation creates long noun phrases to produce a lexically dense style. 


\section{Example 3.44}

Hubble's finding about the expansion of the galaxies revolutionised our understanding of the Universe and its origins.

- Nominalisation lessens the number of clauses and more information can be compacted into a nominal (noun) group. There are three clauses in Example 3.45a while there is only one nominalised clause in Example 3.45b.

\section{Example 3.45}

a. III If this method of control is used / trains will questionably (be able to) run more safely and faster // (even) when the weather conditions are most adverse. |||

b. II The use of this method of control unquestionably leads to safer and faster train running in the most adverse weather conditions. | | |

- With nominalisation, verbs become concepts rather than actions. As a consequence, the writer has the capability of expanding the amount and density of information to make further comment or observation about the concept in the clause. For example:

\section{Example 3.46}

a. The company decided to expand its asset base.

b. The decision to expand the asset base... (The verb is nominalised).

c. The decision to expand the asset base was a significant shift in the company's financial strategy (more information commenting upon the newly formed concept can now be added).

As seen in Example 3.46, the verb in the first clause (3.46a) is nominalised in the second clause (3.46b). As such, the writer can add more information commenting upon the newly formed concept (3.46c).

In scientific discourse, it demands high degree of nominalisation with all the grammatical metaphor that this involves. Two reasons for this are the structure of scientific argument and the structure of scientific knowledge (Halliday, 1993d). It is explained by Halliday (1993d) that 
The core of a scientific text was the development of a chain of reasoning (ultimately based on experiments) in which each step lead on to the next. But in order to lead on to the next, you have to be able to repeat what has gone before and is now being used as the springboard for the next move. (p.131)

With regard to the second function of nominalisation in scientific texts, Halliday (1993d) explains that scientists created a universe that was made of things to codify, extend and transmit scientific knowledge. In order to classify phenomena into a taxonomy of objects, the grammar has to turn them into nouns.

\section{Example 3.47}

... both ethyne and nitrogen oxide are kinetically stable ...

The kinetic stability of nitrogen oxide shows .... (Halliday, 1993d, p. 131) As illustrated in Example 3.47, the adjective group "kinetically stable" in the first clause is nominalised and packed in nominal group "the kinetic stability".

\subsubsection{Classifications of nominalisation}

Various forms of nominalisations have been discussed in literature (Banks, 2005; Halliday, 1993d, 1994, 1998, 2004; Halliday \& Martin, 1993; Halliday \& Matthiessen, 2004; Hartnett, 2004; Humphrey et al., 2012; Martin, 1993a, 1993d, 2008). Overall, nominalisation in light of the functional approach can be divided into two common kinds: verbal nominalisations (e.g., decision for decide) and adjectival nominalisations (strength for strong). There are three sub-types of verbal nominalisations: (i) forms of verbs and nouns have the same stems, (ii) verbs change their stems internally to become nouns, and (iii) suffixes are added to verbs to form nouns. For adjectival nominalisations, suffixes are added to adjectives to form nouns. According to Humphrey et al. (2012), in addition to verbal and adjectival nominalisations, conjunctions can be transferred into nouns to express cause and comparison as illustrated in Examples 3.49 and 3.51.

\section{Example 3.48}

The customer left because the food was cold. 


\section{Example 3.49}

The customer's reason for leaving was the cold food.

\section{Example 3.50}

Roebourne is a small town whereas Karratha is large.

\section{Example 3.51}

One difference between Roebourne and Karratha is size.

In Example 3.48, conjunction "because" is used to express the cause; however, in Example 3.49, "because" is nominalised by "reason". Similarly, in Example 3.50, conjunction "whereas" is used to compare and contrast. In Example 3.51, it is nominalised by "difference".

Based on the classifications of nominalisations in prior research, classification of nominalisation in this study is presented in Table 3.4 below.

Table 3.4. Classification of nominalisations investigated in the study

\begin{tabular}{|c|c|c|}
\hline $\begin{array}{l}\text { Types of } \\
\text { nominalisation }\end{array}$ & Description & Examples \\
\hline \multirow[t]{3}{*}{$\begin{array}{l}\text { From verb to } \\
\text { noun }\end{array}$} & Verbs and nouns have the same stems & $\begin{array}{l}\text { to use - the use } \\
\text { to plan - the plan }\end{array}$ \\
\hline & $\begin{array}{l}\text { Verbs change the stems to become } \\
\text { nouns }\end{array}$ & $\begin{array}{l}\text { to live - the life } \\
\text { to sell - the sale }\end{array}$ \\
\hline & $\begin{array}{l}\text { Verbs are added suffixes to become } \\
\text { nouns }\end{array}$ & $\begin{array}{l}\text { to explore - exploration } \\
\text { to decide - decision }\end{array}$ \\
\hline $\begin{array}{l}\text { From adjective } \\
\text { to noun }\end{array}$ & $\begin{array}{l}\text { Adjectives are added suffixes to become } \\
\text { nouns }\end{array}$ & $\begin{array}{l}\text { dense - density } \\
\text { weak - weakness }\end{array}$ \\
\hline $\begin{array}{l}\text { From } \\
\text { conjunction to } \\
\text { noun }\end{array}$ & $\begin{array}{l}\text { Conjunction which connect two clauses } \\
\text { in a clause complex can be replaced by } \\
\text { a nominalisation }\end{array}$ & because - the reason \\
\hline $\begin{array}{l}\text { From noun to } \\
\text { noun }\end{array}$ & $\begin{array}{l}\text { Nouns are added suffixes to become } \\
\text { another nouns }\end{array}$ & $\begin{array}{l}\text { leader-leadership } \\
\text { champion-championship }\end{array}$ \\
\hline
\end{tabular}


As far as the suffixes added to verbs, adjectives, and nouns to form nominalisation are concerned, this study adopted the classification of nominal endings proposed by Quirk et al. (1972, p. 993) cited in Ravelli (1999, p. 64) as described in Table 3.5.

Table 3.5. Nominal endings for verbs, adjectives and nouns

(Cited in Ravelli, 1999, p. 64)

\begin{tabular}{|c|c|c|c|}
\hline -suffix & \multicolumn{2}{|c|}{ Quirk's description } & Examples \\
\hline -ment & verbs & chiefly abstract nouns & $\begin{array}{l}\text { appointment, } \\
\text { settlement }\end{array}$ \\
\hline -ion & verbs & abstract and collective nouns & perception, suspicion \\
\hline -ation & verbs & abstract and collective nouns & $\begin{array}{l}\text { concentration, } \\
\text { verification }\end{array}$ \\
\hline -ing & verbs & abstract and concrete nouns & reloading, warnings \\
\hline -ity/-ty & adjective & abstract nouns & capacity, ability \\
\hline $\begin{array}{l}\text {-ance/- } \\
\text { ence }\end{array}$ & adjective & abstract nouns & assurance, important \\
\hline -al/-ial & dynamic verbs & countable, abstract nouns & proposal, arrival \\
\hline -ship & nouns & abstract nouns & generalship, leadership \\
\hline -ness & adjectives & abstract nouns & madness, awareness \\
\hline -ism & $\begin{array}{l}\text { nouns, } \\
\text { adjectives }\end{array}$ & abstract nouns & Idealism \\
\hline
\end{tabular}

\subsubsection{Summary}

In this section, the concept of nominalisation, the relations between nominalisation, nouns and nominal groups are discussed. Besides, functions of nominalisations as well as classification of nominalisations are also described. In summary, from the functional point of view, nominalisation is the process of turning verbs or adjectives into nouns. This leads to two main common types of nominalisations: verbal and adjectival nominalisations. However, a noun can be added a suffix to become another noun, and a conjunction used to express cause can be replaced by a noun. Although nominalisation is a form of nouns, not every noun is nominalisation. It has been shown that nominalisation and nominal groups lead to high lexical density of 
the text, as they pack more content meaning. Nominalisation is a typical feature of academic and scientific writing, characterising complexity of written language.

\subsection{Grammatical metaphor}

\subsubsection{What is grammatical metaphor?}

Another linguistic feature that characterises complexity of written language is grammatical metaphor which is originally mentioned by Halliday $(1985 a, 1994)$ and Halliday and Matthiessen (2004, 2014). Grammatical metaphor is "a substitution of one grammatical class, or one grammatical structure by another" (Haliday, 1994, p.79). Halliday $(1985 a, 1994)$ explains that congruent forms are the natural ways that language encodes the meanings they express. The non-congruent ways of encoding language are viewed as metaphorical expression or grammatical metaphor. Thus, to describe "what Mary saw", the speaker might say "Mary saw something wonderful" which includes the structure of "Senser + process + phenomenon". However, that sentence can be expressed in the metaphorical forms "Mary came upon a wonderful sight" or "A wonderful sight met Mary's eyes" which consists of "Actor + Process + Goal" (Halliday, 1985a, p.322). Such kind of metaphorical expressions are realised as grammatical metaphors (Halliday, 1985a, 1994).

Halliday (1994) states that the complexity in spoken language is dynamic while in writing, the complexity is more static since the ideational meaning is densely packed in nominal groups even though the clausal patterns are typically quite simple. Therefore, the complexity of written language relates to grammatical metaphor. Grammatical metaphor includes two main types: metaphors of mood (including modality) and metaphors of transitivity (including nominalisation). In terms of models of semantic functions, these are interpersonal metaphors and ideational metaphors respectively (Halliday, 1985a, 1994; Halliday and Matthiessen, 2004). These concepts are central in functional grammar and have been extensively discussed and studied (Anne, Marie, Vandenbergen, Miriam, \& Louise, 2003; Banks, 2003; Derewianka, 2003; Halliday, 1985a, 1993a, 1994, 1998, 2004, 2008; Halliday \& 
Martin, 1993, Halliday \& Matthiessen, 1999, 2004; Martin, 1992, 1993, 2008;

Ravelli, 1999).

\subsubsection{Grammatical metaphor versus traditional metaphor}

Traditional metaphor or lexical metaphor is the variations in meaning of a given expression. For instance, the word "life" can be literally understood as "the state of being alive" but when we say "Food is life", metaphorically it means "Food is vital". Halliday's concept of grammatical metaphor is vice versa. He looks at the different variations of one given meaning, for example, "many people" can be expressed by the congruent form "a large number" or the metaphorical form "a flood". Halliday (1994) explains that if something is said to be metaphorical, it must be metaphorical by reference to something else. That is why functional grammar looks at metaphor not "from below", as variation in the meaning of a given expression, but rather "from above", as variation in the expression of a given meaning. Therefore, according to Halliday, the notion of "literal" is not appropriate and he uses "congruent" instead to refer to the less metaphorical variant. These two contrastive perspectives on metaphor are summarised in Figure 3.3.

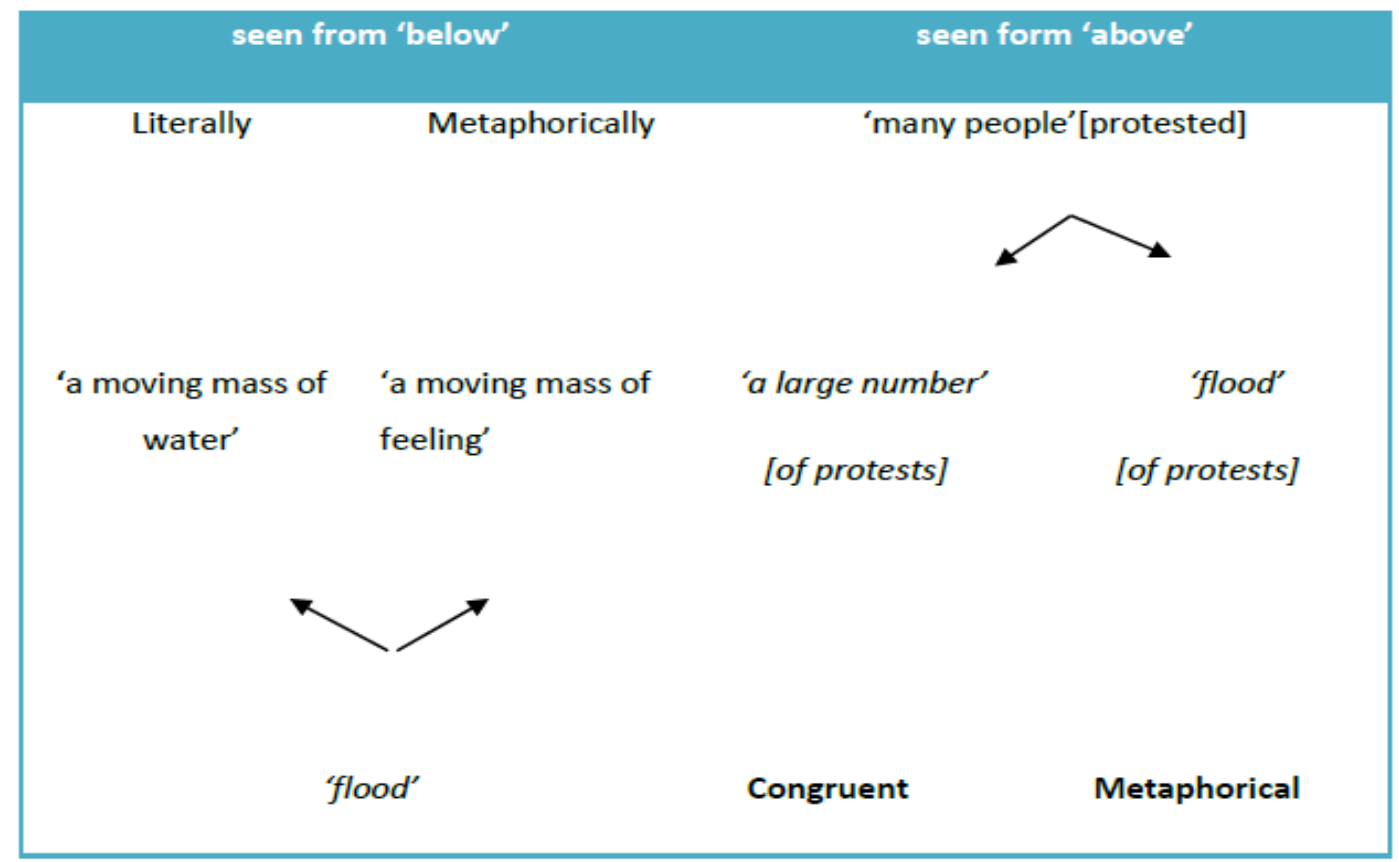

Figure 3.3. Two perspectives on metaphor (Adapted from Halliday, 1994, p. 342) 
Taverniers (2003, pp. 7-8) discusses important consequences of grammatical metaphor which are not explicitly pointed out by Halliday from his view of seeing "from above" as follows.

- What comes to compare are grammatical configurations, whereas in the traditional perspective, the focus is on meanings of a single lexeme. It is exactly this feature which brings in grammatical variation, which can then be interpreted in terms of metaphor.

- Various types of configurations can be compared as expressions of the same meanings. Whereas in the traditional perspective, there is simple opposition between literal and metaphorical, there is now a scale of congruency: some expressions are typical realisations of the given meaning, and are defined as congruent; others are more or less incongruent, as compared to the congruent realizations(s). This feature will be important in the description of various types of metaphors in later work.

- The concept of realisation comes to play an important role: what is compared, in this view, is different realizations of the same meaning. This aspect will be important in the theoretical characterization of grammatical metaphor in later work.

Table 3.6. Two perspectives on metaphorical variation (Taverniers, 2003, p. 8)

\begin{tabular}{|l|l|}
\hline Traditional view: "from below" & New view: "from above" \\
\hline Focus on lexical metaphor & Focus on grammatical metaphor \\
\hline Metaphor as variation in the meaning of a & Metaphor as variation in the expression of a \\
given expression & given meaning \\
\hline Comparison of the meanings of one & Comparison of various grammatical \\
lexeme (in different collocational contexts) & configurations as expressions of the same \\
\hline Literal versus metaphorical (transferred) & meaning \\
meanings of a given lexeme & $\begin{array}{l}\text { less congruent expressions of a given } \\
\text { meaning }\end{array}$ \\
\hline $\begin{array}{l}\text { (realization inherently plays a role in } \\
\text { lexical metaphor, but the concept is not }\end{array}$ & realisations of the same meaning \\
\hline
\end{tabular}




\subsubsection{Ideational metaphor (metaphor of transitivity)}

Ideational metaphor which expresses experiential meaning is mostly characterised through the transitivity system. It is realised by six main processes: material, mental, relational, verbal, existential and behavioural. Each process comprises three elements, namely process, participants and circumstances. Depending on different processes, participants and circumstances can be interpreted as transitivity functions like: Actor, Goal, Senser, Manner, Carrier, Identifier, Sayer, Receiver, Existent and Behaver. The transformations made between the processes and the alterations of participants and circumstances or transitivity functions are what Halliday means by the term grammatical metaphor. Therefore, Halliday (1994) proposes that to interpret a clause in its ideational function as the representation of a process, three phases should be included: (i) choice of process type: material, mental, relational, verbal, existential and behavioural which realised as (ii) configuration of transitivity functions: Actor, Goal, Senser, Manner, Carrier, Identifier, Sayer, Receiver, Existent and Behaver which realised in turn as (iii) categorisation of group-phrase classes: verbal group, nominal group, adverbial group, prepositional phrase, and their various sub-classes. For instance, if we want to express about what Mary saw, we will describe this as follows:

(i) as a mental process of perception,

(ii) having a structure of Process + Senser + Phenomenon,

(iii) this being realized as nominal group (conscious being) + verbal group (perception) + nominal group (anything or fact)

Table 3.7. Analysis of metaphor of transitivity

\begin{tabular}{|l|l|l|l|l|}
\multicolumn{2}{|l}{ Mary } & \multicolumn{2}{l}{ Sow } & Noming \\
\hline (iii) & Nominal group & Verbal group & Nominal group \\
\hline (ii) & Senser & Process & Phenomenon \\
\hline (i) & & Process: mental & & \\
\hline
\end{tabular}


Halliday (1994) proposes that knowing "typical ways of doing things" (p.343) is component of knowing a language. The 'typical' can be understood in many senses. It may be the way someone first learns to say something in their native language, or the way it is universally said, or the way it is used in the nonexistence of any special conditions and they do not eternally occur simultaneously. However, the typical patterns of wording, in other terms, "congruent" forms, are what speakers should recognise so as to find an additional dimension of metaphor existent within the language. Along with identifying congruent forms, we should be aware of other potentials where the typical pattern has not been adopted and the speaker or writer has decided on various alternative ways to describe things. In terms of metaphors of transitivity, we can choose different ways to say things. For instance:

\section{Example 3.51}

a. Mary saw something wonderful.

(Senser: Mary, mental Process: saw, Phenomenon: something)

b. Mary came upon a wonderful sight.

(Actor: Mary, material Process: came upon, Goal: a sight)

c. A wonderful sight met Mary's eyes.

(Actor: a sight, material Process: met, Goal: eyes)

As far as Example 3.51 is concerned, Examples 3.51b and 3.51c are considered the metaphorical forms of Example 3.51a. Saw (mental process: perception) in Example 3.51a is now presented as the material process came upon in Example 3.51b and becomes a participant (Goal) sight. In Example 3.51c, saw (mental process) becomes participant (Actor) sight; the material process is realised by met and another participant (Goal) is eyes. They are representations of the same state of affairs but absolutely not identical, their differences in wording lead to the difference to the entire meaning. Yet, they are potentially co-representational to shape a group of metaphorical variants of an ideational type (Halliday, 1994, p.344).

A question which has been put forward is how to represent metaphorical modes of expression. Technically, incongruent forms can be explored in two manners, either 
taking them at their face value or interpreting them in their congruent form. An example has been given for an illustration for an analysis of two sentences: they arrived at the summit on the fifth day and the fifth day saw them at the summit (Halliday, 1994, p.346).

Table 3.8. Analysis of metaphorical form

\begin{tabular}{|c|c|c|c|}
\hline The fifth day & Saw & hem & at the summit \\
\hline Senser & Mental: Perception & Phenomenon & Place \\
\hline
\end{tabular}

Table 3.9. Analysis of non-metaphorical form

\begin{tabular}{|l|l|l|l|}
\hline \multicolumn{1}{|l|}{ They } & \multicolumn{2}{l|}{ arrived } & \multicolumn{1}{l|}{ on the fifth day } \\
\hline Actor & Material & Place & Time \\
\hline
\end{tabular}

Halliday argues that both ways are not satisfactory since the first neglects the incongruent form "the fifth day saw them" and the second does not express exactly what the speaker or writer actually said. He suggests another way of analysis of metaphorical modes of expression is that a combination of the two above into a single representation. This technique can draw out the dissimilarity in grammatical function, expose the lexical metaphor in the sentence as well as recommend reasons for a metaphorical form.

Table 3.10. Two analyses combined (Halliday, 1994, p.346)

\begin{tabular}{|c|c|c|c|c|}
\hline On the fifth day & & 'they & $\begin{array}{l}\text { "at the } \\
\text { summit" }\end{array}$ & 'arrived' \\
\hline $\begin{array}{l}\text { Circumstance } \\
\text { Time }\end{array}$ & & $\begin{array}{l}\text { Participant } \\
\text { Actor }\end{array}$ & $\begin{array}{l}\text { circumstance } \\
\text { Place }\end{array}$ & $\begin{array}{l}\text { Process } \\
\text { Material }\end{array}$ \\
\hline the fifth day & saw & them & at the summit & \\
\hline $\begin{array}{l}\text { Participant } \\
\text { Senser }\end{array}$ & $\begin{array}{l}\text { Process } \\
\text { Mental: } \\
\text { Perception }\end{array}$ & $\begin{array}{l}\text { Participant } \\
\text { Phenomenon }\end{array}$ & $\begin{array}{l}\text { Circumstance } \\
\text { Place }\end{array}$ & \\
\hline
\end{tabular}


Six process types in the transitivity system are described in Table 3.11; process types and their nuclear participants are shown in Table 3.12; finally process types, their meanings and typical verbs expressing the meaning are summarised in Table 3.13. These classifications are informed by a number of discussions on metaphors of transitivity by functional linguists (Bloor \& Bloor, 1995; Eggins, 1994; Halliday, 1985b; Halliday, 1994; Lock, 1996; Martin et al., 1997; Thomson \& Droga, 2012).

Table 3.11. Process types in English

\begin{tabular}{|c|c|c|}
\hline Process type & Subcategory & Example \\
\hline Material & $\begin{array}{l}\text { event (i.e., happening) } \\
\text { actions (i.e., doing) }\end{array}$ & $\begin{array}{l}\text { The sugar dissolved. } \\
\text { She stirred the coffee. }\end{array}$ \\
\hline Mental & $\begin{array}{l}\text { Perception } \\
\text { cognition } \\
\text { affection }\end{array}$ & $\begin{array}{l}\text { She saw the car. } \\
\text { She forgot his name. } \\
\text { She liked his music. }\end{array}$ \\
\hline Relational & $\begin{array}{l}\text { Attributive } \\
\text { Identifying }\end{array}$ & $\begin{array}{l}\text { Maggie was strong. } \\
\text { Maggie was our leader. }\end{array}$ \\
\hline Behavioural & & She laughed. \\
\hline Verbal & & She replied. \\
\hline Existential & & There was once a beautiful princess. \\
\hline
\end{tabular}

Table 3.12. Process types and nuclear participants

\begin{tabular}{|l|l|l|}
\hline Process type & Nuclear participants & \multicolumn{1}{l|}{ Example } \\
\hline Material & Actor, Goal & She made the coffee. \\
\hline Mental & Senser, Phenomenon & She saw the car. \\
\hline Relational: attributive & Carrier, Attribute & Maggie was strong. \\
Identifying & Token, Value & Maggie was our leader. \\
\hline Behavioural & Behaver & She laughed. \\
\hline Verbal & Sayer & She replied. \\
\hline Existential & Existent & There was a beautiful princess. \\
\hline
\end{tabular}


Table 3.13. Process types, their meanings and typical verbs

\begin{tabular}{|c|c|c|}
\hline Process type & Category meaning & Typical verb \\
\hline Material & 'doing' & \\
\hline Action & 'doing' & transitive verbs: catch, eat, open \\
\hline Event & 'happening' & intransitive verbs: lie, cry, fall \\
\hline Behavioural & 'behaving' & \\
\hline Consciousness & & $\begin{array}{l}\text { look, watch, stare, listen, think, worry, } \\
\text { dream }\end{array}$ \\
\hline $\begin{array}{l}\text { Physiological } \\
\text { processes }\end{array}$ & & $\begin{array}{l}\text { sleep, cry, laugh, smile, frown, sigh, snarl, } \\
\text { whine, breathe, cough, faint, yawn, } \\
\text { chatter, grumble, talk }\end{array}$ \\
\hline $\begin{array}{l}\text { Verbal processes like } \\
\text { behaviour }\end{array}$ & & $\begin{array}{l}\text { chatter, grumble, talk, gossip, argue, } \\
\text { murmur, mouth }\end{array}$ \\
\hline $\begin{array}{l}\text { Body postures \& } \\
\text { pastimes }\end{array}$ & & sing, dance, lie, lie down, sit up, sit down \\
\hline Mental & 'sensing' & \\
\hline Perception & 'seeing' & feel, see, notice, hear, glimpse, taste, smell \\
\hline Cognition & 'thinking' & $\begin{array}{l}\text { remember, think, remind, believe, convince, } \\
\text { recognise, understand, know, discover, } \\
\text { prefer }\end{array}$ \\
\hline Desideration & 'wanting & want, desire, need, intend, plan \\
\hline Emotion & 'feeling' & like, love, hate, fear, frighten, upset \\
\hline Verbal & 'saying' & $\begin{array}{l}\text { say, tell, speak, promise, repeat, describe, } \\
\text { outline, explain, order, ask, make (a } \\
\text { statement), give (an order), praise, insult, } \\
\text { abuse, slander, flatter, blame, criticise, } \\
\text { claim }\end{array}$ \\
\hline Relational & 'being' & \\
\hline Attribution & 'attributing' & $\begin{array}{l}\text { to be, become, turn into, grow into, get, go, } \\
\text { remain, stay as, keep, seem, appear, } \\
\text { qualify as, turn out, end up as, look, sound, } \\
\text { smell, feel, taste, like }\end{array}$ \\
\hline
\end{tabular}




\begin{tabular}{|l|l|l|}
\hline Process type & \multicolumn{1}{|c|}{ Category meaning } & Typical verb \\
\hline Identification & 'identifying' & $\begin{array}{l}\text { play, act as, function as, serve as, mean, } \\
\text { indicate, suggest, imply, show, betoken, } \\
\text { mark, reflect, equal, add up to, make, } \\
\text { comprise, feature, include, represent, } \\
\text { constitute, form, exemplify, illustrate, } \\
\text { express, signify, realise, spell, stand for, be, } \\
\text { become, remain, involve, contain, } \\
\text { comprise, consist of, include, provide, } \\
\text { exclude, owe, deserve, lack }\end{array}$ \\
\hline Existential & 'existing' & $\begin{array}{l}\text { bexist, remain, arise, occur, come about, } \\
\text { happen, take place, follow, ensure, sit, } \\
\text { stand, lie, hang, rise, stretch, emerge, } \\
\text { grow, erupt, flourish, prevail }\end{array}$ \\
\hline
\end{tabular}

\subsubsection{Interpersonal metaphor (metaphor of mood and metaphor of modality)}

Another type of grammatical metaphor is interpersonal metaphor which expresses the interpersonal relationships or interaction between the speaker/writer and the listener/reader. The interpersonal meaning can be seen by means of evaluative words, modality and mood. Interpersonal metaphor consists of metaphor of mood and metaphor of modality.

\subsubsection{Metaphor of modality}

Taverniers (2003) explains about Halliday's concepts of modality metaphor as follows.

In metaphors of modality, the grammatical variation which occurs is based on the logico-semantic relationship of projection. Whereas modal meanings are congruently realised in modal elements in the clause (i.e., modal operators, modal adjuncts or mood adjuncts), interpersonal metaphors are defined by Halliday as expressing modal meanings outside the clause. In this way, metaphors of modality are 
explicit realizations of modal meanings. Speakers can express their opinions in separate clauses in various ways. (p.10)

That is to say, modal meaning or a degree of certainty is conveyed through modal items that occur within the clause which is being modally evaluated (Halliday, 1985b; Halliday, 1994). For example, to express the likelihood of David has left, a modal verb must or certainly can be used as can be seen in Examples 3.52a and 3.52b.

\section{Example 3.52}

\section{Congruent}

a. David must have left.

b. David will certainly have left.

Must and certainly are the expressions of modality from Halliday's point of view. However, a high degree of certainty can also be expressed by employing elements outside the clause such as think, likely, believed, clear which are considered expressions of interpersonal metaphors of modality. For example:

\section{Metaphorical:}

c. I think David has already left.

d. It is very likely that David has already left.

e. Everyone believes that David has already left.

$f$. It is clear that David has already left.

g. It's obvious that John has left.

h. Everyone admits that John has left.

i. It stands to reason that John has left.

j. It would be foolish to deny that John has left.

$k$. The conclusion can hardly be avoided that John has left.

I. Common sense determines that John has left.

m. You can't seriously doubt that John has left. (Halliday, 1985a, p. 334) 
As far as Examples 3.52a-m are concerned, Examples 3.52c-m are the metaphorical form of two original Examples 3.52a-b from the functional perspective. In the same way, to express a high likelihood of being true, there are many ways as follows:

\section{Example 3.53}

a. This must be true.

b. This has to be true.

c. This is definitely true.

d. This is obviously true.

e. It's quite sure that this is true.

$f$. It is certain that this is true.

g. There can be no doubt that this is true.

h. I am convinced that this is true.

i. It is my strong belief that this is true.

j. How could this not be true?

k. How could anyone in their right mind doubt that this is true?

I. If this isn't true, I'll eat my hat. (Lock, 1996, p. 193)

Examples $3.53 \mathrm{e}-\mathrm{I}$ are considered the metaphorical expressions of Examples 3.53a-b. Below is the summary of modality types and modal items which occur inside and outside a clause.

Table 3.14. Modality types and modal items

\begin{tabular}{|c|c|c|c|}
\hline \multicolumn{2}{|c|}{ Modality types } & Modal items & \multirow{2}{*}{$\begin{array}{l}\text { Examples } \\
\text { I think Mary knows }\end{array}$} \\
\hline Modalization & Probability & $\begin{array}{l}\text { I think, I'm certain, will, must, } \\
\text { may, probably, possibly, } \\
\text { certainly, it's likely, it's certain, } \\
\text { can't, won't, needn't }\end{array}$ & \\
\hline & Usuality & $\begin{array}{l}\text { always, usually, sometimes, } \\
\text { rarely, seldom }\end{array}$ & Fred usually sit quiet \\
\hline \multirow[t]{2}{*}{ Modulation } & Obligation & $\begin{array}{l}\text { Must, should, can, required, } \\
\text { supposed, allowed, can't, } \\
\text { shouldn't, needn't }\end{array}$ & $\begin{array}{l}\text { It's expected that } \\
\text { John goes }\end{array}$ \\
\hline & Inclination & determined, keen, willing & Jane's keen to help \\
\hline
\end{tabular}




\subsubsection{Metaphor of mood}

In the same way, interpersonal metaphors of mood are realised when a mood meaning is not expressed in the clause, but rather as an explicit element outside the clause. Common speech-functional formulae are originally the typical illustrations of mood metaphors which can be seen in the examples below.

- Command functioning as warning

- Metaphorical: I wouldn't ... if I were you

- Congruent: don't ...!

- Modalized offer, typically functioning as threat

- Metaphorical: I've a good mind to ....

- Congruent: Maybe l'll ...

- Modulated command, typically functioning as advice

- Metaphorical: She'd better ....

- Congruent: She should ... (Halliday, 1985a, p.343)

Mood includes declarative, interrogative, imperative and exclamative performing different functions - known as speech acts in terms of four basic categories: statements, questions, directives and exclamations respectively. Statements are used to give information; questions used to ask for information; directives used to get people to do things and exclamation used to express feelings (Lock, 1996). For example:

\section{Example 3.54}

a. They put the books into the boxes.

b. Did they put the books into the boxes?

c. Put the books into the boxes.

d. What a mess the books are in!

As far as imperative is concerned, it is used to make a command as in Example 3.54c. However, there are other ways to express a command which employs interrogative mood or declarative mood instead of imperative mood as follows: 
e. Can you put the books into the boxes?

f. Could you put the books into the boxes?

g. Why don't you put the books into the boxes?

h. Would you mind putting books into the boxes?

i. Perhaps you should put the books into the boxes.

j. I think you should put the books into the boxes.

Example 3.54c above is considered a non-metaphorical command and Examples 3.54e-f are considered metaphorical commands. The shift in mood, for example, in the realisational domain of commands from imperative to indicative clauses which can be either declarative or interrogative as mentioned in Examples 3.54e-f, is what Halliday (1985a, 1994) and Halliday and Matthiessen (2004) call mood metaphors.

\subsubsection{Grammatical metaphor and Nominalisation}

Nominalisation "is the single most powerful resource for creating grammatical metaphor" (Halliday \& Matthiessen, 2014, p. 729). Through this device, processes (linguistically realized as verbs) and properties (linguistically realised, in general, as adjectives) are reworded metaphorically as nouns, enabling an informational dense discourse. Therefore, instead of functioning in the clause as Process or Attribute, they function as Thing in the nominal group (Halliday \& Matthiessen, 2014, p.729).

$$
\text { is impaired by alcohol }
$$

they allocate an extra packer

some shorter, some longer

they were able to reach the computer

technology is getting better alcohol impairment

the allocation of an extra packer

of varying length

their access to the computer

advances in technology

In the phrases above, impairment, allocation, length, access, advances are considered as metaphor involving nominalised process which replaced the congruent forms of original expressions.

Metaphor of nominalisation probably evolved first in scientific and technical registers, then has gradually emerged in other varieties of adult discourse and tends 
to turn out to be a mark of prestige and power (Halliday \& Matthiessen, 2004, p.657). It helped construct hierarchies of technical terms on the one hand and developed an argument in science using complex passages 'packaged' in nominal form as Themes on the other hand. Martin (2008) states that:

science discourse necessarily involves grammatical metaphor in order to build knowledge and organize text. As far as building knowledge is concerned, grammatical metaphor is crucial to establishing technical terms and relating them to one another, and to explaining causal relations among processes. As far as organizing text is concerned, grammatical metaphor is crucial to appropriately parcelling out information as peaks of thematic prominence, providing readers with an angle on the field and peaks of news building on from what can be assumed. (p.804)

However, in the process of replacing nominal patterns by clausal patterns, some of the information is lost. For example, the "Classifier + Thing" construction alcohol impairment gives no indication of the semantic relation between the two and could be agnate to alcohol impairs (alcohol as an Actor), alcohol is impaired (alcohol as a Goal). The writer knows what it means, but the reader might not. This type of highly metaphorical discourse tends to mark off the expert from those who are uninitiated (Halliday and Matthiessen, 2014).

Grammatical metaphor involving nominalisation and nominalisation itself is often confusing. (Christie \& Derewianka, 2008) clarifies the concepts of nominalisation and grammatical metaphor because in most cases the two terms are used interchangeably. She explains that nominalisation is a broad term referring to the phenomenon of construing various meanings in nominal form. However, not all nominalisations involve grammatical metaphor. If nominalisation cannot be unpacked to the congruent form, it is not metaphorical or not a type of grammatical metaphor. For instance, organization in Example 3.55a cannot be unpacked to the congruent form, so it is just a verbal nominalisation of the verb organize. However, in Example 3.55b, organization can be unpacked to the congruent form as can be 
seen in Example 3.55c; thus, organization in Example 3.55b is a grammatical metaphor.

\section{Example 3.55}

a. It is a great organization.

b. The success of the party was due to her great organization.

c. The party was a success because she organised things so well.

\subsubsection{Summary}

It is assumed that grammatical metaphor is characteristically complex, while the non-metaphorical form is greatly simple (Halliday \& Matthiessien, 2014). Grammatical metaphor is the significant grammatical feature in academic writing and scientific discourse. This section has discussed metaphor in the traditional and Hallidayan views, and pointed out the differences between the two approaches. Two kinds of grammatical metaphors, namely ideational metaphor and interpersonal metaphor have also been examined, and nominalisation that involves ideational metaphor has been discussed.

\subsection{Thematic structure}

\subsubsection{What is Theme-Rheme?}

When speakers/writers produce a message, they produce only one word at a time, and they have to choose a starting point for their message (McCabe, 1999). Halliday (1985a, 1994) defines the point of departure of the message as Theme, and the remainder of the message as Rheme. In other words, Theme is the element which comes first in the message, while Rheme is the one which provides additional information to the starting point and is available for subsequent development in the text. The clause as message is therefore organised into Theme + Rheme. The system of Theme relates to the textual metafunction of the language. It organises "the clause to show what its local context is in relation to the general context of the text it serves" (Martin et al., 1997) (Martin, Matthiessen \& Painter, 1997, p.21).

Distinction between Theme and Rheme is summarised in Table 3.15. 
Table 3.15. Distinction between Theme and Rheme

(Martin, Matthiessen \& Painter, 1997, p.22)

\begin{tabular}{|c|c|}
\hline Theme & Rheme \\
\hline $\begin{array}{l}\text { Point of departure of clause as message; } \\
\text { local context of clause as a piece of text }\end{array}$ & $\begin{array}{l}\text { Non-theme - where the presentation } \\
\text { moves after the point of departure; what is } \\
\text { presented in the local context set up by } \\
\text { Theme. }\end{array}$ \\
\hline Initial position in the clause & Position following initial position \\
\hline
\end{tabular}

As Theme is the first constituent of the clause, and Rheme is the rest of the clause; the different choice of Theme contributes to a different meaning and different organisation of the text as can be seen in the examples in Table 3.16.

Table 3.16. Examples of Theme choice (Adapted from Thompson, 1996, pp.118-119)

\begin{tabular}{|l|l|}
\hline Theme & Rheme \\
\hline For centuries, & yellow canaries have been used to 'test' the air in mining. \\
\hline Yellow canaries & $\begin{array}{l}\text { have been used to 'test' the air in mining for centuries } \\
\text { have used yellow canaries to 'test' the air for centuries }\end{array}$ \\
\hline Miners & \begin{tabular}{l} 
yellow canaries have been used to 'test' the air for centuries \\
\hline In mining
\end{tabular} \\
\hline $\begin{array}{l}\text { To 'test' the air in } \\
\text { mining }\end{array}$ & $\begin{array}{l}\text { hellow canaries have been used for centuries } \\
\text { canaries }\end{array}$ \\
\hline The air & \\
\hline
\end{tabular}

\subsubsection{Types of Theme}

\subsubsection{Simple Themes (topical Theme or experiential Theme)}

Simple Themes are also recognised as experiential (topical) theme (Halliday, 1994) or ideational Theme (Martin et al., 1997). Simple Themes are divided into unmarked topical Theme and marked topical Theme. If the first topical element of a 
declarative clause is also the Subject, it is an unmarked Theme. Vice versa, nonsubject Themes are marked (Martin et al., 1997). Simple Theme is the first element in the clause that conveys the 'representational' meaning. It contains only one structural element which is constituted by just one unit: one nominal group, adverbial group or prepositional phrase (Halliday, 1994). Therefore, it might be a 'participant' (a), a 'circumstance' (b), giving information about time, place, manner, cause, etc. or the process (c) (Martin et al., 1997). In Examples 3.56, 3.57 and 3.58, Themes are recognised in italic face.

\section{Example 3.56}

Many people in North America begin college at the age of eighteen.

(Unmarked Theme as a participant)

(Anderson, 2003a, p.32)

\section{Example 3.57}

In the United States, the cost of a college education can be quite expensive.

(Marked Theme as a circumstance)

(Anderson, 2003a, p.32)

\section{Example 3.58}

Says Mr Smith: "It's too early to draw any conclusions yet".

(Marked Theme as the process)

(Martin et al., 1997, p.24)

\subsection{Unmarked Theme}

Unmarked Theme functions as the subject of the clause. It may be a noun or pronoun realised as a nominal group or a nominalisation.

\subsection{Marked Theme}

Unmarked Theme functions as adjunct or complement of the clause. Adjunct consists of adverbial group or prepositional phrase. Complement can be a nominal group or a nominalisation. The distinction between marked and unmarked topical Theme (Halliday \& Mathiessen, 2004, p.74) is shown in Table 3.17. 
Table 3.17. Unmarked Theme and marked Theme in declarative clauses

\begin{tabular}{|c|c|c|c|}
\hline \multicolumn{3}{|c|}{ Functions } & Clause example \\
\hline \multirow[t]{3}{*}{$\begin{array}{l}\text { Unmarked } \\
\text { Theme }\end{array}$} & \multirow[t]{3}{*}{ Subject } & $\begin{array}{l}\text { Nominal group: } \\
\text { pronoun as Head }\end{array}$ & I had a little nut-tree \\
\hline & & $\begin{array}{l}\text { Nominal group: } \\
\text { common or proper } \\
\text { noun as Head }\end{array}$ & $\begin{array}{l}\text { A wise old owl lived in an oak. } \\
\text { Mary had a little lamb. }\end{array}$ \\
\hline & & Embedded clause & $\begin{array}{l}\text { What I want is a proper cup of } \\
\text { coffee. }\end{array}$ \\
\hline \multirow{5}{*}{$\begin{array}{l}\text { Marked } \\
\text { Theme }\end{array}$} & \multirow[t]{2}{*}{ Adjunct } & Adverbial group & Merrily we roll along \\
\hline & & Prepositional phrase & On Saturday night I lost my wife \\
\hline & \multirow[t]{3}{*}{ Complement } & $\begin{array}{l}\text { Nominal group: } \\
\text { common or proper } \\
\text { noun as Head }\end{array}$ & $\begin{array}{l}\text { A bag-pudding the King did } \\
\text { made } \\
\text { Eliot you're particularly fond of }\end{array}$ \\
\hline & & $\begin{array}{l}\text { Nominal group: } \\
\text { pronoun as Head }\end{array}$ & This they should refuse \\
\hline & & Embedded clause & $\begin{array}{l}\text { What they could not eat that } \\
\text { night the Queen next morning } \\
\text { fried. }\end{array}$ \\
\hline
\end{tabular}

\subsubsection{Multiple Themes (textual and interpersonal Themes)}

We have discussed simple or topical Theme which expresses the representational function and construes a quantum of human experience in the clause. There are also other elements preceding the topical Theme which are either textual or interpersonal in function, playing no part in the experiential meaning of the clause (Halliday \& Matthiessen, 2004). When there is a topical Theme plus textual Themes and/or interpersonal Themes in a clause, the clause has multiple Themes. Multiple Themes are normally ordered like this: textual ${ }^{\wedge}$ interpersonal ${ }^{\wedge}$ experiential. In all cases, the experiential (the topical Theme) comes last and the one followed is part of the Rheme. 


\subsection{Textual Theme}

"Textual Themes almost always constitute the first part of the Theme, coming before any interpersonal Themes. They give thematic prominence to textual elements with a linking function" (Martin et el., 1997, p.24). Textual theme can be recognised by conjunctions, relative pronouns, conjunctives, and continuatives which are in bold face in Examples 3.58-3.62.

- Structural conjunctions

- linking two clauses in a coordinating relation

\section{Example 3.58}

Now, I often eat soup when I am tired or worried, and it helps me feel better. (Anderson, 2003a, p.12)

- marking one clause as dependent on another

\section{Example 3.59}

As she approaches, your classmate suddenly raised her eyebrows. (Anderson, 2003a, p.140)

- Relatives

\section{Example 3.60}

We heard Professor Smith's lecturer, which was a great disappointment. (Martin et el., 1997, p.26)

- Conjunctives

\section{Example 3.61}

However, the English language has many variations. (Anderson, 2003a, p.116)

- Continuatives

\section{Example 3.62}

Oh, what a surprise to see you here! (Anderson, 2003a, p.140) 


\subsection{Interpersonal Theme}

The Interpersonal Theme is any combination of vocative, modal and mood-marking (Halliday, 1994, p.53). Besides, Martin et al (1997, p.25) describe many ways to define interpersonal Theme based on the factors below.

- Finite which is normally realised as auxiliary verbs

\section{Example 3.63}

Did you use paper money to buy it? (Anderson, 2003a, p.12)

- Wh- element

\section{Example 3.64}

What is this book made of? (Anderson, 2003a, p.12)

- A vocative

\section{Example 3.65}

Mr Wolf, Mr. Wolf, may we cross your golden waters?

- An Adjunct which is normally realised as an adverb

\section{Example 3.66}

In 1857, the first soccer team was created in Sheffield, England. (Anderson, 2003a, p.87)

- Interpersonal Theme in Examples 90-91 are also treated as interpersonal metaphors of modality (Halliday, 1985a, 1994).

\section{Example 3.67}

I don't suppose you need Old English and Anglo-Saxon.

\section{Example 3.68}

Do you think I should take an early play like the Prometheus? (Martin et al., 1997, p.25)

The components of textual and interpersonal Themes can be summarised in Appendix 8. An example about a multiple Theme which consists of six types of nontypical element in thematic position is presented in Table 3.19. 
Table 3.18. Analysis of multiple Themes

\begin{tabular}{|c|c|c|c|c|c|c|c|}
\hline Well & but & then & surely & Jean & wouldn't & the best idea & be to join in \\
\hline Cont & Stru & Conj & Modal & Voc & Finite & Nominal & \\
\hline \multicolumn{3}{|c|}{ Textual } & \multicolumn{3}{|c|}{ Interpersonal } & Topical & \\
\hline \multicolumn{7}{|c|}{ Theme } & Rheme \\
\hline
\end{tabular}

\subsubsection{Thematic equatives}

"Halliday uses the term 'thematic equative' because the Theme-Rheme structure is expressed in the form "Theme=Rheme" (Thompson, 1996, p.126). Examples 3.69 and 3.70 are illustrations of thematic equatives and Examples 3.71, 3.72 and 3.73 are illustrations of marked thematic equatives. In these examples, themes are in bold face.

\section{Example 3.69}

What no one seemed to notice was the writing on the wall.

\section{Example 3.70}

The thing that impressed me most is their enthusiasm for the job.

\section{Example 3.71}

That's not what I said.

\section{Example 3.72}

Three thousand dollars a month is what I need.

\section{Example 3.73}

Marking assignments is, after all, what she does best.

\subsubsection{Predicated Themes}

Cleft sentence is a traditional term replaced by predicated Theme by Halliday is the system of Theme predication which involves a particular of thematic and 
informational choices (Halliday \& Mathiessen, 2014, p.122). Sentences 3.74, 3.75 are examples of predicated Themes.

\section{Example 3.74}

It wasn't the job that was getting me down.

\section{Example 3.75}

It wasn't until 1986 that we finally came back to work in the UK.

\subsubsection{Group/phrase complexes as Theme}

Simple Themes discussed in Section 3.6.2.1 consist of one structural element functioning as Themes. However, Themes may include two or more number of nominal groups, adverbial groups or prepositional phrases as illustrated in Examples 3.76, 3.77, 3.78 and 3.79, which are taken from Halliday \& Mathiessen (2014, p.92).

\section{Example 3.76}

The Walrus and the Carpenter were walking close at hand.

\section{Example 3.77}

Tom, Tom, the piper's son stole a pig [and away did run].

\section{Example 3.78}

From house to house I wend my way.

\section{Example 3.79}

On the ground or in the air small creatures live and breathe.

\subsubsection{Theme in clause complexes}

Our discussions so far are about Themes in single clauses. Themes in clause complexes which contain a dependent clause and a main clause can be analysed in two ways (Halliday, 1985a, 1994; Halliday \& Mathiessen, 2004, 2014; Thompson, 1996).

(i) analysing Theme and Rheme in each clause separately (Example 3.80a)

(ii) analysing Theme and Rheme of a clause complex as a whole (Example $3.80 \mathrm{~b})$. If the dependent clause comes first, it is the Theme. If the main 
clause comes first, the Theme of the clause complex is the Theme of the first clause.

Example 3.80a

\begin{tabular}{|c|c|c|l|}
\hline As the universe & expanded, & the temperature of the radiation & decreased \\
\hline Theme $^{1}$ & Rheme $^{1}$ & Theme $^{2}$ & Rheme $^{2}$ \\
\hline
\end{tabular}

Example 3.80b

\begin{tabular}{|l|l|l|l|}
\hline As the universe & expanded, & the temperature of the radiation & decreased \\
\hline \multicolumn{2}{|l|}{ Theme $^{1}$} & Rheme $^{1}$ & Rheme $^{3}$ \\
\hline Theme $^{2}$ & Rheme $^{2}$ & Theme $^{3}$ &
\end{tabular}

What if there are more than one dependent clauses or dominant clauses in a clause complex? The answer might lie on the decision of unit of analysis. (Fries, 1994) states that T-Unit is the most effective way for analysing Theme, others might base on simple clause or clause complex as the basic unit of Theme analysis. It is argued by the researcher that irrespective of the approach chosen, consistency in doing the analysis to fulfil the research aims is the first and foremost important factor.

\subsubsection{Theme and Mood}

\subsubsection{Theme in declarative clauses}

Themes in declarative clauses include unmarked and marked themes as discussed in Section 3.6.2.1. Unmarked theme which is the subject of the clause might be a nominal group or an embedded clause. Marked theme functions as adjunct consisting of adverbial or prepositional phrases; or complement comprising of nominal group and embedded clause (Halliday, 1994). "Soccer" in Example 3.81 is unmarked Theme of this sentence, while "in 1863" is marked Theme of Example 3.82 . 


\section{Example 3.81}

Soccer is one of the most popular sports in the world.

\section{Example 3.82}

In 1863, eleven English teams met to form the first Football Association.

\subsubsection{Theme in interrogative clauses}

Interrogative is another clause type, which seeks to find out some missing information by asking questions. There are two kinds of questions: Wh-questions and Yes/No questions. Wh-interrogative is the identity of some element in the content. In other words, the speakers want to know something missing information. Wh-interrogatives are realised by Wh-elements such as: who, what, when, where, how, etc. (Halliday \& Matthiessen, 2014). Themes in Wh-interrogatives are constituted merely by the Wh-elements as can be seen in Example 3.83.

\section{Example 3.83}

Who was the winner in the game? Yes/No Interrogative is also known as Polarity "yes or no". The element functioning as Theme is the element embodying the expression of polarity called the Finite verbal operator such as: can, could, is, are, do, didn't, haven't, etc. However, the Finite operator is not a component of in the experiential structure of the clause; the Theme, therefore extends over the Subject as well (Halliday \& Matthiessen, 2014, p.102).

\section{Example 3.84}

Have you ever been to the United States?

\section{Example 3.85}

Can you speak Spanish?

In addition to unmarked themes as typical of interrogative clause, marked themes sometimes occur in interrogatives, as can be seen in Example 3.86

Example 3.86

After dinner, will you go out with me? 


\subsubsection{Theme in imperative clauses}

Imperative clauses include two types. The first type is "I want you to do something" (Halliday \& Matthiessen, 2014, p.103) which can be in positive or negative forms such as: go away, don't go away, you go away, don't you go away. If the subject is absent in the first type of imperative (go way, don't go way), the Theme is the verb functioning as Predicator or don't plus Predicator. If the subject is present as in you go away, don't you go away, the Theme is the subject (you) or don't plus the Subject (don't you).

The second type of imperative is "I want use (you and me) to do something" (Halliday \& Matthiessen, 2014, p.103) which is also in the two forms: positive or negative, for example: let's go, don't let's go. The Theme with regard to this type is let's, let me or don't plus let's, let me. It is worth noting that the imperative is the only type of clause in which the Predicator (the verb) is regularly found as Theme, whereas this is not impossible in other mood (Halliday \& Matthiessen, 2014, p.103). Examples of unmarked theme in imperative clauses can be seen in Example 3.87.

\section{Example 3.87}

Speak out loud.

Don't give up.

You sing a song.

Don't you sing a song.

Let's take a stroll.

Don't let's argue about it.

Don't let me down.

Imperative clause can have a marked Theme with starts with an Adjunct as can be seen in Example 3.88

Example 3.88

You go on holiday this summer, will you?

On arrival in Launceston, take a subtle bus to the university.

At the second traffic lights, turn left.

For security, lock the door before going to bed. 


\subsubsection{Theme in exclamative clauses}

In an exclamative, the exclamatory $\mathrm{WH}$-element functions as Theme as can be seen in Example 3.89.

\section{Example 3.89}

What a lovely present that I've got!

\section{How wonderful it is!}

To summarise, how to recognise unmarked Theme in different mood of clauses is shown in Table 3.19.

Table 3.19. Mood type and unmarked Theme selection (Halliday \& Mathiessen, 2014, p.104)

\begin{tabular}{|l|l|l|}
\multicolumn{2}{|l|}{ Mood of clause } & \multicolumn{2}{l|}{ Typical unmarked Theme } \\
\hline Declarative & Nominal group functioning as Subject \\
\hline Interrogative & Yes / No & $\begin{array}{l}\text { First word (finite operator) of verbal group plus } \\
\text { nominal group functioning as Subject }\end{array}$ \\
\cline { 2 - 4 } & Wh- & $\begin{array}{l}\text { Nominal group, adverbial group or prepositional } \\
\text { phrase functioning as interrogative (Wh-) element }\end{array}$ \\
\hline Imperative & 'you' & $\begin{array}{l}\text { Verbal group functioning as Predicator, plus } \\
\text { preceding don't if negative }\end{array}$ \\
\cline { 2 - 3 } & 'you and me' & Let's plus preceding don't if negative \\
\hline Exclamative & & $\begin{array}{l}\text { Nominal group or adverbial group functioning as } \\
\text { exclamative (Wh-) element }\end{array}$ \\
\hline
\end{tabular}

\subsubsection{Summary}

Theme is an important concept in text organisation in realising clause as a message. This section has discussed various types of Theme including simple Theme, multiple Theme, thematic equatives, group/phrase complexes as Theme and Theme in clause complexes. The relationship between Theme and Mood consisting of Theme in declaratives and non-declaratives has also been examined. 


\subsection{Hierarchy of periodicity}

Hierarchy of periodicity is a characteristic of written discourse. Periodicity refers to information flow in a text known as the rhythm of discourse (Martin \& Rose, 2003). The term wave is used to compare information flow and semantic unfolding of discourse with semantic waves within the clause itself (Halliday, 1985a, 1994) and beyond the clause (Martin, 1993a; Martin \& Rose, 2003). At the clausal level, information flow is concerned with little waves realised in Themes and News. Theme is the point of departure of the message concerned with the peak of prominence, giving the orientation of what will happen in the rest of the clause. Theme conflating with subject of the message in declaratives is called unmarked Theme or topical Theme. When the ideational meaning realised in Complements and Adjuncts comes before the subject in declaratives, it is known as marked Theme. New is the other end of the clause recognised through tonic prominence, expanding information when text unfolds. Theme and New are both concerned with the textual metafunction of language (Halliday, 1985a, Martin, 1993, Martin \& Rose, 2003).

At the discourse level, waves of Theme and New are displayed by larger phases of discourse: bigger waves realised in hyperThemes and hyperNews at the paragraph level and tidal waves realised in macroThemes and macroNews at the whole text level. HyperThemes, higher level Themes, refer to the topic sentences of paragraphs or phases of discourse, predicting what each phase of discourse will be about. New information is often distilled in final sentences of phases, functioning as hyperNews to those phases (Martin \& Rose, 2003). Generally, "writing looks forward more often than it looks back. Therefore, hyperThemes are more common than hyperNews; there's more prospect than retrospect" (Martin \& Rose, p.182). At the whole text level, macroThemes, higher level Themes predicting hyperThemes, refer to introductions of texts; and macroNews referring to the text conclusions. Wave patterns displayed by layers of Themes with reference to hyperThemes and macroThemes construct the text's hierarchy of periodicity. Layers of Themes build the method of development of a text which is strongly associated with stages of genres. Layers of News develop the ideational meanings of discourse with a 
particular focus on the text field. Layers of Themes and News in discourse are summarised in Figure 3.4 (Martin \& Rose, 2003).

\section{Method of Development}

(genre focus)

macroTheme

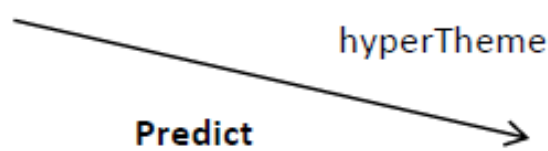

Theme
Point

(field focus)

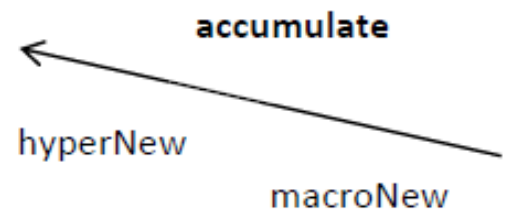

Figure 3.4. Layers of Themes and News in discourse (Martin \& Rose, 2003, p.186) Regarding the role of grammatical metaphor in text organisation in relation to its hierarchy of periodicity, Martin (1993a) states that grammatical metaphor is "the grammar's most powerful resource for packing meanings" (p.242), grouping them into Theme and New. It "is not simply a field-oriented resource for reasoning and defining terms, but a mode-oriented resource as well" (Martin, 1993a, p. 241) . However, "higher level Themes and News have more information to predict and distil than lower ones. This puts even more pressure on them to deploy grammatical metaphors that pack in the information they predict and distil." (Martin \& Rose, 2003, p. 194)

\subsection{Review of previous studies}

\subsubsection{Research on lexical density}

The first method of calculating lexical density was originally proposed by Ure (1971a), which is the proportion of lexical items per total words. In her paper presented at a conference in Cambridge in 1971, Ure discussed the distinction between lexical density of spoken texts and that of written texts. She found that spoken language has a lexical density value of less than $40 \%$ while written language has a lexical density of over $40 \%$. Halliday (1985b) proposes two methods of lexical 
density in which the first measure is similar to Ure's method, which is based on total words of the texts. The second measure of lexical density proposed by Halliday $(1985 b)$ is based on clauses, which is a ratio of the number of lexical items per the number of clauses. Halliday also investigated the difference between written and spoken language. He states that spoken language has a lower lexical density value (ranging between 1.5 and 2) than written language (ranging from 3 to 6 ) and complexity of written language is lexical while it is grammatical in spoken language (Halliday, 1985b). O'Loughlin (1994) discussed the strengths and weaknesses of Ure and Halliday's studies. She comments that Ure's findings is of great importance as it measures the degree of "orality" versus "literacy" in a text (O'Loughlin, 1994, p.5); however, the distinction between lexical items and grammatical items is not clear in Ure's study. With regard to Halliday's research, he provides a useful framework for distinguishing between lexical and grammatical items. He also proposes the framework for determining high frequency lexical items which have half of value of the low frequency lexical one. Nevertheless, the distinction between lexical and grammatical items in Halliday's view is just based on the sentence level only and neglects the discourse phenomema in speech (O'Loughlin, 1994). Therefore, in her study on output on two versions of an oral proficient test, O'Loughlin (1994) proposes that discourse makers, interjections, reactive tokens and lexical filled pauses belong to grammatical items system in addition to other word classes belonging to grammatical items proposed by Halliday (1985b). The distinction between grammatical items and lexical items has also been much discussed by linguists (Castello, 2008; Haspelmath, 2001; Lyons, 1968; Palmer, 1974; Quirk et al., 1972; Stubbs, 1986).

Since then, measures of lexical density proposed by Ure (1971) and Halliday (1985b) have been adopted in calculating lexical density in studies of texts and different outcomes have been achieved. With reference to written texts, Martin (2006) studied lexical density of two articles in the Newsweek magazine with a focus on politics and business text types, and found out that the political article was lexically much denser compared with the business article. Irina (2011a) in her Master's thesis analysed the systemic function of arts textbooks in a primary school from 
Grade 2 to Grade 5 in Virginia revealing that although there is a general assumption that the language of textbook instruction continuously grows more complex with the gradual increase of grade level, there was an absence of factual evidence to show this change. The lexical density and lexical variation across levels were not considerable. Moreover, Narelle et al. (1994) investigated difficulties encountered in students' statistics examinations in their first year at an Australian university. They analysed 186 students' examination papers with the hypothesis that language difficulty would influence student performances in the examinations. Then, the lexical density of the texts was determined and compared with the performances of students obtaining full points and those who obtained no points. However, the finding was unexpected. There was no connection between student achievement and the linguistic complexity of the questions in terms of lexical density. Likewise, Cheryl (1995) examined the correlation of lexical proficiency to the quality of English as a second language (ESL) compositions written by students at Indiana University in the matters of lexical density, lexical errors and lexical variations. The essay topics given to students had a relatively average lexical density. As four lexical measurements were used in the study, lexical density could be the most concisely interpreted. The results indicated a non-significant relationship between the proportion of content words and the quality of essays. It should be added that Vidakovic and Barker (2009) found a similar result. The aims of their research were to explore the lexical progression in general purpose English target texts. They investigated a dataset of 100 passing Cambridge Certificates in English as a second or other language (ESOL) Skills for Life with writing scripts of 36 million words taken from the Cambridge Learner Corpus. Thenceforward, 20 students from each of five levels (Entry 1, Entry 2, Entry 3, Level 1, Level 2) were selected to represent levels A1-C1 of the Common European Framework of Reference. Students wrote between 53 and 1003 words which provided 2,300-14,000 words per level. The results suggested that although the average length of words and sentences, the number of different words, as well as lexical variation increased with proficiency, lexical density did not differentiate according to proficiency levels. 
Aside from written texts, lexical density has been scrutinised in spoken texts as well (Hilary, 2001; John \& Paul, 2002). John and Paul (2002) surveyed the transcriptions of 88 recorded IELTS Speaking Tests from band 4 to band 8 at 21 test centres worldwide in order to access the candidates' vocabulary use in terms of lexical density, lexical diversity, lexical sophistication, and the use of formulaic language. The results revealed a decreasing pattern from band 8 to band 4 regarding the lexical features indicated as well as a substantial disparity within bands which indicates that these lexical statistics do not provide a reliable foundation to assess speaking proficiency levels. It also showed that candidates at the advanced level used fluently a variety of formulaic expressions containing many high-frequency words rather than low-frequency words, while candidates at band 4 rarely used formulaic language (John \& Paul, 2002). Hilary (2001) analysed the BASE corpus of authentic academic speech with 30 undergraduate lectures delivered at Warwick University between 1998 and1999 to examine lexical density and the relationship between lecturing purpose and delivery style. The findings show that lectures which were delivered more quickly tended to be sparser, while lectures produced more slowly tended to be denser. Moreover, the professional speakers delivered speeches with the highest densities and the language used in these speaking contexts was formulaic and pre-rehearsed.

It is worth noting that lexical density in written and spoken languages has been compared (Belinda, 2007; Halliday, 1985b; Yu, 2007). As noted earlier, there are several formulas to calculate lexical density in a text. It can be expressed either by the proportion of the number of content words per the total words (Halliday, 1985b; O'Loughlin, 1994; Ure, 1971) or as a ratio of the amount of lexical words per clause (Halliday, 1985). Irrespective of the parameters adopted, research over the past years has indicated that, overall, writing is much denser lexically compared to speech (Belinda, 2007; Halliday, 1985b; Yu, 2007). Interestingly, the lexical density of various languages other than English has also been examined, including Bantu languages (Oliver, 2007), Swedish and German (Linnarud \& Thoursie, 2008) and Dutch (Henrichs, 2010). Although a considerable number of studies have been done to investigate lexical density in a variety of registers in literature, no research has 
been conducted to examine lexical density in international English textbooks used in TEFL in developing countries.

\subsubsection{Research on nominalisation}

Nominalisation is another concept related to linguistic complexity. Nominalisation types and its application have been a focus for investigation and discussion in research in recent years (Billig, 2008; Hartnett, 2004; Janelle, 2011; Jeremy \& Timothy, 2008; Matthias, 2012; Wenyan, 2012). Harnett (2004) studied nominalisations that are made by transforming a verb, either internally or by adding a suffix. She names this type of grammatical metaphor verb-change nominalisations, whilst other linguists call them non-zero derived deverbal nouns or stativation. According to Hartnett (2004), nominalisation is most frequent in writing, less common in standard speech, and least often in non-standard varieties; heavy nominalisation makes a text sound authoritative, formal, impersonal and prestigious. Janelle (2011) carried out a practical research with the purpose of focusing on how and what secondary teacher learn about nominalisations. The research involved three secondary teachers and three academic coaches at the secondary level in the Spring Hills Unified School District Situated in the Central Valley of California. The study recognised, used and comprehended nominalisation by doing a test and involves in personal interviews. The outcome confirms that teachers, on the whole, demonstrated limited understanding of nominalisations in texts. Hence, the importance of teaching nominalisations to teachers and students should be emphasised.

Additionally, Jeremy and Timothy (2008) refer to a dataset for use in identifying and interpreting compound nominalisations. In their point of view, a compound noun is a sequence of two or more nouns, for example cat house means "a house for a cat" or house cat means "a cat which lives in a house." Compound nominalisations are one of the subclass of compound noun occurring when the head noun is deverbal, and this type of nominalisation should be taken into consideration (Jeremy \& Timothy, 2008). Billig (2008) mentions nominalisation, passivisation and some ideological features associated with these notions as well as 
some potential problems of nominalisation analysis. Most recently, Wenyan (2012) carried out a formal comparative analysis of medical papers written by native English writers and those by Chinese academic writers in terms of three aspects of nominalisations, lexical density and thematic progression. The result revealed that the Chinese writers were lacking of sufficient use of nominalisation in medical papers while the native writers of English demonstrated a higher proportion of nominalisation use which has greatly contributed to their papers' fluency and coherence.

It is evident in the studies that nominalisations are of the utmost importance and have great impact in teaching and learning English (Jones et al., 1989; Thomson \& Droga, 2012) and in academic and scientific discourse (Halliday, 1993b, 1998, 2004; Halliday \& Martin, 1993, Halliday \& Matthiessen, 2004; Martin, 1993a, 1993b, 2008). Nominalisation is also adopted in Critical Discourse Analysis (Booth, 1961; Dijk, 2008; Fairclough, 2008). Besides academic fields, nominalisation appears in a variety of discourses in law and administrative bureaucracies (Halliday \& Martin, 1993; Hartnett, 2004).

Nominalisations shorten explanations and effectively organise known information, building on it to develop new knowledge. Nominalisations help to reorganise much expository writing rhetorically, instead of in the real-world's time and location sequence. Nominalisation construct abstracts and generalisations in humanities, interpret changes in social sciences and name processes, classifications and measurements in physical sciences. (Harnett, 2004, p. 185)

Nevertheless, there are still some criticisms against nominalisations. Yaser (2012b) argues that in some circumstances, nominalisations are necessary since full clauses would hinder the flow of information in the discourse, but in others separating clauses without nominalisation are crucial to provide poignancy. Harnett (2004) also proclaims that verbs are essential for narratives, action stories and news reports of events because before spectators concentrate on descriptions of something, they need verbs to tell what happens to make it deserve describing. Nominalisations, 
nevertheless, are insufficient to achieve this purpose. However, for the strong advocates of a verbal style, it is undeniable that avoiding using nominalisations (usage, modifiers, variety and references, etc.) is hard (Billig, 2008).

As nominalisation is a typical feature of complexity of written language, a number of research has been done in the studies of texts; however, limited attention has been paid to the investigation of nominalisation in English textbooks used in TEFL in the developing countries with particular reference to the Vietnam context.

\subsubsection{Research on grammatical metaphors}

Grammatical metaphor is a linguistic concept initially proposed by Halliday (1985a) in his first edition of the book An introduction to functional grammar, and then discussed further in his consecutive works in 1994, 2004, and 2014. As mention earlier, grammatical metaphor is a substitution of a grammatical class, or a grammatical structure by another. There are two principal types of grammatical metaphors: interpersonal metaphors and ideational metaphors (Halliday, 1985a). Ideational metaphors include the metaphors of transitivity and nominalisation whereas the interpersonal metaphors comprise the metaphors of mood and modality. These concepts are central in the systemic functional grammar and received much attention of functional and educational linguists (Banks, 2003; Derewianka, 2003; Halliday, 1993d, 1998, 2004, 2008; Halliday \& Martin, 1993; Halliday \& Matthiessen, 1999a; Martin, 1992a; Ravelli, 1999; Simon-Vandenbergen, Taverniers, \& Ravelli, 2003; Yaser, 2012a; Ye, 2010). The following paragraph reviews findings of several typical studies of grammatical metaphor in texts.

Yaser (2012b) performed a comparative analysis of the ideational metaphors in three business texts with the same number in political ones. The aims were to determine the number of ideational metaphors used in these texts. Also, the role and function of ideational metaphor were analysed. The results have shown that ideational metaphor has truly spread through political and business texts. Nominalisations were employed in both genres, transforming the process into a concept, which contributed to the texts' abstract and formality. However, the 
instances of grammatical metaphor in politics were covered by relations of power, supremacy and ideology which were not vivid in business writings. In addition, Ye (2010) analysed the interpersonal metafunction of Barack Obama's Victory Speech including the analysis of mood, modality and the use of personal pronouns. The finding revealed that Barack Obama's Victory Speech was dominated with positive declarative clauses; meanwhile, imperative clauses took the second position and some modal verbs like "will", "can" and "must" appear constantly as operators to express the modality in the speech. Some feasible implications were put forward in order to help the learners deliver better speeches.

Taverniers (2006) discusses grammatical metaphor and lexical metaphor from the semantic variation adopting the framework of systemic functional linguistics and using the perspectives of onomasiological and semasiological as two supportive viewpoints on metaphorical expression on the whole. Furthermore, grammatical metaphors have been studied in a variety of discourse such as school discourse (Christie \& Derewianka, 2008; Derewianka, 2003), news discourse (Wu \& Tang, 2010), emails discourse (Ho, 2010), reasoning discourse (Marianna \& Pankova, 2010) and in physics (Brookes \& Etkina, 2007). Grammatical metaphor, however, has received little attention in international textbooks chosen for teaching English as an additional language in the developing world.

\subsubsection{Research on thematic structure}

Among different structures which mapped on to each other to build up a clause, the one that provides the clause its character as a message is known as thematic structure (Halliday, 1985a). As mentioned earlier, a clause is made of two parts whereby theme is followed by Rheme. Theme is the starting-point for the message; it is the ground from which the clause is taking off (Halliday, 1994). A number of studies have focused on thematic structure (Edwin, 1996), thematic progression, cohesion and information development in Iranian textbooks (Ebrahimi \& Khedri, 2012; Ebrahimi, 2012), students' compositions (Liu \& Le, 2011), interpretation texts (Haigang, 2011), annual report (Clatworthy \& Jones, 2001), and thematic structure of talk (Ping, 2000). 
Ebrahimi and Khedri (2012) performed a functional analysis of thematic progression patterns in Iranian English textbooks which are widely used for teaching Prerequisite, English for General Purposes and English for Specific Purposes courses at Iranian universities at the bachelor level. Twelve units, from six textbooks were randomly selected for data analysis based on thematic progression model declared by McCabe (1999). The finding shows that different types of patterns of thematic progression (linear, constant, split Rheme, and split Theme) were used in the textbooks. The occurrence of linear and miscellaneous patterns was different across the three textbooks, which attributed to textbooks' different levels. Besides, Liu and Le (2011) investigated the impact of thematic structure in the assessment of English compositions written by Chinese students in College English Test (CET)-4 examinations. The study shows that the themes and thematic progression were distributed variously in different scored compositions. Also, higher-score achievers resulted from the success of using a variety of thematic structure.

Furthermore, Clatworthy and Jones (2001) investigated the readability of annual reports in terms of thematic structure from systemic functional grammar perspective in the UK. Based on analysis of 60 UK chairman's statements, the results indicate that the introductions to the chairman's statements were systematically easier to read than the other parts of the chairman's statements. The thematic structures within the statements were indeed a key driver of the variability of annual report readability. However, no research focusing on Theme choice as a linguistic resource charactering complexity of written language has been found in EFL textbooks commonly used for teaching English in non-English speaking nations.

\subsubsection{Research on functional grammar in Vietnam}

Linguists and researchers in Vietnam have put substantial efforts to keep themselves informed of the advances in linguistics internationally. In Vietnam, functional grammar has been applied in studies of text in two dimensions. Firstly, the functional point of view have been adopted to the study of the Vietnamese language (Cao, 1991; Hoang, 1997, 2005; Thai, 1998, 2004) and also to the 
contrastive analysis of English and Vietnamese syntax and semantics (Dang, 2012; Nguyen, 2011a; Nguyen, 2012a; Nguyen, 2011b; Nguyen, 2012b; Nguyen, 2011c; Thai, 1998, 2004). With reference to the Vietnamese context, Vietnamese linguists have paid attention to the comprehensive issues of Vietnamese functional grammar. Hoang (1997) conducted a doctoral research on transitivity systems in the Vietnamese language with reference to the experiential grammar of the Vietnamese clause from the functional perspective. Following that, Hoang (2005) examined the meaning and structure of a science fiction story employing a systemic functional perspective. He firstly described the context of the chosen text then analysed the clauses, clause complexes, the transitivity pattern, the Mood pattern, the Theme-Rheme pattern, the grammatical and lexical cohesion before putting an end to a summary of the context of situation of the text in terms of the three contextual parameters: field, tenor and mode (Hoang, 2005). Thai (1998) described metafunction profile of Vietnamese grammar from grammar and discourse perspectives. Later on, in Thai (2004), a description of Vietnamese grammar with particular reference to metafunctions, namely the system of Theme, the system of Mood, and the system of transitivity was stated. Also, Diep (2005) presents a functional analysis of Vietnamese grammar in relation to its representation, exchange and textuality. Secondly, in terms of contrastive analysis of functional grammar in English and Vietnamese, several studies at the doctoral levels in Vietnam have been carried out (Ngo, 2004; Nguyen, 1994). Here and there, some master theses on functional grammar and its aspects have been conducted with samples taken from newspapers, poetry, political speeches, short stories and novels (see Dang, 2012; Nguyen, P.C.T., 2011, Nguyen, TH., 2012; Nguyen, T.X.M., 2012; Nguyen, V.V., 2011). It is evident that the application of SFL theory to the studies of texts in Vietnam has still been under-investigated. It is also obvious that no research employing the theoretical framework of SFL has been conducted to investigate the language of textbooks, either government-approved textbooks in school or international EFL textbooks adopted in language education programs in EFL centres or universities in Vietnam. 


\subsection{Conclusion}

In summary, linguistic complexity has increasingly become appealing to researchers because of the growing number of publications on the topic as indicated by the researcher's review. Even though the notion of complexity is very central to literacy and language education; there is, in fact, no standard linguistic measure towards it (Rimmer, 2008). It is argued that linguistic complexity should be examined from a specific linguistic theory (Crystal, 1970). Following different views on linguistic complexity of different approaches including traditional grammar, Chomsky's TGG, Halliday's SFL, this chapter critically examined linguistic concepts characterising linguistic complexity in Hallaydian theory of SFL, namely lexical density, grammatical intricacy, nominalisation, grammatical metaphor, thematic structure, and hierarchies of periodicity. Finally, the chapter provided an overview of previous studies which employed Halliday's concepts and theoretical framework in the studies of texts globally and nationally. It is concluded that within the context that the language of EFL textbook texts has still been under- investigated, an examination of linguistic complexity of EFL textbooks from the functional perspective is needed to benefits educators and teachers in developing nations in teaching English, textbook choice and writing, and curriculum design. 


\section{Chapter 4: Methodology}

\subsection{Introduction}

In Chapter 2, linguistic complexity and an overview of linguistic complexity from the point of views of three different linguistic theories, specifically traditional grammar, Chomsky's transformational generative grammar and Halliday's functional grammar were introduced. Subsequently, Chapter 3 discussed six linguistic concepts related to the complexity of language from a Hallidayan approach namely lexical density, grammatical intricacy, nominalisation, grammatical metaphor, thematic structure, and hierarchies of periodicity. Chapter 3 also reviewed research on the linguistic features mentioned in literature and pointed out the gap in research on linguistic complexity in EFL textbooks. In this chapter, the aim and objectives of the research project are specified. Quantitative research approach with the descriptive research design is discussed. Subsequently, this chapter describes the selected textbooks and texts for data analysis. Detailed data analysis with regard to the analysis of lexical density, grammatical intricacy, nominalisation, grammatical metaphor, thematic structure, and the text periodicity are explained. Finally, reliability of data analysis and some limitations of the research are stated.

\subsection{Research aim and objectives}

The main aim of this study is to investigate the linguistic complexity in reading comprehension texts in English textbooks used in teaching reading skills for speakers of languages other than English across textbook levels and in science and non-science domains. The study employed Halliday's functional grammar (Halliday, 1985a, 1994, Halliday \& Matthiessen, 2004, 2014) as the principal theoretical and methodological framework. From the functional perspective, six linguistic aspects, which are considered the typical features for managing complexity of language, are the key focus of the investigation. They are lexical density, grammatical intricacy, nominalisation, grammatical metaphor, thematic structure, and the text periodicity. 
The following five objectives are developed to achieve the key research purpose mentioned.

- Objective 1: Critically examining linguistic complexity in terms of Halliday's concepts of lexical density, grammatical intricacy, nominalisation, grammatical metaphor, and thematic structure.

- Objective 2: Investigating how the complexity of language differs across various levels in the chosen English textbooks.

- Objective 3: Examining how the complexity of language differs in science and non-science fields in the chosen English textbooks.

- Objective 4: Identifying the relationships among linguistic features charactering the complexity of the investigated textbook texts.

- Objective 5: Determining how the complexity of language differs according to stages of text types and what effects they have on the text periodicity.

\subsection{Research design}

"Research is a systematic investigation to find answers to a problem" (Burns, 1997, p.1) . Like research in other areas, educational research has been divided into two main methods: the scientific empirical tradition and the naturalistic phenomenological mode. In the scientific method, social reality is objective and external to individual, while it is considered as a creation of individual consciousness or personal and subjective construction in the naturalistic approach (Burns, 1997). Also, for the scientific method, quantitative research methods are adopted to make general laws or principles, while the naturalistic phenomenological focuses on qualitative analysis and emphasises the importance of subjective experience of individuals (Burns, 1997).

Quantitative and qualitative research approaches have distinctly different features. They "have their own characteristics based on different purposes and paradigms underlying the research" (Wiersma \& Jurs, 2005, p.15). Krathwohl (1993) defines that qualitative research describes phenomena in words instead of numbers or measures, while quantitative research describes phenomena in numbers and 
measures instead of words. Therefore, in education, it can be said that from a quantitative research approach, "teaching is a science", and from a qualitative research approach, "teaching is an art" (Suter, 2012, p. 55). Qualitative research involves inductive process with reasoning moving from specific descriptions or observations to more general principles or conclusions. On the contrary, quantitative research is closely involved in deductive process with reasoning moving from general principles or theories to specific situations or hypotheses (Suter, 2012; Wiersma \& Jurs, 2005). As a result, qualitative research does not base on a certain theory to be studied at the beginning of the research; rather, a theory is grounded in data and developed when the research is in progress. Quantitative, on the other hand, is theory-based from the onset because of its deductive nature (Wiersma \& Jurs, 2005). Qualitative research is based on the concept of context sensitivity and emphasises a holistic interpretation. On the contrary, quantitative research is more context-free and focuses on individual variables and factors. One more distinguishing feature between these two research approaches is that qualitative research depends mainly on narrative description while quantitative relies heavily on statistical analysis (Wiersma \& Jurs, 2005, 2009). As far as quantitative research is concerned, having originated in positivism, it is considered the traditional scientific research method (Burns, 1997). It deals with hypothesis testing and objective data gathering to achieve the findings that are systematic, generalisable, and open to replication by other investigators (Ary, Jacobs, Sorensen, \& Walker, 2014). Quantitative research involves question of relationship, cause and effect, or current status by gathering and statistically analysing numeric data (Ary et al., 2014).

This study employs Hallidayan functional grammar approach as the principal theoretical framework to perform a linguistic analysis of twenty-four reading comprehension texts in four EFL textbooks. The functional analysis of the chosen texts consists of five main aspects, namely lexical density, grammatical intricacy, grammatical metaphor, nominalisation, and thematic structure. The main purpose of the research was to see how the chosen linguistic features presented and changed within two domains: science and non-science texts, and across four levels 
consisting of elementary, lower-intermediate, intermediate and upper-

intermediate. Thus, quantitative research was chosen as the key research approach in this investigation, as the heart of this research on textbooks lies in the analysis and interpretation of quantitative data resulted from linguistic analysis of the chosen textbooks. The quantitative results were then supported by qualitative analysis of four full texts to see how complexity differs according to stages of genres and what effect they have on the text periodicity.

The procedure for quantitative data analysis in this study is as follows. Firstly, the researcher identified and analysed five linguistic features mentioned in the selected textbooks. These features were then evaluated statistically by manually counting their occurrences and put them in frequencies and percentages, applying linguistic measures described in the data analysis section. These raw numbers were then imported into the SPSS software, Version 22 to obtain the descriptive statistic regarding Mean, Standard deviation, Minimum and Maximum values of the linguistic features examined. These results were presented in tables. Inferential statistical techniques were employed where possible to identify the relationship between the linguistic features investigated as well as to determine the significance of the results. Finally, data were described and interpreted to explain about the linguistic features investigated to achieve the aim and objectives of the study.

Qualitative analysis was conducted with four full texts to find out how linguistic complexity differs according to stages of texts and what effect linguistic features charactering complexity have on the text periodicity. Genre analysis was employed in the qualitative analysis, together with hierarchy of periodicity of the texts. Two information report and explanation texts were chosen for the analysis. Each of texts was analysed based on their linguistic features employed in each stage of text, and hierarchy of the text periodicity known as macroTheme, hyperTheme, hyperNew Theme, New, and macroNew. The general trends in the four texts were identified and interpreted. 


\subsection{Description of the chosen textbooks and texts}

\subsubsection{Description of the chosen textbooks}

As mentioned earlier, this study examined linguistic complexity of four EFL textbooks at four different levels from low to high named Active Skills for Reading (Anderson, 2003a, 2003b, 2003c, 2003d). These textbooks were compiled by a TESOL expert and published by a highly reputed publisher. The chosen textbooks have also been widely used as the main English reading textbooks in the language education programs in universities and language centres in Vietnam since 2007. The book series includes Books 1, 2, 3, and 4 and are intended for four levels: elementary, pre-intermediate, intermediate and upper-intermediate respectively. Each book consists of 32 reading passages covering various genres and belongs to both science and non-science domains. Totally, there are 128 reading texts in four textbooks. The main reasons for choosing these textbooks with a focus on four levels to investigate in this study are as follows.

- Firstly, as the main focus of this study is to investigate linguistic complexity of written language in English textbooks, textbooks used in teaching reading skills are the best choice for taking samples for data analysis.

- Secondly, the chosen English reading textbooks are published by a wellknown international publisher, and include four different levels from elementary to upper-intermediate. This fulfils the main aim of the research that it investigates how linguistic features are presented and change across levels from low to high in EFL textbooks.

- Thirdly, several studies on functional grammar in EFL textbooks have focused on different textbooks for English for specific purposes, and general English. No research has been done to find out the relationship between linguistic complexity and textbooks levels from low to high.

- Fourthly, in those books, there are a variety of reading passages with topics focusing on two fields: science and non-science. Thus, they fulfil the purpose of investigating linguistic features in scientific and non-scientific texts in 
textbooks used for TEFL. The science field in those textbooks includes topics on space, astronomy, robotic surgeons, etc. and the non-science field comprises of topics on education, culture, marriage, leisure activities, sport, etc.

- Finally, there are different text types in those books including academic genres such as exposition, discussion, report, description, procedure and explanation (Martin, 1989). Because this study focuses on examining academic genre in English textbooks, choosing those textbooks help achieve this aim and provide implications and recommendations for teaching language and literacy with a focus on academic writing.

In general, the choice of "Active Skills for Reading" as EFL textbooks for this study has been done on purpose to fulfil the aim of the study on investigating complexity of written language in academic texts with reference to science and non-science domains in English textbooks for speakers of other languages.

\subsubsection{Text selection and categorisation}

As the main purpose of this research project was to examine how the language of textbook texts changes over different topics, genres and domains within a level, and across various levels in a book series, the procedure for selection and categorisation of texts for the analysis was based on the classification of genres and domains which included four major steps.

The first step involved screening all the 32 reading passages in each book, and eliminating the texts that were conversations, interviews, personal recounts, and narratives. Two reasons for this exclusion are: a) conversations and interviews are characterised by spoken language which is not aligned with the purpose of investigating written texts in this study; and b) personal recounts and narratives are about story-telling which contains personal elements which are typical of spoken language (Humphrey et al., 2012; Martin, 1989; Martin \& Rose, 2008; Rose \& Martin, 2012). Thus, these types of text were excluded from the analysis. Specifically, there are eight conversations/interviews in Book 1, six 
conversations/interviews and two personal recounts in Book 2, two interviews in Book 3, and six conversations/interviews and ten personal recounts/narratives in Book 4. Totally, 34 texts were omitted, and the numbers of texts chosen for the second stage of text categorising are 94 texts including 24 texts in Book 1, 24 texts in Book 2, 30 texts in Book 3, and 16 texts in Book 4 (see Table 3.2). These 94 texts were marked to distinguish them from 34 texts that were already omitted in the screening stage.

The second step of text selection dealt with classifying the chosen texts at stage one into science and non-science domains. The classification between science-related texts and non-science ones was based on previous research on scientific discourse (Halliday, 1993a, 1993d, 1998, 2004; Halliday \& Martin, 1993). As informed by these studies, scientific discourse comprises the disciplines of natural sciences including physics (e.g., astronomy, chemistry, universe, Earth science) and biology (e.g., botany, zoology, medicine); formal sciences (e.g., mathematics, computer science, technology); and social sciences (e.g., anthropology, archaeology, linguistics, psychology, environment). Therefore, in the study, texts were categorised into science domain if their ideational meanings relate to scientific description or explanation of things or phenomena in the disciplines mentioned. This is informed by Halliday (1998) that the language of science is concerned with "the various forms of discourse in which activities of doing science are carried out" (p.185). Guided by these understandings, the 94 were categorised as science and non-science texts. The result of the analysis shows that there are six science-related texts and 18 nonscience ones in Book 1; four science-related texts and 18 non-science ones in Book 2; ten scientific texts and 20 non-scientific texts in Book 3, seven scientific texts and nine non-scientific texts in Book 4 (see Table 4.2). The science field includes topics on space, astronomy, robotic surgeons, numerology, astrology, psychology; and the non-science field consists of topics on education, culture, marriage, travelling, leisure activities, and sport. 
Table 4.1. Texts in science and non-science domains

\begin{tabular}{|l|c|c|c|c|c|}
\hline Book & 1 & 2 & 3 & 4 & Total \\
\hline Science texts & 6 & 4 & 10 & 7 & 27 \\
\hline Non-science texts & 18 & 18 & 20 & 9 & 67 \\
\hline Total & 24 & 24 & 30 & 16 & 94 \\
\hline
\end{tabular}

The third step was to identify the genre of texts in science and non-science fields. The analysis of genre was based on the social purpose of the text as Martin (1992) argues that genre is "a staged, goal-oriented, purposeful activity in which speakers engage as members of our culture" (Martin, 2001, p.155). The classification of genres in this research was based on genre families proposed by Rose and Martin (2012) as seen in Figure 4.1. As narratives and personal recounts were already eliminated at the stage one, this step involved identifying other genres such as description, explanation, report, historical recount, procedure, exposition, and discussion. The result of genre analysis of 94 texts in science and non-science domains in this study is shown in Table 4.2.

Table 4.2. Genre in science and non-science domains

\begin{tabular}{|c|c|c|c|c|c|c|c|c|c|c|c|}
\hline Field & \multicolumn{2}{|c|}{ Science } & \multicolumn{8}{|c|}{ Non-science } & \multirow[t]{2}{*}{ Total } \\
\hline Genre & EL & $\mathrm{R}$ & $E L$ & $\mathrm{R}$ & HR & $B R$ & $\mathrm{FR}$ & $P$ & EP & D & \\
\hline Book 1 & 6 & 0 & 2 & 9 & 7 & 0 & 0 & 0 & 0 & 0 & 24 \\
\hline Book 2 & 3 & 1 & 0 & 10 & 5 & 1 & 0 & 2 & 2 & 0 & 24 \\
\hline Book 3 & 6 & 4 & 4 & 9 & 2 & 2 & 0 & 2 & 1 & 0 & 30 \\
\hline Book 4 & 3 & 5 & 1 & 3 & 0 & 0 & 1 & 0 & 1 & 2 & 16 \\
\hline Total & 18 & 10 & 7 & 31 & 14 & 3 & 1 & 4 & 4 & 2 & 94 \\
\hline
\end{tabular}

Explanation of abbreviations in Table 4.2
EL: Explanation
IR: Report

HR: Historical recount

BR: Biographical recount

FR: Factual recount

P: Procedure

EP: Exposition

D: Discussion 


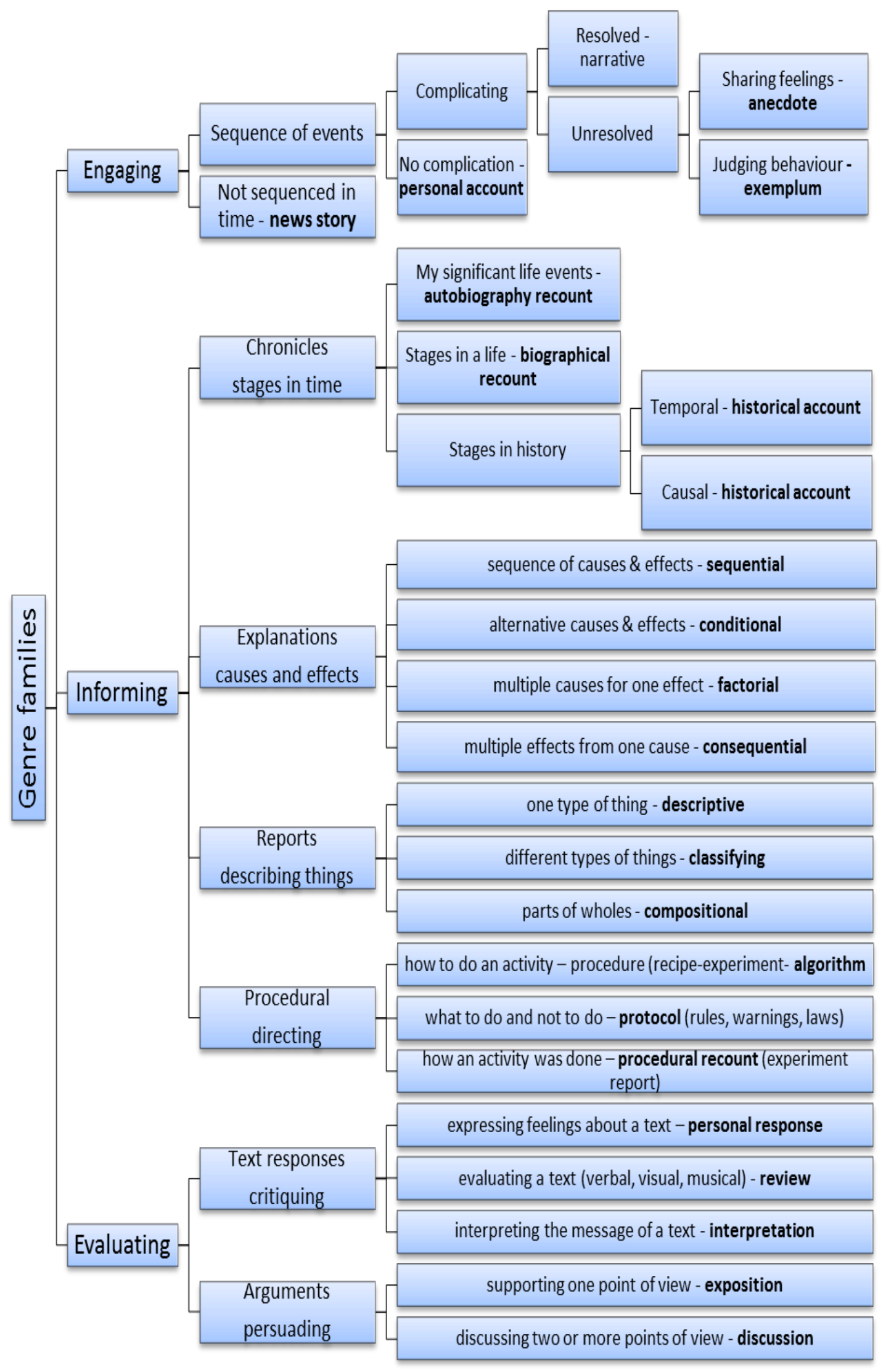

Figure 4.1. Maps of genre in school (adapted from Rose \& Martin, 2012, p.128) 
The final step concerned with the selection of the dominant texts in each field which were also found in all four textbook levels for coding and conducting the analysis. As demonstrated in Table 4.3, Explanation and Report were the dominant genres in the science field across four levels. In Table 4.2, Reports and Historical recounts were common in the non-science field. However, as Historical recounts were not found in Book 4, and Reports were not found in science field in Book 1; both of these genres were excluded from the analysis. Accordingly, texts chosen for the analysis were Explanation in science and Report in non-science category. In Table 4.2, the number of these text types was not the same across four levels of books. To make a fair comparison in terms of quantity of texts in two fields across levels, three Explanation and Report texts were chosen for detailed analysis. Thus, in total, the analysis was conducted with 24 texts as listed in Table 4.3. For the purpose of identification, 24 chosen texts were coded as described in Table 4.3. Details of text tittles and their sources were provided in Appendix 1.

Table 4.3. Total number, codes, genre and domain of texts chosen for the analysis

\begin{tabular}{|c|c|c|c|c|c|}
\hline $\begin{array}{c}\text { Field } \\
\text { /Genre }\end{array}$ & \multicolumn{3}{|c|}{ Science/ Explanation } & \multicolumn{3}{c|}{ Non-science/ Report } & Total \\
\hline Book & Number of texts & Text codes & Number of texts & Text codes & \\
\hline Book 1 & 3 & E1, E2, E3 & 3 & E4, E5, E6 & 6 \\
\hline Book 2 & 3 & P1, P2, P3 & 3 & P4, P5, P6 & 6 \\
\hline Book 3 & 3 & I1, I2, I3 & 3 & I4, I5, I6 & 6 \\
\hline Book 4 & 3 & U1, U2, U3 & 3 & U4, U5, U6 & 6 \\
\hline Total & 12 & & 12 & & 24 \\
\hline
\end{tabular}

Regarding the number of words in the chosen texts, each reading passages in Book 1 contains around 253 words to 259 words, in order to easily compare the linguistic features in four textbooks, chosen texts in the other three also have approximately similar number of words in Book 1, although reading passages in Books 2, 3, 4 are much longer. Therefore, each text in Books 2, 3, 4 was chosen from its beginning to the end of a sentence which marks the total words of that passage falling around 253-271 words. The corpus consisted of 24 texts at the four levels comprising of 6,293 words in total. 


\subsection{Data analysis}

This study mainly used quantitative research design. Descriptive statistics described values of lexical density, grammatical intricacy, nominalisation, grammatical metaphor and theme types in science and non-science domains and across textbook levels in terms of mean, standard deviation, and range. Data distributions were also examined for appropriate tests to determine the significance of the results. If data are normally distributed, parametric tests such as correlation, one-way ANOVA will be used to examine whether there were statistically significant differences of linguistic features investigated across two domains and four textbook levels. Otherwise, non-parametric tests such as Spearman Correlation, Mann Whitney, Kruskal Wallis will be employed. Results were considered statistically significant at $p=<0.05$.

Also, one of the main objectives of the research was to identify the relationship between the linguistic features mentioned; thus, the examination of correlations between these linguistic features was conducted. Specifically, this research investigated the relationships between two different methods of lexical density measures, between Halliday's lexical density and grammatical intricacy, between Halliday's lexical density and nominalisation, between Halliday's lexical density and grammatical metaphor.

Correlation coefficients indicate the strength of association between two variables. As Wiersma and Jurs (2005) defined, the correlation coefficient is a measure of the relationship between two variables that can take on values from -1.00 to +1.00 , inclusive. The sign on coefficient, plus or minus, not only indicates the direction of the relationships between variables but also the strength of the relationships. In terms of the direction of the relationships, if the correlation coefficient $(z)$ is greater than zero and less than or equal +1.00 , it indicates a positive relationship between the variables. On the other hand, if $z$ is less than zero and greater than or equal 1.00 , it indicates a negative relationship. A correlation of zero indicates no relationship between variables. In terms of the strength of the relationship, the end points of the interval indicate a perfect correlation between variables. 
There are many various types of correlation coefficients such as: the Pearson Product-Moment, the Spearman Rank Order, Kendall's Tau, The Phi Coefficient, the Point Biserial, the Biserial or the Coefficient of contingency (Ary et al., 2014; Rasinger, 2008; Wiersma and Jurs, 2005). They are different from one another based two distinctive features: the scale of measurement of the measures used and the number of variables (Ary et al., 2014). The researcher chooses the appropriate statistical method based on these two aspects. However, the Pearson ProductMoment which is symbolised $r$ is the most widely used descriptive statistic of correlation (Ary et al., 2014; Rasinger, 2008; Wiersma and Jurs, 2005). The Pearson Coefficient is appropriate for use for parametric data when variables are normally distributed and measured on an interval or ratio scale as the means of the distributions must be computed. The Spearman Correlation, on the other hand, is appropriate for use for non-parametric data when variables are not normally distributed (Rasinger, 2008). Rasinger (2008) suggests ways to distinguish between normal distribution and non-normal distribution of data. She states that if the frequencies of variables are distributed in the way that mean, median and mode are identical, this means the data is normally distributed. If the distribution is skewed, and the mean and the median are different, there is not equal distribution of variables; therefore, non-parametric test which refers to the Spearman Correlation should be considered.

Regarding the analysis of four texts at the whole text level, complexity was analysed based on genre analysis according to hierarchies of the text periodicity. Therefore, it employed both quantitative and qualitative approaches to this analysis. The quantitative result reveals how linguistic complexity differed according to stages of texts based on descriptive statistics. The qualitative result reports what the employment of grammatical metaphor have effect on the text periodicity. Details of research design are described in Figure 4.2. Linguistic concept maps for the analysis in this study is summarised in Figure 4.3. 


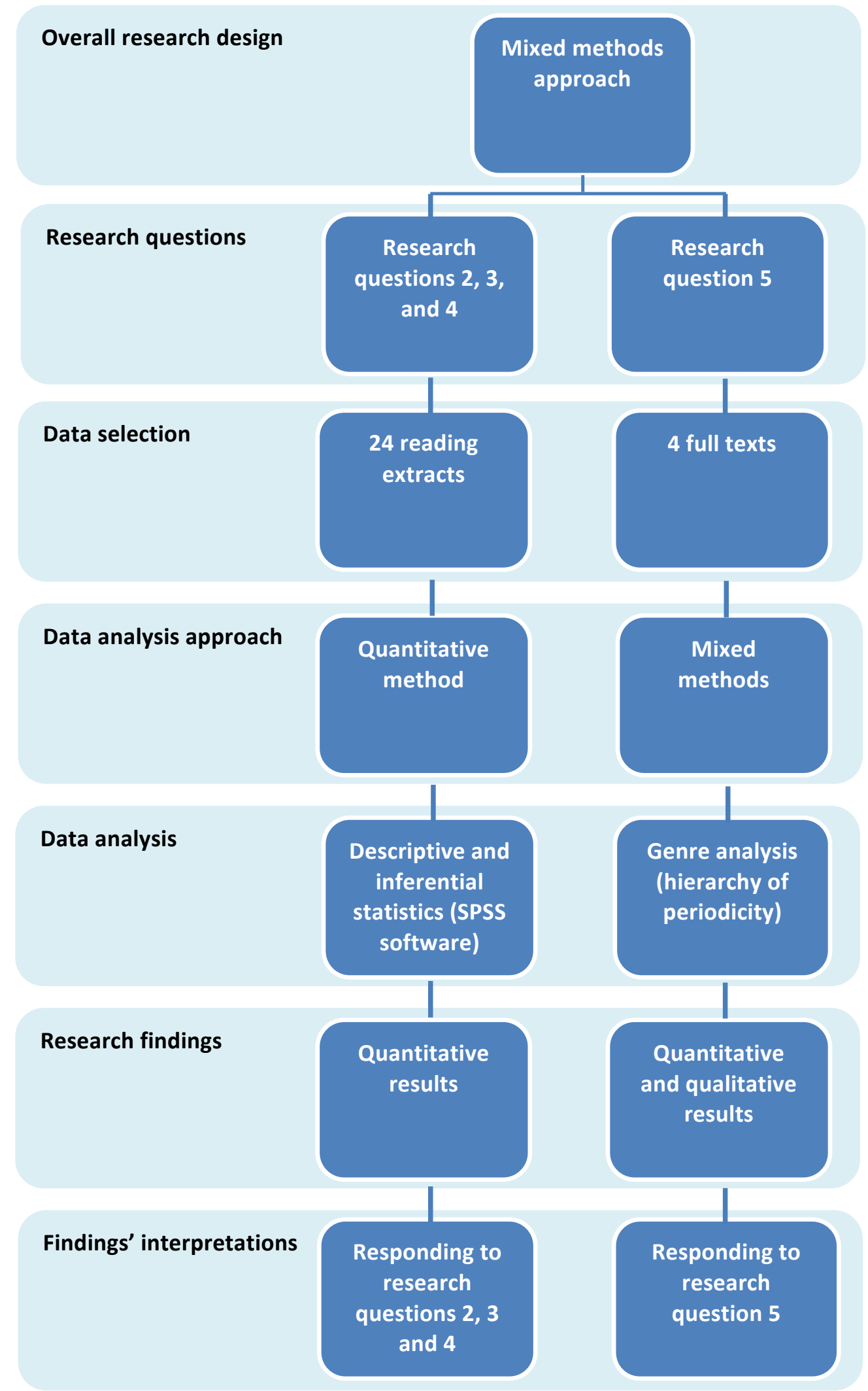

Figure 4.2. Research design of the study 


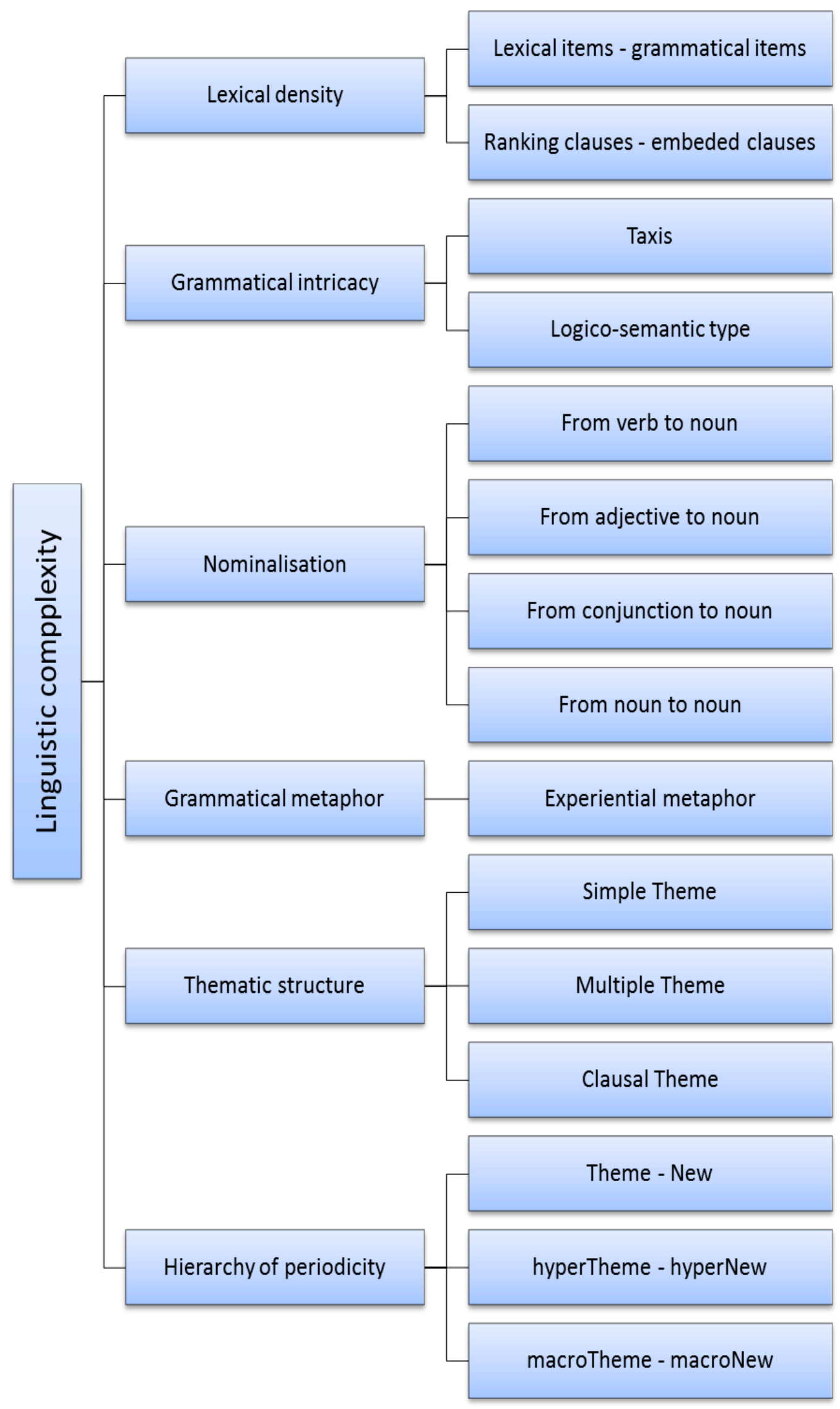

Figure 4.3. Theoretical concept maps of the study 
This above section gives an overview of the statistic methods adopted to interpret the raw quantitative data. Sections 4.5.1 - 4.5.6 discusses in detail the analytical framework employed in analysing six linguistic concepts as seen in Figure 4.3, which is followed by a relevant sample analysis.

\subsubsection{Lexical density analysis}

\subsubsection{Selection of methods}

There are two methods to measure lexical density in English texts proposed by Ure (1971) and Halliday (1985b) as discussed in Chapter 3 (Section 3.2.2). The first measure of lexical density is the proportion of lexical items to total running words (Halliday, 1985b; Ure, 1971). This method has been adopted in a number of works in investigating lexical density in both spoken and written discourse (Castello, 2008; Eggins, 1994; John \& Paul, 2002; Stubbs, 1986; Zora \& Johns-Lewis, 1989). Regarding this measure, if the number surpasses $40 \%$, it accounts for higher lexical density which is typical of written language. Spoken language has a lexical density value below 40\% (Ure, 1971). Because this method is firstly proposed by Ure (1971), in this research, it is named Ure's method to easily distinguish with the second method of lexical density based on clause proposed by Halliday (1985b) which is called Halliday's method.

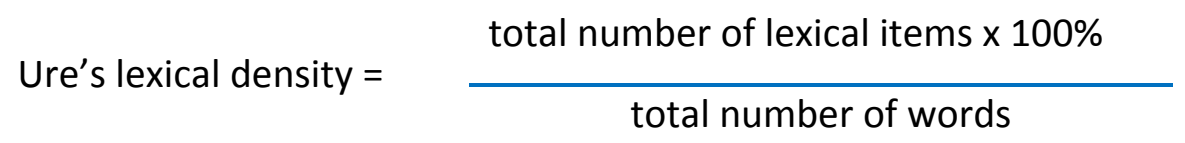

The second method of calculating lexical density which is based on ranking clauses is the ratio of lexical items per total clauses (Halliday, 1985b). In terms of the second method, Halliday (1985b) found that a typical average lexical density for written texts is between 3 and 6 , depending on the text formality. The higher the index, the more difficult the text is. The figures for spoken language, conversely, fall to between 1.5 and 2. This method of calculating lexical density based on clauses is employed by functional linguists and researchers (Castello, 2008; Christie \& Derewianka, 2008; Eggins, 1994; Halliday, 1993d; Holtz, 2011). 


$$
\text { Halliday's lexical density }=\frac{\text { total number of lexical items }}{\text { total number of ranking clauses }}
$$

It is worth noting that the use of both measures of lexical density in the same corpus to see how they correlate with each other has received less attention by researchers in literature. Castello (2008) used both methods to calculate lexical density to examine text complexity and text difficulty of twenty-five reading comprehension tests including 10,613 words. However, he treated the two methods separately as he argued that lexical density in Halliday's method based on clause complex which distinguishes between hypotaxis and embedding clause. Thus, lexical density in Halliday's method involves grammatical intricacy and it is good to deal with them individually to discuss grammatical complexity in the reading tests.

In this research, one of the objectives was to investigate the relationship between lexical density and the text levels, it is worth to utilise both methods discussed to best achieve the reliability and preciseness of data analysis. In this study, the correlation between Ure's and Halliday's method was taken into consideration to examine if the employment of the two measures can lead to similar results in the same selected texts. Lexical density analysis was done consistently based upon the clear distinction between lexical items and grammatical items proposed in Chapter 3 (Section 3.2.3) as well as the separation of ranking clauses and embedding clauses (Chapter 3, Section 3.2.4). The use of two methods in calculating lexical density was hoped to achieve some interesting findings and to provide some further implications for the investigation of lexical density.

\subsubsection{Lexical density analysis: Manual or computational?}

Lexical density analysis can be performed manually or computationally by researchers in literature regarding spoken and written discourse. This section first discusses some research which has employed both methods in analysing lexical density, the advantages of both methods and then proposes why the manual approach to lexical density analysis was adopted in this study. 
With regard to the manual approach, all lexical items are manually counted by the analyst and percentages are determined afterwards. One of the advantage of this approach is that it has a greater degree of accuracy in determining lexical items or content words because the analyst, as a human linguist can easily handle the problems that might happen in the process of analysing data (Zora \& Johns-Lewis, 1989). The manual approach of lexical density analysis is also best used when the amount of texts investigated is small or limited (Zora \& Johns-Lewis, 1989). An illustration of adopting this approach can be seen in Ure's (1971) work. Ure (1971) manually counted the number of lexical items and the total number of orthographical words to calculate lexical density and its frequency. She carried out the manual analysis of lexical density in the corpus of 34 spoken texts and 30 written texts comprising approximately 42,000 words in total. The findings show that lexical density in written texts in the corpus had a lexical density of greater than $40 \%$, while it was less than $40 \%$ for spoken texts. Ure's finding is of great importance as it measures the degree of "orality" versus "literacy" in a text (O'Loughlin, 1994, p.5); however, the distinction between lexical items and grammatical items is not clear in Ure's study (O'Loughlin, 1994).

The second approach to lexical density analysis is carried out automatically by the assistance of a computer program. Stubbs (1986) states that manual analysis of lexical density is a tedious and time consuming process for texts that are over a few hundred words; thus, it is more convenient to program a computer to do the analysis. He conducted an analysis of lexical density in the London-Lund corpus of 87 spoken texts of 5,000 words each; totally comprising of 435, 000 running words of recordings of highly-educated informants. Stubbs (1986) results are significantly different from those of Ure's (1971). In his corpus, lexical density in spoken texts ranged from $44 \%$ to $56 \%$, whilst in Ure's (1971) corpus, spoken language had the tendency of a lexical density at less than $40 \%$. The reason is explained by Stubbs (1986) that the methods employed in doing the calculation and the nature of the corpora studied in his and Ure's research are different.

Similarly, the application of software was used in calculating lexical density by John and Paul (2002) to survey the transcriptions of 88 recorded IELTS Speaking Tests 
from Band 4 to Band 8 at 21 test centres worldwide in order to access the candidate's vocabulary use. They used WordSmith tools (Smith, 1998) to identify the most frequently occurring content words and D-Tools (Meara \& Miralpeix, 2004) to measure lexical diversity. It is worth noting that Zora and Johns-Lewis (1989) adopted the two approaches of lexical density analysis in their study. They investigated conversations and interviews of postgraduate and undergraduate students to see how lexical density was presented in their speaking. The data was first analysed manually and then computationally. Two computer programs ALFSORT and FREQSORT were employed in their study to identify all lexical and grammatical items. Wilcoxon's Matched Ranked Pairs Test was then utilised to test the statistical significance of their findings. Lexical density values in these spoken texts are noticeably greater than those in Ure's (1971) research and closer to those reported by Stubbs (1986).

It is evident that the adoption of computer program or software in lexical density analysis is efficient and reliable with large quantities of data. However, a number of problems dealing with automatic analysis should be taken into consideration because these are not easily handled by a computer or solved by an algorithm. Stubbs (1986) discusses five typical problems that a software may encounter in analysing lexical density due to the ambiguity in determining lexical items and grammatical items. He then made an explicit distinction between lexical items and grammatical items regarding five aspects discussed in his computational studies including (1) phrases such as in spite of, run up; (2) modal verbs will, can; (3) short forms I'd, you'll; (4) repetition; and (5) hyphenated words.

Nevertheless, a computer cannot recognise when be, do, have are auxiliaries functioning as grammatical items and when they are lexical verbs functioning as lexical items. The ambiguity in identifying their functions significantly effects lexical density value as do and have are considered high-frequency lexical items in texts (Halliday, 1985b). Moreover, lexical density is the density of information (Halliday, 1993d) which is frequently understood from a chain of words such as phrasal verbs and they should be treated as lexical items (Halliday, 1985b). However, with 
computer analysis, phrasal verbs are treated separately, for example, run up is combined of a lexical item run and a grammatical item up (Stubbs, 1986).

As the quantities of data in this study is small, the researcher aimed to achieve the highest quality and accuracy of data analysis, avoiding some limitations of computational analysis discussed and taking the advantage of manual analysis as the analyst can handle all the problems that a computer cannot solve. For these reasons, the manual approach to lexical density analysis was adopted in this study.

\subsubsection{Procedure of lexical density analysis}

The process of analysing lexical density in the texts selected in this study was described in the following steps. Firstly, total words in each text were calculated using Microsoft Word. Next, lexical items in each text were identified and manually counted based on the classification of lexical items and grammatical items proposed in the study (Section 3.2.3, Chapter 3). Subsequently, ranking clauses were determined based on the classification of ranking clauses and embedded clauses mentioned (Section 3.2.4, Chapter 2). After identifying the total words, lexical items and ranking clauses, Ure and Halliday's formulas of lexical density were applied to obtain the lexical density index. The same procedure for lexical density analysis was applied for twenty-four texts. Finally, results obtained from lexical density calculations were imported into SPSS to find out if there were statistically significantly differences of lexical density between different textbook levels. Also, the correlations between Ure's and Halliday's measure of lexical density was determined. The results were shown in tables and graphs, and then compared with other linguistic features at the later stage.

\subsubsection{Sample lexical density analysis}

An example of lexical density analysis was conducted with an extract of Text E3 of Book 1 as seen in Box 4.1. In the following text, lexical items were in bold and ranking clauses and clause complexes were determined using notational conventions in SFL. Lexical items and ranking clauses were manually counted. As can be referred from the analysis of the extract of Text E3 below, there are 158 
words in total, 79 lexical items, and 24 ranking clauses. Thus applying Ure and Halliday's measure of lexical density, lexical density values are $50 \%$ and 3.3 respectively.

Box 4.1. Sample analysis of lexical density

|| For years, people thought ||that sleep was an unimportant, passive activity.

|||Today, we know || that sleep is important for good physical and mental health.

|| We have also learned ||that while a person is asleep, || the brain is very active. || |

|||To understand sleep, ||scientists study brain waves. |||By doing this ||they have learned || that there are five stages of sleep. || |Stage one sleep is very light. | | | During this time, a person awakens easily. || As we move into stage two, || our eyes stop moving ||and our brain waves move more slowly. || During stages three and four (often called 'deep sleep'), it is very hard to awaken a person. | | | During this time, the body repairs itself || and makes more cells. || |n children and young adults, the body makes a chemical used for growing. | | In the next stage - REM sleep - we begin to breathe faster | |and our eyes move around quickly, | |but our bodies do not move. || |During this stage, we dream. |||

\subsubsection{Grammatical intricacy analysis}

\subsubsection{Method of analysis}

Grammatical intricacy is another kind of complexity which is typical in spoken language (Halliday, 1985b). Halliday (1985b) states that "the complexity of the written language is static and dense. That of spoken language is dynamic and intricate" (p.87). Lexical density involves grammatical intricacy as "the highly information-packed, lexically dense passages of writing often tend to be extremely simple in their grammatical structure as far as the organisation of the sentence (clause complex) is concerned" (p.87). An investigation of grammatical intricacy together with lexical density will help explain complexity in texts from different aspects. Grammatical intricacy is measured as the number of ranking clauses in the clause complex (Halliday, 2008). 
Grammatical intricacy $=\quad \frac{\text { total number of ranking clauses }}{\text { total number of clause complexes }}$

As far as the formula of calculating grammatical intricacy is concerned, "the intricacy of grammar is captured in terms of how many clauses join together to form a clause complex, and the higher the index is, the more intricate the text." (Castello, 2008, p.97)

\subsubsection{Procedure of grammatical intricacy analysis}

Grammatical intricacy was determined based on the following steps. First, ranking clauses which are non-embedded including hypotactic and paratactic clauses were counted based on the classification of parataxis, hypotaxis and embedded clauses discussed in Chapter 3 (Section 3.2.4). To summarise briefly, parataxis includes 'and/or' type complexes, 'i.e. /e.g. -type complexes, 'then/so/but' - type complexes and direct speech complexes. Hypotaxis includes 'besides/instead of' - type complexes, 'non-defining relative' complexes, 'when/because/if' -type complexes and indirect speech complexes (Halliday, 1985b, p.83). Embedded clauses were not counted in calculating grammatical intricacy. Second, total of clause complexes were determined. As for clause complex, it is defined as "a language structure that consists of one clause working by itself, or a group of clauses that work together through some kind of logical relationship" (Butt et al., 2000, p.30). In other words, the clause complex determined in this study coincides with the orthographic unit of sentence ending with full stops. The ratio of ranking clauses per clause complexes is the grammatical intricacy index.

\subsubsection{Sample grammatical intricacy analysis}

Similarly, in sample intricacy analysis, notational conventions in SFL as explained earlier were adopted. As can be seen in Box 4.2, there are 9 ranking clauses and 7 clause complexes, giving the grammatical intricacy value of 1.29 for this extract. 
III Marriage is an ancient religious and legal practice [[celebrated around the world]] III. (x $\beta$ ) Although the reasons that people marry are similar in many places, $\|(\alpha)$ wedding customs vary from country to country $\mid \|$.

II In many countries, it is customary for the bride to wear a white dress as symbol of purity. | I In traditional Japanese wedding ceremonies, the bride wears a white kimono. || The tradition of wearing a special white dress only for the wedding ceremony started around 150 years ago. || Before that, most women could not afford to buy a dress that they would only wear once. III (1) Now, bridal dresses can be bought in a variety of styles and fabries, $\|(+2)$ and many brides have their dress specially made || .

\subsubsection{Nominalisation analysis}

\subsubsection{Classification of nominalisation and procedure for analysis}

As discussed in Section 3.4.4 in Chapter 3, being informed by a number of studies on nominalisation (Banks, 2005; Halliday, 1993d, 1994, 1998, 2004; Halliday \& Martin, 1993; Halliday \& Matthiessen, 2004; Hartnett, 2004; Humphrey et al., 2012; Martin, 1993a, 1993d, 2008), nominalisation in this study were recognised in analysis as follows.

- A verb is nominalised to become a noun, which includes three sub-types:

- Verb and noun have the same stem (e.g., to visit - a visit).

- A verb change its stem to become a noun (e.g., to live - a life).

- A verb is added a suffix to become a noun (e.g., to explore - an exploration).

- An adjective is nominalised to become a noun (e.g., dense - density).

- A conjunction is nominalised to become a noun (e.g., because - reason)

- A noun is added a suffix to become another noun (e.g., leader-leadership) 
Thus, nominalisations were analysed based on the following steps. First, they were identified based on the classification of nominalisation mentioned, which included four groups and sub-groups based on the changing of the root according to derivational morphology. Next, the instances of nominalisation in this research were manually counted based on token analysis, not type analysis. Finally, the proportion of total tokens of nominalisation to total ranking clauses in each text was determined.

\subsubsection{Sample nominalisation analysis}

As can be observed from the analysis of the extract of Text P4 in Box 4.3, there are 7 instances of nominalisation (nominalisations are in bold face and italic), and 12 ranking clauses in this text, giving the proportion of 0.58 nominalisation per ranking clause.

Box 4.3. Sample analysis of nominalisation

II| College gives people the chance to learn and make friendships that will last a lifetime. || | Many people in North America begin college at the age of eighteen. || | Many students go to school and || work part time to help pay for their education. |||

II In the United States, the cost of a college education can be quite expensive. III Undergraduate tuition at a public university can cost between $\$ 2,000$ and $\$ 10,000$ a year. | | That amount rises to between $\$ 14,000$ and $\$ 24,000$ a year at a private university. || | Students must also pay for textbooks and stationery. || These can cost $\$ 500$ to $\$ 800$ per year. | | | Students who live in campus housing pay between $\$ 3,500$ and $\$ 9,000$ per year for room and board. | I| Add money for clothes, travel, and other personal expenses, and one year at a university can cost as much as $\$ 35,000 !|1|$ 


\subsubsection{Grammatical metaphor analysis}

\subsubsection{Types of grammatical metaphor investigated in this study}

Grammatical metaphor is a term used to indicate the use of non-congruent lexicogrammatical forms (Banks, 2003). Grammatical metaphor involves a shift in strata from grammatical level to discourse semantic level (Halliday, 2004). Halliday and Matthiessen (1999) and Halliday (2004) proposed thirteen types of grammatical metaphor which deals with four major groups: (1) shift to thing, (2) shift to quality, (3) shift to process, and (4) shift to circumstance. These four groups are the main focus of research by Derewianka (2003) in the study of metaphor in the transition to adolescence. Since one of the aims of the present study was to investigate the complexity of language which involves the relationship between nominalisation and grammatical metaphor, this study examined one category of grammatical metaphor proposed by Halliday (2004) and Halliday and Matthiessen (1999) with a particular focus on shift to thing/entity which involves the nominalised process. This is to say, only ideational metaphor which helps construe the ideational meaning was investigated, interpersonal metaphor was not taken into consideration at this stage. Moreover, as introduced earlier, ideational metaphor includes experiential metaphor and logical metaphor. Specifically, only experiential metaphor was the focus of the investigation in this study. Logical metaphor was excluded from the analysis at this stage. Therefore, the term grammatical metaphor used in this study refers to experiential metaphor. The analysis of grammatical metaphor in this study was well-grounded on the distinction between nominalisation and grammatical metaphor explained in the following section. Frequency of grammatical metaphor was determined by the ratio of its instances per ranking clauses.

As this study examined reading texts in the science field, technicality was included in the analysis as it is considered as "the predominant discourse feature of the scientific texts" (Martin, 1993a). Technicality or technical terms "refers to the use of terms or expressions (but mostly nominal group constituents) with a specialised field-specific meaning" (Wignell et al., 1993, p. 144). Technical terms can be realised 
by: (1) single nouns (e.g., mesas, consumers), (2) nominal groups (e.g., physical environment, frontal rainfall, convection currents), (3) nominalisation (e.g., condensation, evaporation) (Wignell et al., 1993, pp. 145-146). Technicality was analysed and presented alongside with grammatical metaphor in this study.

\subsubsection{Grammatical metaphor, transcategorisation and nominalisation}

Transcategorisation is a feature of grammar of everyday language. Through the process of transcategorising, one word class can be transferred to another class by some syntactic and/or morphological means. In English and other Indo-European languages, typically a root can be transcategorised by derivational morphemes (Halliday \& Matthiessen, 1999). However, "many instances of transcategorisation are often mistaken for grammatical metaphor. Whether an expression is metaphorical or not depends on its context of use. The same word may be an example of transcategorisation in one context and an example of grammatical metaphor in another" (Derewianka, 2003, p.190). The word "possession" in Examples 4.1 and 4.2 are two illustrations.

\section{Example 4.1}

After carrying my possessions for what seems like an endless trek.

\section{Example 4.2}

She was sent to gaol for the possession of stolen goods.

In Example 4.1, the word "possessions" cannot be unpacked to the congruent form, while the word "possession" in Example 4.2 can be unpacked to "possess" like "She was sent to gaol because she possessed stolen goods". Thus, possession in Example 4.1 is a kind of transcategorisation, while it is a grammatical metaphor in Example 4.2 (Derewianka, 2003, p. 190).

Since nominalisation is the process of deriving what is not normally nouns into nouns (Bloor \& Bloor, 2000), it is a kind of transcategorisastion which involves deriving one word class into another (Halliday \& Matthiessen, 1999). A clear distinction between nominalisation and grammatical metaphor are momentous in data analysis in this study. Nominalisation and grammatical metaphor are different 
in terms of strata of language. While nominalisation is realised at the level of grammar, extending the lexical resources of a language; grammatical metaphor interfaces grammar with discourse semantics, extending a language's meaning potential (Martin, 2008). As proposed by Halliday and Matthiessen (2004), nominalisation "is the single most powerful resource for creating grammatical metaphor" (p.656). Through this device, process linguistically realised as verb and quality linguistically realised as adjective are reworded metaphorically as nouns referring to things or entities in another processes, enabling an informational dense discourse (Halliday \& Matthiessen, 2004). However, not all nominalisations involve grammatical metaphor. If a nominalisation can be unpacked to the congruent form, it is an ideational metaphor; if a nominalisation cannot be unpacked to the congruent alternative, it is just a form of transcategorisation (Christie \& Derewianka, 2008). An example of nominalisation and grammatical metaphor can be seen in Examples 4.3a, 4.3b, and 4.3c. As can be seen, the word "organisation" in Example 4.3a refers to an entity which cannot be unpacked to the congruent form. Thus, it is just a kind of transcategorisation or nominalisation. The word "organization" in Example 4.3b, in contrast, can be unpacked to the congruent form "organize" as can be seen in Example 4.3c. Therefore, it is an instance of grammatical metaphor (Christie \& Derewianka, 2008, pp. 26-27).

\section{Example 4.3}

- This is a great organization.

- The success of the party was due to her great organization.

- She organized the party successfully.

\subsubsection{Sample grammatical metaphor and nominalisation analysis}

In text P2, some instances of nominalisation and grammatical metaphor were analysed and distinguished from each other as follows. As seen in Table 4.4, there are 4 instances of nominalisation (personalities, numerology, predictions, personality), but only one nominalisation "prediction" can be unpacked to the congruent form "predict". Thus, "prediction" is considered a grammatical metaphor. 
Also, in the examples in Table 4.4, there is an instance of technicality "numerology" which is a nominalisation at the same time.

Table 4.4. Sample analysis of grammatical metaphor and nominalisation

\begin{tabular}{|c|c|c|c|}
\hline \multirow[t]{2}{*}{ No } & \multirow[t]{2}{*}{ Nominalisation } & \multicolumn{2}{|c|}{ Grammatical metaphor } \\
\hline & & Metaphorical & Congruent \\
\hline 1 & $\begin{array}{l}\text { We can use numbers to understand } \\
\text { our personalities. }\end{array}$ & - & - \\
\hline 2 & $\begin{array}{l}\text { Numerology is a way of using } \\
\text { numbers to describe a person's } \\
\text { character, and to make predictions } \\
\text { about future life events }\end{array}$ & $\begin{array}{l}\text { Numerology is a } \\
\text { way of using } \\
\text { numbers to } \\
\text { describe a person's } \\
\text { character, and to } \\
\text { make predictions } \\
\text { about future life } \\
\text { events }\end{array}$ & $\begin{array}{l}\text { Numerology is a } \\
\text { way of using } \\
\text { numbers to } \\
\text { describe a person's } \\
\text { character, and to } \\
\text { predict future life } \\
\text { events }\end{array}$ \\
\hline 3 & $\begin{array}{l}\text { Numerologists use the numbers } 1 \text { to } \\
9,11 \text { and } 22 \text { - also known as the } \\
\text { 'master' numbers - to help a person } \\
\text { understand his or her personality. }\end{array}$ & - & - \\
\hline
\end{tabular}

\subsubsection{Thematic analysis}

\subsubsection{Unit of analysis}

In thematic structure analysis, choosing a unit of analysis is crucial. Martin (1992a) suggests that theme can be analysed at the level of clause, clause complex, paragraph, and even at the text level. In literature, researchers have chosen different units for thematic analysis including clause (Cloran, 1995; Francis, 1990; Ghadessy, 1995) or T-Unit (Berry, 1995; Fries, 1992, 1994; Fries, 1995; Fries, 2002; Fries \& Francis, 1992; Hunt, 1970). 
Whatever unit of analysis is chosen, "the choice of unit to investigate must be governed by the purpose of the investigator" (Fries and Francis, 1992, p.47). As one of the purposes of this research was to examine how the deployment of various themes across level of textbook texts, the analysis of this study focused on three types of themes discussed by Halliday (1985a, 1994) consisting of simple themes, multiple themes and clausal themes. Halliday (1985a) and Fries and Francis (1992) argue that independent clauses are the most appropriate unit of analysis for thematic analysis concerning the textual metafunction. Therefore, independent clauses or independent conjoinable clause complex in Fries' (1981) term were chosen for examining theme in the present study.

To identify independent clauses, understanding clause complex is crucial, as clause complex is "a language structure that consists of one clause working by itself, or a group of clauses that work together through some kind of logical relationship" (Butt et al., 2000, p. 30). Thus, a clause complex which contains one, two or more than two independent clauses, theme of each clause is examined separately because each independent clause can work by itself. For a clause complex which consists of one independent clause preceded or followed by one or more than one dependent clause (i.e. an alpha ${ }^{\wedge}$ beta, or beta ${ }^{\wedge}$ alpha), dependent clause $(\mathrm{s})$ are treated as part of a clause complex. This is because traditionally, dependent or subordinate clauses have been known as adverbial clauses or circumstantial adjuncts. Fries and Francis (1992) argue that "the structure of beta clause, including their thematic structure, tends to be constrained by the alpha clause" (p.47). Therefore, a clause complex which contains one dependent clause following by one independent clause, dependent clause is treated as an adverbial clause and functions as the Theme of that clause complex which is known as clausal Theme (Halliday, 1985a, 1994), and the independent clause is the Rheme. By contrast, a clause complex which contains one dependent clause proceeding by one independent clause, Theme of the main clause is the Theme of the clause complex, and the rest of the clause complex is the Rheme (Halliday, 1985a, 1994). 


\subsubsection{Procedure of theme analysis}

Thematic structure analysis in this study involves the following steps. Firstly, the researcher divided each selected texts into clause complexes as defined in this study. Theme and Rheme of each clause were then identified and categorised in three groups of themes and sub-groups of each type as described in Figure 4.4. The instances of each theme and sub-theme were manually counted and the frequency of theme in the data was obtained by the proportion of each theme per total clause complexes. The results of thematic analysis were statistically evaluated and displayed in tables and graphs.

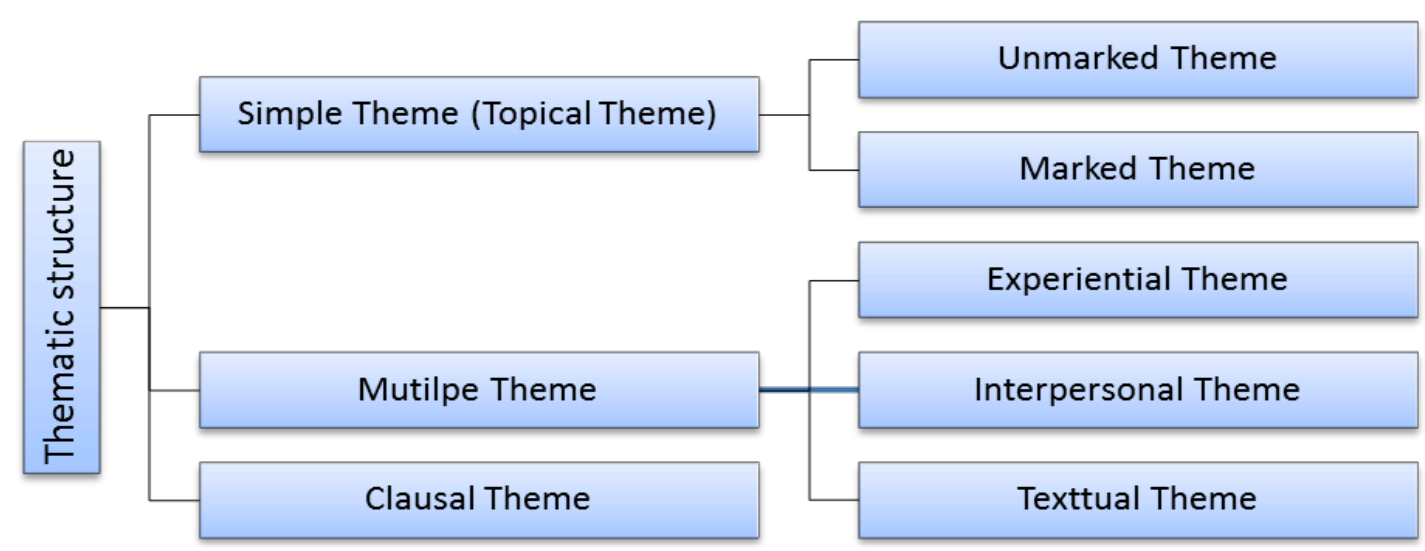

Figure 4.4. Thematic structure investigated in this study (Halliday, 1985a, 1994)

\subsubsection{Sample theme analysis}

Sample analysis of theme was conducted with an extract of Text E3 as demonstrated in Table 4.5. In the following analysis, Theme and Rheme were distinguished from each other by \#. Themes occurred in the text were marked with $(+)$; Themes that were not used in the text were recognised by (-). Some abbreviations are: marked theme $(M)$, unmarked theme $(U)$, textual theme $(T)$, interpersonal theme (I). As observed in Table 4.5, there are five simple themes including one marked themes and four unmarked themes; there are two multiple themes; and there is no instance of clausal theme. 
Table 4.5. Sample analysis of thematic structure

\begin{tabular}{|c|c|c|c|c|c|c|c|c|}
\hline \multirow[t]{3}{*}{ No } & \multirow[t]{3}{*}{ Clause Complex } & \multirow{2}{*}{\multicolumn{2}{|c|}{$\begin{array}{l}\text { Simple } \\
\text { Theme }\end{array}$}} & \multicolumn{4}{|c|}{ Multiple theme } & \multirow{3}{*}{$\begin{array}{l}\text { Clausal } \\
\text { theme }\end{array}$} \\
\hline & & & & & & & & \\
\hline & & M & $U$ & T & 1 & M & U & \\
\hline 1 & $\begin{array}{l}\text { Some people \# have extraordinary } \\
\text { memories }\end{array}$ & - & + & - & - & - & - & - \\
\hline 2 & $\begin{array}{l}\text { According to the Guinness World } \\
\text { Records }^{\mathrm{RM},} \text { 2001, \# Gert Mittring of } \\
\text { Germany can look at a list of twenty- } \\
\text { seven numbers for just four seconds }\end{array}$ & + & - & - & - & - & - & - \\
\hline 3 & and remember \# all of them & - & - & + & - & - & + & - \\
\hline 4 & $\begin{array}{l}\text { Most people,\# though, have trouble } \\
\text { at times remembering where they } \\
\text { out their door keys, or recalling the } \\
\text { names of people they've recently } \\
\text { met for the first time. }\end{array}$ & - & + & - & - & - & - & - \\
\hline 5 & $\begin{array}{l}\text { The process by which we store and } \\
\text { retrieve information in our brains \# } \\
\text { has been the focus of scientific } \\
\text { research for many years }\end{array}$ & - & + & - & - & - & - & - \\
\hline 6 & $\begin{array}{l}\text { The brain \# is a highly complex organ } \\
\text { that is not fully understood, }\end{array}$ & - & + & - & - & - & - & - \\
\hline 7 & $\begin{array}{l}\text { and theories about how it works \# } \\
\text { remain a topic of debate }\end{array}$ & - & - & + & - & - & + & - \\
\hline \multirow[t]{2}{*}{ Total } & 7 & 1 & 4 & 2 & 0 & 0 & 2 & 0 \\
\hline & 7 & \multicolumn{2}{|c|}{5} & \multicolumn{4}{|c|}{2} & 0 \\
\hline
\end{tabular}

\subsection{Reliability and validity of the study}

"Quantitative research depends on measurement" (Ary et al., 2014, p. 241). Two important concepts that involve measuring instruments are reliability and validity. Reliability is concerned with the method repeatedly and consistently measuring whatever it is supposed to measure (Rasinger, 2013). In other words, it refers to the 
consistency of the findings gained from a piece of research (Nunan, 1992). Reliability is divided into two types: internal reliability and external reliability. "Internal reliability refers to the consistency of data collection, analysis, and interpretation. External reliability refers to the extent to which independent researchers can reproduce a study and obtain results similar to those obtained in the original study." (Nunan, 1992, p.14)

Validity refers to the relevance and accuracy to what is measured (Rasinger, 2013). Validity comes in several different forms and shapes; but the most important one for linguistics research is measurement validity. Measurement validity is also called validity referring to the issue of whether the method used actually measures what it is supposed, allowing the researcher to draw appropriate conclusions (Rasinger, 2013). Similar to reliability, there are two types of validity: internal validity and external validity. "Internal validity refers to the interpretability of research" (Rasinger, 2013, p.14), and "external validity refers to the extent to which the results can be generalised from samples to populations." (Rasinger, ibid)

In this study, measures of linguistic complexity in terms of lexical density, grammatical intricacy, nominalisation, grammatical metaphor and thematic structure were done consistently adopting Halliday's systemic functional linguistics approach. Firstly, in measuring lexical density, a clear distinction between lexical items and grammatical items was discussed and proposed in the study. In addition, ranking clauses and embedded clauses were also made clear in calculating lexical density. Only ranking clauses which include paratactic and hypotactic clauses were counted. Embedded clauses did not count in measuring lexical density based on the ratio of lexical items per total of ranking clauses (Halliday, 1985b). Secondly, in measuring grammatical intricacy which is determined by the proportion of ranking clauses per total of clause complexes, ranking clauses were examined similarly as they were in calculating lexical density. Clause complex in SFL is defined as an independent clause working by itself or working with other independent or dependent clauses by means of some logical relationship (Halliday, 1985a, 1994; Butt et al, 2000). With respect to nominalisation, grammatical metaphor and thematic structure, the consistency in determining types of nominalisation, 
grammatical metaphor and thematic structure and categorising them helped achieve the reliability of the results.

This research not only looked at each single linguistic feature mentioned but also examined the relationships among them to see how they contributed to the complexity of language in textbook texts. How grammatical intricacy is related to lexical density was identified. Similarly, the relationship between nominalisation and lexical density; between grammatical metaphor and lexical density; and between thematic structure and text levels were examined. Investigation of a number of linguistic features and the relationships among them and between them and the text levels allowed the researcher to draw appropriate conclusions toward the overall linguistic complexity in the English textbooks chosen at four levels: elementary, pre-intermediate, intermediate and upper-intermediate respectively. To sum up, the consistency in measuring six linguistic concepts investigated in the study and the examination of the relationships among them help obtain the reliability and validity of the results.

Apart from adopting well-established SFL measures and being consistent in data analysis drawing on work of functional linguists, several analysis samples of linguistic features in this research was also checked by experts in this area. First, some analysis samples of linguistic features investigated consisting of lexical density, nominalisation, grammatical metaphor and thematic structure of this study was included in the research proposal which was checked and given feedback by a world expert in functional grammar (Martin, 2014). Moreover, regarding the language used in one specific scientific text with reference to the language variation framework (Mahboob, 2014) was checked by the founder of the language variation model. Results of the study were already presented at two major conferences in the field of educational linguistics in 2014, specifically at the $17^{\text {th }}$ World Congress of the International Association in Applied Linguistics (To, 2014a) and at the annual conference of the Australian Systemic Functional Linguistics Association (To, 2014b) for validation the methods used in this study. 


\subsection{Conclusion}

This chapter presented the aim and objectives of the study as well as the methodology employed for data analysis. As the main purpose of this research was to investigate linguistic features in textbooks across four levels with a focus on descriptive statistics, quantitative research was chosen as the main research approach for the investigation. Selection of textbooks and texts for data analysis were described concerning two main fields: science and non-science. Details of data analysis with reference to methods chosen for each linguistic feature analysis, procedure for the analysis and sample analysis in relation to lexical density, grammatical intricacy, nominalisation, grammatical metaphor and thematic structure were presented. This chapter ends with the discussions of the reliability and validity of the study. 


\section{Chapter 5: Analysis of Linguistic Complexity across Levels}

\subsection{Introduction}

This chapter reports on the results of quantitative data analysis of linguistic features characterising linguistic complexity in 24 reading extracts. The findings in this chapter are presented in relation to three research objectives on investigating: (1) the complexity of language across various levels in the chosen English textbooks, (2) the complexity of language in science and non-science fields in the chosen English textbooks, and (3) the relationships among linguistic features charactering the complexity of textbook texts investigated. The analysis in this chapter will help answer three research questions:

- Research question 2: How do linguistic features charactering complexity including lexical density, grammatical intricacy, nominalisation, grammatical metaphor and thematic structure differ across levels in the chosen English textbooks?

- Research question 3: How do linguistic features charactering complexity including lexical density, grammatical intricacy, nominalisation, grammatical metaphor and thematic structure differ in science and non-science fields in the chosen English textbooks?

- Research question 4: What are the relationships among lexical density, grammatical intricacy, nominalisation, and grammatical metaphor?

The chapter starts with a brief summary of linguistic measures adopted. It also presents steps to data analysis including descriptive and inferential statistics, examination of data distribution that has led to the selection of appropriate tests for the analysis, follow-up tests and interpretations of the results. Finally, three main findings regarding quantitative analysis of complexity in 24 reading texts across textbook levels and fields are presented. 


\subsection{A snapshot of analysis techniques}

Concerning lexical density analysis, two methods proposed by Ure (1971) and Halliday (1985b) were applied to obtain lexical density values in reading passages (see Sections 4.5.1). Halliday's (2008) measure of grammatical intricacy was applied to determine this score (see Section 4.5.2.). Frequency of nominalisation and grammatical metaphor was obtained by the division of instances of these two linguistic features per ranking clauses (see Sections 4.5.3 and 4.5.4 respectively). In terms of thematic analysis, different themes comprising of simple themes, multiple themes and clausal themes were identified and categorised. Percentage of theme types was determined by each type of theme per clause complex (see Section 4.5.5). Twenty-four chosen texts were classified into four groups: Elementary ( $n=$ 6), Pre-intermediate $(n=6)$, Intermediate $(n=6)$ and Upper intermediate $(n=6)$. These 24 texts were also divided into two fields: Science $(n=12)$ and Non-science ( $n$ = 12). Text coding was described in Table 4.4 (see Section 4.4.2) as follows:

Elementary (Science: E1, E2, E3; Non-science: E4, E5, E6), Pre-intermediate (Science: P1, P2, P3; Non-science: P4, P5, P6), Intermediate (Science: 11, 12, 13; Non-science: 14, 15, 16), Upper-intermediate (Science: U1, U2, U3; Non-science: U4, U5, U6). All raw data of five linguistic features including lexical density, grammatical intricacy, nominalisation, grammatical metaphor and theme were imported into SPSS version 22 for data analysis.

The examination of data distribution was conducted to identify the appropriate tests for the analysis. The tests of distribution of the raw data of each linguistic feature show that there were some degrees of outliers, as assessed by boxplot. However, the data was normally distributed for each variable investigated, as assessed by Shapiro-Wilk test ( $p>.05)$; and there was homogeneity of variances, as assessed by Levene's test of homogeneity of variances $(p>.05)$. Thus, the inferential statistical techniques including a one-way ANOVA and Tukey post-hoc tests were employed to determine the significance of the results. Results were considered statistically significant at $\mathrm{p}<=0.05$. 
In this chapter, for each linguistic feature, descriptive statistics of the data were first displayed as mean \pm standard deviation plus minimum and maximum values. Also, one-way ANOVA result was presented for variables which had more than two groups. When there was a difference between textbook levels $(p<=0.05)$ displayed by ANOVA test, Tukey post-hoc test was presented to find out which group was statistically different. Following this, the relationships among the selected linguistic features were determined based on the correlational analysis, adopting Pearson correlation test depending on the normality of data distribution. All the results were presented in tables and some demonstrated by bar graphs in the following order: (1) linguistic features analysis across four levels of textbooks, (2) linguistic features analysis in science and non-science field, and (3) correlations among linguistic features.

\subsection{Linguistic features analysis across four levels of textbooks}

\subsubsection{Lexical density in Ure's method across textbook levels}

As discussed in Chapter 4, this study adopted two methods in measuring lexical density. The first method is originally proposed by Ure (1971), which measures lexical density by the proportion of lexical items per total running words. This measurement of lexical density is identical with one of the two methods stated by Halliday (1985b). Traditionally, lexical items includes nouns, verbs, adjectives and some kinds of adverbs (Halliday, 1985b); and grammatical items consist of determiners such as articles, pronouns, most prepositions, conjunctions, some classes of adverb and finite verbs (Halliday, 1985b; Lyons, 1968; Palmer, 1974; Robins, 1964). In most cases it is unambiguous to define which one is a lexical item or a grammatical item; however, in some cases, it is more difficult to define. English prepositions and certain classes of adverb, always and perhaps, for instance, fall on this borderline (Halliday, 1985b). As stated by Halliday (1985b), the most crucial thing in lexical density analysis is consistency. Although grammar and lexis are complementary (Halliday, 2008), in this study, for the purpose of achieving consistent results, the clear distinction between lexical items and grammatical items 
are proposed in Section 3.2.3 and are applied consistently in calculating lexical density.

In this study, lexical items include all nouns, all adjectives, all lexical verbs except the verb to be (all forms of the verb to be are considered as grammatical items), and two kinds of adverbs: adverbs of manner (quickly, beautifully) and sentence adverbs (happily, luckily) as they greatly contribute to the lexical meaning. Grammatical items comprise of all pronouns, all determiners, all finite verbs, all conjunctions, all prepositions, all discourse makers, interjections, reactive tokens and some kinds of adverbs such as setting adverbs (now, here, there), degree adverbs (very, too), negative and interrogative adverbs (never, where, why) (see Section 3.2.3).

Employing Ure's method, this study calculated lexical density in 24 reading texts at four levels which included six texts in each book. At each level, texts were divided into two categories: science and non-science field. The raw data of the analysis of lexical density in the chosen texts was shown in Appendix 2 in relation to the instances of lexical items, total words and percentage of lexical density in each text. For the purpose of comparing means of lexical density among levels of textbooks, lexical density values which were presented in percentage according to Ure's method were converted to frequency to easily import data into SPSS software version 22. For example, Text E1 which had the lexical density score of $46.48 \%$ was coded .46 in the SPSS software.

A one-way ANOVA test was conducted to determine if Lexical Density calculated by Ure's formula was different for different levels of books in a book series. Table 5.1 displays descriptive statistics of lexical density measured by Ure's method across four levels of textbooks. Particularly, data distribution is presented as mean \pm standard deviation plus minimum and maximum values. 
Table 5.1. Descriptive statistics on lexical density measured by Ure's method across levels

\begin{tabular}{|c|c|c|c|c|c|}
\hline Levels of textbook & $\mathbf{N}$ & Mean & Std. Deviation & Minimum & Maximum \\
\hline Elementary & 6 & .4733 & .02503 & .43 & .50 \\
\hline Pre-intermediate & 6 & .4483 & .04792 & .37 & .49 \\
\hline Intermediate & 6 & .4717 & .03189 & .44 & .51 \\
\hline Upper-intermediate & 6 & .4800 & .02098 & .46 & .51 \\
\hline
\end{tabular}

As shown in Table 5.1, the Lexical Density mean score decreased from the Elementary ( $.4733 \pm 0.02503$, equivalent to $47.33 \% \pm 2.50 \%)$, to Pre-intermediate (.4483 \pm .04792 , equivalent to $44.84 \% \pm 4.79 \%)$ before maintaining the relatively similar scores at the Intermediate $(.4717 \pm .03189$, equivalent to $47.17 \% \pm 3.20 \%)$ and the Upper intermediate levels (.4800 .02098 , equivalent to $48 \% \pm 2.1 \%)$. These scores indicate that on average, there were 47.33 lexical items per 100 running words at Elementary level. The figures were 44.83, 47.17 and 48.00 in the remained three levels respectively (Pre-intermediate, Intermediate, Upper-intermediate). It should be noticed that on average, the mean scores of Ure's lexical density in the chosen reading texts were higher than $40 \%$ which is considered the typical density of written language (Ure, 1971). However, the minimum score of Pre-intermediate level texts indicates that there was one text in the non-science field in the corpus scoring a lexical density of $37 \%$ which is lower than the average number of density in written text indicated by Ure (1971), while the maximum score of lexical density in the data is $51 \%$.

The result of comparison of means of lexical density among textbook levels assessed by one-way ANOVA in Table 5.2 demonstrates that there were no statistically significant differences in lexical density measured by Ure's method between different levels of textbooks as $F(3,20)=1.045$ and $p=0.394>0.05$. This means that lexical density calculated by Ure's method did not correspond to the textbook levels. 
Table 5.2. Comparisons of lexical density measured by Ure's method between levels

\begin{tabular}{|l|l|l|l|l|l|}
\hline Ure's lexical density & \multicolumn{1}{|l|}{ Sum of squares } & df & Mean Square & F & Sig. \\
\hline Between groups & .003 & 3 & .001 & 1.045 & .394 \\
\hline Within groups & .022 & 20 & .001 & & \\
\hline Total & .025 & 23 & & & \\
\hline
\end{tabular}

\subsubsection{Lexical density in Halliday's method across textbook levels}

The second measurement of lexical density which is initially proposed by Halliday (1985b) is the ratio of lexical items per ranking clauses. Regarding this method, consistency in determining lexical items and ranking clauses is the key in calculating lexical density value. As discussed in Section 3.2.4, ranking clauses include paratactic and hypotactic clauses which are counted in lexical density analysis, while embedded clauses do not count. In traditional terms, parataxis and hypotaxis refer to the notions of co-ordination and subordination respectively. The distinction between paratactic clauses, hypotactic clauses and embedded clause are crucial to lexical density and grammatical intricacy analysis according to Halliday's methods.

The raw data of lexical density calculated by Halliday's measurement, which includes instances of ranking clauses, lexical items and lexical density scores was described in Appendix 2. Table 5.3 displays descriptive statistics of lexical density measured by Halliday's method across four levels of textbooks. Particularly, data is presented as mean \pm standard deviation. The Lexical Density score showed a gradual increase pattern from the Elementary $(3.99 \pm 0.42)$ to Pre-intermediate $(4.43 \pm .74)$ and to Intermediate level $(5.15 \pm .82)$. Lexical density at the Upperintermediate level maintained the similar score as it was in intermediate texts (5.06 士.73). These figures indicate that on average, there were 3.99 lexical items per ranking clause in Elementary texts. The figures were 4.43, 5.15 and 5.06 in Preintermediate, Intermediate and Upper-intermediate texts respectively. 
Table 5.3. Descriptive statistics on lexical density measured by Halliday's method across levels

\begin{tabular}{|c|c|c|c|c|c|}
\hline Levels of textbook & $\mathbf{N}$ & Mean & Std. Deviation & Minimum & Maximum \\
\hline Elementary & 6 & 3.99 & .42 & 3.54 & 4.71 \\
\hline Pre-intermediate & 6 & 4.43 & .74 & 3.48 & 5.26 \\
\hline Intermediate & 6 & 5.15 & .82 & 4.14 & 6.57 \\
\hline Upper-intermediate & 6 & 5.06 & .73 & 3.81 & 5.77 \\
\hline
\end{tabular}

The results obtained from the comparison of means of lexical density among textbook levels assessed by one-way ANOVA in Table 5.4 reveal that the lexical density scores calculated by Halliday's formula were statistically significantly different between different levels of textbooks as $F(3,20)=3.704$ and $p=0.03<$ 0.05 . The effect size score $\omega^{2}=0.24$ is believed to be a small effect size. Tukey posthoc test was performed to find out which group were statistically significantly different from one another. The analysis in Table 5.5 reveals that the increase of Lexical Density score from Elementary level to Intermediate level (-1.155, 95\% Cl (2.28 to -0.03 ) was statistically significant $(p=.042<0.05)$ but no other group differences were found to be statistically significant.

Table 5.4. Comparisons of lexical density measured by Halliday's method between levels

\begin{tabular}{|l|l|l|l|l|l|}
\hline $\begin{array}{l}\text { Halliday's lexical } \\
\text { density }\end{array}$ & Sum of squares & df & Mean Square & S & Sig. \\
\hline Between groups & 5.360 & 3 & 1.787 & 3.704 & .029 \\
\hline Within groups & 9.648 & 20 & .482 & & \\
\hline Total & 15.00 & 23 & & & \\
\hline
\end{tabular}


Table 5.5. Tukey HSD test on multiple comparisons of Halliday's lexical density

\begin{tabular}{|c|c|c|c|c|c|c|}
\hline & & $\begin{array}{l}\text { Mean } \\
\text { Difference }\end{array}$ & & Error & \multicolumn{2}{|c|}{$\begin{array}{c}\text { 95\% Confidence } \\
\text { Interval }\end{array}$} \\
\hline & & $(I-J)$ & & & $\begin{array}{l}\text { Lower } \\
\text { Bound }\end{array}$ & $\begin{array}{l}\text { Upper } \\
\text { Bound }\end{array}$ \\
\hline \multirow[t]{3}{*}{ Elementary } & Pre-intermediate & -.433 & .401 & .705 & -1.56 & .69 \\
\hline & Intermediate & -1.16 & .401 & .042 & -2.28 & -0.03 \\
\hline & Upper-intermediate & -1.06 & .401 & .068 & -2.18 & 0.06 \\
\hline \multirow{3}{*}{$\begin{array}{l}\text { Pre- } \\
\text { intermediate }\end{array}$} & Elementary & .433 & .401 & .705 & -.69 & 1.56 \\
\hline & Intermediate & -.722 & .401 & .303 & -1.84 & .40 \\
\hline & Upper-intermediate & -.628 & .401 & .419 & -1.75 & .49 \\
\hline \multirow[t]{3}{*}{ Intermediate } & Elementary & 1.155 & .401 & .042 & .03 & 2.28 \\
\hline & Pre-intermediate & .721 & .401 & .303 & -.40 & 1.84 \\
\hline & Upper-intermediate & .093 & .401 & .995 & -1.03 & 1.22 \\
\hline \multirow{3}{*}{$\begin{array}{l}\text { Upper- } \\
\text { intermediate }\end{array}$} & Elementary & 1.061 & .401 & .068 & -.06 & 2.18 \\
\hline & Pre-intermediate & .628 & .401 & .419 & -.50 & 1.75 \\
\hline & Intermediate & -.093 & .401 & .995 & -1.22 & 1.03 \\
\hline
\end{tabular}

\subsubsection{Grammatical intricacy across textbook levels}

Grammatical intricacy is another kind of complexity which deals with how various clauses are connected in clause complex. The reason for investigating grammatical intricacy in this study as suggested by Halliday (1985b) is that when the information is packed and lexically dense, its grammatical structure tends to be really simple. Therefore, examining grammatical intricacy to see how the lexical items are packed or scattered over ranking clauses is worthwhile, as density and intricacy are complementary to each other (Halliday, 2008). As mentioned earlier in Section 4.5.2, grammatical intricacy can be measured by the ratio of ranking clauses per total clause complexes (Halliday, 2008). A clause complex as defined by Butt et al. $(2000, p .30)$ is "a language structure that consists of one clause working by itself, or a group of clauses that work together through some kind of logical relationship." Another similar definition of clause complex which is stated by Eggins (2004, p.255) is that clause complex is the "grammatical and semantic unit formed when two or 
more clauses are linked together in certain systematic and meaningful ways." The relationship between clauses in a clause complex can be determined on the basis of two systems: taxis and logico-semantics. In the intricacy analysis, only ranking clauses based on the classification of parataxis and hypotaxis were determined, embedded clauses were not counted (see Section 3.2.4).

The raw data on grammatical intricacy including the number of ranking clauses, clause complexes and grammatical intricacy score of each text was displayed in Appendix 2. As demonstrated in Table 5.6, data is presented as mean \pm standard deviation plus minimum and maximum scores. The grammatical intricacy mean score increased from the Elementary $(1.58 \pm .30)$ to Pre-intermediate $(1.76 \pm .41)$ to Intermediate $(1.80 \pm .28)$ and maintained the relatively similar figure at the Upper intermediate level $(1.73 \pm .28)$. These figures indicate that on average, there were 1.58 ranking clauses per clause complex in the Elementary book. The number of ranking clauses per clause complex in the other three levels of book was 1.76, 1.80 and 1.73 from low to high respectively. A one-way ANOVA test was conducted to determine if grammatical intricacy formula was different for the four levels of books. Although grammatical intricacy increased in accordance with the book levels, there were no statistically significant differences in grammatical intricacy scores among different levels of textbooks as assessed by one-way ANOVA test $(F(3,20)=$ $.548, p=0.655>0.05)$ as seen in Table 5.7.

Table 5.6. Descriptive statistics on grammatical intricacy across levels

\begin{tabular}{|c|c|c|c|c|c|}
\hline Levels of textbook & $\mathbf{N}$ & Mean & Std. Deviation & Minimum & Maximum \\
\hline Elementary & 6 & 1.58 & .30 & 1.20 & 1.88 \\
\hline Pre-intermediate & 6 & 1.76 & .41 & 1.53 & 2.58 \\
\hline Intermediate & 6 & 1.80 & .28 & 1.31 & 2.07 \\
\hline Upper-intermediate & 6 & 1.73 & .28 & 1.29 & 2.08 \\
\hline
\end{tabular}


Table 5.7. Comparisons of grammatical intricacy between levels

\begin{tabular}{|l|l|l|l|l|l|}
\hline Halliday's lexical density & $\begin{array}{l}\text { Sum of } \\
\text { squares }\end{array}$ & df & Mean Square & F & Sig. \\
\hline Between groups & .169 & 3 & .056 & .548 & .655 \\
\hline Within groups & 2.060 & 20 & .103 & & \\
\hline Total & 2.229 & 23 & & & \\
\hline
\end{tabular}

\subsubsection{Nominalisation across textbook levels}

The raw data of nominalisation in 24 texts which included the instances of nominalisation and the frequency of nominalisation per ranking clauses was demonstrated in Appendix 2. A one-way ANOVA was conducted to determine if nominalisation was different for different levels of books. Similar to the analysis methods in the previous sections, texts in each book were classified into four groups: Elementary $(n=6)$, Pre-intermediate $(n=6)$, Intermediate $(n=6)$ and Upper intermediate $(n=6)$. There were some degrees of outliers, as assessed by boxplot; but data was normally distributed for each group, as assessed by Shapiro-Wilk test ( $p$ > .05); and there was homogeneity of variances, as assessed by Levene's test of homogeneity of variances $(p=.067)$. Table 5.8 displays descriptive statistics data on nominalisation across the four levels of book including mean scores, standard deviation, minimum and maximum scores. The mean scores increased from the Elementary $(.27 \pm .12)$ to Pre-intermediate $(.50 \pm .23)$, to Intermediate $(.78 \pm .23)$, and maintained the relatively similar value at the Upper intermediate $(.74 \pm .34)$. These scores indicate that there were .27 instances of nominalisation per ranking clause in Elementary texts. The figure nearly doubled in Pre-intermediate texts and continued rising by 0.28 in the next two levels.

Table 5.8. Descriptive statistics on nominalisation across levels

\begin{tabular}{|l|l|l|l|l|l|}
\hline Levels of textbook & $\mathrm{N}$ & Mean & Std. Deviation & Minimum & Maximum \\
\hline Elementary & 6 & .27 & .12 & .14 & .50 \\
\hline Pre-intermediate & 6 & .50 & .23 & .15 & .76 \\
\hline Intermediate & 6 & .78 & .23 & .52 & 1.14 \\
\hline Upper-intermediate & 6 & .74 & .34 & .44 & 1.23 \\
\hline
\end{tabular}


One-way ANOVA test reveals that the nominalisation scores were statistically significantly different between different levels of textbooks as $F(3,20)=5.830$ and $p$ $=0.05$. The effect size figure $\omega^{2}=0.38$ is considered as having little effect size. Turkey post-hoc analysis revealed that the increase of Nominalisation scores from Elementary level to Intermediate level (-.510, $95 \% \mathrm{Cl}(-.90$ to -.12$))$ was statistically significant $(p=.007<0.05)$. Turkey post-hoc analysis also found that the increase of Nominalisation scores from Elementary level to Upper-Intermediate level (-.472, $95 \% \mathrm{Cl}(-.86$ to -.08$))$ was statistically significant $(p=.014<0.05)$ but no other group differences were statistically significant. Comparisons of means of nominalisation between levels are presented in Table 5.9. Tukey post-hoc test result is shown in Table 5.10.

Table 5.9. Comparisons of nominalisation between levels

\begin{tabular}{|l|l|l|l|l|l|}
\hline Nominalisation & \multicolumn{3}{|l|}{ Sum of squares } & df & \multicolumn{2}{l|}{ Mean Square } & F Sig. \\
\hline Between groups & 1.009 & 3 & .336 & 5.830 & 0.05 \\
\hline Within groups & 1.154 & 20 & .058 & & \\
\hline Total & 2.163 & 23 & & & \\
\hline
\end{tabular}


Table 5.10. Tukey HSD test on multiple comparisons of nominalisation between levels

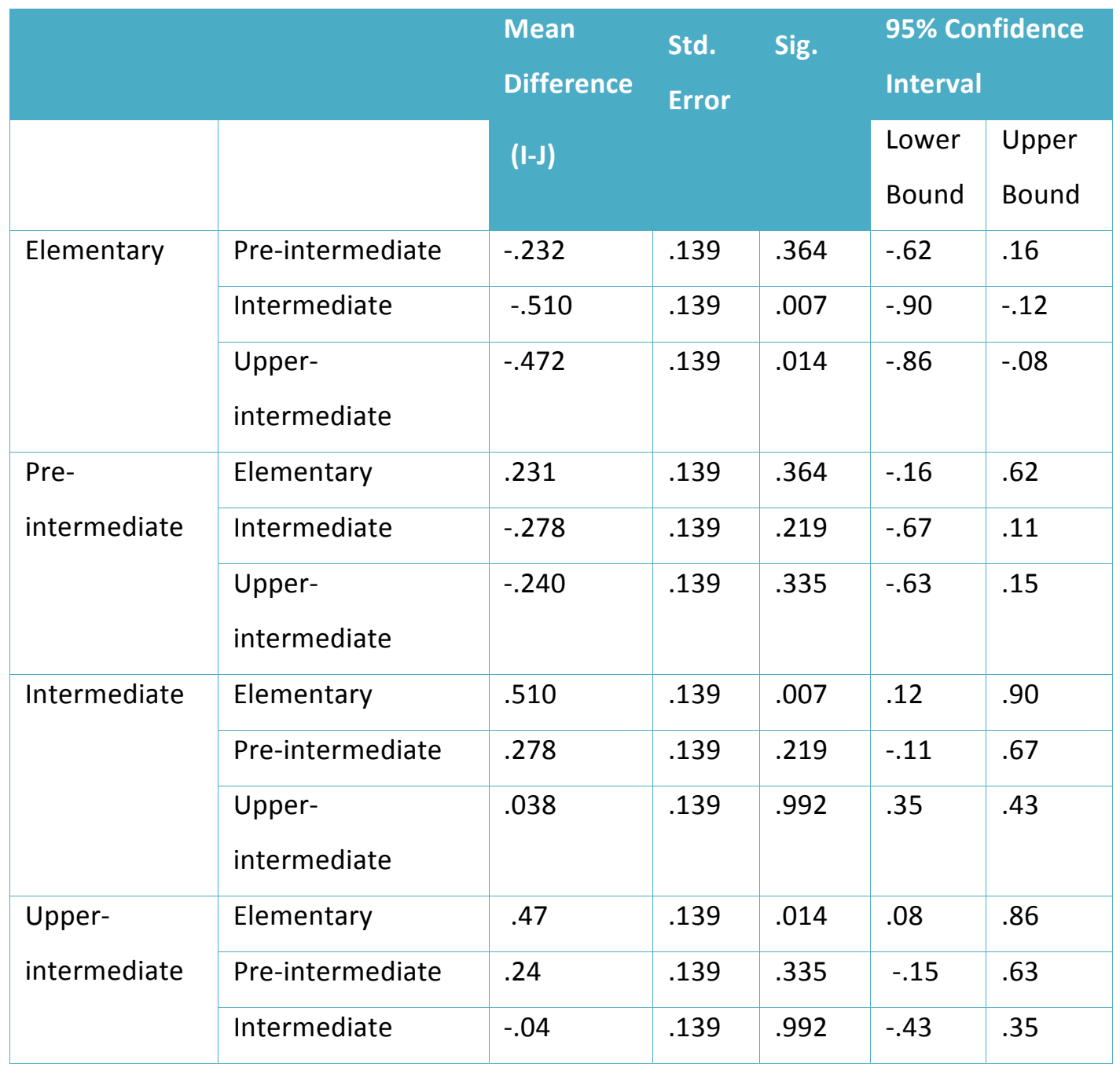

\subsubsection{Grammatical metaphor across textbook levels}

In this study, only ideational metaphor which involves nominalised process was investigated. The result of grammatical metaphor analysis including its instances occurred in the data and its frequency was presented in Appendix 2. A one-way ANOVA was conducted to determine if grammatical metaphor was different for different levels of books. Table 5.11 presents the mean scores, standard deviation, minimum and maximum values. As presented in Table 5.11, the grammatical metaphor score increased from Elementary $(.15 \pm .14)$ to Pre-intermediate $(.22 \pm$ $.19)$, to Intermediate $(.31 \pm .09)$, and Upper intermediate $(.34 \pm .19)$. In other words, these figures indicate that generally Elementary texts displayed an average of .15 
instances of grammatical metaphor per ranking clause. However, the grammatical metaphor scores were not statistically significant between different levels of textbooks $(F(3,20)=1.731$ and $p=0.193)$ as seen in Table 5.12 .

Table 5.11. Descriptive statistics on grammatical metaphor across levels

\begin{tabular}{|l|l|l|l|l|l|}
\hline Levels of textbook & N & Mean & Std. Deviation & Minimum & Maximum \\
\hline Elementary & 6 & .15 & .14 & .04 & .42 \\
\hline Pre-intermediate & 6 & .22 & .19 & .04 & .52 \\
\hline Intermediate & 6 & .31 & .09 & .17 & .43 \\
\hline Upper-intermediate & 6 & .34 & .19 & .08 & .59 \\
\hline
\end{tabular}

Table 5.12. Comparisons of grammatical metaphor between levels

\begin{tabular}{|l|l|l|l|l|l|}
\hline Nominalisation & \multicolumn{2}{|c|}{ Sum of squares } & df & Mean Square & \multicolumn{1}{c|}{ Sig. } \\
\hline Between groups & .130 & 3 & .043 & 1.731 & .193 \\
\hline Within groups & .500 & 20 & .025 & & \\
\hline Total & .630 & 23 & & & \\
\hline
\end{tabular}

\subsubsection{Technicality across textbook levels}

As this study examined reading texts in the science field, technicality was included in the analysis as it is considered as "the predominant discourse feature of the scientific texts" (Martin, 1993d, p.223). Technicality or technical terms "refers to the use of terms or expressions (but mostly nominal group constituents) with a specialised field-specific meaning" (Wignell et al., 1993, p. 144). Technical terms can be realised by: (1) single nouns (e.g., mesas, consumers), (2) nominal groups (e.g., physical environment, frontal rainfall, convection currents), (3) nominalisation (e.g., condensation, evaporation) (Wignell et al., 1993, pp.145-146).

Concerning technicality in scientific texts, Table 5.13 shows that a small number of this feature were found in the data. There were 5 instances of technical terms found in Book 1 (Elementary), 11 in Book 2 (Pre-intermediate), 27 in Book 3 (Intermediate) and 7 in Book 4 (Upper-intermediate), displaying the frequency of $0.03,0.07,0.18$ and 0.05 in those books respectively. Some examples of technical 
terms found in the scientific texts are gravity-free environment, weightless environment, hippocampus, frontal lobe, cerebral cortex, chromosome, genre, posttraumatic stress disorder. It is worth noting that almost all of the technical terms utilised in the scientific texts were nouns and nominal groups which did not involve nominalisation.

Table 5.13. Technicality in scientific texts across levels

\begin{tabular}{|c|c|c|c|c|c|}
\hline & & Elementary & $\begin{array}{l}\text { Pre- } \\
\text { inter }\end{array}$ & Intermediate & $\begin{array}{l}\text { Upper- } \\
\text { intermediate }\end{array}$ \\
\hline \multirow[t]{2}{*}{ Technicality } & Instances & 5 & 11 & 27 & 7 \\
\hline & Frequency & 0.03 & 0.07 & 0.18 & 0.05 \\
\hline
\end{tabular}

\subsubsection{Thematic structure across textbook levels}

Themes were categorised in three types including simple theme, multiple theme and clausal theme. Multiple theme consists of experiential theme, interpersonal theme and textual theme. Instances and percentage of various theme types found in the data were described in Appendix 3. Table 5.14 describes mean scores of theme types across four textbook levels.

Table 5.14. Percentage of theme types across textbook levels ( $n=6$ per book)

\begin{tabular}{|l|l|l|l|l|l|}
\hline & \multicolumn{2}{l}{$\begin{array}{l}\text { Multiple Theme } \\
\text { (Experiential } \\
\text { Theme) }\end{array}$} & $\begin{array}{l}\text { Experiential } \\
\text { Theme }\end{array}$ & $\begin{array}{l}\text { Interpersonal } \\
\text { Theme }\end{array}$ & $\begin{array}{l}\text { Textual } \\
\text { Theme }\end{array}$ \\
\hline Elementary & $67.50 \%$ & $14.67 \%$ & $1.17 \%$ & $14.67 \%$ & $2.33 \%$ \\
\hline Pre-intermediate & $62 \%$ & $18.17 \%$ & $0.5 \%$ & $18.17 \%$ & $1.67 \%$ \\
\hline Intermediate & $55.33 \%$ & $19.33 \%$ & $1.33 \%$ & $18.50 \%$ & $5.33 \%$ \\
\hline Upper- & $55.50 \%$ & $18.50 \%$ & $0.75 \%$ & $19.83 \%$ & $6.17 \%$ \\
intermediate & & & & & \\
\hline Sig. & .431 & .586 & .414 & .575 & .282 \\
\hline
\end{tabular}

As far as thematic analysis is concerned, Table 5.14 shows that textbooks at different levels employed three types of theme: simple theme, multiple theme and 
clausal theme. However, the distribution of these themes was slightly different in different levels of books. Specifically, the percentage of simple theme in the first level of book was the highest accounting for $67.5 \%$. The figure was lower in the next three levels, specifically it accounted for $62 \%$ in Pre-intermediate level, $55.33 \%$ in Intermediate and $55.50 \%$ in Upper-intermediate respectively. Multiple theme and clausal theme, in contrast, demonstrates an increasing pattern from low to high level of textbook. Particularly, $30.17 \%$ of multiple theme was used in Elementary texts, 36.33\% in Pre-intermediate texts and around 38\% in the two highest levels of book. Clausal theme which includes a dependent clause as the beginning of a clause complex was less used in the first two levels of book (around 2\%). The number was approximately three times higher in the two latter books, but still small number.

As far as the function of theme is concerned, the experiential theme was used most in the four books as the experiential theme or topical theme is obligatory theme that constitutes the departure of a message contributing to the development of a text. Similarly, interpersonal theme which involves questions was less used across levels of books as this study investigated reading texts which mainly include declarative sentences. It is worth noting that while $14.67 \%$ of textual theme was used in the Elementary texts, the numbers were relatively similar in the next three levels, standing at $18.17 \%, 18.50 \%$ and $19.83 \%$ for Pre-intermediate, Intermediate and Upper-intermediate respectively. One way ANOVA was conducted to find out if different types of theme were statistically different between textbook levels. However, the result reveals that there were no statistically differences on theme between different levels of textbooks as the $p$-value was greater than 0.05 for all kinds of theme as observed in Table 5.14.

\subsection{Linguistic features in scientific and non-scientific texts}

\subsubsection{Ure's lexical density in scientific and non-scientific texts}

As far as Table 5.15 is concerned, the average lexical density of scientific texts and non-scientific ones at four levels ranged from $43.67 \%$ to $48.67 \%$, which are the typical lexical density values in written language according to Ure's (1971) findings. 
Overall, lexical density in each domain demonstrated a similar pattern with the general trend of lexical density in the four books. This means that the lexical density in the four books maintained the relatively scores except a slight drop in Preintermediate texts. Specifically, lexical density in scientific texts decreased from $48 \%$ at elementary level to $46 \%$ at pre-intermediate level, and went up to around $47 \%$ in at the next two levels. Similarly, non-scientific texts maintained the same lexical density value in elementary and intermediate texts (47.47\%), decreased by $3 \%$ in pre-intermediate text, and increased to $48.67 \%$ at the highest level. It is worth noting that within the same level of book, the lexical density mean scores in the scientific texts were slightly higher than those of the non-scientific texts. The result of one-way ANOVA shows that lexical density in science and non-science field at four levels of textbooks were not significantly different, $F(1,22)=.368, p=.550>$ .005 as indicated in Table 5.16 .

Table 5.15. Descriptive statistics on Ure's lexical density in scientific and non-scientific texts

\begin{tabular}{|l|l|l|l|l|l|l|l|l|l|l|}
\hline \multicolumn{1}{|c|}{} & \multicolumn{1}{|c|}{ Science } \\
textbook & $\mathrm{N}$ & Mean & SD & Min & Max & $\mathrm{N}$ & Mean & SD & Min & Max \\
\hline Elementary & & & & & & & & & & \\
\hline Pre-intermediate & 3 & .48 & .02 & .46 & .50 & 3 & .47 & .03 & .43 & .49 \\
\hline Intermediate & 3 & .47 & .03 & .41 & .49 & 3 & .44 & .06 & .37 & .48 \\
\hline $\begin{array}{l}\text { Upper- } \\
\text { intermediate }\end{array}$ & 3 & .47 & .02 & .46 & .50 & 3 & .49 & .02 & .47 & .51 \\
\hline
\end{tabular}

Table 5.16. Comparisons of ULD between scientific and non-scientific texts

\begin{tabular}{|l|l|l|l|l|l|}
\hline Ure's lexical density & \multicolumn{1}{|c|}{ Sum of squares } & df & Mean Square & F & Sig. \\
\hline Between groups & .000 & 1 & .000 & .368 & .550 \\
\hline Within groups & .025 & 22 & .001 & & \\
\hline Total & .025 & 23 & & & \\
\hline
\end{tabular}




\subsubsection{Halliday's lexical density in scientific and non-scientific texts}

As far as lexical density calculated by Halliday's method in scientific and nonscientific texts is concerned, Table 5.17 reveals that lexical density in both fields had the similar increasing patterns with the overall patterns of the books across textbook levels. Particularly, the mean scores of lexical density in science field increased gradually from 3.84 at Elementary level to 4.47 at Pre-intermediate level, and kept rising to 5.00 in the Intermediate texts before experiencing a slight fall at the highest level. The mean scores in the non-science field were 4.14, 4.38, 5.30 and 5.23 for the four levels mentioned respectively. However, with reference to lexical density in each field within the same book, scientific texts displayed lower mean scores of lexical density than non-scientific ones in Books 1, 3 and 4, although they scored a slightly higher number in Book 2 (Pre-intermediate level).

Table 5.17. Descriptive statistics on lexical density measured by Halliday's method in scientific and non-scientific texts

\begin{tabular}{|l|l|l|l|l|l|l|l|l|l|l|}
\hline \multicolumn{10}{|c|}{ Science } \\
\hline Levels of textbook & $\mathrm{N}$ & Mean & SD & Min & Max & N & Mean & SD & Min & Max \\
\hline Elementary & 3 & 3.84 & .37 & 3.54 & 4.25 & 3 & 4.14 & .50 & 3.78 & 4.71 \\
\hline Pre-intermediate & 3 & 4.47 & .91 & 3.48 & 5.26 & 3 & 4.38 & .73 & 3.54 & 4.81 \\
\hline Intermediate & 3 & 5.00 & .36 & 4.71 & 5.40 & 3 & 5.30 & 1.22 & 4.14 & 6.57 \\
\hline $\begin{array}{l}\text { Upper- } \\
\text { intermediate }\end{array}$ & 3 & 4.88 & .93 & 3.81 & 5.35 & 3 & 5.23 & .62 & 4.56 & 5.77 \\
\hline
\end{tabular}

Table 5.18. Comparisons of HLD between scientific and non-scientific texts

\begin{tabular}{|l|l|l|l|l|l|}
\hline $\begin{array}{l}\text { Halliday's lexical } \\
\text { density }\end{array}$ & \multicolumn{1}{l}{ Sum of squares } & df & Mean Square & F & Sig. \\
\hline Between groups & .277 & 1 & .277 & .414 & .526 \\
\hline Within groups & 14.730 & 22 & .670 & & \\
\hline Total & 15.008 & 23 & & & \\
\hline
\end{tabular}

A one-way ANOVA test was conducted to determine if the Lexical Density was significantly different in science $(n=12)$ and non-science fields $(n=12)$. The data was 
normally distributed for each group, as assessed by Shapiro-Wilk test ( $p>.05)$; and there was homogeneity of variances, as assessed by Levene's test of homogeneity of variances $(p=.992)$. As demonstrated in Table 5.18 , the Lexical Density score was not significantly different between two fields, $F(1,22)=.414, p=.526>.005$.

\subsubsection{Grammatical intricacy in scientific and non-scientific texts}

Table 5.19 shows that while there was an increase in intricacy value from low to high level of scientific texts, non-scientific ones featured relatively similar mean scores of intricacy across four levels. Particularly, scientific texts in the elementary level displayed a mean score of intricacy at 1.53. The mean score rose to 1.94 in the pre-intermediate texts, 1.9 in intermediate ones and 1.77 in the highest level. However, texts in the non-science field displayed the mean score of around 1.6 for all levels. With reference to the comparison of grammatical intricacy between the two fields, Table 5.19 shows that on average, scientific texts were more intricate at all four levels of textbooks except the elementary level. However, the grammatical intricacy score was not significantly different between these two fields, $F(1,22)=$ $1.320, p=.263>.005$, according to the result of a one-way ANOVA conducted to determine the difference of grammatical intricacy in science $(n=12)$ and non-science fields ( $n=12$ ) displayed in Table 5.20.

Table 5.19. Descriptive statistics on grammatical intricacy measured in scientific and nonscientific texts

\begin{tabular}{|l|l|l|l|l|l|l|l|l|l|l|}
\hline \multicolumn{19}{|c|}{ Science } \\
\hline Levels of textbook & $\mathrm{N}$ & Mean & SD & Min & Max & $\mathrm{N}$ & Mean & SD & Min & Max \\
\hline Elementary & 3 & 1.53 & .29 & 1.27 & 1.84 & 3 & 1.62 & .37 & 1.20 & 1.88 \\
\hline Pre- & 3 & 1.94 & .56 & 1.59 & 2.58 & 3 & 1.57 & .06 & 1.53 & 1.63 \\
intermediate & & & & & & & & & & \\
\hline Intermediate & 3 & 1.90 & .11 & 1.79 & 2.00 & 3 & 1.69 & .38 & 1.31 & 2.07 \\
\hline $\begin{array}{l}\text { Upper- } \\
\text { intermediate }\end{array}$ & 3 & 1.77 & .20 & 1.64 & 2.00 & 3 & 1.68 & .40 & 1.67 & 2.08 \\
\hline
\end{tabular}


Table 5.20. Comparisons of grammatical intricacy between scientific and non-scientific texts

\begin{tabular}{|l|l|l|l|l|l|}
\hline $\begin{array}{l}\text { Grammatical } \\
\text { intricacy }\end{array}$ & $\begin{array}{l}\text { Sum of } \\
\text { squares }\end{array}$ & df & Mean Square & F & Sig. \\
\hline Between groups & .126 & 1 & .126 & 1.320 & .263 \\
\hline Within groups & 2.103 & 22 & .096 & & \\
\hline Total & 2.229 & 23 & & & \\
\hline
\end{tabular}

\subsubsection{Nominalisation in scientific and non-scientific texts}

As far as nominalisation in texts in science and non-science fields are concerned, Table 5.21 states that the frequency of nominalisation employed in the scientific texts increased gradually from the lowest to the highest level of textbooks. Nonscientific texts showed a steady rise in nominalisation use from the elementary to intermediate levels, but the highest book level did not employ the highest instances of nominalisation. With regard to the extent to which nominalisation adopted in two fields in the same book, the frequency of nominalisation was relatively the same in both fields in Book 2 (Pre-intermediate) and Book 4 (Upper-intermediate), while the figures were a bit lower in scientific texts in Books 1 (Elementary) and Book 3 (Intermediate) as can be seen in the descriptive statistics in Table 5.21. In addition, this result was further confirmed by the parametric test assessed by oneway ANOVA to determine if the nominalisation was statistically different in science $(n=12)$ and non-science fields $(n=12)$. Table 5.22 shows that nominalisation score was not significantly different between the two fields, $F(1,22)=.261, p=.615>$ .005 , which was quite an unexpected result.

Table 5.21. Descriptive statistics on nominalisation in scientific and non-scientific texts

\begin{tabular}{|l|l|l|l|l|l|l|l|l|l|l|}
\hline \multicolumn{19}{|c|}{ Science } \\
\hline Levels of textbook & $\mathrm{N}$ & Mean & SD & Min & Max & $\mathrm{N}$ & Mean & SD & Min & Max \\
\hline Elementary & 3 & .23 & .08 & .14 & .29 & 3 & .31 & .16 & .19 & .50 \\
\hline Pre-intermediate & 3 & .51 & .17 & .32 & .65 & 3 & .50 & .31 & .15 & .76 \\
\hline Intermediate & 3 & .65 & .12 & .52 & .75 & 3 & .92 & .24 & .66 & 1.14 \\
\hline Upper- & 3 & .78 & .27 & .60 & 1.09 & 3 & .70 & .46 & .44 & 1.23 \\
intermediate & & & & & & & & & & \\
\hline
\end{tabular}


Table 5.22. Comparison of nominalisation scores in scientific and non-scientific texts

\begin{tabular}{|l|l|l|l|l|l|}
\hline Nominalisation & Sum of squares & df & Mean Square & \multicolumn{2}{c|}{ Sig. } \\
\hline Between groups & .025 & 1 & .025 & .261 & .615 \\
\hline Within groups & 2.138 & 22 & .097 & & \\
\hline Total & 2.163 & 23 & & & \\
\hline
\end{tabular}

\subsubsection{Grammatical metaphor in scientific and non-scientific texts}

As far as grammatical metaphor in texts in science and non-science fields are concerned, Table 5.23 shows that the frequency of grammatical metaphor employed in the scientific texts increased gradually from the lowest to the highest level of textbooks (from 0.09 to 0.35 ). Non-scientific texts, however, featured relatively similar mean scores in the first two levels of book and increased by around 0.1 in the next two levels. With regard to the extent to which grammatical metaphor adopted in two fields in the same book, the frequency of grammatical metaphor was relatively the same in both fields in Book 2 (Pre-intermediate) and Book 4 (Upper-intermediate), while the figures were a bit lower in scientific texts in Books 1 (Elementary) and Book 3 (Intermediate) as demonstrated in the descriptive statistics in Table 5.23. Also, the finding of one-way ANOVA parametric test also confirmed that the grammatical metaphor mean score was not significantly different between science $(n=12)$ and non-science fields $(n=12), F(1,22)=.782, p=$ $.386>.005$, as observed in Table 5.24.

Table 5.23. Descriptive statistics on grammatical metaphor in scientific and non-scientific texts

\begin{tabular}{|l|l|l|l|l|l|l|l|l|l|l|}
\hline & \multicolumn{1}{|c|}{ Science } \\
\hline Levels of textbook & $\mathrm{N}$ & Mean & SD & Min & Max & $\mathrm{N}$ & Mean & SD & Min & Max \\
\hline Elementary & 3 & .09 & .04 & .04 & .12 & 3 & .21 & .19 & .06 & .42 \\
\hline Pre-intermediate & 3 & .21 & .17 & .06 & .39 & 3 & .23 & .26 & .04 & .52 \\
\hline Intermediate & 3 & .25 & .08 & .17 & .33 & 3 & .36 & .59 & .32 & .43 \\
\hline Upper-intermediate & 3 & .35 & .15 & .24 & .52 & 3 & .33 & .25 & .08 & .59 \\
\hline
\end{tabular}


Table 5.24. Comparison of grammatical metaphor in scientific and non-scientific texts

\begin{tabular}{|l|l|l|l|l|l|}
\hline Grammatical metaphor & Sum of squares & df & Mean Square & F & Sig. \\
\hline Between groups & .022 & 1 & .022 & .782 & .386 \\
\hline Within groups & .608 & 22 & .028 & & \\
\hline Total & .630 & 23 & & & \\
\hline
\end{tabular}

\subsubsection{Thematic analysis in scientific and non-scientific texts}

Table 5.25 describes the results of thematic structure analysis of texts in science and non-science fields. As far as theme types in scientific texts are concerned, simple theme, multiple theme and clausal theme were employed across four levels of textbooks. However, the distribution of these themes was slightly different in different book levels in scientific texts. Specifically, the percentage of simple theme in the first level of book was the highest accounting for $66.9 \%$. The figure decreased by nearly $10 \%$ in the remaining three levels. Multiple theme, by contrast, demonstrated an increasing pattern from low to high level of textbook. Particularly, $28.50 \%$ of multiple theme was used in Elementary texts, and the proportion of Themes increased by approximately $13 \%$ in the next three levels. Clausal theme which includes a dependent clause as the beginning of a clause complex was used the least in the pre-intermediate book. The number was $1.5 \%$ higher in the elementary texts and $2.8 \%$ and $1.9 \%$ higher in the next two levels of books. These figures indicated that simple themes which were the main component to construe a message at the clausal level were mostly used at all levels in scientific texts.

Similarly, non-scientific texts employed more topical themes in the first two levels of book which accounted for around $68 \%$. In the latter two levels, the percentage of this type of theme decreased by $10 \%$. Multiple theme which includes experiential, interpersonal and textual themes accounted for $32 \%$ in the first two books. The figure increased slightly to around $38 \%$ in the intermediate level and slightly decreased to around $35 \%$ in the highest level of book. The instances of clausal theme, however, were not found in the first two levels of scientific texts, while the proportion were $4.5 \%$ and $7.1 \%$ in the intermediate and upper-intermediate levels respectively. 
Regarding the function of theme, as predicted, experiential theme was mostly used in both science and non-science field. This is not surprising as the experiential theme is compulsory in constituting the starting point of a message contributing to the development of a text. Besides, interpersonal theme dealing with questions was less used in scientific and non-scientific texts as this research examined reading texts which chiefly contained affirmative sentences. The analysis indicated that $13 \%$ of textual theme was employed in the scientific texts at the lowest level, and this number increased to around $20 \%$ in the next three levels. Non-scientific texts displayed the relatively similar percentage of textual theme in the first two level (16\%) and in the latter two level (18\%). These figures indicated that textual theme which is concerned with circumstance of the message (time and place) was all employed in scientific and non-scientific texts at all book levels. Moreover, one way ANOVA was conducted to find out if different types of theme were statistically different between science and non-science fields. However, the result reveals that there were no statistically differences on theme types between two fields as the $p$ values were greater than 0.05 for all kinds of theme as can be observed in Table 5.25 .

Table 5.25. Theme in scientific and non-scientific texts

\begin{tabular}{|c|c|c|c|c|c|c|}
\hline \multirow[t]{2}{*}{ Field } & \multirow{2}{*}{$\begin{array}{l}\text { Levels of } \\
\text { textbook }\end{array}$} & \multirow{2}{*}{$\begin{array}{l}\text { Simple } \\
\text { Theme } \\
\text { (topical } \\
\text { theme) }\end{array}$} & \multicolumn{3}{|c|}{ Multiple Theme } & \multirow{2}{*}{$\begin{array}{l}\text { Clausa } \\
\text { I } \\
\text { Theme }\end{array}$} \\
\hline & & & $\begin{array}{c}\text { Experiential } \\
\text { Theme }\end{array}$ & $\begin{array}{c}\text { Interpersonal } \\
\text { Theme }\end{array}$ & $\begin{array}{l}\text { Textual } \\
\text { Theme }\end{array}$ & \\
\hline \multirow[t]{4}{*}{ Science } & Elementary & $66.9 \%$ & $13.1 \%$ & $2.3 \%$ & $13.1 \%$ & $4.6 \%$ \\
\hline & Pre-intermediate & $55.6 \%$ & $20.7 \%$ & $0.0 \%$ & $20.7 \%$ & $3.1 \%$ \\
\hline & Intermediate & $53.6 \%$ & $20.3 \%$ & $1.4 \%$ & $18.8 \%$ & $5.9 \%$ \\
\hline & $\begin{array}{l}\text { Upper- } \\
\text { intermediate }\end{array}$ & $54.1 \%$ & $20.4 \%$ & $0.0 \%$ & $20.4 \%$ & $5.0 \%$ \\
\hline \multirow{5}{*}{$\begin{array}{l}\text { Non- } \\
\text { science }\end{array}$} & Elementary & $68.0 \%$ & $16.0 \%$ & $0.0 \%$ & $16.0 \%$ & $0.0 \%$ \\
\hline & Pre-intermediate & $68.1 \%$ & $15.4 \%$ & $1.1 \%$ & $15.4 \%$ & $0.0 \%$ \\
\hline & Intermediate & $57.3 \%$ & $18.4 \%$ & $1.4 \%$ & $18.4 \%$ & $4.5 \%$ \\
\hline & $\begin{array}{l}\text { Upper- } \\
\text { intermediate }\end{array}$ & $57.5 \%$ & $16.5 \%$ & $0.0 \%$ & $18.9 \%$ & $7.1 \%$ \\
\hline & Sig. & .385 & .432 & .600 & .735 & .377 \\
\hline
\end{tabular}




\subsection{Correlations among linguistic features}

This section reports on findings of correlation analysis of linguistic features investigated, namely lexical density measured by both Ure's and Halliday's methods, grammatical intricacy, nominalisation and grammatical metaphor. As introduced in the analysis techniques section, the Pearson correlations test was adopted in the analysis of correlations. The results of correlation analysis were displayed in Table 5.26. The interpretation of the strength of the $p$-value was suggested by Cohen (1988) and Pallant (2005) as follows.

- Small strength: $r=0.01$ to 0.29 or $r=-0.01$ to -0.29

- Medium strength: $r=0.30$ to 0.49 or $r=-0.30$ to -0.49

- Large strength: $r=0.50$ to 1.00 or $r=-0.50$ to -1.00

Table 5.26. Pearson correlations among linguistic features

\begin{tabular}{|c|c|c|c|c|c|}
\hline & ULD & HLD & GI & $\mathbf{N}$ & GM \\
\hline Ure's lexical density (ULD) & $\ldots$ & & & & \\
\hline Halliday's lexical density (HLD) & $.489^{*}$ & 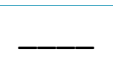 & & & \\
\hline Grammatical intricacy (GI) & -.260 & $-.465 *$ & & & \\
\hline Nominalisation (N) & .129 & $.740^{* *}$ & -.236 & & \\
\hline Grammatical metaphor (GM) & .112 & $.615^{* *}$ & -.298 & $.796^{* *}$ & \\
\hline
\end{tabular}

\subsubsection{Grammatical metaphor and Halliday's lexical density}

As stated by Halliday and Mathiessen (2004), the employment of grammatical metaphor results in high lexical density value. However, high lexical density may not necessarily involve grammatical metaphor. The use of strings of lexical items only can also lead to lexically dense texts (Halliday, 1993). Examples can be seen from sentences 5.1 and 5.2 taken from the data.

\section{Example 5.1}

A body that is deprived of gravity also experiences changes in the distribution of bodily fluids. (Text 12) 


\section{Example 5.2}

Ancient astronomers examined the night sky hoping to learn more about the universe. (Text 12)

Examples 5.1 and 5.2 have the same number of 8 lexical items per ranking clause. However, there are two instances of grammatical metaphor (e.g., changes and distribution) in Example 5.1, while there is none of these found in Example 5.2.

Based on Halliday's studies, the hypotheses regarding the relationship between grammatical metaphor and lexical density in this study were formulated as follows.

$\mathrm{H}_{1:}$ Quantitative analysis of grammatical metaphor and lexical density in this study showed that they were positively associated.

$\mathrm{H}_{0 \text { : }}$ Quantitative analysis of grammatical metaphor and lexical density in this study showed that they were not positively associated.

The result of the correlational analysis in Table 5.26 above shows that the significance level ( $p$-value) was $0.01<0.05$. Thus, the null hypothesis $\mathrm{H}_{0}$ was rejected. The grammatical metaphor and lexical density demonstrated a relatively strong positive relationship with the correlation coefficient $r=.615$.

\subsubsection{Nominalisation and Halliday's lexical density}

Nominalisation is one of the lexical items that conveys the lexical meaning, thus it has the potential of contributing to the text's high density. For instance, in Sentence 128 , there are seven lexical items in two ranking clauses, giving the lexical density at 3.5 according to Halliday's method. However, in Example 5.3, with the employment of nominalisation "care" and "loss", two ranking clauses in Example 5.3 are combined into one clause as seen in Example 5.4. As a result, lexical density goes up higher with the density value of 6 lexical items per clause.

\section{Example 5.3}

People must look after the environment because if they don't we will lose resources that are already becoming scarce.

\section{Example 5.4}

Environmental care will prevent the loss of scarce resources. 
Two hypotheses regarding the relationship between nominalisation and lexical density were tested in this study as follows.

$\mathrm{H}_{1}$ : Quantitative analysis of nominalisation and lexical density in this study showed that they were positively associated.

$\mathrm{H}_{0 \text { : }}$ Quantitative analysis of nominalisation and lexical density in this study showed that they were not positively associated.

As displayed in Table 5.26, the significance level ( $p$-value) was $0.01<0.05$. Thus, the null hypothesis $\mathrm{H}_{0}$ was rejected. The nominalisation and lexical density in this study were strongly associated with the positive correlation coefficient $r=.740$.

\subsubsection{Grammatical metaphor and nominalisation}

Nominalisation is the powerful resources for producing grammatical metaphor (Halliday, 1985a, 1994, 2004). An example can be seen in Example 5.5. There are three instances of nominalisation which function as ideational grammatical metaphor at the same time.

\section{Example 5.5}

Exposure to radiation is another serious hazard that astronauts face (Text 12).

In order to see how strong the relationship between these two features was in the data, two following hypotheses were formulated.

$\mathrm{H}_{1 \text { : }}$ Quantitative analysis of nominalisation and grammatical metaphor in this study showed that they were positively and strongly associated.

$\mathrm{H}_{0 \text { : }}$ Quantitative analysis of nominalisation and grammatical metaphor in this study showed that they were not positively and strongly associated.

As observed in Table 5.26, the significance level ( $p$-value) was smaller than 0.01; thus, we rejected the null hypothesis $\mathrm{H}_{0}$, accepting the alternative hypothesis $\mathrm{H}_{1}$. The nominalisation and grammatical metaphor were strongly and positively associated with the positive correlation coefficient $r=.796$. 


\subsubsection{Grammatical intricacy and Halliday's lexical density}

High lexical density may result in low grammatical intricacy (Halliday, 1985b); however, high density does not necessarily involve low intricacy. Texts that are more intricate can also be dense, and texts that have simple grammatical structures might display low lexical density values. Examples for these cases can be seen in Sentences 5.7 and 5.8 .

\section{Example 5.7}

Stage one sleep is very light. (Text E3)

There are 3 lexical items, 1 ranking clauses and 1 clause complex in Example 5.7, giving the lexical density index of 3 and grammatical intricacy of 1 for this sentence. It can be said that this sentence has low lexical density and low intricacy scores.

\section{Example 5.8}

Images of robotic equipment being used in operating rooms were once seen only in science-fiction movies. (Text I1)

There are 8 lexical items, 1 ranking clauses and 1 clause complex in Example 5.8, giving the lexical density index of 9 and grammatical intricacy of 1 for this sentence. It can be said that this sentence has high density and low intricacy scores.

\section{Example 5.9}

/ / (1)The two expressions are often mentioned in the same breath // (+2) yet they are used quite differently in primate displays, with the smile expressing affection and appeasement rather than playfulness // (Text U1)

There are 12 lexical items, 2 ranking clauses and 1 clause complex in Example 5.9, giving the lexical density index of 6 and grammatical intricacy of 2 for this sentence. It can be said that this sentence has high density and a bit high intricacy scores.

In this study, we hypothesised the relationship between density and intricacy as follows. 
$\mathrm{H}_{1:}$ Quantitative analysis of lexical density and grammatical intricacy in this study showed that they were negatively associated.

$\mathrm{H}_{0 \text { : }}$ Quantitative analysis of lexical density and grammatical intricacy in this study showed that they were not negatively associated.

Table 5.26 reveals that the $p$-value was $0.02>0.05$. Thus, we rejected the null hypothesis $\mathrm{H}_{0}$. This means lexical density and grammatical intricacy featured a moderate negative relation $(r=-.465)$.

\subsubsection{Halliday's lexical density and Ure's lexical density}

While Halliday's lexical density is measured based on the ratio of lexical items per clauses, Ure's measure of lexical density is based on the proportion of lexical items per total words. In order to examine the extent to which these two formulas were correlated and if they were consistent in calculating lexical density, two hypotheses were formulated as follows.

$\mathrm{H}_{1:}$ Quantitative analysis of Halliday's lexical density and Ure's lexical density in this study showed that they were positively associated.

$\mathrm{H}_{0 \text { : }}$ Quantitative analysis of Halliday's lexical density and Ure's lexical density in this study showed that they were not positively associated.

As shown in Table 5.26, the p-value was smaller than 0.05. Thus, we rejected the null hypothesis $\mathrm{H}_{0}$. This means that Halliday's lexical density and Ure's lexical density displayed a moderate positive relation $(r=.489)$.

\subsection{Conclusion}

In this chapter, 24 reading extracts were analysed in terms of lexical density, grammatical intricacy, nominalisation, grammatical metaphor and theme. The analysis was carried out at two levels: the rising level of textbook texts from elementary to advanced, and the level of text fields including science and nonscience. The results of the analysis in this chapter answered research questions 2 , 3 and 4 introduced in the introduction chapter. Based on the quantitative results of 
this chapter, Chapter 6 presents an analysis of full reading texts at the elementary and intermediate levels in both science and non-science domains in terms of how complexity differs according to stages of texts and what effect it has on the text's hierarchy of periodicity. Thus, the next chapter will give a respond to the final research question of the study. 


\section{Chapter 6: Analysis of Linguistic Complexity at the Full Text Levels}

\subsection{Introduction}

This chapter presents a qualitative and quantitative analysis of linguistic complexity in four full academic reading passages. The analysis in this chapter helps address the final research objective on investigating how the complexity of language differs according to stages of text types and what effects they have on the text periodicity, Thus, it will help respond to the last research question of the study.

- Research question 5: How do linguistic features including lexical density, grammatical intricacy, nominalisation, and grammatical metaphor differ according to stages of text types and what effects do they have on the text periodicity?

Specifically, the purpose of this section is to illustrate how linguistic complexity characterised was realised at the level of context. The analysis of four full texts at elementary and intermediate levels in both science and non-science field focused on lexical density measured by Halliday's method, grammatical intricacy, nominalisation and grammatical metaphor. These linguistic features were examined according to stages of text types to identify some general trends of linguistic features examined. This section also looked at how these linguistic features help build the ideational and textual meaning at the level of discourse. The effect of grammatical metaphor might have on the text's hierarchy of periodicity was revealed. In order to do this, this chapter starts with the description of text selection for the analysis. It then provides a general explanation on the analysis. Finally, the analysis of four full texts is presented. 


\subsection{Choosing texts for the illustration}

Hierarchy of periodicity which is concerned with the information flow of the text was analysed in this section based on the quantitative results of linguistic features in four levels of textbooks stated in Section 5.3 of Chapter 5. As far as the quantitative findings across four levels of textbooks are concerned, there were statistically differences in the employment of lexical density and nominalisation between two levels: elementary and intermediate. In addition, although the number of grammatical metaphor was not statically different between these groups, they did show an increasing trend in the frequency of these features from elementary to intermediate level. For these two reasons, qualitative analysis regarding the text periodicity was performed with texts adopted at these two levels to see how complexity shifted from low to high. As this study investigated texts in both science and non-science domains, at each level, a scientific text and a nonscientific one were chosen for qualitative analysis in this section. Totally, the qualitative analysis was conducted with four full texts of Texts E2, E5, 12 and 14 as described in Table 6.1.

Table 6.1. Numbers of texts chosen for periodicity analysis

\begin{tabular}{|c|c|c|c|}
\hline \multicolumn{2}{|c|}{ Level } & \multicolumn{2}{|c|}{ Intermediate } \\
\hline Field & & & 2 \\
\hline Science & Text 1 (E2) & Text 2 (I2) & 2 \\
\hline Non-science & Text 3 (E5) & Text 4 (14) & $\mathbf{4}$ \\
\hline Total & 2 & 2 & 2 \\
\hline
\end{tabular}

\subsection{General explanation of the analysis}

To examine how linguistic features differ according to stages of texts in detail, the analysis focused on lexical density measured by Halliday's method was correlated well with other linguistic features such as grammatical intricacy, nominalisation, and grammatical metaphor as demonstrated in Table 5.32. The whole text was separated into ranking clauses as indicated in the first column. The second column is about the text script. Text script was divided into stages of genre: Phenomenon 
and Explanation stages for the Explanation genre; and General Statement and Description for the Report genre. The instances of lexical items, logic-semantic types, nominalisation and grammatical metaphor of each ranking clause were stated in the following columns and in the same row of each ranking clause. Following this, the result of quantitative data of complexity according to stages of the text types was decided. The analysis of each text was followed by the analysis of Theme and New to see if grammatical metaphor has the effect on this layer.

Below are the explanations of notational conventions in SFL and how lexical items, nominalisation and grammatical metaphor were recognised in the text analysis in this chapter. In addition, explanations of abbreviation used in the analysis were also provided.

$\alpha, \beta, \gamma, \ldots$

$1,2,3, \ldots$

$=$

$+$

$\mathrm{X}$

/1

।

Lexical items

Nominalisation

Grammatical metaphor

LI

$C L$

$N$

GM clause complex boundary

ranking clause boundary

hypotactic structure

paratactic structure

expansion: elaboration

expansion: extension

expansion: enhancement

projection: locution

projection: idea

bold

bold italics

bold italics underlined

lexical item

clause complex

nominalisation

grammatical metaphor 


\subsection{Analysis of four chosen texts}

\subsubsection{Text 1}

\subsubsection{Description of Text 1}

The tittle of this text is "What's that sound?" which is a reading passage in Book 1 (Elementary level) belonging to the science field. This text explains how dolphins and whales make sound in order to communicate and locate things such as food, even in the dark. The text includes five paragraphs consisting of an introduction, three paragraphs in the body section and a short conclusion. The introduction identifies the phenomenon to explain, which includes a thesis statement functioning as macroTheme of the text. The next three paragraphs are the Explanation stage which explains how dolphins and whales make sound and how these animals use sound (whistles and songs) to communicate and see things. The topic sentence of each paragraph in the body section is known as hyperTheme of that paragraph. In total, the text comprises three hyperThemes which are named hyperTheme 1, hyperTheme 2 and hyperTheme 3 in this analysis. The final paragraph is the conclusion which is considered as macroNew in the SFL terminology.

\subsubsection{Analysis of Text 1}

6.4.1.2.1 Analysis of linguistic features according to stages of the text type and hierarchy of periodicity of Text 1

Table 6.2. Linguistic complexity analysis of Text 1

\begin{tabular}{|c|c|c|c|c|c|}
\hline NO. & TEXT SCRIPT & LI & $C L$ & $N$ & GM \\
\hline & PHENOMENON & & & & \\
\hline 1 & $\begin{array}{l}\text { III Like humans, all animals communicate in some ways. } \\
\text { III }\end{array}$ & 4 & - & 0 & 0 \\
\hline 2 & ||| Many use sounds or actions: & 3 & 1 & 0 & 0 \\
\hline 3 & || birds 'sing' || & 2 & $1=2$ & 0 & 0 \\
\hline 4 & or tap their beaks, || & 2 & $2+3$ & 0 & 0 \\
\hline
\end{tabular}




\begin{tabular}{|c|c|c|c|c|c|}
\hline NO. & TEXT SCRIPT & $L I$ & $C L$ & $N$ & GM \\
\hline 5 & and dogs bark. ||| & 2 & $2+4$ & 0 & 0 \\
\hline 6 & $\begin{array}{l}\text { [macroTheme] || Dolphins and whales use sound to } \\
\text { communicate and to locate objects in the dark.||| }\end{array}$ & 8 & - & 0 & 0 \\
\hline & EXPLANATION & & & & \\
\hline 7 & [hyperTheme 1] || | It is often hard to see underwater, || & 3 & 1 & 0 & 0 \\
\hline 8 & so sound is very important to whales and dolphins. || | & 4 & $\mathrm{X} 2$ & 0 & 0 \\
\hline 9 & |||To make most sounds, || & 2 & $x \beta$ & 0 & 0 \\
\hline 10 & $\begin{array}{l}\text { these animals blow air through a hole on top of their } \\
\text { bodies. III }\end{array}$ & 6 & $\alpha$ & 0 & 0 \\
\hline 11 & III Large whales make low-pitched sounds; & 5 & 1 & 0 & 0 \\
\hline 12 & $\begin{array}{l}\text { ||smaller whales and dolphins make high-pitched } \\
\text { ones. ||| }\end{array}$ & 5 & $=2$ & 0 & 0 \\
\hline 13 & $\begin{array}{l}\text { II Many of these sounds are indiscernible to the human } \\
\text { ear. ||| }\end{array}$ & 4 & - & 0 & 0 \\
\hline 14 & || Only the animals can hear them.||| & 2 & _- & 0 & 0 \\
\hline 15 & $\begin{array}{l}\text { [hyperTheme 2] || | Dolphins use a whistle-like sound to } \\
\text { communicate. ||| }\end{array}$ & 5 & - & 0 & 0 \\
\hline 16 & ||| Scientists think || & 2 & $\alpha$ & 0 & 0 \\
\hline 17 & that every dolphin has its own whistle. III & 3 & ‘ $\beta$ & 1 & 0 \\
\hline 18 & III This is like the animal's name, or signature. III & 3 & - & 0 & 0 \\
\hline 19 & III A dolphin might make this sound to greet others. III & 4 & - & 0 & 0 \\
\hline 20 & III It may also whistle loudly to signal for help. III & 4 & - & 1 & 1 \\
\hline 21 & $\begin{array}{l}\text { III Whales also use whistles and 'song' to communicate } \\
\text { with other whales. III }\end{array}$ & 6 & - & 2 & 2 \\
\hline 22 & $\begin{array}{l}\text { III Some of these songs can travel thousands of miles } \\
\text { through the water. III }\end{array}$ & 4 & - & 1 & 0 \\
\hline 23 & $\begin{array}{l}\text { [hyperTheme 3] || | Dolphins and whales also use sound } \\
\text { to 'see' things || }\end{array}$ & 6 & $\alpha$ & 0 & 0 \\
\hline 24 & by sending clicking sounds into water. III & 4 & $x \beta$ & 0 & 0 \\
\hline 25 & III If the 'click' hits something, II & 2 & $x \beta$ & 1 & 0 \\
\hline 26 & for example a rock, it creates an echo. III & 3 & $\alpha$ & 1 & 0 \\
\hline 27 & III This echo returns II & 2 & 1 & 1 & 0 \\
\hline 28 & and gives whales and dolphins important information. III & 5 & +2 & 0 & 0 \\
\hline 29 & III It tells them where something is, and how big it is. III & 2 & - & 0 & 0 \\
\hline 30 & III By using the clicks and echoes, II & 3 & $x \beta$ & 2 & 0 \\
\hline
\end{tabular}




\begin{tabular}{|c|c|c|c|c|c|}
\hline NO. & TEXT SCRIPT & LI & $C L$ & $N$ & $G M$ \\
\hline 31 & dolphins and whales can swim around || & 3 & $\alpha 1$ & 0 & 0 \\
\hline 32 & and locate food - even in the dark. III & 3 & & 0 & 0 \\
\hline 33 & $\begin{array}{l}\text { III [macroNew] Today, scientists are studying these } \\
\text { animals to better understand them, and the important } \\
\text { sounds they create. III }\end{array}$ & 7 & $=\alpha$ & 0 & 0 \\
\hline \multirow[t]{2}{*}{34} & $\begin{array}{l}\text { IIIThey might have a lot to teach us about } \\
\text { communication. III }\end{array}$ & 3 & - & 1 & 1 \\
\hline & Total & 126 & 22 & 11 & 4 \\
\hline
\end{tabular}

\subsection{Analysis of Theme and New of Text 1}

Table 6.3. Theme and New analysis of Text 1

\begin{tabular}{|c|c|c|c|}
\hline NO. & MARKED THEME & SUBJECT/THEME & NEW \\
\hline 1 & Like humans & all animals & communicate in some ways. \\
\hline 2 & & Many & use sounds or actions: \\
\hline 3 & & Birds & sing' \\
\hline 4 & & (or) (birds) & tap their beaks, \\
\hline 5 & & and dogs & bark. \\
\hline 6 & & Dolphins and whales & $\begin{array}{l}\text { use sound to communicate and to } \\
\text { locate objects in the dark. }\end{array}$ \\
\hline 7 & & It & is often hard to see underwater, \\
\hline 8 & & (so) sound & $\begin{array}{l}\text { is very important to whales and } \\
\text { dolphins. }\end{array}$ \\
\hline 9 & $\begin{array}{l}\text { To make most } \\
\text { sounds, }\end{array}$ & these animals & $\begin{array}{l}\text { blow air through a hole on top of their } \\
\text { bodies. }\end{array}$ \\
\hline 10 & & Large whales & make low-pitched sounds, \\
\hline 11 & & $\begin{array}{l}\text { smaller whales and } \\
\text { dolphins }\end{array}$ & make high-pitched ones. \\
\hline 12 & & Many of these sounds & are indiscernible to the human ear. \\
\hline 13 & & Only the animals & can hear them. \\
\hline 14 & & Dolphins & $\begin{array}{l}\text { use a whistle-like sound to } \\
\text { communicate. }\end{array}$ \\
\hline 15 & & Scientists & $\begin{array}{l}\text { think that every dolphin has its own } \\
\text { whistle. }\end{array}$ \\
\hline
\end{tabular}




\begin{tabular}{|c|c|c|c|}
\hline NO. & MARKED THEME & SUBJECT/THEME & NEW \\
\hline 16 & & This & is like the animal's name, or signature. \\
\hline 17 & & A dolphin & might make this sound to greet others. \\
\hline 18 & & It & $\begin{array}{l}\text { may also whistle loudly to signal for } \\
\text { help. }\end{array}$ \\
\hline 19 & & Whales & $\begin{array}{l}\text { also use whistles and 'song' to } \\
\text { communicate with other whales. }\end{array}$ \\
\hline 20 & & Some of these songs & $\begin{array}{l}\text { can travel thousands of miles through } \\
\text { the water. }\end{array}$ \\
\hline 21 & & Dolphins and whales & $\begin{array}{l}\text { also use sound to 'see' things by } \\
\text { sending clicking sounds into water. }\end{array}$ \\
\hline 22 & $\begin{array}{l}\text { If the 'click' hits } \\
\text { something, for } \\
\text { example a rock, }\end{array}$ & It & creates an echo. \\
\hline 23 & & This echo & returns \\
\hline 24 & & (and) (this echo) & $\begin{array}{l}\text { gives whales and dolphins important } \\
\text { information. }\end{array}$ \\
\hline 25 & & It & $\begin{array}{l}\text { tells them where something is, and } \\
\text { how big it is. }\end{array}$ \\
\hline 26 & $\begin{array}{l}\text { By using the } \\
\text { clicks and } \\
\text { echoes, }\end{array}$ & dolphins and whales & $\begin{array}{l}\text { can swim around and locate food - } \\
\text { even in the dark. }\end{array}$ \\
\hline 27 & Today, & Scientists & $\begin{array}{l}\text { are studying these animals to better } \\
\text { understand them, and the important } \\
\text { sounds they create. }\end{array}$ \\
\hline 28 & & They & $\begin{array}{l}\text { might have a lot to teach us about } \\
\text { communication. }\end{array}$ \\
\hline
\end{tabular}

\subsubsection{Interpretation of the analysis of Text 1}

As observed in Table 6.2, lexical items were used to express the meaning of processes (e.g., communicate, sing, bark, see, locate), participants (e.g., scientists, animals, whales, dolphins), things (e.g., songs, whistles, helps, sound, information, communication), and qualities (e.g., hard, large, smaller, big, important,). The use of these lexical items helps build the ideational meaning of the text in relation to its 
overall social purpose in explaining how whales and dolphins create sound to communicate and locate objects. Although this text belongs to the science field, no technical terms were found in the text. Overall, the text employed everyday written global language to talk about the topic of science according to the language variation framework (Mahboob, 2014a). Regarding intricacy, the majority of clause complexes include one simple ranking clause. In some clause complexes, logicalsemantic relations of expansion were used to connect meaning between clauses in clause complexes. For example, additional extension (e.g., and, or), causalconditional enhancement (e.g., so), and projection of idea (e.g., Scientists think that every dolphin has its own whistle). This text used several instances of nominalisation (e.g., communication, whistles, songs, click) and grammatical metaphor (e.g., communication, whistles, songs, help). However, no nominalisation or grammatical metaphor was used in macroTheme, hyperThemes. Only one instance of grammatical metaphor (e.g., communication) which was employed in macroNew as referred from Table 6.2. Table 6.3 reveals that all the instances of grammatical metaphor were found in News, and those of nominalisation were employed in Themes.

Take a closer look at how density, intricacy, grammatical metaphor differ according to stages of the text. As described in Table 6.4, overall the text displayed an average number of 3.7 lexical items per ranking clauses, 1.55 ranking clauses per clause complex, 0.32 nominalisation and 0.12 grammatical metaphors per ranking clause. With regard to two stages in this text, Table 6.4 shows that Explanation stage employed a greater number of lexical items, nominalisation and grammatical metaphor but was less intricate compared with the Phenomenon stage. Thus, it can be said that the explanation stage is more complex than the phenomenon stage. In summary, this is a simple scientific text which employed lexical items to build the ideational meaning of the text. Nominalisations and grammatical metaphors were employed to certain extent; however, technicality did not involve in this scientific text. Regarding the effect of grammatical metaphor on building the field of the text, it is evident that grammatical metaphor had little effect on building the field of 
discourse or creating coherent text. Several grammatical metaphors used in this text were found in New as shown in Table 6.3.

Table 6.4. Result of linguistic analysis according to stages of Text 1

\begin{tabular}{|c|c|c|c|c|}
\hline & Density & Intricacy & Nominalisation & $\begin{array}{c}\text { Grammatical } \\
\text { metaphor }\end{array}$ \\
\hline \multicolumn{5}{|l|}{ Stages } \\
\hline - Phenomenon & 3.5 & 2 & 0 & 0 \\
\hline - Explanation & 3.75 & 1.47 & 0.32 & 0.12 \\
\hline Overall & 3.7 & 1.55 & 0.32 & 0.12 \\
\hline
\end{tabular}

\subsubsection{Text 2}

\subsubsection{Description of Text 2}

The tittle of this text is "The challenge of space travel." This text is extracted in Book 3 (Intermediate level) and belongs to the science field. The text explains the effects that astronauts suffer when returning to the Earth from their space travel. The extract consists of seven paragraphs including an introduction, five paragraphs in the body section and a conclusion. The first two paragraphs are the introduction identifying the phenomenon to explain which includes a thesis statement functioning as macroTheme of the text. The next five paragraphs belong to the explanation stage which states two physiological problems and one psychological issue that effect astronauts, and the predicted manned mission to Mars in the future of space travel. The topic sentence of each paragraph in the body section is known as hyperTheme of that paragraph. In total, the text comprises four hyperThemes which were named hyperTheme 1, hyperTheme 2, hyperTheme 3 and hyperTheme 4 in this analysis. The lower layer of hyperTheme is Theme which is the starting point of the message and followed by New realised by the mark of intonation in the rest of the clause. Theme and New in the explanation Stage explain the causes for the effect stated in each hyperTheme. HyperNew which have the function of distilling information and are often the last sentences of paragraphs 
are not found in the sample text below. Similarly, macroNew which refers to the conclusion of the text is not included.

\subsubsection{Analysis of Text 2}

6.4.2.2.1 Analysis of linguistic features according to stages of the text type and hierarchy of periodicity of Text 2

Table 6.5. Linguistic complexity analysis of Text 2

\begin{tabular}{|c|c|c|c|c|c|}
\hline NO. & TEXT SCRIPT & LI & $C L$ & $N$ & GM \\
\hline & PHENOMENON & & & & \\
\hline 1 & || For centuries, humans have looked up the sky I| & 4 & 1 & 0 & 0 \\
\hline 2 & $\begin{array}{l}\text { and wondered what exists beyond the realm of our } \\
\text { planet. ||| }\end{array}$ & 4 & +2 & 0 & 0 \\
\hline 3 & || Ancient astronomers examined the night sky || & 5 & $\alpha$ & 0 & 0 \\
\hline 4 & hoping to learn more about the universe. ||| & 3 & $=\beta$ & 0 & 0 \\
\hline 5 & $\begin{array}{l}\text { II| More recently, movies such as Stanley Kubrick's } \\
\text { 2001: A Space Odyssey explored the possibility of } \\
\text { sustaining human life in outer space, || }\end{array}$ & 12 & $\alpha$ & 2 & 1 \\
\hline 6 & $\begin{array}{l}\text { while other films have questioned whether } \\
\text { extraterrestrial life forms may have visited our planet. } \\
\text { III }\end{array}$ & 7 & $+\beta$ & 1 & 0 \\
\hline 7 & $\begin{array}{l}\text { II S Since astronaut Yuri Gagarin became the first man to } \\
\text { travel in space in } 1961, \|\end{array}$ & 7 & $\beta$ & 0 & 0 \\
\hline 8 & $\begin{array}{l}\text { scientists have researched what conditions are like } \\
\text { beyond Earth's atmosphere, and what effects space } \\
\text { travel has on the human body. III }\end{array}$ & 11 & $\alpha$ & 2 & 2 \\
\hline 9 & $\begin{array}{l}\text { II [macroNew] Although most astronauts do not spread } \\
\text { more than a few months in space, } \|\end{array}$ & 4 & $x \beta$ & 0 & 0 \\
\hline 10 & $\begin{array}{l}\text { many experience physiological and psychological } \\
\text { problems }\end{array}$ & 4 & $\alpha$ & 0 & 0 \\
\hline 11 & ||when they return to Earth. $\| \mid$ & 2 & $x y$ & 0 & 0 \\
\hline 12 & || | Some of these ailments are short-live; || & 2 & 1 & 1 & 1 \\
\hline \multirow[t]{2}{*}{13} & others may be long lasting. | II & 2 & $=2$ & 0 & 0 \\
\hline & EXPLANATION & & & & \\
\hline
\end{tabular}




\begin{tabular}{|c|c|c|c|c|c|}
\hline NO. & TEXT SCRIPT & $L$ & $C L$ & $\mathbf{N}$ & GM \\
\hline 14 & $\begin{array}{l}\text { III [hyperTheme 1] More than two-thirds of all astronauts } \\
\text { suffer from motion sickness || }\end{array}$ & 4 & $\alpha$ & 2 & 2 \\
\hline 15 & while travelling in space. \|\| & 2 & $+\beta$ & 0 & 0 \\
\hline 16 & $\begin{array}{l}\text { II | In the gravity-free environment, the body cannot } \\
\text { distinguish up from down. || }\end{array}$ & 4 & - & 0 & 0 \\
\hline 17 & $\begin{array}{l}\text { IIIThe body's internal balance system sends confusing } \\
\text { signals to the brain, || }\end{array}$ & 8 & $\alpha$ & 2 & 1 \\
\hline 18 & $\begin{array}{l}\text { which can result in nausea lasting as long as a few days. } \\
\|\|\end{array}$ & 4 & $=\beta$ & 0 & 0 \\
\hline 19 & $\begin{array}{l}\text { III A body that is deprived of gravity also experiences } \\
\text { changes in the distribution of bodily fluids. II }\end{array}$ & 8 & - & 2 & 2 \\
\hline 20 & $\begin{array}{l}\text { III More fluid than normal ends up in the face, neck, and } \\
\text { chest, }\end{array}$ & 6 & $\alpha$ & 0 & 0 \\
\hline 21 & $\begin{array}{l}\text { || resulting in a puffy face, bulging neck veins, and a } \\
\text { slightly enlarged heart. }|| \mid\end{array}$ & 9 & $=\beta$ & 0 & 0 \\
\hline 22 & $\begin{array}{l}\text { III [hyperTheme 2] Throughout the durations of a } \\
\text { mission, astronauts' bodies experience some potentially } \\
\text { dangerous disorders. III }\end{array}$ & 8 & - & 1 & 1 \\
\hline 23 & $\begin{array}{l}\text { III One of the most common is loss of muscle mass and } \\
\text { bone density. II }\end{array}$ & 6 & - & 2 & 2 \\
\hline 24 & $\begin{array}{l}\text { I| Another effect of the weightless environment is || that } \\
\text { astronauts tend not to use their legs as much, || }\end{array}$ & 6 & 1 & 1 & 1 \\
\hline 25 & so the muscles gradually atrophy. III & 2 & $\mathrm{X} 2$ & 0 & 0 \\
\hline 26 & $\begin{array}{l}\text { II This, combined with the shift of fluid to the upper } \\
\text { body and the resulting loss of essential minerals such as } \\
\text { calcium causes bones to weaken. } \|\end{array}$ & 13 & - & 2 & 2 \\
\hline 27 & $\begin{array}{l}\text { II Bone density can decrease at a rate of } 1 \text { to } 2 \text { percent a } \\
\text { month }\end{array}$ & 5 & 1 & 2 & 1 \\
\hline 28 & $\begin{array}{l}\text { II and, as a result, many astronauts are unable to walk } \\
\text { properly for a few days upon their return to earth. } \|\end{array}$ & 6 & +2 & 1 & 1 \\
\hline 29 & $\begin{array}{l}\text { III Exposure to radiation is another serious hazard that } \\
\text { astronauts face. }\end{array}$ & 6 & - & 3 & 3 \\
\hline 30 & II| Without the earth's atmosphere to protect them, II & 3 & $+\beta$ & 0 & 0 \\
\hline
\end{tabular}




\begin{tabular}{|c|c|c|c|c|c|}
\hline NO. & TEXT SCRIPT & $L I$ & $C L$ & $N$ & GM \\
\hline 31 & $\begin{array}{l}\text { astronauts can be exposed to intense radiation from the } \\
\text { sun and other galactic bodies, } \|\end{array}$ & 7 & $\alpha$ & 1 & 1 \\
\hline 32 & leaving them at risk of cancer. ||| & 3 & & 0 & 0 \\
\hline 33 & $\begin{array}{l}\text { II [hyperTheme 3] In addition to physiological difficulties, } \\
\text { astronauts who travel for extended periods may also } \\
\text { suffer from psychological stress. }||\end{array}$ & 9 & - & 2 & 2 \\
\hline 34 & || Astronauts live || & 2 & 1 & 0 & 0 \\
\hline 35 & and work in small, tight spaces, I| & 4 & +2 & 0 & 0 \\
\hline 36 & $\begin{array}{l}\text { and they must be able to deal both physically and mentally } \\
\text { with the confined environment. III }\end{array}$ & 5 & +3 & 0 & 0 \\
\hline 37 & $\begin{array}{l}\text { III In addition, long periods away from family and friends } \\
\text { can leave space travellers feeling lonely and depressed. }\end{array}$ & 10 & - & 0 & 0 \\
\hline 38 & $\begin{array}{l}\text { III [hyperTheme 4] Now that man has been to the Moon } \\
\text { and unmanned missions have been sent to Mars, II }\end{array}$ & 6 & & 0 & 0 \\
\hline 39 & many believe || & 1 & $\alpha$ & 0 & 0 \\
\hline 40 & $\begin{array}{l}\text { that next major step in space travel will be a manned } \\
\text { mission to and from Mars. } \| \mid\end{array}$ & 7 & ‘ $\beta$ & 2 & 2 \\
\hline 41 & $\begin{array}{l}\text { II| Differences between the orbits of Earth and Mars } \\
\text { mean || }\end{array}$ & 5 & $\alpha$ & 1 & 1 \\
\hline 42 & $\begin{array}{l}\text { that such a mission would take almost three years to } \\
\text { complete. ||| }\end{array}$ & 4 & $' \beta$ & 0 & 0 \\
\hline 43 & $\begin{array}{l}\text { III The National Space Biomedical Research Institute } \\
\text { (NSBRI) is currently investigating whether such an } \\
\text { operation is possible in light of the hazards astronauts } \\
\text { face. III }\end{array}$ & 14 & - & 2 & 1 \\
\hline 44 & $\begin{array}{l}\text { III During short missions, some of the physical and } \\
\text { mental challenges of space travel can be controlled with } \\
\text { diet and regular exercise. } \|\end{array}$ & 11 & - & 3 & 3 \\
\hline 45 & $\begin{array}{l}\text { II In the case of long-term space travel, however, it is still } \\
\text { not entirely clear II }\end{array}$ & 5 & $\alpha$ & 1 & 1 \\
\hline 46 & if the human body could adapt and survive. || | & 4 & $+\beta$ & 0 & 0 \\
\hline 47 & $\begin{array}{l}\text { III [macroNew] In 2010, the NSBRI is due to present its } \\
\text { findings to NASA }\end{array}$ & 4 & 1 & 1 & 1 \\
\hline 48 & II and present a 'go' or 'no go' recommendation regarding & 7 & +2 & 1 & 1 \\
\hline
\end{tabular}




\begin{tabular}{|l|l|c|c|c|c|}
\hline NO. & \multicolumn{1}{|c|}{ TEXT SCRIPT } & CL & N & GM \\
\hline 49 & $\begin{array}{l}\text { a manned mission to Mars. III } \\
\text { III As new technologies develop to help scientists further } \\
\text { pursue their goals, II }\end{array}$ & 7 & $\mathrm{x} \beta$ & 0 & 0 \\
\hline 50 & $\begin{array}{l}\text { we may one day see humans walk on distant planets. III } \\
\begin{array}{l}\text { Total } \\
\hline\end{array}\end{array}$ & 4 & $\alpha$ & 0 & 0 \\
\hline
\end{tabular}

\subsection{Analysis of Theme and New in Text 2}

Table 6.6. Theme and New analysis of Text 2

\begin{tabular}{|c|c|c|c|}
\hline NO. & MARKED THEME & SUBJECT/THEME & NEW \\
\hline 1 & For centuries & humans & have looked up the sky \\
\hline 2 & & (and) & $\begin{array}{l}\text { wondered what exists beyond the } \\
\text { realm of our planet. }\end{array}$ \\
\hline 3 & & ancient astronomers & $\begin{array}{l}\text { examined the night sky, hoping to } \\
\text { learn more about the universe. }\end{array}$ \\
\hline 4 & More recently, & $\begin{array}{l}\text { movies such as Stanley } \\
\text { Kubrick's 2001: A } \\
\text { Space Odyssey }\end{array}$ & $\begin{array}{l}\text { explored the possibility of } \\
\text { sustaining human life in outer } \\
\text { space, }\end{array}$ \\
\hline 5 & & (while) other films & $\begin{array}{l}\text { have questioned whether } \\
\text { extraterrestrial life forms may have } \\
\text { visited our planet. }\end{array}$ \\
\hline 6 & $\begin{array}{l}\text { Since astronaut } \\
\text { Yuri Gagarin } \\
\text { became the first } \\
\text { man to travel in } \\
\text { space in 1961, }\end{array}$ & Scientists & $\begin{array}{l}\text { have researched what conditions } \\
\text { are like beyond Earth's } \\
\text { atmosphere, and what effects } \\
\text { space travel has on the human } \\
\text { body. }\end{array}$ \\
\hline 7 & $\begin{array}{l}\text { Although most } \\
\text { astronauts do not } \\
\text { spread more than } \\
\text { a few months in } \\
\text { space, }\end{array}$ & Many & $\begin{array}{l}\text { experience physiological and } \\
\text { psychological problems when they } \\
\text { return to Earth. }\end{array}$ \\
\hline 8 & & $\begin{array}{l}\text { Some of these } \\
\text { ailments }\end{array}$ & are short-live; \\
\hline 9 & & Others & may be long lasting, \\
\hline
\end{tabular}




\begin{tabular}{|c|c|c|c|}
\hline NO. & MARKED THEME & SUBJECT/THEME & NEW \\
\hline 10 & & $\begin{array}{l}\text { More than two-thirds } \\
\text { of all astronauts }\end{array}$ & $\begin{array}{l}\text { suffer from motion sickness while } \\
\text { travelling in space; }\end{array}$ \\
\hline 11 & & The body & cannot distinguish up from down. \\
\hline 12 & $\begin{array}{l}\text { In the gravity-free } \\
\text { environment }\end{array}$ & $\begin{array}{l}\text { the body's internal } \\
\text { balance system }\end{array}$ & sends confusing signals to the brain \\
\hline 13 & & which & $\begin{array}{l}\text { can result in nausea lasting as long } \\
\text { as a few days. }\end{array}$ \\
\hline 14 & & $\begin{array}{l}\text { A body that is } \\
\text { deprived of gravity }\end{array}$ & $\begin{array}{l}\text { also experiences changes in the } \\
\text { distribution of bodily fluids. }\end{array}$ \\
\hline 15 & & $\begin{array}{l}\text { More fluid than } \\
\text { normal }\end{array}$ & $\begin{array}{l}\text { ends up in the face, neck, and chest, } \\
\text { resulting in a puffy face, bulging neck } \\
\text { veins, and a slightly enlarged heart }\end{array}$ \\
\hline 16 & $\begin{array}{l}\text { Throughout the } \\
\text { durations of a } \\
\text { mission }\end{array}$ & astronauts' bodies & $\begin{array}{l}\text { experience some potentially } \\
\text { dangerous disorders. }\end{array}$ \\
\hline 17 & & $\begin{array}{l}\text { One of the most } \\
\text { common }\end{array}$ & $\begin{array}{l}\text { is loss of muscle mass and bone } \\
\text { density. }\end{array}$ \\
\hline 18 & & $\begin{array}{l}\text { Another effect of the } \\
\text { weightless } \\
\text { environment }\end{array}$ & $\begin{array}{l}\text { is that astronauts tend not to use } \\
\text { their legs as much, so the muscles } \\
\text { gradually atrophy. }\end{array}$ \\
\hline 19 & & This & $\begin{array}{l}\text { combined with the shift of fluid to } \\
\text { the upper body and the resulting } \\
\text { loss of essential minerals such as } \\
\text { calcium. }\end{array}$ \\
\hline 20 & & (This) & causes bones to weaken. \\
\hline 21 & & Bone density & $\begin{array}{l}\text { can decrease at a rate of } 1 \text { to } 2 \\
\text { percent a month }\end{array}$ \\
\hline 22 & & $\begin{array}{l}\text { (and, as a result,) } \\
\text { many astronauts }\end{array}$ & $\begin{array}{l}\text { are unable to walk properly for a few } \\
\text { days upon their return to earth. }\end{array}$ \\
\hline 23 & & Exposure to radiation & $\begin{array}{l}\text { is another serious hazard that } \\
\text { astronauts face. }\end{array}$ \\
\hline 24 & $\begin{array}{l}\text { Without the earth's } \\
\text { atmosphere to } \\
\text { protect them }\end{array}$ & astronauts & $\begin{array}{l}\text { can be exposed to intense radiation } \\
\text { from the sun and other galactic } \\
\text { bodies, leaving them at risk of }\end{array}$ \\
\hline
\end{tabular}




\begin{tabular}{|c|c|c|c|}
\hline NO. & MARKED THEME & SUBJECT/THEME & NEW \\
\hline & & & cancer. \\
\hline 25 & $\begin{array}{l}\text { In addition to } \\
\text { physiological } \\
\text { difficulties }\end{array}$ & $\begin{array}{l}\text { astronauts who travel } \\
\text { for extended periods }\end{array}$ & $\begin{array}{l}\text { may also suffer from psychological } \\
\text { stress. }\end{array}$ \\
\hline 26 & & Astronauts & live and \\
\hline 27 & & (and) (Astronauts) & work in small, tight spaces \\
\hline 28 & & (and) they & $\begin{array}{l}\text { must be able to deal both physically } \\
\text { and mentally with the confined } \\
\text { environment. }\end{array}$ \\
\hline 29 & & $\begin{array}{l}\text { (In addition ) long } \\
\text { periods away from } \\
\text { family and friends }\end{array}$ & $\begin{array}{l}\text { can leave space travellers feeling } \\
\text { lonely and depressed. }\end{array}$ \\
\hline 30 & & Now that man & has been to the Moon. \\
\hline 31 & & $\begin{array}{l}\text { (and) unmanned } \\
\text { missions }\end{array}$ & have been sent to Mars. \\
\hline 32 & & Many & $\begin{array}{l}\text { believe that next major step in space } \\
\text { travel will be a manned mission to } \\
\text { and from Mars. }\end{array}$ \\
\hline 33 & & $\begin{array}{l}\text { Differences between } \\
\text { the orbits of Earth and } \\
\text { Mars }\end{array}$ & $\begin{array}{l}\text { mean that such a mission would take } \\
\text { almost three years to complete }\end{array}$ \\
\hline 34 & & $\begin{array}{l}\text { The National Space } \\
\text { Biomedical Research } \\
\text { Institute (NSBRI) }\end{array}$ & $\begin{array}{l}\text { is currently investigating whether } \\
\text { such an operation is possible in light } \\
\text { of the hazards astronauts face }\end{array}$ \\
\hline 35 & $\begin{array}{l}\text { During short } \\
\text { missions }\end{array}$ & $\begin{array}{l}\text { some of the physical } \\
\text { and mental challenges } \\
\text { of space travel }\end{array}$ & $\begin{array}{l}\text { can be controlled with diet and } \\
\text { regular exercise. }\end{array}$ \\
\hline 36 & $\begin{array}{l}\text { In the case of long- } \\
\text { term space travel }\end{array}$ & however, it & $\begin{array}{l}\text { is still not entirely clear if the human } \\
\text { body could adapt and survive. }\end{array}$ \\
\hline 37 & In 2010 & the NSBRI & $\begin{array}{l}\text { is due to present its findings to } \\
\text { NASA }|| \\
\text { and present a 'go' or 'no go' } \\
\text { recommendation regarding a }\end{array}$ \\
\hline
\end{tabular}




\begin{tabular}{|l|l|l|l|}
\hline NO. & MARKED THEME & \multicolumn{1}{|l|}{ SUBJECT/THEME } & \multicolumn{1}{l|}{ NEW } \\
\hline 38 & $\begin{array}{l}\text { As new } \\
\text { technologies } \\
\text { develop to help } \\
\text { scientists further } \\
\text { pursue their goals }\end{array}$ & we & $\begin{array}{l}\text { manned mission to Mars. } \\
\text { may one day see humans walk on } \\
\text { distant planets. }\end{array}$ \\
\hline
\end{tabular}

\subsubsection{Interpretation of the analysis of Text 2}

As seen in Table 6.5, grammatical metaphor (ailments) and strings of lexical items packed in the nominal group (physiological and psychological problems) were deployed in macroTheme giving an orientation of what the text will be about. In the body section, grammatical metaphor was used in each hyperTheme referring to the effects of space travel on human body. Particularly, motion sickness was used in hyperTheme 1, (dangerous) disorders in hyperTheme 2 and (psychological) stress in hyperTheme 3. In each phase of the Explanation stage, metaphors were used in Theme (e.g., balance system, effect, bone density, exposure to radiation) and News (e.g. signals, changes, distribution, loss, disorder, shift, hazard, risk) to explain the causes for the effects stated in hyperThemes. As illustrated in Tables 6.5 and 6.6, grammatical metaphor was employed in the text for reasoning and packing the ideational information in hierarchy of periodicity realised in macroTheme, hyperThemes, Themes and News which predict and distil information at the clausal and discourse level. Thus, grammatical metaphor is not only a field-oriented but a mode-oriented resource (Martin, 1993a).

Lexical items were used to express the meaning of processes (e.g., suffer, result in, experience, end up, cause, work, live, atrophy), people (e.g., Yuri Gagarin, astronauts, travellers, scientists, family, friends), things (e.g., effect, changes, loss, hazard, ailments, motion sickness, balance system, bodily fluids, bone density, muscle mass, human body, disorder), places (e.g., space, Earth, atmosphere) and qualities (e.g., weightless, gravity-free, dangerous, intense, serious, short-live, lasting, confined, lonely, depressed). The use of these lexical items helps build the 
ideational meaning of the text in relation to its overall social purpose in explaining effects of space travel on human body. Specialised language in the field of space travel known as technical terms was employed such as gravity-free environment, weightless environment, gravity, radiation. With reference to the language variation framework (Mahboob, 2014), Text 2 above is a complex scientific text which employed specialised written global language to construe meaning of the text. Regarding intricacy, logical-semantic relations of expansion were used to connect meaning between clauses in clause complexes, between clause complexes in phases, and between phases of the text. For examples, finite and non-finite elaborating clauses (e.g., which can result in nausea lasting as long as a few days; ,leaving them a risk of cancer), additional extension (e.g., and, in addition, while, without), temporal enhancement (e.g., when, since) and causal-conditional enhancement (e.g., although, as a result).

Concerning the analysis of density, intricacy, grammatical metaphor according to stages and phases of the text, Table 6.7 shows that overall the text displayed an average number of 5.61 lexical items per ranking clauses, 1.76 ranking clauses per clause complex, 0.73 nominalisation and 0.67 grammatical metaphors per ranking clause. With regard to two stages in this text, Table 6.7 shows that Explanation stage employed a greater number of lexical items, nominalisation and grammatical metaphor but was less intricate compared with the Phenomenon stage. In brief, complexity of this text can be seen in the adoption of grammatical metaphor in explaining causes and effects of space travel on human body. It helps predict information in macroTheme, hyperThemes, Themes and distil information in News, creating a coherent text. Complexity can also be seen in how lexical items packed or scattered over clauses in phases and stages to create a dense but less intricate writing. 
Table 6.7. Result of linguistic analysis according to stages of Text 2

\begin{tabular}{|l|l|l|l|l|}
\hline \multicolumn{2}{|c|}{ Density } & Intricacy & Nominalisation & $\begin{array}{c}\text { Grammatical } \\
\text { metaphor }\end{array}$ \\
\hline Stages & & & \\
\hline - Phenomenon & 5.15 & 2.17 & 0.46 & 0.31 \\
\hline - Explanation & 5.76 & 1.65 & 0.82 & 0.79 \\
\hline Overall & 5.61 & 1.76 & 0.73 & 0.67 \\
\hline
\end{tabular}

\subsubsection{Text 3}

\subsubsection{Description of Text 3}

The tittle of this text is "How do you celebrate?" which was extracted from Book 1 (Elementary level) belonging to the non-science domain and Information Report genre. This text describes what people do on the New Year occasion as well as how they celebrate the New Year in different parts of the world. The text includes six short paragraphs. The first paragraph is a general statement about the New Year. The second paragraph is about New Year's resolutions in Western countries. The third paragraph mentions the Lunar New Year in Asian nations. The final three paragraphs describe Carnival festival which takes place in Europe and the United States.

\subsubsection{Analysis of Text 3}

6.4.3.2.1 Analysis of linguistic features according to stages of the text type and hierarchy of periodicity of Text 3

Table 6.8. Linguistic complexity analysis of Text 3

\begin{tabular}{|l|l|l|l|l|l|}
\hline NO. & \multicolumn{1}{|c|}{ TEXT SCRIPT } & CL & N & GM \\
\hline & GENERAL STATEMENT & & & \\
\hline 1 & $\begin{array}{l}\text { III [macroTheme] People everywhere celebrate the New } \\
\text { Year. III }\end{array}$ & 4 & - & 0 \\
\hline 2 & III It is a time to say goodbye to the past and to think & 7 & - & 1 & 1 \\
\hline
\end{tabular}




\begin{tabular}{|c|c|c|c|c|c|}
\hline NO. & TEXT SCRIPT & LI & $C L$ & $\mathbf{N}$ & GM \\
\hline & about new beginnings. III & & & & \\
\hline 3 & $\begin{array}{l}\text { III In many countries, people get together with family } \\
\text { and friends on December } 31||\end{array}$ & 6 & $\alpha$ & 0 & 0 \\
\hline 4 & to eat, || & 1 & $x \beta 1$ & 0 & 0 \\
\hline 5 & drink, || & 1 & $\beta+2$ & 0 & 0 \\
\hline 6 & dance, || & 1 & $\beta+3$ & 0 & 0 \\
\hline 7 & and welcome January 1 at midnight. III & 3 & $\beta+4$ & 0 & 0 \\
\hline & DESCRIPTION & & & & \\
\hline 8 & $\begin{array}{l}\text { III [hyperTheme 1] In many Western countries people } \\
\text { make New Year's resolutions. III }\end{array}$ & 7 & - & 1 & 0 \\
\hline 9 & $\begin{array}{l}\text { III They make promises to themselves to make changes } \\
\text { in their lives over the coming year, II }\end{array}$ & 7 & 1 & 3 & 2 \\
\hline 10 & such as to lose weight, || & 2 & $1=2$ & 0 & 0 \\
\hline 11 & get a new job, II & 3 & $2+3$ & 0 & 0 \\
\hline 12 & or learn a new skill. |l| & 3 & $2+4$ & 0 & 0 \\
\hline 13 & $\begin{array}{l}\text { III [hyperTheme 2] In many Asian countries, people also } \\
\text { celebrate the Lunar New Year, usually in late January or } \\
\text { early February. }\end{array}$ & 11 & - & 0 & 0 \\
\hline 14 & II| People spend time with family || & 4 & 1 & 0 & 0 \\
\hline 15 & and eat special foods. III & 3 & +2 & 0 & 0 \\
\hline 16 & III In most countries, the holiday lasts for several days. & 4 & $\ldots$ & 0 & 0 \\
\hline 17 & $\begin{array}{l}\text { III [hyperTheme 3] In late February or early March, some } \\
\text { countries celebrate a special festival called Carnival. III }\end{array}$ & 10 & - & 0 & 0 \\
\hline 18 & III Many think |I & 1 & $\alpha$ & 0 & 0 \\
\hline 19 & that Carnival first started in Italy or Greece. III & 4 & ‘ $\beta$ & 0 & 0 \\
\hline 20 & | || People dressed in costumes, || & 3 & 1 & 0 & 0 \\
\hline 21 & wore colourful masks, || & 3 & +2 & 0 & 0 \\
\hline 22 & ate, II & 1 & +3 & 0 & 0 \\
\hline 23 & drank, || & 1 & +4 & 0 & 0 \\
\hline 24 & $\begin{array}{l}\text { and danced all night on the Tuesday before the start of } \\
\text { Lent. III }\end{array}$ & 5 & +5 & 1 & 1 \\
\hline 25 & $\begin{array}{l}\text { III This tradition spread to France, Spain, and Portugal, } \\
\text { and later, to Brazil and the United States III }\end{array}$ & 8 & - & 0 & 0 \\
\hline
\end{tabular}




\begin{tabular}{|c|c|c|c|c|c|}
\hline NO. & TEXT SCRIPT & LI & $C L$ & $N$ & GM \\
\hline 26 & $\begin{array}{l}\text { III Now, two of the biggest Carnivals take place in Rio de } \\
\text { Janeiro in Brazil, and New Orleans in the United States. }\end{array}$ & 12 & - & 0 & 0 \\
\hline 27 & $\begin{array}{l}\text { III People still wear flamboyant costumes, || and at } \\
\text { Carnival in Rio }\end{array}$ & 6 & - & 0 & 0 \\
\hline 28 & there is a huge parade that lasts for four days. III & 4 & - & 1 & 1 \\
\hline 29 & II I In New Orleans, Carnival is called Mardi Gras, | | & 6 & 1 & 0 & 0 \\
\hline 30 & and lasts for three weeks. III & 2 & +2 & 0 & 0 \\
\hline 31 & $\begin{array}{l}\text { III Both celebrations combine music and traditions from } \\
\text { all over the world. III }\end{array}$ & 5 & - & 1 & 1 \\
\hline 32 & $\begin{array}{l}\text { III Millions of visitors travel from around the world to } \\
\text { join the party. III }\end{array}$ & 5 & - & 0 & 0 \\
\hline & Total & 141 & 18 & 8 & 6 \\
\hline
\end{tabular}

\subsection{Analysis of Theme and New in Text 3}

Table 6.9. Analysis of Theme and New in Text 3

\begin{tabular}{|c|c|c|c|}
\hline NO. & MARKED THEME & SUBJECT/THEME & NEW \\
\hline 1 & & People & everywhere celebrate the New Year. \\
\hline 2 & & It & $\begin{array}{l}\text { is a time to say goodbye to the past and to } \\
\text { think about new beginnings. }\end{array}$ \\
\hline 3 & $\begin{array}{l}\text { In many } \\
\text { countries, }\end{array}$ & People & $\begin{array}{l}\text { get together with family and friends on } \\
\text { December } 31 \text { to eat, drink, dance, and } \\
\text { welcome January } 1 \text { at midnight. }\end{array}$ \\
\hline 4 & $\begin{array}{l}\text { In many Western } \\
\text { countries }\end{array}$ & People & make New Year's resolutions. \\
\hline 5 & & They & $\begin{array}{l}\text { make promises to themselves to make } \\
\text { changes in their lives over the coming year, } \\
\text { such as to lose weight, get a new job, or } \\
\text { learn a new skill. }\end{array}$ \\
\hline 6 & $\begin{array}{l}\text { In many Asian } \\
\text { countries, }\end{array}$ & People & $\begin{array}{l}\text { also celebrate the Lunar New Year, usually } \\
\text { in late January or early February. }\end{array}$ \\
\hline 7 & & People & $\begin{array}{l}\text { spend time with family and eat special } \\
\text { foods. }\end{array}$ \\
\hline
\end{tabular}




\begin{tabular}{|c|c|c|c|}
\hline NO. & MARKED THEME & SUBJECT/THEME & NEW \\
\hline 8 & $\begin{array}{l}\text { In most } \\
\text { countries, }\end{array}$ & the holiday & lasts for several days. \\
\hline 9 & $\begin{array}{l}\text { In late February } \\
\text { or early March, }\end{array}$ & some countries & celebrate a special festival called Carnival. \\
\hline 10 & & Many & $\begin{array}{l}\text { think That Carnival first started in Italy or } \\
\text { Greece. }\end{array}$ \\
\hline 11 & & People & $\begin{array}{l}\text { dressed in costumes, wore colourful masks, } \\
\text { ate, drank, and danced all night on the } \\
\text { Tuesday before the start of Lent. }\end{array}$ \\
\hline 12 & Now, & This tradition & $\begin{array}{l}\text { spread to France, Spain, and Portugal, and } \\
\text { later, to Brazil and the United States. }\end{array}$ \\
\hline 13 & & $\begin{array}{l}\text { two of the } \\
\text { biggest Carnivals }\end{array}$ & $\begin{array}{l}\text { take place in Rio de Janeiro in Brazil, and } \\
\text { New Orleans in the United States. }\end{array}$ \\
\hline 14 & & People & still wear flamboyant costumes. \\
\hline 15 & & $\begin{array}{l}\text { (and) (at } \\
\text { Carnival in Rio) } \\
\text { there }\end{array}$ & is a huge parade that lasts for four days. \\
\hline 16 & In New Orleans, & Carnival & is called Mardi Gras. \\
\hline 17 & & (And) (Carnival) & lasts for three weeks. \\
\hline 18 & & $\begin{array}{l}\text { Both } \\
\text { celebrations }\end{array}$ & $\begin{array}{l}\text { combine music and traditions from all over } \\
\text { the world. }\end{array}$ \\
\hline 19 & & $\begin{array}{l}\text { Millions of } \\
\text { visitors }\end{array}$ & $\begin{array}{l}\text { travel from around the world to join the } \\
\text { party. }\end{array}$ \\
\hline
\end{tabular}

\subsubsection{Interpretation of the analysis of Text 3}

As displayed in Table 6.8, lexical items were used to express the meaning of processes (e.g., celebrate, eat, drink, dance, welcome, lose), people (e.g. people, visitors), things (e.g., parade, celebration, tradition, resolutions, promises, changes), and qualities (e.g., new, special, late, early). The use of these lexical items helps build the ideational meaning of the text in relation to its overall social purpose in describing how people celebrate the New Year in different countries in the globe. With reference to the language variation model (Mahboob, 2014), this text 
employed everyday written global language to construe the meaning of the text. Regarding intricacy, logical-semantic relations of expansion and projection were used to connect meaning between clauses in clause complexes. For instance, additional extension (e.g., and), alternation extension (e.g., or), causal-conditional enhancement (e.g., to eat, drink, dance), and projection of idea (e.g., Many think that Carnival first started in Italy or Greece). This text used several instances of nominalisation (e.g., beginnings, resolutions, promises, changes) and grammatical metaphor (e.g., beginnings, promises, changes, start, parade, celebrations). However, these nominalisation and grammatical metaphor were not found in macroTheme and hyperThemes of the text. As observed in Table 6.9, most of the nominalisation and grammatical metaphor occurred in News except the instance of "celebrations" which was conflated with Theme.

Table 6.10 shows that overall the text displayed an average number of 4.55 lexical items per ranking clauses, 1.83 ranking clauses per clause complex, 0.26 nominalisation and 0.19 grammatical metaphors per ranking clause. Within two stages in the text, Table 6.10 shows that the Description stage employed a greater number of lexical items, nominalisation and grammatical metaphor but was less intricate in comparison with the General Statement stage. To sum up, this is a simple non-scientific text which employed lexical items to produce high density text. The employment of nominalisation and grammatical metaphor was found to some extent. However, these instances just occurred in News as seen in Table 6.9. Thus, grammatical metaphor had little effect on building thematic prominence of the text; rather, it built the textual prominence given in News.

Table 6.10. Result of linguistic analysis according to stages of Text 3

\begin{tabular}{|c|c|c|c|c|}
\hline & Density & Intricacy & Nominalisation & $\begin{array}{c}\text { Grammatical } \\
\text { metaphor }\end{array}$ \\
\hline \multicolumn{5}{|l|}{ Stages } \\
\hline - General statement & 3.1 & 2.3 & 0.14 & 0.14 \\
\hline - Description & 4.58 & 1.73 & 0.27 & 0.19 \\
\hline Overall & 4.55 & 1.83 & 0.26 & 0.19 \\
\hline
\end{tabular}




\subsubsection{Text 4}

\subsubsection{Description of Text 4}

The tittle of this text is "Wedding customs" which was extracted in Book 3

(Intermediate level). This text belongs to the non-science domain and Information Report genre. There are seven paragraphs in the text including one introduction, five paragraphs in the body section and one conclusion. The introduction gives a general statement about wedding customs, which is considered the macroTheme of the text. The second paragraph introduces the custom of wearing white dress in wedding ceremony in some parts of the world. The third paragraph introduces the custom of using other colours other than white in wedding ceremony. Wearing a veil by bride is described in the fourth paragraph. The use of rings and flowers in wedding ceremony are described in the fifth and six paragraphs in the body section respectively. The topic sentence of each paragraph in the body section is known as hyperTheme of that paragraph. In total, there are five hyperThemes which were named hyperTheme 1, hyperTheme 2 , hyperTheme 3 , hyperTheme 4 , hyperTheme 5 in the analysis. The final paragraph is a conclusion of the text which is known as the text's macroNew.

\subsubsection{Analysis of Text 4}

6.4.4.2.1 Analysis of linguistic features according to stages of the text type and hierarchy of periodicity of Text 4

Table 6.11. Linguistic complexity analysis of Text 4

\begin{tabular}{|c|c|c|c|c|c|}
\hline \multirow[t]{2}{*}{ NO } & TEXT SCRIPT & $L I$ & $C L$ & N & GM \\
\hline & GENERAL STATEMENT & & & & \\
\hline 1 & $\begin{array}{l}\text { III Marriage is an ancient religious and legal practice } \\
\text { celebrated around the world. III }\end{array}$ & 7 & - & 2 & 0 \\
\hline 2 & $\begin{array}{l}\text { III Although the reasons that people marry are similar } \\
\text { in many places, }\end{array}$ & 5 & $x \alpha$ & 1 & 1 \\
\hline 3 & | | wedding customs vary from country to country. ||| & 5 & $\beta$ & 0 & 0 \\
\hline & DESCRIPTION & & & & \\
\hline
\end{tabular}




\begin{tabular}{|c|c|c|c|c|c|}
\hline NO. & TEXT SCRIPT & $L$ & $C L$ & $N$ & GM \\
\hline 4 & $\begin{array}{l}\text { III [hyperTheme 1] In many countries, it is customary for } \\
\text { the bride to wear a white dress as symbol of purity. III }\end{array}$ & 8 & - & 1 & 1 \\
\hline 5 & $\begin{array}{l}\text { III In traditional Japanese wedding ceremonies, the } \\
\text { bride wears a white kimono. III }\end{array}$ & 8 & - & 0 & 0 \\
\hline 6 & $\begin{array}{l}\text { III The tradition of wearing a special white dress only } \\
\text { for the wedding ceremony started around } 150 \text { years ago. } \\
\text { III }\end{array}$ & 9 & - & 0 & 0 \\
\hline 7 & $\begin{array}{l}\text { III Before that, most women could not afford to buy a } \\
\text { dress that they would only wear once. III }\end{array}$ & 5 & - & 0 & 0 \\
\hline 8 & $\begin{array}{l}\text { III Now, bridal dresses can be bought in a variety of } \\
\text { styles and fabries, I| }\end{array}$ & 6 & 1 & 1 & 1 \\
\hline 9 & and many brides have their dress specially made III & 4 & +2 & 0 & 0 \\
\hline 10 & $\begin{array}{l}\text { III [hyperTheme 2] In different countries, colors other } \\
\text { than white are worn by the bride II }\end{array}$ & 6 & 1 & 0 & 0 \\
\hline 11 & or used as part of the wedding ceremony. III & 4 & +2 & 0 & 0 \\
\hline 12 & $\begin{array}{l}\text { III In certain Asian countries and in the Middle East, red } \\
\text { and orange are considered symbols of joy and happiness. } \\
\text { III }\end{array}$ & 11 & - & 1 & 1 \\
\hline 13 & $\begin{array}{l}\text { III In Chinese cultures, wedding invitations are usually } \\
\text { red and gold }\end{array}$ & 6 & $\alpha$ & 1 & 0 \\
\hline 14 & $\begin{array}{l}\text { II as these are colors symbolic of wealth and happiness. } \\
\text { III }\end{array}$ & 4 & $x \beta$ & 1 & 1 \\
\hline 15 & $\begin{array}{l}\text { III Wedding guests give gifts of money to the } \\
\text { newlyweds in small red envelopes. III }\end{array}$ & 9 & - & 0 & 0 \\
\hline 16 & $\begin{array}{l}\text { III Not all cultures, though, consider money a suitable } \\
\text { gift. III }\end{array}$ & 5 & - & 0 & 0 \\
\hline 17 & $\begin{array}{l}\text { III In many Western countries, especially the U.K., } \\
\text { wedding guests give the bride and groom household } \\
\text { items that they may need for their new home. III }\end{array}$ & 13 & - & 0 & 0 \\
\hline 18 & $\begin{array}{l}\text { III [hyperTheme 3] As part of many traditional wedding } \\
\text { ceremonies, a bride wears a veil. III }\end{array}$ & 7 & - & 0 & 0 \\
\hline 19 & $\begin{array}{l}\text { III Wearing a veil that covers the head and face is a } \\
\text { tradition that is over } 2,000 \text { years old. III }\end{array}$ & 8 & - & 0 & 0 \\
\hline
\end{tabular}




\begin{tabular}{|c|c|c|c|c|c|}
\hline NO. & TEXT SCRIPT & $L I$ & $C L$ & N & GM \\
\hline 20 & $\begin{array}{l}\text { II I Veils were originally worn as a sign of secrecy and } \\
\text { modesty II }\end{array}$ & 6 & 1 & 2 & 2 \\
\hline 21 & $\begin{array}{l}\text { and could only be removed by the husband after the } \\
\text { ceremony. III }\end{array}$ & 3 & +2 & 0 & 0 \\
\hline 22 & $\begin{array}{l}\text { Today, many brides wear a veil, but only for decoration. } \\
\text { III }\end{array}$ & 5 & - & 1 & 1 \\
\hline 23 & $\begin{array}{l}\text { III In some countries, a veil is placed between the bride } \\
\text { and groom during the wedding ceremony || }\end{array}$ & 7 & $\alpha$ & 0 & 0 \\
\hline 24 & so that they can not see || & 1 & $x \beta$ & 0 & 0 \\
\hline 25 & or touch each other II & 1 & $\beta+1$ & 0 & 0 \\
\hline 26 & until they are married. III & 1 & $x y$ & 0 & 0 \\
\hline 27 & $\begin{array}{l}\text { III [hyperTheme 4] In many cultures, couples exchange } \\
\text { rings, usually made of gold or silver, during the marriage } \\
\text { ceremony. III }\end{array}$ & 9 & - & 1 & 0 \\
\hline 28 & $\begin{array}{l}\text { III The circular shape of the ring is symbolic of the } \\
\text { couple's eternal union. III }\end{array}$ & 7 & - & 2 & 2 \\
\hline 29 & $\begin{array}{l}\text { III In Brazil, it is traditional to have the rings engraved, } \\
\text { with the bride's name on the groom's ring, and vice } \\
\text { versa. III }\end{array}$ & 9 & - & 0 & 0 \\
\hline 30 & $\begin{array}{l}\text { III The wedding ring is usually worn on the third finger } \\
\text { of the left or right hand, }\end{array}$ & 7 & $\alpha$ & 0 & 0 \\
\hline 31 & || because it was once believed || & 1 & $x \beta$ & 0 & 0 \\
\hline 32 & that a vein ran directly from this finger to the heart. III & 5 & ' $\gamma$ & 0 & 0 \\
\hline 33 & $\begin{array}{l}\text { III [hyperTheme 5] Flowers play an important role in } \\
\text { most weddings. }\end{array}$ & 5 & - & 0 & 0 \\
\hline 34 & III Roses are said to be the flowers of love, II & 4 & 1 & 1 & 0 \\
\hline 35 & and because roses usually bloom in June, II & 3 & $+2 x \alpha$ & 0 & 0 \\
\hline 36 & $\begin{array}{l}\text { this has become the most popular month for weddings in } \\
\text { many countries. III }\end{array}$ & 5 & $\beta$ & 0 & 0 \\
\hline 37 & III Ivy is also used in wedding bouquets II & 3 & $\alpha$ & 0 & 0 \\
\hline 38 & $\begin{array}{l}\text { because in early Greek times, it was thought to be sign of } \\
\text { everlasting love. III }\end{array}$ & 7 & $x \beta$ & 1 & 1 \\
\hline 39 & III After the wedding ceremony, it is customary in many & 13 & - & 0 & 0 \\
\hline
\end{tabular}




\begin{tabular}{|c|c|c|c|c|c|}
\hline \multirow[t]{2}{*}{ No. } & TEXT SCRIPT & \multirow[t]{2}{*}{$L$} & \multirow[t]{2}{*}{$C L$} & \multirow[t]{2}{*}{ N } & \multirow[t]{2}{*}{ GM } \\
\hline & $\begin{array}{l}\text { countries for the bride to throw her bouquet into a } \\
\text { crowd of wellwishers - usually her single female friends. } \\
\text { III }\end{array}$ & & & & \\
\hline 40 & III It is said II & 1 & $\alpha$ & 0 & 0 \\
\hline 41 & $\begin{array}{l}\text { that the person who catches the bouquet will be the next } \\
\text { one to marry. }\end{array}$ & 4 & ‘ $\beta$ & 0 & 0 \\
\hline 42 & III In Turkey, when a woman gets married, | | & 4 & $x \beta$ & 0 & 0 \\
\hline 43 & $\begin{array}{l}\text { her female friends write their names on the inside of the } \\
\text { shoes }\end{array}$ & 6 & $\alpha$ & 0 & 0 \\
\hline 44 & the bride will wear on her wedding day. III & 4 & - & 0 & 0 \\
\hline 45 & $\begin{array}{l}\text { III After the ceremony, if someone's name has rubbed } \\
\text { off } \|\end{array}$ & 3 & $x \beta 1$ & 0 & 0 \\
\hline 46 & and cannot be read, II & 1 & $\beta 2$ & 0 & 0 \\
\hline 47 & it is said that || & 1 & $\alpha$ & 0 & 0 \\
\hline 48 & this person will be the next to marry. III & 2 & ‘ $\gamma$ & 0 & 0 \\
\hline 49 & $\begin{array}{l}\text { III [macroNew ] Many wedding customs that originated } \\
\text { in one part of the world have been incorporated into } \\
\text { marriage ceremonies in other countries. III }\end{array}$ & 9 & - & 1 & 0 \\
\hline 50 & $\begin{array}{l}\text { III Today, couples can choose from many of the world's } \\
\text { traditional customs to create their own special wedding } \\
\text { ceremony. III }\end{array}$ & 10 & - & 0 & 0 \\
\hline & Total & 277 & 31 & 15 & 9 \\
\hline
\end{tabular}

\subsection{Analysis of Theme and New of Text 4}

Table 6.12. Analysis of Theme and New of Text 4

\begin{tabular}{|l|l|l|l|} 
NO. & MARKED THEME & \multicolumn{1}{l}{ SUBJECT/THEME } & NEW \\
\hline 1 & Marriage & $\begin{array}{l}\text { is an ancient religious and legal } \\
\text { practice celebrated around the world }\end{array}$ \\
\hline 2 & $\begin{array}{l}\text { Although the } \\
\text { reasons that } \\
\text { people marry are } \\
\text { similar in many } \\
\text { places }\end{array}$ & wedding customs & vary from country to country \\
\hline
\end{tabular}




\begin{tabular}{|c|c|c|c|}
\hline NO. & MARKED THEME & SUBJECT/THEME & NEW \\
\hline 3 & In many countries & it & $\begin{array}{l}\text { is customary for the bride to wear a } \\
\text { white dress as symbol of purity. }\end{array}$ \\
\hline 4 & $\begin{array}{l}\text { In traditional } \\
\text { Japanese } \\
\text { wedding } \\
\text { ceremonies, }\end{array}$ & the bride & wears a white kimono. \\
\hline 5 & & $\begin{array}{l}\text { The tradition of } \\
\text { wearing a special } \\
\text { white dress only for } \\
\text { the wedding } \\
\text { ceremony }\end{array}$ & started around 150 years ago. \\
\hline 6 & Before that, & most women & $\begin{array}{l}\text { could not afford to buy a dress that } \\
\text { they would only wear once. }\end{array}$ \\
\hline 7 & Now, & bridal dresses & $\begin{array}{l}\text { can be bought in a variety of styles } \\
\text { and fabries }\end{array}$ \\
\hline 8 & & and many brides & have their dress specially made. \\
\hline 9 & $\begin{array}{l}\text { In different } \\
\text { countries }\end{array}$ & $\begin{array}{l}\text { colors other than } \\
\text { white }\end{array}$ & are worn by the bride; \\
\hline 10 & & $\begin{array}{l}\text { (or) (colors other than } \\
\text { white) red and orange }\end{array}$ & $\begin{array}{l}\text { used as part of the wedding } \\
\text { ceremony. }\end{array}$ \\
\hline 11 & $\begin{array}{l}\text { In certain Asian } \\
\text { countries and in } \\
\text { the Middle East }\end{array}$ & red and orange & $\begin{array}{l}\text { are considered symbols of joy and } \\
\text { happiness. }\end{array}$ \\
\hline 12 & $\begin{array}{l}\text { In Chinese } \\
\text { cultures }\end{array}$ & wedding invitations & are usually red and gold \\
\hline 13 & & as these & $\begin{array}{l}\text { are colors symbolic of wealth and } \\
\text { happiness. }\end{array}$ \\
\hline 14 & & Wedding guests & $\begin{array}{l}\text { give gifts of money to the newlyweds } \\
\text { in small red envelopes. }\end{array}$ \\
\hline 15 & & $\begin{array}{l}\text { Not all cultures, } \\
\text { though, }\end{array}$ & consider money a suitable gift. \\
\hline 16 & $\begin{array}{l}\text { In many Western } \\
\text { countries, }\end{array}$ & wedding guests & $\begin{array}{l}\text { give the bride and groom household } \\
\text { items that they may need for their }\end{array}$ \\
\hline
\end{tabular}




\begin{tabular}{|c|c|c|c|}
\hline NO. & MARKED THEME & SUBJECT/THEME & NEW \\
\hline & $\begin{array}{l}\text { especially the } \\
\text { U.K., }\end{array}$ & & new home. \\
\hline 17 & $\begin{array}{l}\text { As part of many } \\
\text { traditional } \\
\text { wedding } \\
\text { ceremonies }\end{array}$ & a bride & wears a veil. \\
\hline 18 & & $\begin{array}{l}\text { Wearing a veil that } \\
\text { covers the head and } \\
\text { face }\end{array}$ & $\begin{array}{l}\text { is a tradition that is over } 2,000 \text { years } \\
\text { old. }\end{array}$ \\
\hline 19 & & Veils & $\begin{array}{l}\text { were originally worn as a sign of } \\
\text { secrecy and modesty }\end{array}$ \\
\hline 20 & & (and)( veils) & $\begin{array}{l}\text { could only be removed by the } \\
\text { husband after the ceremony. }\end{array}$ \\
\hline 21 & Today, & many brides & wear a veil, but only for decoration. \\
\hline 22 & $\begin{array}{l}\text { In some } \\
\text { countries, }\end{array}$ & a veil & $\begin{array}{l}\text { is placed between the bride and } \\
\text { groom during the wedding ceremony } \\
\text { so that they cannot see or touch each } \\
\text { other until they are married. }\end{array}$ \\
\hline 23 & In many cultures & couples & $\begin{array}{l}\text { exchange rings, usually made of gold } \\
\text { or silver, during the marriage } \\
\text { ceremony. }\end{array}$ \\
\hline 24 & & $\begin{array}{l}\text { The circular shape of } \\
\text { the ring }\end{array}$ & $\begin{array}{l}\text { is symbolic of the couple's eternal } \\
\text { union. }\end{array}$ \\
\hline 25 & In Brazil, & It & $\begin{array}{l}\text { is traditional to have the rings } \\
\text { engraved, with the bride's name on } \\
\text { the groom's ring, and vice versa }\end{array}$ \\
\hline 26 & & The wedding ring & $\begin{array}{l}\text { is usually worn on the third finger of } \\
\text { the left or right hand, because it was } \\
\text { once believed that a vein ran directly } \\
\text { from this finger to the heart. }\end{array}$ \\
\hline 27 & & Flowers & $\begin{array}{l}\text { play an important role in most } \\
\text { weddings. }\end{array}$ \\
\hline 28 & & Roses & are said to be the flowers of love. \\
\hline
\end{tabular}




\begin{tabular}{|c|c|c|c|}
\hline NO. & MARKED THEME & SUBJECT/THEME & NEW \\
\hline 29 & $\begin{array}{l}\text { and because } \\
\text { roses usually } \\
\text { bloom in June }\end{array}$ & this & $\begin{array}{l}\text { has become the most popular month } \\
\text { for weddings in many countries. }\end{array}$ \\
\hline 30 & & Ivy & $\begin{array}{l}\text { is also used in wedding bouquets } \\
\text { because in early Greek times, it was } \\
\text { thought to be sign of everlasting love. }\end{array}$ \\
\hline 31 & $\begin{array}{l}\text { After the } \\
\text { wedding } \\
\text { ceremony }\end{array}$ & it & $\begin{array}{l}\text { is customary in many countries for the } \\
\text { bride to throw her bouquet into a } \\
\text { crowd of well-wishers - usually her } \\
\text { single female friends. }\end{array}$ \\
\hline 32 & & It & $\begin{array}{l}\text { is said that the person who catches } \\
\text { the bouquet will be the next one to } \\
\text { marry }\end{array}$ \\
\hline 33 & $\begin{array}{l}\text { In Turkey, } \\
\text { when a woman } \\
\text { gets married }\end{array}$ & her female friends & $\begin{array}{l}\text { write their names on the inside of the } \\
\text { shoes }\end{array}$ \\
\hline 34 & & the bride & will wear on her wedding day. \\
\hline 35 & $\begin{array}{l}\text { After the } \\
\text { ceremony, if } \\
\text { someone's name } \\
\text { has rubbed off } \\
\text { and cannot be } \\
\text { read, }\end{array}$ & it & $\begin{array}{l}\text { is said that this person will be the } \\
\text { next to marry. }\end{array}$ \\
\hline 36 & & $\begin{array}{l}\text { Many wedding } \\
\text { customs that } \\
\text { originated in one part } \\
\text { of the world }\end{array}$ & $\begin{array}{l}\text { have been incorporated into marriage } \\
\text { ceremonies in other countries. }\end{array}$ \\
\hline 37 & Today, & couples & $\begin{array}{l}\text { can choose from many of the world's } \\
\text { traditional customs to create their } \\
\text { own special wedding ceremony. }\end{array}$ \\
\hline
\end{tabular}




\subsubsection{Interpretation of the analysis of Text 4}

In Text 4, lexical items were used to express the meaning of processes (e.g., wear, decoration, celebrated, afford,), people (e.g. bride, groom, women,), things (e.g., wedding ceremony, happiness, wealth, invitation, tradition), places (e.g. Asians countries, Middle East, Western countries, Turkey) and qualities (e.g., modesty, secrecy, special, different). The employment of these lexical items helps build the ideational meaning of the text in relation to its overall social purpose in describing wedding customs around the world. Everyday written global language was used with reference to the language variation framework (Mahboob, 2014). Concerning intricacy, logical-semantic relations of expansion and projection were used to connect meaning between clauses in clause complexes, between clause complexes in phases, and between phases of the text. For examples, additional extension (e.g., and), temporal enhancement (e.g., after, when), causal-conditional enhancement (e.g., because, as, although, if), and projection of idea (e.g., it is said that this person will be the next to marry).

Table 6.11 shows that nominalisation (marriage, practice) and grammatical metaphor (reasons) were used in macroTheme which predicts what comes next in the text. In the body section, grammatical metaphor (purity) was used in hyperTheme 1. Other instances of grammatical metaphor (variety, happiness, secrecy, modesty, decoration) were used in News as can be referred from Table 6.12. It is worth noting that marked Theme which signals the circumstance including time (before that, now, today) and place (in many countries, in different countries) was adopted in Text 4.

With regard to the analysis of density, intricacy, nominalisation, and grammatical metaphor according to stages and phases of the text, Table 6.13 shows that overall Text 4 featured an average number of 5.54 lexical items per ranking clauses, 1.61 ranking clauses per clause complex, 0.3 nominalisation and 0.18 grammatical metaphors per ranking clause. Take a closer look at two stages in this text, Table 6.13 shows that the Description stage was more dense and intricate but employed a lower number of nominalisation and grammatical metaphor in comparison with the General Statement stage. Generally, the complexity of this text can be seen in high 
density and low intricacy. Although nominalisation and grammatical metaphor were used to some extent, this had little effect on Theme and hyperThemes. Rather, the use of grammatical metaphor mainly helped build the textual prominence which is realised in News.

Table 6.13. Result of linguistic analysis of Text 4

\begin{tabular}{|c|c|c|c|c|}
\hline & Density & Intricacy & Nominalisation & $\begin{array}{c}\text { Grammatical } \\
\text { metaphor }\end{array}$ \\
\hline \multicolumn{5}{|l|}{ Stages } \\
\hline - General statement & 5.53 & 1.62 & 1.00 & 0.33 \\
\hline - Description & 5.67 & 1.50 & 0.25 & 0.15 \\
\hline Overall & 5.54 & 1.61 & 0.30 & 0.18 \\
\hline
\end{tabular}

\subsection{Conclusion}

This chapter presented the analysis of the linguistic features investigated in four textbooks at four different levels. The results of the analysis included four main sections. The first section reported on results of lexical density, readability, grammatical intricacy, nominalisation, grammatical metaphor and thematic structure across four levels of books. The second section revealed findings of linguistic features analysis of science and non-scientific texts. Following that, the correlations between the linguistic features characterising complexity were identified and presented in the third section. Finally, detailed analysis of linguistic complexity in four full texts were performed to illustrate how linguistic features chosen characterising complexity at the level of context. This analysis also revealed the extent to which linguistic features were used and differed in stages of genres, as well as illustrated how complexity in each field shifted from low to high levels. General trends of the linguistic features investigated in four texts were also identified. 


\section{Chapter 7: Discussion}

\subsection{Introduction}

Chapters 5 and 6 reported the main findings of the study regarding the analysis of linguistic complexity in 24 reading extracts on a quantitative analysis basic and complexity regarding genre analysis and the text periodicity of four full texts. The analysis reveals four principal outcomes which are categorised in relation to four research objectives. In Chapter 5, firstly, results of analysis of linguistic features in reading texts across textbook levels were described with reference to the mean scores, standard deviations, and values of minimum and maximum. Also, the statistically significant differences of linguistic complexity between textbook levels were determined by the assistance of one-way ANOVA and post-hoc tests. Secondly, linguistic complexity of texts in science and non-science domains was shown. Thirdly, the correlations among linguistic features charactering complexity of textbook texts were identified using the analysis of the Pearson Correlation. Finally, Chapter 6 reported findings of the analysis of linguistic features according to stages of texts in science and non-science fields at two different levels. This chapter responds to research questions 2, 3, 4 and 5 set up in the introduction chapter and revisited in research objectives in the methodology. The discussion is based on the findings shown in Chapters 5 and 6 . In response to these research questions, this chapter also discusses the extent to which these four research questions have been addressed, and how the results of the study support or expand the previous research in the relevant literature.

\subsection{Linguistic complexity of texts across textbook levels}

This section answers the second research question of the study on how linguistic features charactering complexity including lexical density, grammatical intricacy, nominalisation, grammatical metaphor and thematic structure differ across levels in the chosen English textbooks. This section firstly gives a general discussion of the 
results of the linguistic features examined in the four books across levels. Then it presents in-depth discussions with reference to specific aspect of each linguistic feature in the following parts.

As referred to the introductory and literature review chapters, the past three decades have seen increasing research in the field of SFL. Central to the SFL studies is the studies of texts in regard to the examination of various text types and their linguistic features. Research has shown that different text types have different distinctive features comprising genre (stages/phases), lexical density, grammatical complexity, use of grammatical metaphor, nominalisation and theme (Banks, 2003; Derewianka, 2003; Halliday, 1985a, 1985b, 1993a, 1993b, 1998, 2004, 2008; Halliday \& Martin, 1993; Halliday \& Matthiessen, 1999, 2004; J. R. Martin, 1992, 1993a, 1993b, 2008; Ravelli, 1999). With reference to the language variation framework (Mahboob, 2014), these differences have also been found to have relevance in developing this model and their implications for TEFL. Informed by these understandings, one of our anticipations in this study was that there was a gradual shift across levels of textbooks which makes the textbook texts more similar to authentic texts. This anticipation was realised in the second research objective proposed earlier in the Introduction chapter: Investigating how the complexity of language differs across various levels in the chosen English textbooks.

The results of the analysis show that overall the language of four textbooks grew more complex when their levels advanced. Specifically, lexical density measured by Halliday's method, the frequency of nominalisation and grammatical metaphor increased from low to high levels of book. Specifically, the statistically significant differences were found between the elementary and intermediate book levels in the use of lexical items, nominalisation, and readability; however, no significant difference was found in the other book levels. This finding supports the general assumption that linguistic complexity increases in accordance with the book levels from low to high in a book series. This finding is predictable as displaying a gradual increase of complexity across book levels might be one of the author's purposes in writing books for various levels. It is worth noting that Books 1, 2 and 3 in the corpus were written by one author; thus, this could be a valid justification for 
explaining why complexity was well-controlled across the first three levels of textbooks. However, it is interesting to find out that the highest level of the books did not entail the topmost complexity. Rather, the two latter book levels, namely intermediate and upper-intermediate books featured the relatively similar scores of linguistic features investigated. It is worth noticing that while the reading texts in the first three books were written by the same author, those in Book 4 were extracted from various sources such as New Scientist, American Scientist, CBC news online, International Wildlife, etc.

In this study, two formulas were applied to calculate lexical density to see how it changed across levels. The first formula is referred to as Ure's method as it is first suggested by Ure (1971) resulting from her analysis of 34 spoken and written texts. Her measurement of lexical density indicates that lexical density is measured by dividing the total number of lexical items to the total number of running words in the text. Ure's method has been applied in calculating lexical density manually and computationally over the past 30 decades in a number of researches in two registers: spoken and written language. Although there is a general assumption that lexical density may increase gradually in accordance with textbook levels, there was an absence of factual evidence to support this view in this study. The differences of lexical density calculated by Ure's formula among four levels of textbooks were not statistically significant. Particularly, the four textbooks chosen for the investigation at four different levels recorded relatively the same lexical density index across levels, around $45 \%$ for pre-intermediate texts and around $47 \%$ for the other three levels. This finding is somehow unexpected but not a surprise, as several studies on lexical density using Ure's method has shown that this is not a reliable method in measuring lexical density in textbooks across grade levels (Irina, 2011), student language proficiency level (Cheryl, 1995; John \& Paul, 2002; Vidakovic \& Barker, 2009) or student achievement (Narelle et al., 1994).

With respect to Halliday's measurement of lexical density which is based on the ratio of the total number of lexical items per total number of ranking clauses, the finding shows that there was a steady increase in lexical density from the Elementary to Intermediate level. However, the highest level of book did not display 
the topmost density; rather, it featured the similar figure as in the Intermediate level. This result supports the common assumption that lexical density which is a feature of linguistic complexity (Halliday, 1985b) had a positive correlation with textbook levels. This result also indicates that Halliday's formula of lexical density is more reliable in measuring linguistic complexity. This is consistent with the result of our first explanatory research on lexical density across text levels in EFL textbooks used in teaching English in Vietnam (To, Fan, \& Thomas, 2013). Although there were some differences in the results of lexical density analysis measured by two methods mentioned, these findings shared some similarities in the way that the figures displayed the average density of written language. This finding is, therefore, aligned with a number of previous studies on lexical density of written texts (see Castello, 2008; Halliday, 1985b; O'Loughlin, 1994; Ure, 1971; Stubss, 1986). Examples of lexical items employed per ranking clause in low and high level texts are provided in Boxes 7.1 and 7.2 as below. As seen in Box 7.1, the introduction of text E3 had 19 lexical items and seven ranking clauses, giving the lexical density index of this paragraph of 2.7; while the introduction of text 14 used 17 lexical items and 3 ranking clauses, giving the lexical density score of 5.7. Both the introductory paragraphs had the average lexical density values of written language but they significantly differentiate from each other in terms of textbook levels.

Box 7.1. Illustration of lexical density in an elementary text

III ( $\alpha$ ) For years, people thought || (' $\beta$ ) that sleep was an unimportant, passive activity. || | ( $\alpha$ ) Today, we know || (' $\beta)$ that sleep is important for good physical and mental health. || $(\alpha)$ We have also learned II (' $\beta+\beta)$ that while a person is asleep, I| $(\beta \alpha)$ the brain is very active. III (Extracted from Text E3) 
Box 7.2. Illustration of lexical density in an upper-intermediate text

III Marriage is an ancient religious and legal practice [[celebrated around the world]]. II ( $(x \beta)$ Although the reasons [that people marry are similar in many places], II $(\alpha)$ wedding customs vary from country to country. | | (Extracted from Text 14)

Regarding grammatical intricacy analysis, the finding shows that although the intricacy values displayed the increasing pattern from 1.58 ranking clauses per clause complex in Book 1 to 1.8 ranking clauses per clause complex in Book 3, the figures were not statistically significantly different. It is also worth noting that there were no differences in grammatical intricacy scores in Book 2 set for the preintermediate level, and Book 4 set for the upper-intermediate level (grammatical intricacy score was 1.7 for both levels). Overall, intricacy values in 24 texts in four books ranged from the minimum of 1.2 to the maximum of 2.58 , which are considered the typical intricacy score of written language. The reason for the low intricacy score at the lowest level of book was that texts in Book 1 employed more simple clause complexes in comparison with the other books, while the number of words for all texts were relatively similar. As such, there were a higher number of simple clauses and a higher number of clause complexes, giving lower intricacy values. Texts in the other three books used higher number of ranking clauses which are connected by logico-semantic types in a clause complex, giving higher grammatical intricacy value given that intricacy is measured by the ratio of ranking clauses per clause complex. An extract in Text E2 of Book 1, and another one in Text U1 of Book 4 give an illustration for what has been explained. As seen in Box 7.3, there are eight ranking clauses, and seven clause complexes, giving the intricacy of this extract at 1.1. As observed, six out of eight ranking clauses functioned as simple clause complexes. There is only one clause complex consisting of two ranking clauses connected by the hypotactic taxis and logico-semantic type of idea projection (e.g., scientists think that...). Therefore, the intricacy score of this paragraph is really low. Extract in Text U1, on the contrary, displays a higher intricacy scores (two ranking clauses per clause complex). Two ranking clauses in 
each clause complex in this extract were connected by paratactic taxis and logicosemantic types of extensive expansion (e.g., and, yet).

Box 7.3. Illustration of grammatical intricacy in an elementary text

|| Dolphins use a whistle-like sound to communicate. ||| ( $\alpha$ ) Scientists think || (' $\beta$ ) that every dolphin has its own whistle. II|This is like the animal's name, or signature. || |A dolphin might make this sound to greet others. II| It may also whistle loudly to signal for help. || Whales also use whistles and 'song' to communicate with other whales. II Some of these songs can travel thousands of miles through the water. III (Extracted from Text E2)

Box 7.4. Illustration of grammatical intricacy in an upper-intermediate text

II (1) Laughter: A scientific Investigation builds on this work in that it assumes animal origins of laughter, ||$(+2)$ and follows van Hooff's distinction between the laugh and the smile. ||| (1) The two expressions are often mentioned in the same breath || (+2) yet they are used quite differently in primate displays, with the smile expressing affection and appeasement rather than playfulness. || (Extracted in Text U1)

In terms of the use of nominalisation across textbook levels, the result demonstrates that nominalisation featured the similar pattern with Halliday's lexical density and readability. Specifically, mean scores of nominalisation demonstrated the increasing trend from the elementary texts $(0.27)$ to pre-intermediate $(0.5)$, intermediate (0.78) and upper-intermediate text levels (0.74). This means, at the lowest, on average, there was around one instance of nominalisation per four ranking clauses; the number was one instance of nominalisation per two ranking clauses in pre-intermediate texts; and approximately one nominalisation was used in a ranking clause at the two highest levels. This is to say, higher levels of textbook employed higher number of nominalisation per ranking clauses. It is an expected result when the gradual shift in the use of nominalisation was found across level. As nominalisation is a typical linguistic feature constructing technicality in science and 
abstraction in humanities (Halliday, 1993b; Martin, 1993b), but abstraction cannot be easily grasped by beginners of English; thus, it is expected that higher level of textbooks reflect this abstract concepts, and prepare EFL learners to be familiar with and acquire abstraction which is often seen in the academic texts. This may also explain why there was a steady increase in the complexity of language used in textbooks across levels realised by the employment of nominalisation, but the statistically significant difference was only found between two textbook levels, elementary and intermediate, no other group differences were significant. Example of nominalisation used in low and high levels of textbook can be seen in this following extracts. As can be seen in Box 7.5, the introduction of Text E3 which is set for the elementary ESL learners did not employ any instances of nominalisation. Text I5, in contrast, used four instances of nominalisation which are bolded and italic in its introductory paragraph (see Box 7.6).

Box 7.5. Illustration of the unemployment of nominalisation in an elementary text

For years, people thought that sleep was an unimportant, passive activity. Today, we know that sleep is important for good physical and mental health. We have also learned that while a person is asleep, the brain is very active. (Introduction of Text E3)

Box 7.6. Illustration of nominalisation in an intermediate text

Every culture has its own unwritten list of behaviour that is acceptable. Every society also has its taboos, or types of behaviour that are considered a violation of good manners. If you travel to another country, on business or vacation, it is helpful to learn some of that country's customs so that you don't insult the local people. (Introduction of Text 15)

Similarly, grammatical metaphor mean score demonstrated a rising pattern from the lowest to the highest level of textbooks, specifically, from 0.15 at the elementary level to 0.22 at the pre-intermediate level, to 0.31 at the intermediate level, and 0.34 at the highest level of book. As discussed by Halliday (1985a, 1994), 
congruent forms are the natural ways that language encodes the meanings they express. The non-congruent ways of encoding language are viewed as metaphorical expressions or grammatical metaphors. In the congruent way, verbs are used to express actions and events, and nouns are for people and things. However, when grammatical metaphor involves, everything has been turned into nouns. Thus, instead of constructing the world of happening as people were accustomed to, the image of the world has been reconstructed as the world made out of things (Halliday, 1993b). In other words, we present a different view of the world with the metaphorical expression, and because of this, the use of grammatical metaphor often causes difficulties and problems to the learner (Halliday, 1993b). Mastering grammatical metaphor is partly the question of maturity of the learner (Halliday, 1993b). This also depends on the learner's language proficiency level (Devo, 2012). Therefore, it is expected that textbook texts should reflect from the congruent form to the metaphorical form from low to high level, and the result of this study is meaningful. As seen in Boxes 7.7 and 7.8, both extracts belong to the information report genre and the description stage, but the extract in Box 7.7 which is set for the elementary level was more congruent, say, using action verbs (e.g., celebrate, dressed, wore, ate, drank, danced, spread) to express what happened. The extract in Box 7.8 which is for the intermediate learner employed relating verbs (e.g., are) to make a connection between things which are realised in nominal group (e.g., red and orange, symbols of wealth and happiness). Grammatical metaphor (e.g., happiness) is used in the nominal group to construe the ideational meaning by saying what the world made out of things (e.g., symbols of wealth and happiness).

Box 7.7. Illustration of grammatical metaphor in an elementary text

In late February or early March, some countries celebrate a special festival called Carnival. Many think that Carnival first started in Italy or Greece. People dressed in costumes, wore colourful masks, ate, drank, and danced all night on the Tuesday before the start of Lent. This tradition spreads to France, Spain, and Portugal, and later, to Brazil and the United States. (Extracted from Text E5) 
Box 7.8. Illustration of grammatical metaphor in an intermediate text

In different countries, colors other than white are worn by the bride or used as part of the wedding ceremony. In certain Asian countries and in the Middle East, red and orange are considered symbols of joy and happiness. In Chinese cultures, wedding invitations are usually red and gold as these are colors symbolic of wealth and happiness. (Extracted from Text 14)

It should be noticed that in examining grammatical features of scientific texts, technicality should also be taken into account as it is known as common discourse feature of scientific discourse (Halliday \& Martin, 1993; Martin, 1993). Scientific knowledge is constructed by means of taxonomy which involves a series of technical terms for describing and reasoning. Halliday (1993) argues that "technical terms are an essential part of scientific language; it would be impossible to create a discourse of organised knowledge without them" (p.4). As technical terms are concerned with specialised field-specific meaning, it causes difficulty to the learner. As predicted, technicality in this research was found less in the two lower levels of textbooks (elementary and pre-intermediate), while the intermediate textbook texts featured the highest percentage of technicality. It is interesting to find out that the upper-intermediate text level did not show the highest instances of technical terms. However, it can be explained from Halliday's (1993) argument that "of course, technical terms are an essential part of scientific language; it would be impossible to create a discourse of organised knowledge without them. But they are not the whole story. The distinctive quality of scientific language lies in the lexico-grammar (the 'wording') as a whole, and any response it engenders in the reader is a response to the total patterns of the discourse." (p.4). The illustration of technicality at low and high level can be seen in the following extracts in Boxes 7.9 and 7.10. As referred from Boxes 7.9 and 7.10, both extracts are talking about science: the first extract explains the stages of sleep, and the second one explains the process of creating memories. However, it was hard to find technical terms in the first extract except two words, deep sleep and REM sleep, which did not really 
build up technicality. The second extract in Box 7.8, by contrast, employed a number of technical terms in the explanation (e.g., neurons, sensory stimuli, immediate memory, hippocampus, short-term memory, long-term memory, frontal lobe, cerebral cortex.). With reference to the language variation framework (Mahboob, 2014), this is to say, global everyday language can also be used to talk about science-related topic as seen in extract in Box 7.9; while the authentic scientific text should employ global specialised language in scientific writing as can be observed in Box 7.10. Thus, it is an expectation that textbook writing should reflect the shift from the non-technical language to technical language. This will equip students with specialised range of vocabulary in the specific discipline of science to prepare them for success when they pursue further studies which often deal with English for specific purposes. From this perspective, the finding of this study which reflects the growth of complexity from elementary to intermediate level in terms of technicality is a satisfactory and expected result.

Box 7.9. Illustration of technicality in an elementary text

To understand sleep, scientists study brain waves. By doing this they have learned that there are five stages of sleep. Stage one sleep is very light. During this time, a person awakens easily. As we move into stage two, our eyes stop moving and our brain waves move more slowly. During stages three and four (often called 'deep sleep'), it is very hard to awaken a person. During this time, the body repairs itself and makes more cells. In children and young adults, the body makes a chemical used for growing. In the next stage - REM sleep - we begin to breathe faster and our eyes move around quickly, but our bodies do not move. During this stage, we dream. (Extracted from Text E3)

Box 7.10. Illustration of technicality in an intermediate text

Although the process of creating memories is only partially understood, it is thought to involve three main steps. Scientists believe that brain cells called neurons first transform the sensory stimuli we experience into images in our immediate memory. Then, these images are sent to the hippocampus and stored temporarily in short-term memory. In the hippocampus information is organised, and it is during this process that parts of the image of our experience fade away. Finally, certain information is then transferred to long-term memory in a section in the frontal lobe of the brain known as the cerebral cortex. (Extracted from Text 13) 
Concerning the use of Theme in the chosen texts in this research, the result shows that various theme types were employed across textbook levels. However, it is interesting to find out that there were no statistically differences on theme choice between different levels of textbooks, although there were some general patterns. Specifically, the results show that simple theme was used most across levels which was accounted for the highest percentage in Book 1 (67.5\%), and the number decreased gradually to $55 \%$ in Book 4 . However there was a slight decrease in the use of simple themes from low to high level. Multiple theme took the second position, but there was a slight increase in the employment of multiple theme across levels. Clausal theme was used the least in the textbook texts, although this kind of theme showed an increase from elementary to upper-intermediate level. These results indicate three things. Firstly, simple theme which includes topical theme and marked theme is the main component to construe the starting point of the message, in which marked theme which includes circumstances help construe the textual meaning and create the coherent texts across levels. Secondly, among components of multiple theme, textual theme was employed relatively the same across levels to build the textual meaning, the instances of interpersonal themes was not considerable. Thirdly, higher levels of textbooks employed a higher percentage of multiple and clausal themes, and slightly lower of simple theme, although these differences were not statically significant.

Moreover, regarding the function of theme, experiential theme displayed the highest frequency in four books, interpersonal theme was less used, and textual theme was relatively similar across textbook levels. It is not surprising that experiential theme was used most in the four books as the experiential theme or topical theme is obligatory theme that constitutes the departure of a message contributing to the development of a text (Halliday, 1985a, 1994). Thus, the result found in this study is quite expected. It is not surprising either when interpersonal theme which involves questions was less used across levels of book as this study investigated academic genres which mainly include declarative sentences. The similarity of textual themes employed across levels indicates that all textbook texts 
across levels were written coherently due to the adoption of marked theme and textual theme, which indicates time or place a process happens among levels. It can be concluded in this study that the choice of theme types was not significantly different according to the textbook levels. Illustration of theme types that contributing to the coherence of the texts across four levels are provided in Boxes $7.11,7.12,7.13$, and 7.14 respectively. In the following examples, Theme (in italic) and Rheme (in normal case) were distinguished from each other by \#, types of theme were written in smaller font in the brackets followed immediately after themes. As can be seen, various thematic structures were employed in texts across levels contributing to the textual meaning of the messages.

\section{Box 7.11. Types of theme in an elementary text}

II In many Latin cultures (marked theme) \#, a young woman's fifteenth birthday is important.||| At this age (marked theme) \#, she is considered an adult. |||To mark this special day (clausal theme) \#, I families with teenage daughters have a celebration called a Quinceanera. III The day (unmarked theme) \# begins with young woman and her family going to church. || Later (textual theme), there (unmarked theme) \# is a party, || and (textual theme) many guests (unmarked theme) \# are invited. | || (Extracted from Text E6)

Box 7.12. Types of theme in a pre-elementary text

III In many countries (marked theme) \#, sixteen or eighteen is the age at which a person becomes an adult. || Young men and women (unmarked theme) \# at this age can get a part-time job, $\mid$ and (textual theme) begin (unmarked theme) \# to receive an income of their own. |I They (unmarked theme) \# no longer have to rely on their parents for money all the time. III In many parts of North Americans (marked theme) \#, sixteen is also the age when one can obtain a driver's license; I| in England (marked theme) \#, it is seventeen. | I (Extracted from Text P6) 
Box 7.13. Types of theme in an intermediate text

II In many countries (marked theme) \#, it is customary for the bride to wear a white dress as symbol of purity. II In traditional Japanese wedding ceremonies (marked theme) \#, the bride wears a white kimono. ||| The tradition of wearing a special white dress only for the wedding ceremony (unmarked theme) \# started around 150 years ago. | | Before that (textual theme), most women (unmarked theme) \# could not afford to buy a dress that they would only wear once. | I Now (marked theme) \#, bridal dresses can be bought in a variety of styles and fabries, || and (textual theme) many brides (unmarked theme) \# have their dress specially made. | I (Extracted from Text 14)

Box 7.14. Types of theme in an upper-intermediate text

|| Their food (unmarked theme) \# is tied, literally, to the frozen ocean.||| Within layers of sea ice (marked theme) \#, microscopic algae bloom in profusion as sunlight floods in from above. II| When the sea ice melts with the beginning of summer (clausal theme) \#, II the ice algae escape into the water, where they are grazed on by dense swarms of krill - a type of shrimplike crustacean.||| The krill (unmarked theme) \#, in turn, are the Adelie penguins primary food source. |||To eat them (clausal theme) \#, Adelies spend their entire lives on, around, or beneath the Antarctic pack ice. II (Extracted from Text U6)

To sum up, the language of textbook texts in the chosen series grew complex when their levels advanced. This increase was realised in the gradual shift of lexical density (based on clauses), readability, nominalisation, grammatical intricacy and grammatical metaphor from low to high level. Specifically, the significant differences were found between elementary and intermediate textbook texts in terms of lexical density, readability and nominalisation. Other linguistic features also showed similar increasing patterns, although the statistic differences were not significant. Logio-semantic types realised in grammatical intricacy and thematic choice contributed to the textual meaning of texts across levels. These results are both expected and interesting. It is predictable as in general the steady increase in 
complexity of language use in textbooks was found, which suits the learner's language proficiency levels proposed by the writers. It is interesting when two highest levels of textbooks in the book series which are supposed for intermediate and upper-intermediate level featured relatively similar mean scores of linguistic features investigated. It is understood that the intermediate texts written by the author reflect similar linguistic features employed in the authentic texts, as the intermediate book was written by the author, while the upper-intermediate book was the collection of real world texts taken from reliable sources such as New Scientist, American Scientist, CBC news online, International Wildlife. Therefore, it can be concluded that the language of the chosen textbooks in the series which have been commonly used for TEFL with special reference to the Vietnamese context reflect authentic texts.

It is worth mentioning that while this study identified the overall trend of complexity across levels based on the mean scores of linguistic features investigated, the standard deviation, Min and Max values indicate that a few specific texts in high-level textbooks were less complex compared with the other ones in lower-level textbooks and vice versa. An example might be found in Book 4 with the Min score of lexical density of 3.81, while it was 3.6 in Book 1. Another example can be observed in the use of grammatical metaphor. A low-level text may employ the same amount of grammatical metaphor as it does in the higher level text. Max values of grammatical metaphor in Book 1 and Book 3 are two illustrations. Although these cases were not many in the data, the result is also important as it indicates that to choose appropriate texts or textbooks suitable for the leaner levels and teaching purposes, detailed examination of particular texts might be essential in addition to the whole book. 


\subsection{Linguistic complexity of science-related and non-science texts}

This section answers the third research question of the study on how linguistic features charactering complexity including lexical density, grammatical intricacy, nominalisation, grammatical metaphor and thematic structure differs in science and non-science fields in the chosen English textbooks.

Rigorous research on complexity of written language in general and in scientific discourse in particular from the functional grammar perspective has been undertaken by Halliday (1985b, 1998, 1993, 2004, 2008), the father of SFL theory and well-known functional and educational linguists (Banks, 2003, 2005, Martin, 1993, 2008; Ravelli, 1999). In fact, SFL has produced well-established measures towards linguistic complexity despite its real complexity in social contexts (Martin \& Rose, 2003). Looking at complexity through the lens of SFL provides useful insights into language and the fuller picture of it regarding how complexity works and why it works in the way it does at the levels of grammar, discourse and context (Martin \& Rose, 2003). In addition, it does help explain the functions of language in the social contexts. One of the main contributions of this study is that it expands prior research by examining complexity of language in international textbooks used for TEFL within the current context that research on EFL textbooks in light of SFL has still been under-investigated. Although there is a general assumption that textbooks, expectedly grow more complex when their levels advance, this study has statistically proved this assumption by using SFL principles as discussed in the previous section.

This research also expands previous studies on scientific texts when it looked at the language of science-related texts in textbooks for teaching general English for second language learners. Interestingly, the finding shows that overall scientific texts and non-scientific ones in the same book were not significantly different in terms of linguistic features. The chosen texts involving science-related topics displayed relatively similar or even a bit lower figures of density, readability, grammatical intricacy, nominalisation, grammatical metaphor and theme types in 
comparison with non-scientific texts in the same textbook level. This is to say, although chosen texts in the same book level are different in terms of topic, genre and domain; there are no significant differences in the linguistic features of those texts. This finding was somehow contradictory with prior research on scientific discourse (Halliday, 1993a, 1993b, 1998, 2004; Halliday and Martin, 1993; Martin, 1993a, 1993b).

According to the findings of research conducted to investigate the complexity of scientific writing from the SFL point of view (Banks, 2003, 2005; Halliday, 1993a, 1993b, 1994, 1998, 2004; Halliday \& Martin, 1993; Martin 1993, 2008), scientific texts are considered having heavily dense, nominalised and metaphorical style; but at the same time adopt a very simple sentence structure (Halliday, 1993a, 1993b, 1994, 1998, 2004; Halliday \& Martin, 1993; Martin 1993). Because of the density, heavy nominalisation, and grammatical metaphor, scientific English texts are difficult for both learners of English as a second language and for those of English as a first language (Halliday, 1993a). Halliday (1993a) argues that although scientific texts are generally found to be difficult to read because of their jargons or technical terms, "the difficulty lies more with grammar than with the vocabulary" (p.71). This is to say, the problems are more with the complex relationships among technical terminology than the technicality itself (Halliday, 1993a). Based on the analysis of scientific documents including Australian school science and mathematics textbooks, recorded science lecturers in England, writings from the Scientific American, and historical survey and works, Halliday (1993a) suggests seven characteristics of scientific English to help understand why the science text is written in the way it is. Among these features, lexical density, nominalisation, grammatical metaphor are typical linguistics factors of the scientific discourse that cause scientific texts difficult to comprehend.

However, with respect to the language variation framework (Mahboob, 2014), which has been developed based on the register variation according to the users and uses of the language, and the mode of the communication (Figure 7.1), these three dimensions of language variation provide insights into eight possibilities of mapping language variation (Mahboob, 2014) as described in Table 7.1. As shown in 
Table 7.1, written or oral language can employ local or global language, as well as every day or specialised to express meaning regarding the same topic and field or various topic and fields. For example, to talk about the benefits of vegetable to people's health, non-specialists such as students can use global everyday language to express their experience, but specialists will use a global technical language to talk in depth about the topic. Science-related topics such as the ones investigated in this study can be written in every day or specialised language to some extent. The analysis of the language used in 12 investigated scientific texts from the language variation model revealed that even though technical terms were employed in those texts to some extent (see Table 4.22), and this is unavoidable when talking about specific fields of science; nine out of 12 texts in the science field employed global written everyday language. This explains why overall science-related texts chosen did not demand high lexical density values as well as high frequency of nominalisation, grammatical metaphor, and low intricacy in comparison with nonscientific texts in the same book level. An example of text that used global everyday language to talk about science can be seen in Box 7.15.

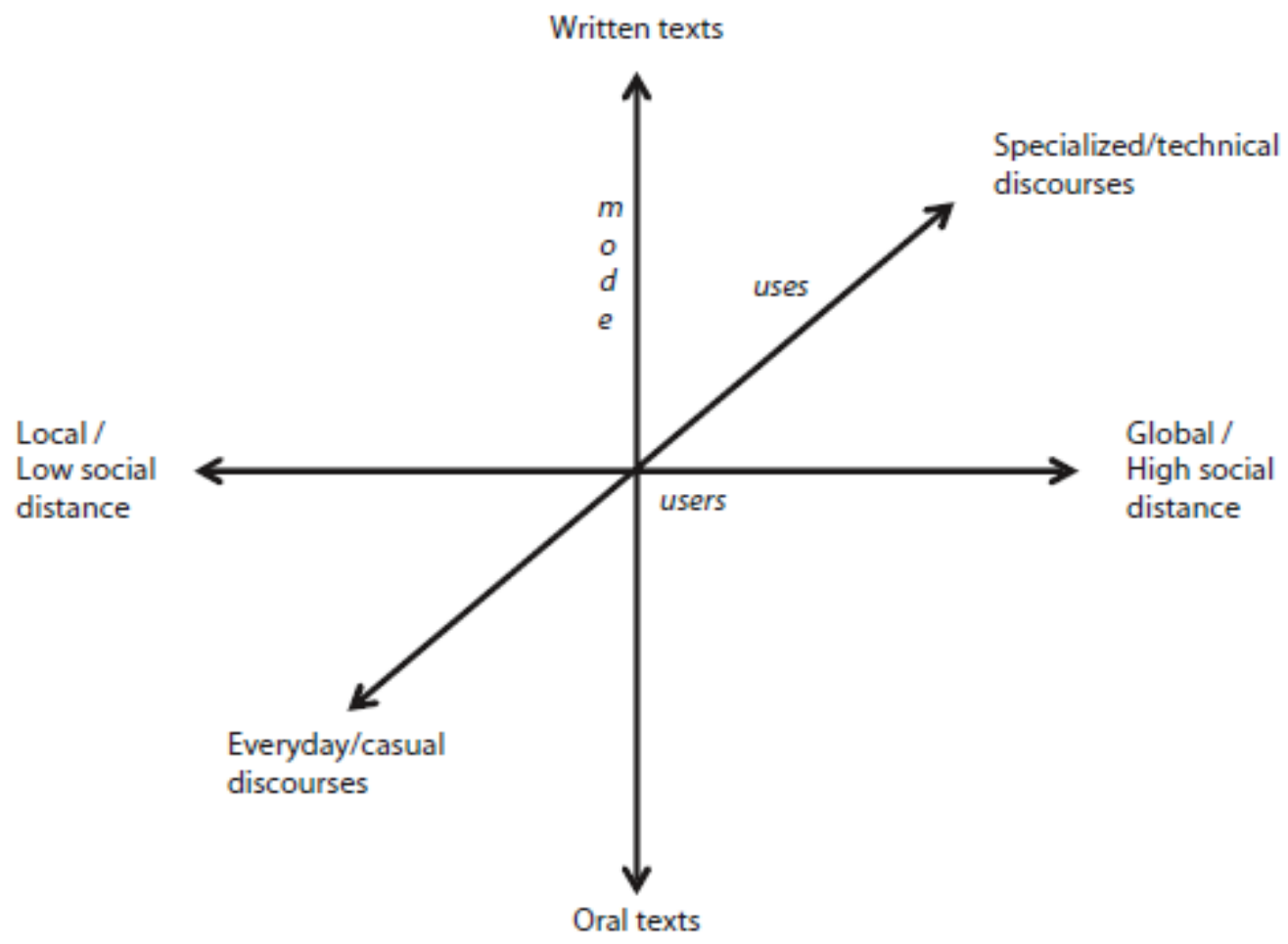

Figure 7.1. Three dimensional model of language variation (Mahboob, 2014, p.5) 
Table 7.1. Domains of language variation (Mahboob, 2014, p.5)

\begin{tabular}{|l|l|l|}
\hline \multicolumn{2}{|c|}{ Domains } & \multicolumn{1}{|c|}{ Examples } \\
\hline $\mathbf{1}$ & Local, written, everyday & Friends writing letters to each other \\
\hline 2 & Local, oral, everyday & $\begin{array}{l}\text { Friends talking to each other about their plans for } \\
\text { the holidays }\end{array}$ \\
\hline 3 & Local, written, specialised & Text written by and for a local group of farmers \\
\hline 4 & Local, oral, specialised & Farmers discussing specifics about their crops \\
\hline 5 & Global, written, everyday & International news agencies reporting on events \\
\hline 6 & Global, oral, everyday & Conversations amongst people from different parts \\
& & of the world \\
\hline 7 & Global, written, specialised & Academic writing research papers \\
\hline 8 & Global, oral, specialised & Conference presentations \\
\hline
\end{tabular}

Box 7.15. Examples of science-related texts employing global everyday language

\section{Science-related text in Book 1}

Dolphins use a whistle-like sound to communicate. Scientists think that every dolphin has its own whistle. This is like the animal's name, or signature. A dolphin might make this sound to greet others. It may also whistle loudly to signal for help. Whales also use whistles and 'song' to communicate with other whales. Some of these songs can travel thousands of miles through the water. (Extracted from Text E2)

\section{Science-related text in Book 3}

What is about laughter that makes it unstoppable even if triggered by circumstances that aren't amusing? Extreme episodes of laughter, marked by loss of motor control, shedding of tears or gasping for air, are positively worrying. What weird trick has been played on us to make us express ourselves with such stupid "ha, ha, ha" sounds? Why don't we just leave it at "that was funny"? (Extracted from Text U1)

As shown in Box 7.15, two extracts are taken from two scientific texts at the lowest level (Elementary) and the highest level (Upper-intermediate), but neither of them 
used field specific specialised language to construe the meaning. It is hard to find out any instances of nominalisation, grammatical metaphor or technicality in these two science-related excerpts. In addition, to illustrate the non-significant difference of linguistic complexity between science and non-science field, introduction of texts in both fields at the intermediate level were provided in Boxes 7.16 and 7.17 respectively.

Box 7.16. Scientific text at the intermediate level

III Images of robotic equipment [being used in operating rooms] were once seen only in science-fiction movies. III (1) Today, the use of robotic equipment for certain types of surgery is no longer make-believe - || (=2) it's real! || (Extracted from text I1)

As can be seen in the introduction of a science-related text in Box 7.16, there are 17 lexical items, three ranking clauses, two clause complexes, and one instance of nominalisation, which gives the lexical density score of 5.7 , grammatical intricacy of 1.5 , and 0.33 nominalisation per ranking clauses. Likewise, the introduction of the non-scientific text has the same number of lexical items, ranking clauses and clause complexes, which give the same density and intricacy values with the excerpt in Box 7.16. However, there is a little bit different in terms of the deployment of nominalisation with the frequency of one nominalisation per ranking clause. Although these two introductions are in different fields, their linguistic features are relatively similar.

Box 7.17. Non-scientific text at the intermediate level

II| Marriage is an ancient religious and legal practice [celebrated around the world.] || | $(x \beta)$ Although the reasons [that people marry are similar in many places], II ( $\alpha$ ) wedding customs vary from country to country. | I (Extracted from text 14) 


\subsection{Correlations among linguistic features charactering complexity}

This section answers the fourth research question of the study on relationships of linguistic features characterising complexity including lexical density, grammatical intricacy, nominalisation, and grammatical metaphor.

Regarding the relationships among linguistic features characterising complexity, this finding supports Halliday's $(1985 a, 1993,1994)$ studies when the strong positive correlations among lexical density calculated by Halliday's measure, nominalisation and grammatical metaphor were found. This means that when nominalisation rose in accordance with the book levels, this entailed the increase of grammatical metaphor and lexical density. The strong association between nominalisation and grammatical metaphor $(r=.796)$ also confirms that nominalisation is the powerful resource for producing grammatical metaphor (Halliday, 1985a, 1994, Halliday \& Mathiessen, 2004). This is a logical result as two of the four types of nominalisation investigated in this study realised at the level of lexicogrammar are nominalisation of verbs and nominalisation of adjectives. Semantically and congruently, verbs are realised as processes and adjectives realised as quality. However, when grammatical metaphor involves, processes and quality are metaphorically realised as things in another process. This means that the ideational content which is congruently expressed in clauses is densely packed in nominal groups when grammatical metaphor occurs. This explains why grammatical metaphor often follows high lexical density (Halliday \& Mathiessen, 2004). The relatively strong correlation between grammatical metaphor and density in this study $(r=.615)$ confirms this. However, grammatical metaphor does not always necessarily involve lexically dense texts, as the lexical meaning or ideational content can also be densely packed in strings of lexical items (involving nominalisation). That says, nominalisation is significantly associated with lexical density. The coefficient correlation between nominalisation and density in this study $(r=.740)$ illustrated this. Put them all together, it can be concluded in this study that nominalisation, grammatical metaphor and lexical density are interrelated linguistic features, characterising linguistic complexity in textbooks across levels. 
In regard to intricacy, as stated by Halliday (1985b) and Ravelli (1999), high lexical density involves low intricacy as high lexical density can often be realised in simple clause complexes, given that there are fewer ranking clauses per clause complex. More ranking clauses per clause complex, in contrast, reduce lexical density. This leads to a hypothesis that lexical density is strongly and negatively associated with grammatical intricacy. However, the moderate negative correlation between these two features found in this study $(r=-.465)$ implies four possibilities: (1) high density involves low intricacy, (2) low density involves high intricacy, (3) high density involves high intricacy and (4) low density involves low intricacy. The mean scores of lexical density and grammatical intricacy show that when density increased from Book 1 to Books 2 and 3 before slightly decreasing in Book 4, intricacy displayed a similar pattern. This indicates that low lexical density involving low intricacy and high density involving high intricacy (possibilities three and four mentioned above) were also the cases occurred in this study. It should also be clarified that at the first level of textbook, clause complexes which consist one simple ranking clause and does not involve nominalisation and grammatical metaphor were used more. This leads to the fact that there were a higher number of simple clauses and a higher number of clause complexes, giving lower intricacy values. At the later levels of books, texts chosen for analysis have the same number of words as those in the lowest level, but a clause complex in higher-level texts may consist of several ranking clauses connected by different logical-semantic relations. This means that there were more ranking clauses and less clause complexes, giving higher intricacy scores, given that intricacy is measured by the ratio of ranking clauses per clause complex. This explains why texts at higher levels of books were more intricate. Illustrations for this can be seen in Texts E2, P4, 15 and U5 in the raw data in Appendix 2.

\subsection{Linguistic features in the whole text levels}

This section answers the final research question of the study on how linguistic features including lexical density, grammatical intricacy, nominalisation, and 
grammatical metaphor differ according to stages of genre and what effects do they have on the text periodicity.

The detailed analysis of two scientific texts in the Elementary and Intermediate books show that two texts shared some similar features as well as had distinctive characteristics. As far as common features are concerned, both explanatory texts in the science field displayed a greater degree of complexity in the Explanation stage in comparison with the Phenomenon stage. Specifically, complexity in two texts in the Explanation genre can be seen in higher density, nominalisation, grammatical metaphor and lower intricacy in the Explanation stage, while the Phenomenon stage, in contrast, displayed lower density, nominalisation, grammatical metaphor and higher intricacy. The use of lexical items, logico-semantic types, nominalisation and grammatical metaphor in both texts help build the field of discourse. This can be explained that as Explanation genre involves reasoning expressed by causes and effects (Rose \& Martin, 2008; Martin \& Rose, 2012) which are often found in the main body paragraphs which belong to the Explanation stages. The Phenomenon stages, in contrast, are often conflated with the introductory sections.

Concerning the effect of grammatical metaphor, the analysis reveals that while several instances of grammatical metaphor were employed in Themes, the majority of this feature was found in New. While the scientific text in the Elementary level (Text 1) was relatively simple employing a few instances of grammatical metaphor in New, the scientific text in the Intermediate level (Text 2) was a complex one employing grammatical metaphor in macroTheme, hyperThemes and News. To explain this, further analysis of the language used in both scientific texts shows that while Text 1 at the Elementary level used the everyday global language to talk about the topic of science, Text 3 which was set for the Intermediate level employed specialised global language with reference to the language variation model (Mahboob, 2014). This might explain why technical terms which are often used in scientific texts, but this was not found in Text 1, while Text 3 employed a great deal number of technicality. This also shows that there was a gradual shift in the linguistic complexity of scientific text from elementary to intermediate level. 
Regarding two non-scientific texts which belong to the Information Report genre, the result of the analysis shows that both texts displayed a higher density value in the Description stage, but lower intricacy compared with the General Statement stage. Frequency of nominalisation and grammatical metaphor was a bit higher in the Description Stage than in the General Statement Stage in Text 3 (Elementary level), but the figure was lower in the Description stage in Text 4 compared with the General Statement stage in the same text. This finding indicated that high lexical density of the two non-scientific texts did not result from the use of nominalisation and grammatical metaphor; rather, this resulted from the strings of lexical items employed in these texts. Overall, there was a gradual shift in linguistic complexity from low to high level of text which can be seen in high density, low intricacy, high nominalisation and grammatical metaphor in the Intermediate non-scientific text.

Overall, the analysis according to the text periodicity with reference to the employment of linguistic features in Themes, News, hyperThemes, hyperNews, macroThemes, and macroNews reveals that overall grammatical metaphor was used more in News. Thus, grammatical metaphor had little effect on macroTheme, hyperThemes, macroNew; rather it construed the textual prominence which can be seen in News. This result supported Martin and Rose's (2003) findings when they argue that

Higher level Themes and News have more information to predict and distil than lower levels ones. This puts even more pressure on them to deploy grammatical metaphors that pack in the information they predict and distil. (p.194)

\subsection{Conclusion}

This chapter discussed the main findings of the research in response to research questions 2, 3, 4 and 5 set up earlier in the introduction chapter of the thesis. The discussion was based on the results of the linguistic features investigated in four textbooks across four different levels, linguistic analysis of science and nonscientific texts, correlations among linguistic features examined, and how linguistic 
features characterised in the full text level in various genres in different fields and textbook levels. The discussion in this chapter also pointed out how the findings supported and expanded the literature, what findings were expected, or unexpected. The discussion was grounded on the linguistic analysis of lexical density, grammatical intricacy, nominalisation, grammatical metaphor, thematic structure, and the text hierarchies across four levels of books.

The following chapter is the last chapter of the thesis which will draw a conclusion on the whole research journey. It starts by presenting a summary of the research which includes the major work in each chapter of the thesis. The chapter then briefly revisit the SFL linguistic concepts examined in the study and the methodology to analysing these linguistic features. Following this, a general discussion of the main findings is revisited, and practical implications for English language teaching, teacher training, text and textbook selection and writing, curriculum design are suggested. Knowledge contributions and limitations of the research are highlighted. Recommendations for future work which can be done based on the findings of this study are also provided. 


\section{Chapter 8: Conclusion}

\subsection{Introduction}

This research has now come to an end. As the last part of the thesis, the purpose of this chapter is to reflect on the whole research journey, and examine what has been achieved, how the aims and objectives of the research have been fulfilled, how the outcomes of this research have contributed to the current body of knowledge, as well as what its significance, implications, and recommendations for further studies. This chapter, therefore, initially summarises the main findings of the research. Then, it discusses the research significance in terms of its contribution to the current body of knowledge and how its means to EFL teaching, teacher education, text and textbook choice and writing, and curriculum design in the Vietnamese context. Following this, limitations of the study are discussed, which is followed by recommendations for further research in the area of linguistic complexity. Finally, the thesis ends with the researcher's reflections on personal, social, intellectual, academic and professional achievements through this research journey, and concluding thoughts on the whole thesis.

\subsection{Summary of the key findings}

\subsubsection{Linguistic complexity of texts across textbook levels}

One of the research objectives was to investigate how linguistic complexity differed across levels in the chosen book series. Quantitative analysis of linguistic features in 24 reading extracts in four books shows that the language of textbook texts grew complex according to the rising level from elementary to intermediate. This was due to a higher frequency of lexical items, nominalisation, and grammatical metaphor employed in the higher book level, and all the selected texts were less intricate with the intricacy mean score ranging from 1.6 to 1.8. This is an expected result as the gradual increase in the complexity of language across levels from low to high in a 
book series is what textbook writing should aim at. This result indicates that the language of textbook texts moved gradually from simplicity to complexity from low to high levels of the textbooks and reflected the authentic texts.

The contribution of this research is that it has statistically supported this general assumption by using the SFL measures and principles to quantify complexity which has received less attention in SLL. This result can be understood in the context that the first three levels of textbooks were written by the author who is a world expert in the field of TEFL. Thus, effective control over complexity from Book 1 to Book 3 which is set for Elementary to Intermediate level might be one of the author purposes in writing these books. However, it is surprising that the highest level of book did not demonstrate the highest frequency of nominalisation, grammatical metaphor and lexical density values. The figures of linguistic features in the chosen texts in Book 4 were relatively similar to those in Book 3. It should be noticed that all texts in the final book in the series were written by various authors and collected from different sources such as New Scientist, American Scientist, CBC news online, International Wildlife, and so on.

\subsubsection{Linguistic complexity of science-related and non-science texts}

This study also examined how the language of textbook texts in science and nonscience domains differed in the chosen book series which were commonly used in TEFL. Whilst a substantial body of research has been conducted with scientific texts (Banks, 2003; Halliday, 1993a, 1994; Halliday, 1995; Halliday, 1998, 2004, 2008; Halliday \& Martin, 1993; Halliday \& Matthiessen, 1999a; Halliday \& Matthiessen, 1999b; Halliday \& Matthiessen, 2004; Martin, 1992a, 1993a, 1993d, 2008), looking at how the language of science employed in the EFL textbooks in non-English speaking countries has received little attention. Quantitative analysis of 12 sciencerelated and non-science texts shows that the two fields within the same book were not significantly different in terms of complexity measured by the SFL measures and principles. These two domains demonstrated relatively similar means scores of lexical density, grammatical intricacy, nominalisation and grammatical metaphor. This finding was unexpected but understandable when considering the need of 
balancing complexity of language in the same book level. It can also be explained from the perspective of the language variation framework (Mahboob, 2014). According to this model, language is divided into eight domains (see Figure 7.1 and Table 7.1 in Chapter 7), within domains five and seven, written global language can be everyday or specialised. This means that concerning the same topic of science, everyday language or technical language can be used to express the ideational meaning. For example, writing about the benefit of genetically modified food (GM foods), a student may mention some common words in their writing such as soybean, corn, canola, etc. These are words of everyday language, rather than specialised language. However, a research or an expert in this field may use more advanced technical language such as selective breeding, mutation breeding, genetic engineering, etc. to explain about GM foods. From this perspective, it is expected that the language of science-related texts in EFL textbooks with the purpose of teaching basic and general English to L2Ls is not complicated as it is in the real word scientific texts. However, it would be strategic in textbook writing and curriculum design if higher levels of textbooks reflect the authentic language of scientific texts. This will help students advance in their study and prepare them for access to abstraction, and technicality when they enter the higher level of education which is often related to the specific area of their major.

\subsubsection{Correlations among linguistic features charactering complexity}

Another research objective of this study was to determine the relationships among linguistic features characterising complexity, specifically a) between lexical density and grammatical intricacy; b) between lexical density and nominalisation; c) between lexical density and grammatical metaphor; d) between nominalisation and grammatical metaphor. The results of the analysis of linguistic features mentioned in 24 reading extracts support Halliday's $(1985 a, 1993,1994)$ studies that nominalisation is the powerful resource for producing grammatical metaphor (Halliday, 1985a, 1994, Halliday \& Mathiessen, 2004) resulting in lexically dense written texts. Calculated by the Pearson correlational test, the strong positive correlations among lexical density calculated by Halliday's measure, nominalisation and grammatical metaphor were found. Specifically, the correlation coefficient $r$ 
value between nominalisation and grammatical metaphor was .796; between nominalisation and density being .695; between grammatical metaphor and density being .615 . To conclude, nominalisation, grammatical metaphor and Halliday's lexical density are three interrelated linguistic features, characterising linguistic complexity in textbooks across levels.

Although the relationship between grammatical intricacy and nominalisation, between grammatical intricacy and grammatical metaphor were not significant, lexical density and grammatical intricacy demonstrated a moderate negative relationship with the correlation coefficient $r=-.465$. Halliday (1985b) and Ravelli (1999) state that high lexical density result in low intricacy as high lexical density can often be found in simple clause complexes, given that there are fewer ranking clauses per clause complex. By contrast, if a clause complex consists of a number of ranking clauses, which will lead to sparse texts. However, Ravelli (1999) also argues that high lexically dense texts can also be intricate. The moderate negative correlation between the lexical density and grammatical intricacy in this study ( $r=-$ .341) indicates four possibilities: (1) high density involves low intricacy, (2) low density involves high intricacy, (3) high density involves high intricacy and (4) low density involves low intricacy. Overall, the mean scores of intricacy in four textbooks ranged from 1.6 to 1.8 from the elementary to upper-intermediate level. Texts at the elementary level employed simple clause complexes, while higher levels of textbooks used taxis and logico-semantic types to connect clauses in a clause complex. This results in slightly higher intricacy values in the higher textbook levels.

\subsubsection{Linguistic complexity according to genre analysis and hierarchies of periodicity}

With respect to the analysis of complexity according to genre analysis and the text hierarchy of periodicity, the outcomes show that both explanatory texts demonstrated higher scores of lexical density, nominalisation, grammatical metaphor, and lower intricacy in the explanation stages in comparison with the phenomenon stages. This can be explained that as the explanation genre involves 
reasoning expressed by causes and effects (Martin \& Rose, 2012; Rose \& Martin, 2008) in the explanation stage which has the need to pack more information and make the text denser. The phenomenon stages, in contrast, give the orientation of the text. Regarding two Information Reports, the result of the analysis shows that both texts displayed a higher density value in the Description stage, but lower intricacy compared with the General Statement stage. Frequency of nominalisation and grammatical metaphor was slightly higher in the Description Stage than in the General Statement stage in Text 3 (Elementary level), but the figure was lower in the Description stage in Text 4 compared with the General Statement stage in the same text. The analysis of complexity regarding the text periodicity shows that grammatical metaphors which construe the textual prominence were all employed in Themes, News, hyperThemes, hyperNews, macroThemes, and macroNews. However, its frequency was found mostly in News.

\subsection{Significance of the research}

\subsubsection{Theoretical significance in the area of linguistic complexity}

As discussed earlier, different linguistic theories lead to different perspectives on linguistic complexity. While traditional grammar and Chomsky's TGG look at complexity at the level of syntax, Halliday's functional grammar examines complexity at three strata of language (lexico-grammar, discourse semantics and social context), and three social metafunctions (the ideational, the interpersonal and the textual). Theoretically, this study reinforces the view that Halliday makes significant contributions to understanding and managing linguistic complexity in social contexts. In light of the SFL perspective, linguistic complexity emphasises six linguistic features known as lexical density, grammatical intricacy, grammatical metaphor, nominalisation, thematic structure, and the text periodicity.

In the book Written and Spoken language, Halliday (1985b) states that the kind of complexity that is typical of written language is lexical density. He also mentions that speech and writing have different kinds of complexity. The complexity of written language is lexical, while that of spoken language is grammatical. Thus, 
lexical density and grammatical intricacy are two typical ways of managing complexity (Halliday, 2008). Lexical density is measured by the ratio of lexical items per total words (Halliday, 1985b; Ure, 1971) or per ranking clauses (Halliday, 1985b). The employment of lexical items helps construe the ideational meaning of discourse. In addition, how dense or sparse lexical items are packed in clauses refers to the mode of discourse which is concerned with the textual metafunction of language.

Grammatical intricacy is calculated by the proportion of ranking clauses per total number of clause complexes (Halliday, 2008) as it examines how lexical items are scattered over clauses. As far as the measure of intricacy is concerned, there is inter-dependency relationship between clauses in clause complexes. This interdependency is determined by taxis and logico-semantic types. As mentioned earlier, taxis includes parataxis (equal status) and hypotaxis (unequal status), while logico-semantic types consists of expansion and projection. Expansion can be further divided into elaboration, extension and enhancement; and projection is divided into locution projection and idea projection. The measure of intricacy helps understand the logical metafunction of language which is one of the two ways in construing the ideational meaning. However, the variation in intricacy values also indicates the variation in mode which deals with the textual metafunction.

As such, both lexical density and grammatical intricacy help build the ideational and textual meanings which are related to the field and mode of discourse. Halliday (1985b, 2008) states that the complexity of written language can be seen in the density of strings of lexical items packed in ranking clauses and the simplicity of sentence structure packing those lexical items. In other words, high lexical density can result in low intricacy.

Grammatical metaphor is a linguistic feature which leads to high lexically dense written discourse (Halliday, 2004). There are two kinds of grammatical metaphor, ideational metaphor and interpersonal metaphor. Within the scope of this study, only ideational metaphor which involves nominalised process was investigated. 
Ideational metaphor involves in three social metafunctions of language, Halliday and Matthiessen (2004) state that

Grammatical metaphor of the ideational kind is primarily a strategy enabling us to transform our experience of the world: the model of experience construed in the congruent mode is reconstrued in the metaphorical mode, creating a model that is further removed from our everyday experience- but which has made modern science possible. At the same time, there are also textual and interpersonal consequences of this metaphorical realignment in the grammar: ideational metaphor can be a powerful textual resource for managing the creation of text, creating new mappings between the ideational and textual quanta of information; and it can also be a powerful interpersonal resource for organizing the ongoing negotiation of meaning, creating new mappings between the ideational and interpersonal propositions/proposals. (p.646)

Nominalisation is the process of deriving nouns from other word classes. Nominalisation is the most powerful resource for creating grammatical metaphor. Although grammatical metaphor involves nominalisation, not all forms of nominalisation are grammatical metaphor. The distinction between nominalisation and grammatical metaphor made in this study is that when a grammatical metaphor can be unpacked to the congruent form, it is a kind of metaphorical expression; however, when a grammatical metaphor cannot be unpacked to its non-metaphorical expression, it is just a kind of transcategorisation or nominalisation. Nominalisation not only helps building the field of discourse which is concerned with the ideational meaning of language, but also is an effective tool contributing to the text organisation which deals with the textual metafunction of language.

As far as the three metafunctions of language are concerned, Theme is concerned with the textual metafunction which is about the organisation of the text. Theme defined as the departure of the message predicts what comes next in the rest of the 
clause. Thus, the choice of Theme gives the orientation of the message and results in a different meaning of the clause. The higher layer of Theme is hyperTheme which is conflated with the topical sentence of a phase of discourse. HyperTheme determines what the next supporting clauses in the phase will be about. The higher layer of hyperTheme is macroTheme which is known as the thesis statement of the text which is often found in the introductory section. While Theme, hyperTheme and macroThem predict the text will be about; New, hyperNew and macroNew distill the information of the text. Layers of Themes and News construct the text's hierarchy of periodicity which is concerned with the text's information flow.

In summary, it can be said that Halliday's linguistic theory examines linguistic complexity at three levels of language: (1) lexico-grammar (realised by lexical density, grammatical intricacy, nominalisation and theme), (2) discourse semantics (grammatical metaphor, and hierarchy of periodicity) and (3) social contexts (genre and register); and three metafunctions of language in which the ideational and textual meanings are the main focus of the examination in this study.

\subsubsection{Knowledge contribution}

As discussed earlier, rigorous research on the complexity of written language and scientific writing has been conducted for the past three decades (Banks, 2003, 2005; Halliday, 1985b; Halliday, 1993a, 1993b, 1993d, 1998, 2004; Martin, 1993a; Martin, 1993b; Martin, 1993d; Ravelli, 1999). In fact, SFL has produced well-established measures towards linguistic complexity despite its real complexity in the social contexts. Looking at complexity through the lens of SFL provides useful insights into language and the fuller picture of it regarding how complexity works and why it works in the way it does at the levels of grammar, discourse and context. In addition, it does help explain the functions of language in the social contexts (Martin \& Rose, 2003). One of the main contributions of this study in the field of SFL research is that it expands prior research by examining complexity of language in a set of international textbooks used for TEFL within the current context that research on EFL textbooks in light of SFL in developing countries has still been under- 
investigated. It might be assumed that linguistic complexity increase in accordance to the book levels, this study using the SFL framework reinforced this assumption.

Further, while a substantial body of research has been conducted to examine the language of science in history, and scientific texts in school textbooks in Australia and internationally, no study has yet been carried out to examine texts in science and non-science domains in EFL textbooks used in teaching general English for second language learners (L2Ls). Therefore, this research expands prior work on scientific texts when it looked at the language of science-related texts in EFL textbooks to provide implications for textbook choice and writing to the language education curriculum in the developing world with the particular context of teaching English in Vietnam.

This research is worthwhile as recent research on linguistic complexity in SLL literature seems to neglect the issue of how complexity is realised in international textbooks from Halliday's functional grammar approach (see Benedikt \& Bernd, 2009, 2012; Dahl, 2008; Fred, 2009; Hendrikse \& Van Zweel, 2010; Juola, 2008; Kuiken \& Vedder, 2007; Miestamo, 2009; Ortega, 2003). Our research has filled that gap and confirmed that SFL is a good model to examine linguistic complexity, as it allows us to look at complexity at three levels and social functions of language. Examining complexity from the SFL perspective also helps identify the interrelated relationships among linguistic features characterising complexity; thus, it provides appropriate and convincing explanations of complexity. Further research on linguistic complexity in EFL textbooks and in second language acquisition (SLA) can be greatly expanded based on this study.

\subsubsection{Educational significance in the context of Vietnam}

Practically, this study has important educational and contextual meaning as shown in the analysis of the EFL textbooks used in TEFL in Vietnam. Functional grammar can be seen as one of the most appliable linguistic approaches to language teaching, and has been employed as the theoretical framework in the Australian Curriculum: English. While SFL has been applied in language and literacy teaching 
for the past decades in Australia and internationally, the use of this approach to language teaching is still limited in the Vietnamese context. Being the first thesis investigating complexity of EFL textbooks used in Vietnam, one of the attempts of the thesis was to describe and identify how complexity is realised from different perspectives (see Chapter 2) and from the functional grammar perspective (see Chapter 3). An understanding of the linguistic concepts characterising complexity of language not only provides useful insights into the nature of language, but also provides practical implications to the English language teaching and learning, teacher education, textbook selection and writing, and curriculum design in the Vietnamese context and other countries which have the similar contextual matters in ELT. Therefore, the findings of this research not only theoretically contribute to the current body of knowledge, but also have important educational significance in the context of teaching of English in Vietnam for teachers, educators and policy makers in English language teaching, textbook selection and writing, and curriculum design which will be discussed in greater detail in the following sections.

\subsubsection{Significance of the research to TEFL in the Vietnamese context}

Firstly, the six concepts charactering complexity, namely lexical density, grammatical intricacy, nominalisation, grammatical metaphor, thematic structure, and hierarchies of periodicity have significant implications for the English language education, especially in teaching English writing and reading skills. The gradual increase in the complexity of language according to the rising levels advanced from elementary to intermediate indicate that learners need to be equipped with complex language when their levels of proficiency advance. An applicable approach is to teach students how to deploy the appropriate linguistic resources such as nominalisation, grammatical metaphor, and lexical items in their writings. Also, it is necessary to guide students how to pack the ideational meaning by adopting the taxis and logico-semantic types, and how to use different types of themes to create coherent texts. In doing so, teachers are providing them with explicit knowledge about language, and the linguistic toolkits so that they can be aware of when they come to writing and reading. The concept of hierarchies of periodicity is crucial in teaching students how to construct the organisation of their essays and develop 
their essays in the logical and coherent ways. How to include linguistic features in appropriate stages of text types is also important. The findings can be a guide to teach students about academic writing discourse such as explanation and report. Some specific examples about the application of the investigated linguistic concepts are provided as follows.

- Lexical density, nominalisation and grammatical metaphor are typical features of academic writing. Adopting grammatical metaphor and nominalisation can produce lexically dense style and formality in writing. For example, instead of writing a long sentence "People must look after the environment because if they don't we will lose resources that are already becoming scarce." With nominalisation involving grammatical metaphor "care" and "loss", the ideational meaning of the message is densely packed and conveyed more but in a simple sentence structure such as "Environmental care will prevent the loss of scarce resources." As such, the employment of nominalisation and grammatical metaphor helps increase the density of the text and makes the text less intricate. Another example can be seen in Examples 8.1 and 8.2 cited in Halliday (1985b, p.79).

\section{Example 8.1}

|| You can control the trains this way || and if you do that || you can be quite sure // that they'll be able to run more safely and more quickly than they would otherwise // no matter how bad the weather gets / /

\section{Example 8.2}

The use of this method of control unquestionably leads to safer and faster training running in the most adverse.

Theme is the departure of the message, predicting what will come next in the rest of the clause. Understanding different types of theme will give the learners linguistic choice to make a focus or emphasise what needs for the orientation of the text. As seen in Examples 8.3 and 8.4, unmarked theme in Example 8.3 focuses on 
the participants, while the unmarked theme in Example 8.4 focuses on the circumstance of the text.

\section{Example 8.3}

She \# was talking about her research.

\section{Example 8.4}

On the third of November, \# she was talking about her research.

- In teaching reading skills, as heavily nominalised texts with metaphorical styles and technicality can result in difficulty in comprehension, unpacking nominalisation and grammatical metaphor is good pedagogic strategies to help students make sense of the texts better, and understand the texts in depth. Example 8.5 is an illustration of this.

\section{Example 8.5}

Vaporisation is followed by condensation.

Example 8.5 involves nominalisation which is also grammatical metaphor with the use of "condensation" and "vaporisation". This sentence can be difficult for primary or low-intermediate students to comprehend. To explain this to students, teacher can unpack those metaphors in another way such as "When you heat a liquid, it can change into gas." In the same way, the sentence "Their inability to solve these problems may lead to kinds of behaviour that are totally foreign to them" can be difficult for students to understand" due to the grammatical metaphor of "inability" and "behaviour". Unpacking these metaphorical expressions into the congruent forms can make the text easier to read, for instance "Because they can't solve it themselves, they behave in ways that are totally foreign to them."

To summarise, understanding the usefulness of these linguistic features, Vietnamese educators and teachers of EFL can adopt them to some extent to teaching their students practical knowledge relevant to their specific classroom contexts and appropriate with the curriculum. 


\subsubsection{Significance of the research to teacher training in Vietnam}

In order to teach students linguistic concepts in SFL, introducing teachers knowledge about language, and feedback using SFL principles is essential. Research shows that when students' language proficiency advances, they will be able to use linguistic resources such as nominalisation grammatical metaphor more effectively in the tertiary level (Devo, 2012). It can be argued that an explicit knowledge of the language would be useful for L2Ls so that they can be aware of linguistic resources in writing. An action research has been carried out to train English tutors shared knowledge in SFL to providing feedback for student's writing (Mahboob, Dreyfus, Humphrey, \& Martin, 2010). This approach can be adopted to apply in the Vietnamese context. First of all, teachers who play the direct roles in teaching English should be trained and equipped with knowledge about language so that they can draw on a theoretical framework to talk about language and explain to student what they need to improve in their writing with specific feedback.

After training teacher knowledge about language, teaching them how to provide effective feedback is another important step, as effective feedback can help students improve their performance. Feedback providing has been a focus for research for decades, however, while feedback is traditionally given at the level of lexico-grammar which focuses on word choice and sentence structure, the suggestion in this study is that in terms of the functional grammar approach, feedback should be given at the levels of discourse semantics and social purposes (Mahboob et al., 2010). In their recent project entitled the scaffolding Literacy in Adult and Tertiary Environments (SLATE) project, Mahboob et al. (2010) provide a useful model of feedback which takes the applicable linguistic approach into account. Up to present, this is the first and only project in suggesting ways of giving feedback on students' writing employing SFL as the theoretical framework.

The $3 \times 3$ toolkit (Humphrey, Martin, Dreyfus, \& Mahboob, 2010) is a framework to provide feedback to student writing which takes the three metafunctions of language and three strata of language into account. This model is designed to suit the specific purpose of the SLATE project. It has been successfully applied in this SLATE project, and is now used in some typical schools in Australia. This can be 
adopted to the context of TEFL in Vietnam. Teachers can rely on this framework to evaluate students' persuasive writings or slightly adjust to meet their teaching purposes relevant to their specific contexts. The $3 \times 3$ : A framework for describing linguistic resources of student writing in the academic domain (Humphrey et al., 2010, p. 188) is provided in Appendix 8 as an example of how feedback can be given at the level of three metafunctions and three levels of language from the SFL perspective.

\subsubsection{Significance of the research to textbook selection and writing in Vietnam}

The results of this study provide practical and useful guides to text choice, textbook selection and writing.

- As the complexity of textbook texts corresponded to their levels from elementary to intermediate, this correspondence can be used as a good guideline for writing and selecting textbooks. Textbook writing should include authentic texts, preparing students from everyday global language to specialised global English to be successful in the field-specific areas in further education.

- As the advanced book level did not demonstrate the highest level of complexity among the four books in the chosen book series, it is suggested that to choose appropriate texts or textbooks, Vietnamese educators and teachers of English should examine linguistic features, fields, text types of specific texts in addition to the intended levels proposed by textbook writers.

- While authentic scientific texts are usually complex and difficulty to read, in the chosen books, science-related texts and non-science ones within the same book level did not display the significant differences in terms of complexity. This result can be expected at the low level of textbooks. Nevertheless, higher level of textbooks should reflect the differences 
between these two fields to prepare students to acquire technicality, and specialised field-specific language to advance in their study.

\subsubsection{Significance of the research to English curriculum design in Vietnam}

For many decades, teaching English in Vietnam heavily relies on the traditional grammar approach which focuses on syntax which deals with phrasal and sentence structures. This leads to tedious grammar lessons that most students feel hard to absorb. Students are given grammar lessons and practices at the level of sentence by using correct grammar rules with limited understanding of the use of grammatical structure in real contexts. Similarly, teachers provide true-false or correct-incorrect kind of feedback to the students' exercises or homework. It can be said that teaching grammar in Vietnam has been carried out without much consideration of contexts. SFL is the linguistic theory which views language in the context of use. It considers how specific linguistic features can be used to construct appropriate text types to achieve communicative purposes in social contexts. As such, SFL provides a practical theoretical and pedagogical model to the English curriculum design. Incorporating functional grammar in the language education programs in university will not only help the teaching of grammar become lively with reference to real world texts and contexts, but also help learners to become efficient at using language for specific communicative goals in social contexts.

\subsection{Research limitations}

This research follows a mixed research methods approach with a major emphasis on quantitative research design which mainly deals with statistics. Statistics is the fundamental element in the process of description, visualisation, evaluation and interpretation of quantitative results in linguistics (Holtz, 2011). However, like many other research methodologies, it has some limitations in addition to its advantages. Therefore, to enhance the quality of research, the reliability and the validity of the results, qualitative approach was also employed to conducting text analysis to confirm some general trends revealed by the quantitative results. While this 
research is aligned with functional linguists' studies when confirming the relationship among nominalisation, grammatical metaphor and lexical density, and expands prior research when pointing out four possibilities regarding the relationship between density and intricacy, this study did not find out if the employment of nominalisation and grammatical metaphor entails low intricacy. This could be a question for further studies. Moreover, lexical variation also known as lexical diversity also contributes to the density of the text. Nevertheless, within the scope of this study, this phenomenon has not been investigated. The occurrences of high-frequency lexical items and low-frequency lexical items have not yet been explored in this study. Regarding grammatical metaphor, for the purpose of the research, only ideational metaphor involved nominalised process was examined. Interpersonal metaphor and logical metaphor have not been considered in this research. With respect to hierarchy of periodicity analysis, this study investigated four full texts to identify some overall trends about complexity. Further qualitative and quantitative analysis on this would be helpful to draw a firm trends revealed in this study. Lastly, the study looked at the report and explanation texts in science and non-science fields. Thus, the findings and conclusions in this thesis should be understood within this scope. Despite these inevitable limitations, this research has significant contributions as discussed earlier, as research on EFL textbooks in general and in the context of Vietnam has neglected the issue of complexity from the functional grammar perspective. All the limitations and unsolved matters of the present research can be interesting questions for future studies.

\subsection{Recommendations for further studies}

This study investigated the complexity of written language in reading comprehension texts in EFL textbooks commonly used in language education programs in Vietnam. From the Hallidayan perspective, six linguistic concepts namely lexical density, grammatical intricacy, nominalisation, grammatical metaphor, thematic structure and hierarchies of periodicity are the main focus of the investigation. The study examined the complexity of language in relation to genre and fields of the texts. The research has filled a gap in literature by examining 
linguistic complexity concept in SLL which has not received much research attention in the developing world. However, as stated by Halliday (2008), linguistic complexity is a complex notion. It is a multi-facet phenomenon; thus, what the study has achieved and answered can be seen as an aspect of this complex concept. There are still plenty of rooms for further research investigation which in this study, the researcher suggests a few as follows.

- Investigating high frequency lexical items and low frequency lexical items to obtain the broader view on lexical density.

- Lexical diversity known as lexical variation also contribute to the text complexity, further research in this area is also needed.

- This study did not reveal the relationship between grammatical intricacy and grammatical metaphor, grammatical intricacy and nominalisation, future research is needed to discover these correlations.

- Nominalisation analysis in this study was conducted by token analysis, the investigation of nominalisation by type analysis to make the conclusion about the common nominalisation at a particular level of book, or field will give more insight into textbook writing, and understanding of texts across levels.

- Abstraction and technicality in this study was not investigated in depth, further studies should be done to address this matter.

- With respect to grammatical metaphor, only experiential metaphor involving nominalised process was examined. However, interpersonal metaphor, logical metaphor, and textual metaphor as discussed by Martin (1992) deserve more research attention to provide a deeper understanding of the complexity of language. Also, dead metaphor was not included in this study, further research should discuss live metaphor and dead metaphor.

- The relationship between technicality and lexical density needs further explorations. 
- Theme progression is also needed investigation alongside with thematic structure.

- In-depth investigations of the text hierarchies of periodicity with a larger corpus of texts would be necessary to make a strong conclusion about some general trends proposed in the thesis.

- This study just looks at complexity of two text types (explanation and report), further research can investigate the complexity of different genres such as discussion, exposition, historical recount, and so on.

- Sentence structure such as simple sentences, compound sentence, and complex sentence can also contribute to the complexity of the texts. Examining these structures can provide a greater perspective on complexity.

- Transitivity realised by six process types were not investigated in depth in this study, future research can focus on this matter.

- Action research can be done to investigate the application of the linguistic complexity concepts to language teaching and learning, textbook writing and curriculum design.

- Investigating teachers and students views and perceptions on complexity might also give more insight into this complex notion.

- Last but not least, the relationship between linguistic complexity and student's level of proficiency is an interesting question for further studies.

\subsection{Researcher's reflection on research achievements}

The researcher's reflections on the PhD journey in terms of her achievements will help understand her own research journey and how it relates to the completion of the thesis, and contributes to the meaning of the research journey. As this section reflects on the researcher's achievements and thoughts during her PhD study, the personal pronoun ' $I$ ' will be used through this part to refer to the researcher. 
On this research journey, I have been snowed with a number of mixed feelings including the excitements of being exposed to the new horizons of knowledge, the inspirations of the fascinating SFL linguistic theory, the admiration of the supervisors' wealth of knowledge and expertise, the gratitude of being taught about linguistics and research by supervisors and mentors, and the overwhelming feelings caused by the richness of the SFL theory and the broad horizons of research. Through this challenging but rewarding research journey, my personal, academic, professional, intellectual and social abilities have been strengthened and greatly developed.

Personally, I have found myself more mature through this long, tough but very exciting journey. My personal development has been demonstrated in the ability to adapt quickly to the new study and living environments. Embarking on the PhD journey at one of the world-class research universities, I was extremely keen to learn about its system and rules so that I could endeavour to meet its high standard. In my first year of candidature, I took part in a number of training courses offered for research students at UTas such as research writing workshops, quantitative and qualitative data analysis using research tools SPSS and NVivo, literature search, EndNote referencing system, communication skills, effective speaking, and so on. These programs have greatly enhanced my knowledge and provided me useful insights into the research. I have been extremely keen to work with my supervisors, following their advice and guidance. I have found myself deeply admire my supervisors' expertise, dedication, warm-heartedness and friendliness. This has enhanced my wonderful experience as a PhD candidate. Through this journey, I have also learnt time management skills in juggling life and research, and organisational skills in effectively prioritising tasks in a professional manner.

Completion of this thesis has been considered as my greatest academic achievement with the support of my supervisors and my family. Many concepts and chapters in the thesis have been written in conceptual and research papers, and book chapters in which some have been published, and others are now in press and in the reviewing process. While universities in Vietnam have a great emphasis on teaching and seem to neglect research, research writing skills I have learnt through 
writing this thesis and publications have prepared me to further enter the academic fields in the future. During the process of engaging in research, I have also presented academic papers at a number of national and international conferences in Australia. For example, the Annual National Conference of the Australian Systemic Functional Linguistics Association (ASFLA) in 2013 and 2014, the 17th World Congress of the International Association of Applied Linguistics (AILA), the UTas Biennial Postgraduate Conference, and the Annual National Conference of the Association for Qualitative Research (AQR). These active academic involvements have been beneficial in deepening my knowledge in the field, developing my critical thinking in research, my public speaking skill, and fostering my passion in academic activities.

While I have greatly enjoyed the PhD life with both its offerings and obstacles, I have had several wonderful chances to work for the Faculty of Education at UTas. I have been involved as a research assistant in another project and as a tutor in a literacy unit which have enhanced my research and academic expertise as well as developed my professionalism. I have gained valuable work experiences which will greatly benefit my future profession. In addition, presenting at various major conferences has trained me to be professional in giving talks to suit the target audience, either specialised or general listeners.

Needless to say, the richness of the SFL theory has intellectually stimulated my thinking, and the passion for learning knowledge about language to an enormous extent from the very beginning stages of research to the present. I have been learning about functional grammar with joy and inspirations. I really admire the brilliant works of people in this area which my research has benefited from. I am fortunate enough to have a chance to be taught about linguistics and research by my supervisors and mentors, who are well-known academics. I believe these intellectual inspirations will be guiding me to many future research possibilities through my journey ahead.

Social engagement is one of my long-life commitments. During the past three years, I have devoted my time to work as a UTas Ambassador, a museum guide, and a 
volunteer at the Australia Red Cross. Through these volunteering activities, I have found the real meaning of life when giving time to helping out people without the need of being paid, acknowledged or praised. I have also joined several English speaking clubs with international and local people, and gatherings with my research fellows and my own community. These community involvements have developed my social communication skills, strengthened the social relationships and contributed to the meaning of the PhD journey.

To sum up, through this research journey, I have gained deeper understanding of the SFL theory and research principles. I have developed a number of valuable skills such as writing skills, analysis skills, presentation skills, and publication writing skills. Other soft skills have also been strengthened such as time managements, organisation, negotiation and communication skills. Through this meaningful research journey, I have matured, academically, professionally, intellectually, and socially.

\subsection{Conclusion}

This thesis ended with this concluding chapter presenting an important summary of key research findings, research significance, limitations, recommendations and the researcher's personal reflection on the research journey. This study has addressed a gap in research and provided an answer to a research issue. However, this is not really an end, as now new questions emerge, and this opens windows to many other research possibilities in the future. Through this exciting yet challenging journey, the researcher's abilities have been enhanced in many different aspects. In the moments of writing these last sentences to conclude the thesis, the researcher has felt a strong sense of being deeply indebted to all of those who have helped make this journey a rewarding and meaningful one. 


\section{References}

Anderson, N. J. (2003a). Active skills for reading, Book 1. Massachusetts: Thomson.

Anderson, N. J. (2003b). Active skills for reading, Book 2. Massachusetts: Thomson.

Anderson, N. J. (2003c). Active skills for reading, Book 3. Massachusetts: Thomson.

Anderson, N. J. (2003d). Active skills for reading, Book 4. Massachusetts: Thomson.

Ary, D., Jacobs, L. C., Sorensen, C. K., \& Walker, D. A. (2014). Introduction to research in education (9th ed.). Wadsworth: Cengage Learning.

Banks, D. (2003). The evolution of grammatical metaphor in scientific writing. In A. Simon-Vandenbergen, M. Taverniers \& L. Ravelli (Eds.), Grammatical metaphor: Views from systemic functional linguistics (pp. 127-147). Amsterdam: John Benjamins.

Banks, D. (2005). On the historical origins of nominalized process in scientific text. English for Specific Purpose(24), 347-357.

Beaman, K. (1984). Coordination and subordination revisited: Syntactic complexity in spoken and written narrative discourse. In D. Tannen (Ed.), Coherence in spoken and written discourse (pp. 45-80). Norwood: Ablex.

Belinda, C. C. (2007). The language of business studies lectures: A corpus-assisted analysis. Amsterdam: John Benjamins.

Benedikt, S., \& Bernd, K. (2009). Between simplification and complexification: Nonstandard varieties of English around the world. In G. Sampson, D. Gil \& P. Trudgill (Eds.), Language complexity as an evolving variable (pp. 64-79). Oxford: Oxford University Press.

Benedikt, S., \& Bernd, K. (2012). Introduction: Linguistic complexity second language, acquisition, indigenization, contact. Berlin: De Gruyter.

Berry, M. (1995). Thematic options and success in writing. In M. Ghadessy (Ed.), Thematic development in English texts (pp. 55-84). London: Pinter.

Besser, D., Stone, G., \& Luan, N. (1999). Textbooks and teaching: A lesson from students. Jounalism of Mass Communication Educator, 53(4), 4-17.

Billig, M. (2008). The language of critical discourse analysis: The case of nominalization. Discourse \& Society, 19(6), 783-800. doi: 10.1177/0957926508095894

Bloor, T., \& Bloor, M. (1995). The functional analysis of English: A Hallidayan approach. London: Edward Arnold.

Booth, W. C. (1961). The rhetoric of fiction. Chicago: University of Chicago Press.

Brookes, D. T., \& Etkina, E. (2007). Using conceptual metaphor and functional grammar to explore how language used in physics affects student learning. 
Physical Review Special Topics - Physics Education Research, 3(1), 010105. doi: 10.1103/PhysRevSTPER.3.010105

Burns, R. B. (1997). Introduction to research methods (3rd ed.). Melbourne: Longman.

Butt, D., Rhondda, F., Sue, S., \& Collin, Y. (2000). Using functional grammar: An explorer's guide. Sydney: National centre for English language teaching and research.

Cao, X. H. (1991). Vietnamese: An introduction to functional grammar. Hanoi: Education Publishing House.

Carter, R., \& MacCarthy, M. ( 2006). Cambridge grammar of English. Cambridge: Cambridge University Press.

Castello, E. (2008). Text complexity and reading comprehension tests. Bern: Peter Lang.

Cheryl, A. E. (1995). The relationship of lexical proficiency to the quality of ESL compositions. Journal of Second Language Writing, 4(2), 139-155.

Chomsky, N. (1957). Syntactic structures. Hague: Mouton.

Chomsky, N. (1965). Aspects of the theory of syntax. Cambridge: MIT Press.

Christie, F., \& Derewianka, B. M. (2008). School discourse: Learning to write across the years of schooling (1 ed.). London: Continuum.

Chung, T. Q. (2010). Evaluating EFL materials in Vietnamese state schools: In search of a handy survey questionnaire (pp. 96-103). Hanoi: Education Publishing House.

Clatworthy, M., \& Jones, M. J. (2001). The effect of thematic structure on the variability of annual report readability. Accounting, Auditing and Accountability Journal, 14(3), 311-326.

Cloran, C. (1995). Defining and relating text segments: Subject and Theme in discourse. In R. Hasan \& P. H. Fries (Eds.), On Subject and Theme: A Discourse Functional Perspective (pp. 361-403). Amsterdam: John Benjamins.

Crystal, D. (1971). Linguistics. Lisbon: Dom Quixote.

Dahl, Ö. (2004). The growth and maintenance of linguistic complexity. Amsterdam: John Benjamins.

Dahl, Ö. (2008). Grammatical resources and linguistic complexity: Siriono as a language without NP coordination. In M. Matti, S. Kaius \& K. Fred (Eds.), Language complexity: Typology, contact, change (pp. 153-164). Amsterdam: John Benjamins.

Dahl, Ö. (2009). Testing the assumption of complexity invariance: The case of Elfdalian and Swedish. In G. Sampson, D. Gil \& P. Trudgill (Eds.), Language complexity as an evolving variable (pp. 50-63). Oxford: Oxford University Press. 
Dang, T. T. T. (2012). An investigation into Theme - Rheme structure in English and Vietnamese poetry (M.A), The College of Foreign Languages, University of Danang

David, T. B., \& Eugenia, E. (2007). Using conceptual metaphor and functional grammar to explore how language used in physics affects student learning. Physical Review Special Topics - Physics Education Research, 3(1), 1-16. doi: 10.1103/PhysRevSTPER.3.010105.

Derewianka, B. (1998). A Grammar companion for primary teachers. Newtown, NSW: Primary English Teaching Association.

Derewianka, B. (2003). Grammatical metaphor in the transition to adolescence In A. Simon-Vandenbergen, M. Taverniers \& L. Ravelli (Eds.), Grammatical metaphor: Views from systemic functional linguistics (pp. 185-219). Amsterdam: John Benjamins.

Devo, Y. D. (2012). Developing an approach to teaching grammatical metaphor to ESL writers. In J. S. Knox (Ed.), Papers from the 39th International Systemic Functional Congress (Vol. To boldly proceed, pp. 45-50). Sydney: 39th ISFC Organising Committee.

Diep, Q. B. (2005). Vietnamese grammar. Hanoi: Education Publisher.

Dijk, T. A. V. (2008). Critical discourse analysis and nominalization: Problem or pseudo-problem. Discourse Society, 19(6), 821-828. doi: 10.1177/0957926508095897

Distefano, P., \& Valencia, S. (1980). The effects of syntactic maturity on comprehension of graded reading passages. Journal of Educational Research, 73(5), 247-251.

Droop, M., \& Verhoeven, L. (1998). Background knowledge, linguistic complexity and second language reading comprehension. Journal of Literacy Research, $30(2), 253-271$.

Ebrahimi, S. F., \& Khedri, M. (2012). The importance of thematic structure in students' writing cohesion. Language In India, 12(4), 52-59.

Ebrahimi, S. J. (2012). Interpersonal theme in reading comprehension texts. Language In India, 12(5), 50.

Edwin, W. (1996). Thematic structure in syntax. Journal of Linguistics, 32(1), 221226.

Eggins, S. (1994). An introduction to systemic functional linguistics. London: Pinter.

Fairclough, N. (2008). The language of critical discourse analysis: Reply to Michael Billig. Discourse Society, 19(6), 811-819. doi: 10.1177/0957926508095896

Francis, G. (1989). Thematic selection and distribution in written discourse. Word, 40(1-2), 201-222.

Francis, G. (1990). Theme in the daily press. Occasional papers in Systemic Linguistics, 4, 51-87. 
Fred, K. (2009). Origin and maintenance of clausal embedded complexity. In G. Sampson, D. Gil \& P. Trudgill (Eds.), Language complexity as an evolving variable (pp. 192-202). Oxford: Oxford University Press.

Fries, P. H. (1992). Exploring Theme: Problems for research. Occasional Papers in Systemic Linguistics 6, 45-60.

Fries, P. H. (1994). On Theme, Rheme and discourse goals In M.Coulthard (Ed.), Advances in written text analysis (pp. 229-249). London: Routledge.

Fries, P. H. (1995). Patterns of information in initial position in English. In P. H. Fries \& M. Gregory (Eds.), Discourse in society: Systemic Functional Perspectives (pp. 47-66). Norwood New Jersey: Ablex.

Fries, P. H. (2002). The flow of information in a written text. In P. H. Fries, M. Cummings, D. Lockwood \& W. Spruiell (Eds.), Relations and functions within and around Language (pp. 117-155). London: Continuum.

Fries, P. H., \& Francis, G. (1992). Exploring Theme: Problems for research. Occasional papers in Systemic Linguistics, 6, 45-59.

Ghadessy, M. (1995). Thematic development and its relationship to registers and genres. In M. Ghadessy (Ed.), Thematic development in English texts (pp. 129-146). London: Pinter.

Givón, T. (1991). Markedness in grammar: Distributional, communicative and cognitive correlates of syntactic structure. Studies in language, 15(2), 335370.

Givón, T. (1995). Functionalism and grammar. Amsterdam: John Benjamins.

Haigang, L. (2011). A contrastive analysis of thematic progression patterns of English and Chinese consecutive interpretation texts. Theory and Practice in Language Studies, 1(6), 671-675.

Halliday, M. A. K. (1978). Language as social semiotic: the social interpretation of Inguage and meaning. London: Arnold.

Halliday, M. A. K. (1985a). An introduction to functional grammar. London: Arnold.

Halliday, M. A. K. (1985b). Spoken and written language. Deakin: Deakin University.

Halliday, M. A. K. (1993a). The analysis of scientific texts in English and Chinese. In M. A. K. Halliday \& J. R. Martin (Eds.), Writing science: Literacy and discourse power (pp. 124-132). Washington, D.C: Falmer.

Halliday, M. A. K. (1993b). The construction of knowledge and value in the grammar of scientific discourse: Charles Darwin's the origin of the species. In M. A. K. Halliday \& J. R. Martin (Eds.), Writing science: Literacy and discourse power (pp. 86-105). Washington, D.C: Falmer.

Halliday, M. A. K. (1993c). On the language of physical science. In M. A. K. Halliday \& J. R. Martin (Eds.), Writing science: Literacy and discourse power (pp. 54-68). Washington, D.C: Falmer.

Halliday, M. A. K. (1993d). Some grammatical problems in scientific English. In M. A. K. Halliday \& J. R. Martin (Eds.), Writing science: Literacy and discursive power (pp. 69-85). Washington, D.C: Falmer. 
Halliday, M. A. K. (1994). An introduction to functional grammar (2nd ed.). London: Arnold.

Halliday, M. A. K. (1995). On the grammar of scientific English. In J. J. Webster (Ed.), The language of science (Vol. 5, pp. 181-198). London: Continuum.

Halliday, M. A. K. (1998). Things and relations: Regrammaticising experience as technical language. In J.R.Martin \& R.Veel (Eds.), Reading science: Critical and functional perspectives on discourses of science (pp. 185-235). London: Routledge.

Halliday, M. A. K. (2004). The language of science. London: Continuum.

Halliday, M. A. K. (2008). Complementarities in language. Beijing: The Commercial Press.

Halliday, M. A. K., \& Martin, J. R. (1993). Writing science: Literacy and discursive power. Washington, D.C: Palmer.

Halliday, M. A. K., \& Matthiessen, C. M. I. M. (1999a). Construing experience through meaning: A language-based approach to cognition. London and New York: Cassell.

Halliday, M. A. K., \& Matthiessen, C. M. I. M. (1999b). Construing experience through meaning: A language-based aproach to cognition. London and New York: Cassell.

Halliday, M. A. K., \& Matthiessen, C. M. I. M. (2004). An introduction to functional grammar (3rd ed.). London: Arnold.

Halliday, M. A. K., \& Matthiessen, C. M. I. M. (2014). Halliday's introduction to functional grammar (4th ed.). London: Routledge

Hartnett, C. G. (2004). What should we teach about the paradoxes of English nominalization? In A. F. Joseph (Ed.), Language, education and discourse: Functional approaches (pp. 174-190). London: Cornwall.

Haspelmath, M. (2001). Word classes and parts of speech. International Encyclopedia of the Social and Behavioral Sciences, 16538-16545.

Hendrikse, R., \& Van Zweel, H. ( 2010). A phylogenetic and cognitive perspective on linguistic complexity. Southern African Linguistics \& Applied Language Studies, 28(4), 409-422. doi: 10.2989/16073614.2010.548017

Henrichs, L. F. (2010). Academic language in early childhood interactions: A longitudinal study of 3- to 6-year-old Dutch monolingual children Academic language in early childhood interactions (pp. 45-86). Amsterdam: The University of Amsterdam.

Hilary, N. (2001). A corpus-based analysis of academic lectures across disciplines. In J. Cotterill \& A. Ife (Eds.), Language across boundaries (pp. 201-218). London: BAAL in association with Continuum Press.

Ho, V. (2010). Grammatical metaphor in request E-mail discourse. HKBU Papers in Applied Language Studies, 14, 1-24.

Hoang, V. V. (1997). An experiential grammar of the Vietnamese clause (Ph.D thesis), Macquarie University, Sydney. 
Hoang, V. V. (2005). The meaning and structure of a science fiction story: A systemic functional analysis. VNU Journal of Science, Foreign Languages, 2, 28-45.

Hoang, V. V. (2009). The current situation and issues of the teaching of English in Vietnam. 立命館言語文化研究, 22(1), 7-18.

Holtz, M. (2011). Lexico-grammatical properties of abstracts and research articles. A corpus-based study of scientific discourse from multiple disciplines Retrieved 10th December, 2012, from http://www.isfla.org/Systemics/Print/Theses.html

Huddleston, R. D. (1984). Introduction to the grammar of English. Cambridge: Cambridge University Press.

Hudson, R. A. (1971). English complex sentences: An introduction to systemic grammar. Amsterdam: North-Holland Pub. Co.

Humphrey, S., Droga, L., \& Feez, S. (2012). Grammar and meaning (new ed.). Newtown, NSW: Primary English Teaching Association Australia.

Humphrey, S., Martin, J. R., Dreyfus, S., \& Mahboob, A. (2010). The 3x3: Setting up a linguistic toolkit for teaching academic writing. In A. Mahboob \& N. Knight (Eds.), Appliable Linguistics (pp. 185-199). London: Continuum.

Hunt, K. (1970). Syntactic maturity in schoolchildren and adults. Monographs of the society for research in child development, 35(1), 1-61.

Irina, P. (2011a). Systemic Functional Analysis of Elementary School Language Arts Textbooks. (M.A), Marshall University.

Irina, P. (2011b). Systemic functional analysis of elementary school language arts textbooks. (M.A), Marshall University, Hungtington.

Janelle, S. C. (2011). Comprehend to comprehension: Teaching nominalisation to secondary ELD teachers. (M.A), University of California, Berkeley.

Jeremy, N., \& Timothy, B. (2008). Interpreting compound nominalisations. Paper presented at the LREC workshop towards a shared task for multiword expressions, Morocco.

John, R., \& Paul, N. (2002). An investigation of the lexical dimension of the IELTS speaking test. IELTS Research Reports, 6, 207-231.

Juola, P. (2008). Assessing linguistic complexity. In M. Miestamo, K. Sinnemäki \& F. Karlsson (Eds.), Language complexity: Typology, contact, change (pp. 89108). Amsterdam: John Benjamins

Krathwohl, D. R. (1993). Methods of educational and social science research: An integrated approach. London: Longman.

Kuiken, F., \& Vedder, I. (2007). Task complexity and measures of linguistic performance in L2 writing. International Review of Applied Linguistics in Language Teaching (IRAL), 45(3), 261-284. doi: 10.1515/iral.2007.012

Kusters, W. (2008). Complexity in linguistic theory, language learning and language change. In M. Miestamo, K. Sinnemäki \& F. Karlsson (Eds.), Language complexity: Typology, contact, change (pp. 3-22). Amsterdam: John Benjamins 
Lê, T., \& Wang, X. (2008). Systemic functional linguistics and critical discourse analysis. In T. Le, Q. Le \& M. Short (Eds.), Critical discourse analysis: An interdisciplinary perspective (pp. 25-33). New York: Nova Science Publishers, Inc.

Lê, T., Yue, Y., \& Lê, Q. (2010). Linguistic complexity and its relation to language and literacy education. In T. Le, Q. Le \& M. Short (Eds.), Language and literacy education in a challenging world (pp. 23-32). New York: Nova Science Publishers, Inc.

Linnarud, M., \& Thoursie, S. (2008). English and German in Swedish classrooms: Writing in the two languages compared. Nordic Journal of English Studies, 7(2), 75-98.

Liu, J., \& Lê, T. (2011). The influence of theme theory in the assessment of English compositions. In T. Lê, Q. Lê \& M. Short (Eds.), Language and literacy education in a challenging world (pp. 33-44). New York: Nova Science Publishers.

Lock, G. (1996). Functional English grammar: An introduction for second language teachers. Cambridge: Cambridge Language Education.

Lock, G., \& Jones, R. (2011). Functional grammar in the ESL classroom: Noticing, exploring and practicing. Macmillan: Palgrave Macmillan.

Lukin, A. (2013). Embedded Clause: A guide for the confused but conscientious. Sydney: Macquarie University.

Lyons, J. (1968). Introduction to theoretical linguistics. London: Cambridge University Press.

Lyons, J. (1970). Chomsky. London: Viking Press.

Mahboob, A. (2014a). Epilogue: Understanding language variation: Implications for EIL pedagogy. In R. Marlina \& R. A. Giri (Eds.), The pedagogy of English as an international language: Perspectives from scholars, teachers, and students. Switzerland: Springer.

Mahboob, A. (2014b). Epilogue: Understanding language variation: Implications for EIL pedagogy. In R. Marlina \& R. A. Giri (Eds.), The pedagogy of English as an international language: Perspectives from scholars, teachers, and students (pp. 257-265). Switzerland: Springer.

Mahboob, A., Dreyfus, S., Humphrey, S., \& Martin, J. R. (2010). Appliable linguistics and English language teaching: The Scafffolding Literacy in Adult and Tertiary Enviroment (SLATE) Project. In A. Mahboob \& N. Knight (Eds.), Appliable Linguistics. London: Continuum.

Malton, K. (2014). Knowledge and knowers: Towards a realist sociology of education. London: Routledge.

Marianna, R., \& Pankova. (2010). Toward Mastering the Discourses of Reasoning: Use of Grammatical Metaphor at Advanced Levels of Foreign Language Acquisition. The Modern Language Journal, 94(2), 181-197. 
Martin, J. R. (1989). Factual writing: Exploring and challenging social reality (2nd ed ed.). Oxford: Oxford University Press.

Martin, J. R. (1992b). English Text: System and Structure. Amsterdam: John Benjamins.

Martin, J. R. (1993a). Life as a noun: Arresting the universe in science and humanities. In M. A. K. Halliday \& J. R. Martin (Eds.), Writing science: Literacy and discursive power (pp. 221-267). Washington, D.C: Falmer.

Martin, J. R. (1993b). Literacy in science: Learning to handle text as technology. In M. A. K. Halliday \& J. R. Martin (Eds.), Writing science: Literacy and discourse power (pp. 166-202). Washington, D.C: Falmer.

Martin, J. R. (1993c). Technicality and abstraction: Language for the creation of specilizedspecialized texts. In M. A. K. Halliday \& J. R. Martin (Eds.), Writing science: Literacy and discourse power (pp. 203-220). Washington, D.C: Falmer.

Martin, J. R. (1993d). Technicality and abstration: Language for the creation of specilized texts. In M. A. K. Halliday \& J. R. Martin (Eds.), Writing science: Literacy and discourse power (pp. 203-220). Washington, D.C: Falmer.

Martin, J. R. (2001). Language, register and genre. In A. Burns \& C. Coffin (Eds.), Analysing English in a global context: A reader (pp. 149-166). London: Routlege.

Martin, J. R. (2008). Incongruent and proud: De-vilifying 'nominalization'. Discourse Society, 19(6), 801-810. doi: 10.1177/0957926508095895

Martin, J. R., Matthiessen, C. M. I. M., \& Painter, C. (1997). Working with functional grammar. London: Arnold.

Martin, J. R., \& Rose, D. (2003). Working with discourse: Meaning beyond the clause. London: Continuum.

Martin, J. R., \& Rose, D. (2008). Genre relations: Mapping culture. London: Equinox.

Martin, P. (2006). Transitivity, mood, theme/rheme and lexical density/grammatical metaphor in newsweek magazine articles Retrieved 4th October, 2012, from

http://books.google.com.au/books?id=z6oc3_S1egcC\&printsec=frontcover\& $\mathrm{dq}=$ Transitivity, + Mood, + Theme/Rheme+and+Lexical+Density\&source=bl\&ot s=jiJhNVyyLd\&sig=CsTM9pmwXX7iC6AWbJd5t9FIhME\&hl=en\&sa=X\&ei=n5Ft UICWICSTiAfWsICWCQ\&ved=0CDEQ6AEwAA

Matthias, G. (2012). The typology of nominalization. Language and Linguistics, 13(4), 803-844.

McCabe, A. (2011). An introduction to linguistics and language studies. London: Equinox.

Meara, P., \& Miralpeix, I. (2004). D_Tools computer software, Lognostics (Centre for Applied Language Studies, University of Wales Swansea), Swansea. 
Miestamo, M. (2008). Grammatical complexity in a cross-linguistic perspective. In M. Miestamo, K. Sinnemäki \& F. Karlsson (Eds.), Language complexity: Typology, contact, change (pp. 23-42). Amsterdam: John Benjamins

Miestamo, M. (2009). Implicational hierarchies and grammatical complexity. In G. Sampson, D. Gil \& P. Trudgill (Eds.), Language complexity as an evolving variable (pp. 80-97). Oxford: Oxford University Press.

Minoo, A., \& Nikan, S. (2012). Textbook Evaluation: EFL Teachers' Perspectives on "Pacesetter Series". English Language Teaching, 5(7), 64-68.

Narelle, F. S., Leigh, N. W., Roslyn, K. G., \& Gillian, P. (1994). Analysis of student performance in statistics. Sydney: University of Technology.

Ngo, D. P. (2004). The interpersonal constiturets via. expressive means in utterrances (Doctoral dissertation), Vinh University, Vinh.

Nguyen, P. C. T. (2011a). An investigation into linguistic features of participants in the processes in English and Vietnamese from the functional grammar aspect (M.A), The College of Foreign Languages, Danang.

Nguyen, T. H. (1994). Đối chiếu Đề ngữ Anh Việt. (PhD thesis), Institute of Linguistics.

Nguyen, T. H. (2012a). An investigation into the structure of Theme and Rheme in English and Vietnamese political speeches (M.A), The College of Foreign Languages, Danang.

Nguyen, T. T. (2011b). A study on the structure of the speech "I have a dream" by Martin Luther King : A systemic functional grammar analysis. (M.A Thesis), University of Languages and International Studies, Hanoi.

Nguyen, T. X. M. (2012b). An investigation into projecting processes in English and Vietnamese short stories and novels. (M.A), The College of Foreign Languages, Danang

Nguyen, V. V. (2011c). An Investigation into nominalization in English and Vietnamese newspapers as grammatical metaphor device in the functional grammar perspective (M.A), The College of Foreign Languages, Danang.

Nichols, J. (2009). Linguistic complexity: a comprehensive definition and survey. In G. Sampson, D. Gil \& P. Trudgill (Eds.), Language complexity as an evolving variable (pp. 110-125). Oxford: Oxford University Press.

Nunan, D. (1992). Research methods in language learning. Cambridge: Cambridge University Press.

O'Loughlin, K. (1994). Lexical density in candidate output on two versions of an oral proficiency test. Melbourne papers in language teaching, 1(3), 26-48.

Oliver, S. (2007). Lexical density in oral versus written Rangi texts. SOAS Working Papers in Linguistics, 15, 173-184.

Ortega, L. (2003). Syntactic complexity measures and their relationship to $L 2$ proficiency: A research synthesis of college-level L2 writing Applied Linguistics, 24, 492-518.

Palmer, F. R. (1974). The English Verb. London: Longman. 
Ping, A. L. (2000). The inference-Boundary model: Reinterpreting Theme and Rheme. Language Sciences, 22(1), 1-26.

Quirk, R., Greenbaum, S., Leech, G. N., \& Svartvik, J. (1972). A grammar of contemporary English. Harlow: Longman.

Ravelli, L. (1988). Grammatical metaphor: An initial analysis. In E. H. Steiner \& R. Veltman (Eds.), Pragmatics, Discourse and Text. Some systemically-oriented approaches (pp. 133-147). London: Pinter.

Ravelli, L. (1999). Metaphor, mode and complexity: An exploration of co-varying patterns. Nottingham: Nottingham Trent University.

Ravelli, L. (2003). Renewal of connection: Integrating theory and practice in an understanding of grammatical metaphor. In A. Simon-Vandenbergen, M. Taverniers \& L. Ravelli (Eds.), Grammatical metaphor: Views from systemic functional linguistics (pp. 37-64). Amsterdam: John Benjamins.

Relja, V. (2007). On measuring language complexity as relative to the conveyed linguistic Information SKY Journal of Linguistics 20, 399-427.

Rimmer, W. (2008). Putting grammatical complexity in context. Literacy, 42(1), 2935. doi: 10.1111/j.1467-9345.2008.00478.x

Robins, R. H. (1989). General linguistics: An introductory survey (4th ed.). London: Longman.

Rose, D., \& Martin, J. R. (2012). Learning to write, reading to learn: Genre, knowledge and pedagogy in the Sydney school. Sheffield: Equinox.

Ryshina-Pankova, M. (2010). Toward mastering the discourses of reasoning: Use of grammatical metaphor at advanced levels of foreign language acquisition. The Modern Language Journal, 94(2), 181-197. doi: 10.1111/j.15404781.2010.01016.x

Siegel, J. 2012. Accounting for analyticity in creoles. In B. Kortmann and B. Szmrecsanyi (Eds), Linguistic complexity: Second language acquisition, indigenization, contact (pp.35-61). Berlin/Boston: de Gruyter.

Siewierska, A. (1991). Functional grammar. London: Routledge.

Simon-Vandenbergen, A., Taverniers, M., \& Ravelli, L. (2003). Grammatical metaphor: Views from systemic functional linguistics. Amsterdam: John Benjamins.

Smith, M. (1998). WordSmith tools, version 3.0, computer software. Oxford: Oxford University Press.

Stubbs, M. (1986). Lexical density: A technique and some findings. In M. Coulthard (Ed.), Talking about text (pp. 27-48). Birmingham: University of Birmingham: English Language Research.

Suter, W. N. (2012). An introduction to educational research: A critical thinking approach (2nd ed.). London: SAGE.

Taverniers, M. (2003). Grammatical metaphor in SFL: A historiograhy of the introduction and initial study of the concept. In A. Simon-Vandenbergen, M. 
Taverniers \& L. Ravelli (Eds.), Grammatical metaphor: Views from systemic functional linguistics. Amsterdam/Philadephia: John Benjamins.

Taverniers, M. (2006). Grammatical metaphor and lexical metaphor: Different perspectives on semantic variation. Neophilologus, 90(2), 321-332. doi: 10.1007/s11061-005-0531-y

Thai, M. D. (1998). A systemic functional interpretation of Vietnamese grammar. (Ph.D thesis), Sydney University.

Thai, M. D. (2004). Metafunctional profile of the grammar of Vietnamese. In A. Caffarel, J. R. Martin \& C. M. I. M. Matthiessen (Eds.), Language typology: A functional perspective (pp. 397-428). Amsterdam: John Benjamins.

Thompson, G. (1996). Introducing functional grammar. London: Arnold.

Thomson, E., \& Droga, L. (2012). Effective Academic Writing: An essay-writing workbook for school and university. Australia: Phoenix Education.

To, V. T. (2014a, 30 September - 2 October). Grammatical complexity of English textbooks: A comparative study of two book levels: Elementary and Preintermediate. Paper presented at the Annual National Conference of the Australian Systemic Functional Linguistics Association, The University of New South Wales, Sydney.

To, V. T. (2014b, 10th -15th August). Linguistic complexity in English textbooks: A functional grammar perspective. Paper presented at the 17th World Congress of the International Association of Applied Linguistics, Brisbane convention and exhibition centre, Brisbane.

To, V. T., Fan, S., \& Thomas, D. P. (2013). Lexical density and readability: A case study of English Textbooks. The Internet Journal of Language, Culture and Society(37), 61-71.

To, V. T., \& Lê, T. (2013, 1-3 October). Lexical density and readability: A case study of English textbooks. Paper presented at the Annual National Conference of the Australian Systemic Functional Linguistics Association, Australian Catholic University, Melbourne.

Ure, J. (1971). Lexical density and register differentiation. In G. E. Perren \& J. L. M.Trim (Eds.), Applications of linguistics (pp. 443-452). Cambridge: Cambridge University Press.

Vidaković, I., \& Barker, F. (2009). Lexical development across second language proficiency levels: a corpus-informed study. Paper presented at the Proceedings of The BAAL Annual Conference, Newcastle University.

Weaver, C., \& Weaver, C. (1998). Lessons to share on teaching grammar in context. Portsmouth: Boynton/Cook.

Wenyan, G. (2012). Nominalization in medical papers: A comparative study. Studies in Literature and Language, 4(1), 86-93.

Wiersma, W., \& Jurs, S. (2005). Research methods in education: An introduction (8th ed.). New York: Pearson. 
Wiersma, W., \& Jurs, S. G. (2009). Research methods in education: An introduction. New York: Pearson.

Wignell, P., Martin, J. K., \& Eggins, S. (1993). The discourse of geography: Ordering and explaining the experiential world. In M. A. K. Halliday \& J. K. Martin (Eds.), Writing science: Literacy and discursive power (pp. 136-165). Washington, D.C: Falmer.

Wu, J., \& Tang, L. (2010). Grammatical metaphor in news English discourse. 理论语 言学研究第, 4(1), 13-29.

Yaser, H. (2012). A comparative study of ideational grammatical metaphor in business and political texts. International Journal of Linguistics, 4(2), 348364.

Ye, R. (2010). The interpersonal metafunction analysis of Barack Obama's victory speech. English Language Teaching, 3(2), 146-151.

Yu, G. (2007). Lexical diversity in MELAB writing and speaking task performances. Spaan Fell Retrieved 29 September, 2012, from http://www.cambridgemichigan.org/sites/default/files/resources/SpaanPap ers/Spaan_V5_YuG.pdf

Yule, G. (1996). The study of language (2nd ed.). Cambridge: Cambridge University Press.

Zora , S., \& Johns-Lewis, C. (1989). Lexical density in interview and conversation. York Papers in Linguistics, 14, 89-100. 


\section{Appendix 1 Source of data}

\begin{tabular}{|c|c|c|c|}
\hline Text codes & Text titles & Pages & Books \\
\hline E1 & The Art of Palmistry & $66-67$ & 1 \\
\hline E2 & What's That Sound? & $102-103$ & 1 \\
\hline E3 & A Good Night's Sleep & $152-153$ & 1 \\
\hline E4 & A student budget & $32-33$ & 1 \\
\hline E5 & How Do You Celebrate? & $122-123$ & 1 \\
\hline E6 & The Age of Adulthood & $132-133$ & 1 \\
\hline P1 & Addicted To Chocolate? & $6-7$ & 2 \\
\hline $\mathrm{P} 2$ & Numerology-Using Numbers To Predict The Future & $56-57$ & 2 \\
\hline P3 & Is Your Diet Destroying The Environment? & $136-137$ & 2 \\
\hline P4 & Number and belief & $62-63$ & 2 \\
\hline P5 & Time for Work, And Time For Play & $82-83$ & 2 \\
\hline P5 & How Old is Old Enough? & $102-103$ & 2 \\
\hline 11 & Robotic Surgeons & $98-99$ & 3 \\
\hline 12 & The Challenges of Space Travel & $110-111$ & 3 \\
\hline 13 & How Good Is Your Memory? & $146-147$ & 3 \\
\hline 14 & Wedding Customs & $19-20$ & 3 \\
\hline 15 & Travel Manners & 51 & 3 \\
\hline 16 & Homeschooling-a Better Way to Learn? & $134-135$ & 3 \\
\hline U1 & Laugh and the World Laughs with You & $171-172$ & 4 \\
\hline U2 & Mind Like a Sieve? There's No Need to Worry & $177-178$ & 4 \\
\hline U3 & Genetically Modified Food & $128-129$ & 4 \\
\hline U4 & Creating a Global Resume & $2-3$ & 4 \\
\hline U5 & A House to Save the Earth & $87-88$ & 4 \\
\hline U6 & Caught in a Melting World & 198-199 & 4 \\
\hline
\end{tabular}




\section{Appendix 2 Raw data}

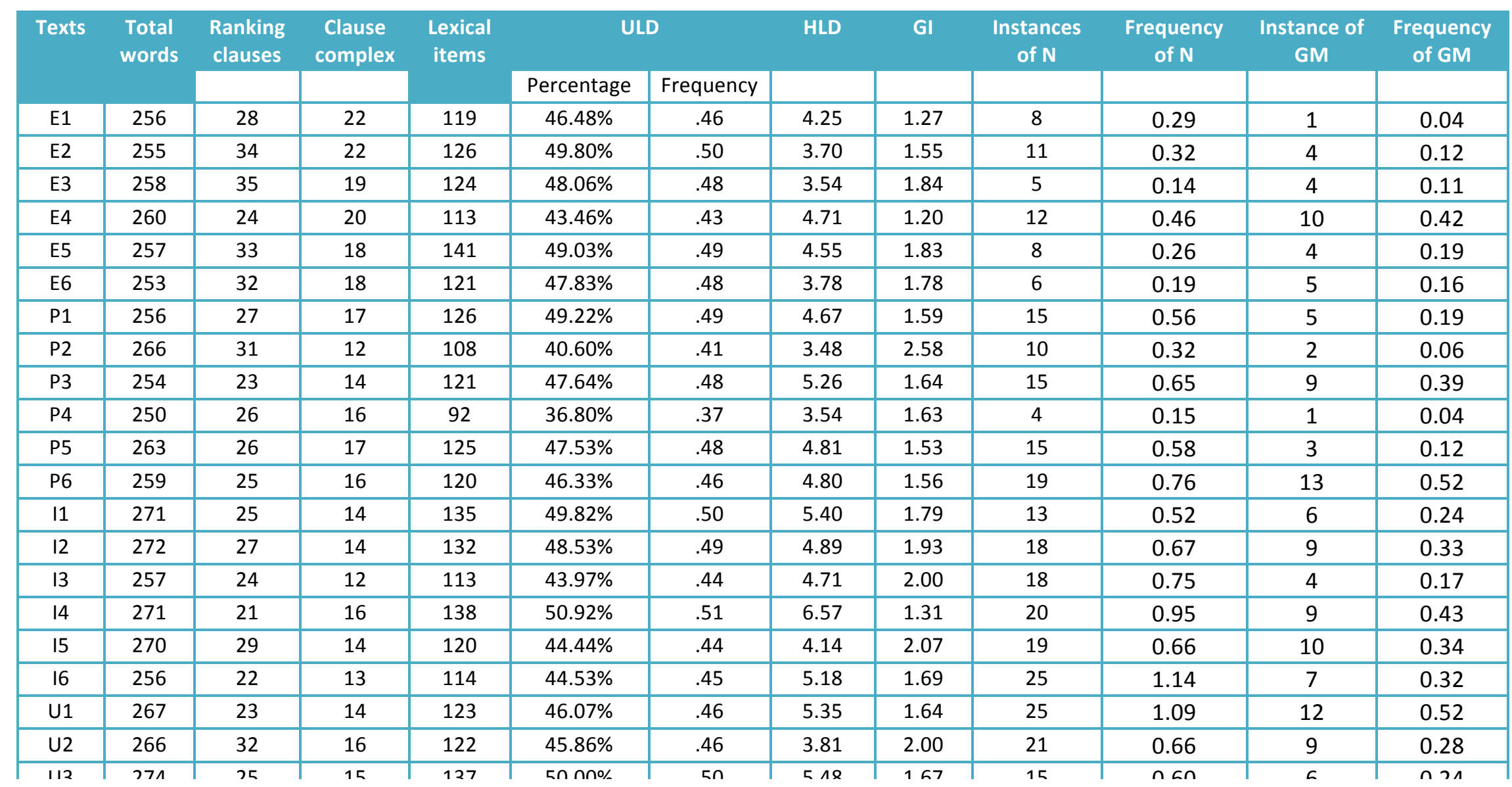




\section{Appendix 3 Instances and percentage of theme}

\begin{tabular}{|c|c|c|c|c|c|c|c|c|c|c|c|c|}
\hline \multirow[t]{3}{*}{ Texts } & \multirow{3}{*}{$\begin{array}{l}\text { Clause } \\
\text { Complex }\end{array}$} & \multirow{2}{*}{\multicolumn{2}{|c|}{ Simple themes }} & \multicolumn{6}{|c|}{ Multiple Themes } & \multirow{2}{*}{\multicolumn{2}{|c|}{ Clausal Theme }} & \multirow[t]{2}{*}{ Total Themes } \\
\hline & & & & \multicolumn{2}{|c|}{$\begin{array}{c}\text { Experiential } \\
\text { Theme }\end{array}$} & \multicolumn{2}{|c|}{$\begin{array}{l}\text { Interpersonal } \\
\text { Theme }\end{array}$} & \multicolumn{2}{|c|}{$\begin{array}{l}\text { Textual } \\
\text { Theme }\end{array}$} & & & \\
\hline & & $\mathrm{n}$ & $\%$ & $\mathrm{n}$ & $\%$ & $\mathrm{n}$ & $\%$ & $\mathrm{n}$ & $\%$ & $\mathrm{n}$ & $\%$ & $\mathrm{~N}$ \\
\hline E1 & 22 & 20 & $80.0 \%$ & 1 & $4.0 \%$ & 1 & $4.0 \%$ & 1 & $4.0 \%$ & 2 & $8.0 \%$ & 25 \\
\hline E2 & 23 & 23 & $67.6 \%$ & 5 & $14.7 \%$ & 0 & $0.0 \%$ & 5 & $14.7 \%$ & 1 & $2.9 \%$ & 34 \\
\hline E3 & 19 & 18 & $52.9 \%$ & 7 & $20.6 \%$ & 1 & $2.9 \%$ & 7 & $20.6 \%$ & 1 & $2.9 \%$ & 34 \\
\hline E4 & 20 & 21 & $84.0 \%$ & 2 & $8.0 \%$ & 0 & $0.0 \%$ & 2 & $8.0 \%$ & 0 & $0.0 \%$ & 25 \\
\hline E5 & 17 & 17 & $73.9 \%$ & 3 & $13.0 \%$ & 0 & $0.0 \%$ & 3 & $13.0 \%$ & 0 & $0.0 \%$ & 23 \\
\hline E6 & 18 & 17 & $45.9 \%$ & 10 & $27.0 \%$ & 0 & $0.0 \%$ & 10 & $27.0 \%$ & 0 & $0.0 \%$ & 37 \\
\hline P1 & 17 & 13 & $59.1 \%$ & 4 & $18.2 \%$ & 0 & $0.0 \%$ & 4 & $18.2 \%$ & 1 & $4.5 \%$ & 22 \\
\hline P2 & 12 & 10 & $47.6 \%$ & 5 & $23.8 \%$ & 0 & $0.0 \%$ & 5 & $23.8 \%$ & 1 & $4.8 \%$ & 21 \\
\hline P3 & 14 & 12 & $60.0 \%$ & 4 & $20.0 \%$ & 0 & $0.0 \%$ & 4 & $20.0 \%$ & 0 & $0.0 \%$ & 20 \\
\hline P4 & 16 & 16 & $51.6 \%$ & 7 & $22.6 \%$ & 1 & $3.2 \%$ & 7 & $22.6 \%$ & 0 & $0.0 \%$ & 31 \\
\hline P5 & 17 & 16 & $80.0 \%$ & 2 & $10.0 \%$ & 0 & $0.0 \%$ & 2 & $10.0 \%$ & 0 & $0.0 \%$ & 20 \\
\hline P6 & 16 & 16 & $72.7 \%$ & 3 & $13.6 \%$ & 0 & $0.0 \%$ & 3 & $13.6 \%$ & 0 & $0.0 \%$ & 22 \\
\hline 11 & 14 & 13 & $76.5 \%$ & 2 & $11.8 \%$ & 0 & $0.0 \%$ & 2 & $11.8 \%$ & 0 & $0.0 \%$ & 17 \\
\hline 12 & 14 & 11 & $47.8 \%$ & 5 & $21.7 \%$ & 1 & $4.3 \%$ & 4 & $17.4 \%$ & 2 & $8.7 \%$ & 23 \\
\hline 13 & 12 & 8 & $36.4 \%$ & 6 & $27.3 \%$ & 0 & $0.0 \%$ & 6 & $27.3 \%$ & 2 & $9.1 \%$ & 22 \\
\hline 14 & 16 & 14 & $66.7 \%$ & 3 & $14.3 \%$ & 0 & $0.0 \%$ & 3 & $14.3 \%$ & 1 & $4.8 \%$ & 21 \\
\hline 15 & 14 & 10 & $43.5 \%$ & 5 & $21.7 \%$ & 1 & $4.3 \%$ & 5 & $21.7 \%$ & 2 & $8.7 \%$ & 23 \\
\hline 16 & 13 & 13 & $61.9 \%$ & 4 & $19.0 \%$ & 0 & $0.0 \%$ & 4 & $19.0 \%$ & 0 & $0.0 \%$ & 21 \\
\hline U1 & 14 & 14 & $70 \%$ & 3 & $15.0 \%$ & 0 & $0.0 \%$ & 3 & $15.0 \%$ & 0 & $0.0 \%$ & 20 \\
\hline U2 & 16 & 12 & $48.0 \%$ & 6 & $24.0 \%$ & 0 & $0.0 \%$ & 6 & $24.0 \%$ & 1 & $4.0 \%$ & 25 \\
\hline U3 & 15 & 8 & $44.4 \%$ & 4 & $22.2 \%$ & 0 & $0.0 \%$ & 4 & $22.2 \%$ & 2 & $11.1 \%$ & 18 \\
\hline U4 & 17 & 15 & $78.9 \%$ & 2 & $10.5 \%$ & 0 & $0.0 \%$ & 2 & $10.5 \%$ & 0 & $0.0 \%$ & 19 \\
\hline U5 & 13 & 8 & $47.1 \%$ & 3 & $17.6 \%$ & 0 & $0.0 \%$ & 3 & $17.6 \%$ & 3 & $17.6 \%$ & 17 \\
\hline U6 & 15 & 13 & $46.4 \%$ & 6 & $21.4 \%$ & 1 & $0.0 \%$ & 8 & $28.6 \%$ & 1 & $3.6 \%$ & 29 \\
\hline
\end{tabular}




\section{Appendix 4 One-way ANOVA test on linguistic complexity across levels}

\begin{tabular}{|c|c|c|c|c|c|c|c|c|c|}
\hline & & \multirow[t]{2}{*}{$\mathbf{N}$} & \multirow[t]{2}{*}{ Mean } & \multirow[t]{2}{*}{$\begin{array}{l}\text { Std. } \\
\text { Deviation }\end{array}$} & \multirow[t]{2}{*}{$\begin{array}{l}\text { Std. } \\
\text { Error }\end{array}$} & \multicolumn{2}{|c|}{$\begin{array}{c}\text { 95\% Confidence Interval for } \\
\text { Mean }\end{array}$} & \multirow[t]{2}{*}{ Minimum } & \multirow[t]{2}{*}{ Maximum } \\
\hline & & & & & & Lower Bound & Upper Bound & & \\
\hline \multirow[t]{5}{*}{ Ure's lexical density } & Elementary & 6 & .4733 & .02503 & .01022 & .4471 & .4996 & .43 & .50 \\
\hline & Pre-intermediate & 6 & .4483 & .04792 & .01956 & .3980 & .4986 & .37 & .49 \\
\hline & Intermediate & 6 & .4717 & .03189 & .01302 & .4382 & .5051 & .44 & .51 \\
\hline & Upper-intermediate & 6 & .4800 & .02098 & .00856 & .4580 & .5020 & .46 & .51 \\
\hline & Total & 24 & .4683 & .03319 & .00677 & .4543 & .4823 & .37 & .51 \\
\hline \multirow[t]{5}{*}{ Halliday's lexical density } & Elementary & 6 & 3.9933 & .42368 & .17297 & 3.5487 & 4.4380 & 3.54 & 4.71 \\
\hline & Pre-intermediate & 6 & 4.4267 & .73788 & .30124 & 3.6523 & 5.2010 & 3.48 & 5.26 \\
\hline & Intermediate & 6 & 5.1483 & .81989 & .33472 & 4.2879 & 6.0088 & 4.14 & 6.57 \\
\hline & Upper-intermediate & 6 & 5.0550 & .73034 & .29816 & 4.2886 & 5.8214 & 3.81 & 5.77 \\
\hline & Total & 24 & 4.6558 & .80778 & .16489 & 4.3147 & 4.9969 & 3.48 & 6.57 \\
\hline \multirow[t]{5}{*}{ Grammatical intricacy } & Elementary & 6 & 1.5750 & .29932 & .12220 & 1.2609 & 1.8891 & 1.20 & 1.88 \\
\hline & Pre-intermediate & 6 & 1.7550 & .40629 & .16587 & 1.3286 & 2.1814 & 1.53 & 2.58 \\
\hline & Intermediate & 6 & 1.7983 & .27644 & .11285 & 1.5082 & 2.0884 & 1.31 & 2.07 \\
\hline & Upper-intermediate & 6 & 1.7250 & .28431 & .11607 & 1.4266 & 2.0234 & 1.29 & 2.08 \\
\hline & Total & 24 & 1.7133 & .31130 & .06354 & 1.5819 & 1.8448 & 1.20 & 2.58 \\
\hline \multirow{4}{*}{ Nominalisation } & Pre-intermediate & 6 & .5033 & .22580 & .09218 & .2664 & .7403 & .15 & .76 \\
\hline & Intermediate & 6 & .7817 & .22516 & .09192 & .5454 & 1.0180 & .52 & 1.14 \\
\hline & Upper-intermediate & 6 & .7433 & .33720 & .13766 & .3895 & 1.0972 & .44 & 1.23 \\
\hline & Total & 24 & .5750 & .30668 & .06260 & .4455 & .7045 & .14 & 1.23 \\
\hline \multirow[t]{5}{*}{ Grammatical metaphor } & Elementary & 6 & .1517 & .13834 & .05648 & .0065 & .2968 & .04 & .42 \\
\hline & Pre-intermediate & 6 & .2200 & .19380 & .07912 & .0166 & .4234 & .04 & .52 \\
\hline & Intermediate & 6 & .3050 & .08961 & .03658 & .2110 & .3990 & .17 & .43 \\
\hline & Upper-intermediate & 6 & .3400 & .18772 & .07664 & .1430 & .5370 & .08 & .59 \\
\hline & Total & 24 & .2542 & .16545 & .03377 & .1843 & .3240 & .04 & .59 \\
\hline
\end{tabular}




\begin{tabular}{|c|c|c|c|c|c|c|}
\hline \multicolumn{7}{|c|}{ ANOVA } \\
\hline & & $\begin{array}{l}\text { Sum of } \\
\text { Squares }\end{array}$ & df & $\begin{array}{l}\text { Mean } \\
\text { Square }\end{array}$ & $\mathrm{F}$ & Sig. \\
\hline \multirow[t]{3}{*}{ Ure's lexical density } & Between Groups & .003 & 3 & .001 & 1.045 & .394 \\
\hline & Within Groups & .022 & 20 & .001 & & \\
\hline & Total & .025 & 23 & & & \\
\hline \multirow[t]{3}{*}{ Halliday's lexical density } & Between Groups & 5.360 & 3 & 1.787 & 3.704 & .029 \\
\hline & Within Groups & 9.648 & 20 & .482 & & \\
\hline & Total & 15.008 & 23 & & & \\
\hline \multirow[t]{3}{*}{ Grammatical intricacy } & Between Groups & .169 & 3 & .056 & .548 & .655 \\
\hline & Within Groups & 2.060 & 20 & .103 & & \\
\hline & Total & 2.229 & 23 & & & \\
\hline \multirow[t]{3}{*}{ Nominalisation } & Between Groups & 1.009 & 3 & .336 & 5.830 & .005 \\
\hline & Within Groups & 1.154 & 20 & .058 & & \\
\hline & Total & 2.163 & 23 & & & \\
\hline \multirow[t]{3}{*}{ Grammatical metaphor } & Between Groups & .130 & 3 & .043 & 1.731 & .193 \\
\hline & Within Groups & .500 & 20 & .025 & & \\
\hline & Total & .630 & 23 & & & \\
\hline
\end{tabular}




\section{Appendix 5 Tukey post-hoc test}

\begin{tabular}{|c|c|c|c|c|c|c|c|}
\hline \multirow[t]{2}{*}{ Dependent Variable } & \multirow[t]{2}{*}{ (I) Levels of texts } & \multirow[t]{2}{*}{ (J) Levels of texts } & \multirow[t]{2}{*}{ Mean Difference (I-J) } & \multirow[t]{2}{*}{ Std. Error } & \multirow[t]{2}{*}{ Sig. } & \multicolumn{2}{|c|}{ 95\% Confidence Interval } \\
\hline & & & & & & Lower Bound & Upper Bound \\
\hline \multirow[t]{12}{*}{ Ure's lexical density } & \multirow[t]{3}{*}{ Elementary } & Pre-intermediate & .02500 & .01910 & .568 & -.0285 & .0785 \\
\hline & & Intermediate & .00167 & .01910 & 1.000 & -.0518 & .0551 \\
\hline & & $\begin{array}{l}\text { Upper- } \\
\text { intermediate }\end{array}$ & -.00667 & .01910 & .985 & -.0601 & .0468 \\
\hline & \multirow{3}{*}{ Pre-intermediate } & Elementary & -.02500 & .01910 & .568 & -.0785 & .0285 \\
\hline & & Intermediate & -.02333 & .01910 & .621 & -.0768 & .0301 \\
\hline & & $\begin{array}{l}\text { Upper- } \\
\text { intermediate }\end{array}$ & -.03167 & .01910 & .371 & -.0851 & .0218 \\
\hline & \multirow[t]{3}{*}{ Intermediate } & Elementary & -.00167 & .01910 & 1.000 & -.0551 & .0518 \\
\hline & & Pre-intermediate & .02333 & .01910 & .621 & -.0301 & .0768 \\
\hline & & $\begin{array}{l}\text { Upper- } \\
\text { intermediate }\end{array}$ & -.00833 & .01910 & .971 & -.0618 & .0451 \\
\hline & \multirow{3}{*}{$\begin{array}{l}\text { Upper- } \\
\text { intermediate }\end{array}$} & Elementary & .00667 & .01910 & .985 & -.0468 & .0601 \\
\hline & & Pre-intermediate & .03167 & .01910 & .371 & -.0218 & .0851 \\
\hline & & Intermediate & .00833 & .01910 & .971 & -.0451 & .0618 \\
\hline \multirow[t]{9}{*}{ Halliday's lexical density } & \multirow[t]{3}{*}{ Elementary } & Pre-intermediate & -.43333 & .40100 & .705 & -1.5557 & .6890 \\
\hline & & Intermediate & $-1.15500^{*}$ & .40100 & .042 & -2.2774 & -.0326 \\
\hline & & $\begin{array}{l}\text { Upper- } \\
\text { intermediate }\end{array}$ & -1.06167 & .40100 & .068 & -2.1840 & .0607 \\
\hline & \multirow[t]{3}{*}{ Pre-intermediate } & Elementary & .43333 & .40100 & .705 & -.6890 & 1.5557 \\
\hline & & Intermediate & -.72167 & .40100 & .303 & -1.8440 & .4007 \\
\hline & & $\begin{array}{l}\text { Upper- } \\
\text { intermediate }\end{array}$ & -.62833 & .40100 & .419 & -1.7507 & .4940 \\
\hline & \multirow[t]{3}{*}{ Intermediate } & Elementary & $1.15500^{*}$ & .40100 & .042 & .0326 & 2.2774 \\
\hline & & Pre-intermediate & .72167 & .40100 & .303 & -.4007 & 1.8440 \\
\hline & & $\begin{array}{l}\text { Upper- } \\
\text { intermediate }\end{array}$ & .09333 & .40100 & .995 & -1.0290 & 1.2157 \\
\hline
\end{tabular}




\begin{tabular}{|c|c|c|c|c|c|c|c|}
\hline \multirow[t]{5}{*}{ Dependent Variable } & \multirow[t]{2}{*}{ (I) Levels of texts } & \multirow[t]{2}{*}{ (J) Levels of texts } & \multirow[t]{2}{*}{ Mean Difference (I-J) } & \multirow[t]{2}{*}{ Std. Error } & \multirow[t]{2}{*}{ Sig. } & \multicolumn{2}{|c|}{ 95\% Confidence Interval } \\
\hline & & & & & & Lower Bound & Upper Bound \\
\hline & \multirow{3}{*}{$\begin{array}{l}\text { Upper- } \\
\text { intermediate }\end{array}$} & Elementary & 1.06167 & .40100 & .068 & -.0607 & 2.1840 \\
\hline & & Pre-intermediate & .62833 & .40100 & .419 & -.4940 & 1.7507 \\
\hline & & Intermediate & -.09333 & .40100 & .995 & -1.2157 & 1.0290 \\
\hline \multirow[t]{12}{*}{ Grammatical intricacy } & \multirow[t]{3}{*}{ Elementary } & Pre-intermediate & -.18000 & .18527 & .767 & -.6986 & .3386 \\
\hline & & Intermediate & -.22333 & .18527 & .631 & -.7419 & .2952 \\
\hline & & $\begin{array}{l}\text { Upper- } \\
\text { intermediate }\end{array}$ & -.15000 & .18527 & .849 & -.6686 & .3686 \\
\hline & \multirow[t]{3}{*}{ Pre-intermediate } & Elementary & .18000 & .18527 & .767 & -.3386 & .6986 \\
\hline & & Intermediate & -.04333 & .18527 & .995 & -.5619 & .4752 \\
\hline & & $\begin{array}{l}\text { Upper- } \\
\text { intermediate }\end{array}$ & .03000 & .18527 & .998 & -.4886 & .5486 \\
\hline & \multirow[t]{3}{*}{ Intermediate } & Elementary & .22333 & .18527 & .631 & -.2952 & .7419 \\
\hline & & Pre-intermediate & .04333 & .18527 & .995 & -.4752 & .5619 \\
\hline & & $\begin{array}{l}\text { Upper- } \\
\text { intermediate }\end{array}$ & .07333 & .18527 & .978 & -.4452 & .5919 \\
\hline & \multirow{3}{*}{$\begin{array}{l}\text { Upper- } \\
\text { intermediate }\end{array}$} & Elementary & .15000 & .18527 & .849 & -.3686 & .6686 \\
\hline & & Pre-intermediate & -.03000 & .18527 & .998 & -.5486 & .4886 \\
\hline & & Intermediate & -.07333 & .18527 & .978 & -.5919 & .4452 \\
\hline \multirow[t]{13}{*}{ Nominalisation } & \multirow[t]{3}{*}{ Elementary } & Pre-intermediate & -.23167 & .13869 & .364 & -.6198 & .1565 \\
\hline & & Intermediate & $-.51000^{*}$ & .13869 & .007 & -.8982 & -.1218 \\
\hline & & $\begin{array}{l}\text { Upper- } \\
\text { intermediate }\end{array}$ & $-.47167^{*}$ & .13869 & .014 & -.8598 & -.0835 \\
\hline & \multirow[t]{3}{*}{ Pre-intermediate } & Elementary & .23167 & .13869 & .364 & -.1565 & .6198 \\
\hline & & Intermediate & -.27833 & .13869 & .219 & -.6665 & .1098 \\
\hline & & $\begin{array}{l}\text { Upper- } \\
\text { intermediate }\end{array}$ & -.24000 & .13869 & .335 & -.6282 & .1482 \\
\hline & \multirow[t]{3}{*}{ Intermediate } & Elementary & $.51000^{*}$ & .13869 & .007 & .1218 & .8982 \\
\hline & & Pre-intermediate & .27833 & .13869 & .219 & -.1098 & .6665 \\
\hline & & $\begin{array}{l}\text { Upper- } \\
\text { intermediate }\end{array}$ & .03833 & .13869 & .992 & -.3498 & .4265 \\
\hline & \multirow{4}{*}{$\begin{array}{l}\text { Upper- } \\
\text { intermediate }\end{array}$} & Elementary & $.47167^{*}$ & .13869 & .014 & .0835 & .8598 \\
\hline & & Pre-intermediate & .24000 & .13869 & .335 & -.1482 & .6282 \\
\hline & & Intermediate & -.03833 & .13869 & .992 & -.4265 & .3498 \\
\hline & & Intermediate & -.03833 & .16553 & .995 & -.5585 & .4818 \\
\hline
\end{tabular}




\begin{tabular}{|c|c|c|c|c|c|c|c|}
\hline \multirow[t]{2}{*}{ Dependent Variable } & \multirow[t]{2}{*}{ (I) Levels of texts } & \multirow[t]{2}{*}{ (J) Levels of texts } & \multirow[t]{2}{*}{ Mean Difference (I-J) } & \multirow[t]{2}{*}{ Std. Error } & \multirow[t]{2}{*}{ Sig. } & \multicolumn{2}{|c|}{ 95\% Confidence Interval } \\
\hline & & & & & & Lower Bound & Upper Bound \\
\hline \multirow[t]{13}{*}{ Grammatical metaphor } & \multirow[t]{3}{*}{ Elementary } & Pre-intermediate & -.06833 & .09127 & .876 & -.3238 & .1871 \\
\hline & & Intermediate & -.15333 & .09127 & .360 & -.4088 & .1021 \\
\hline & & $\begin{array}{l}\text { Upper- } \\
\text { intermediate }\end{array}$ & -.18833 & .09127 & .199 & -.4438 & .0671 \\
\hline & \multirow[t]{3}{*}{ Pre-intermediate } & Elementary & .06833 & .09127 & .876 & -.1871 & .3238 \\
\hline & & Intermediate & -.08500 & .09127 & .789 & -.3405 & .1705 \\
\hline & & $\begin{array}{l}\text { Upper- } \\
\text { intermediate }\end{array}$ & -.12000 & .09127 & .565 & -.3755 & .1355 \\
\hline & \multirow{3}{*}{ Intermediate } & Elementary & .15333 & .09127 & .360 & -.1021 & .4088 \\
\hline & & Pre-intermediate & .08500 & .09127 & .789 & -.1705 & .3405 \\
\hline & & $\begin{array}{l}\text { Upper- } \\
\text { intermediate }\end{array}$ & -.03500 & .09127 & .980 & -.2905 & .2205 \\
\hline & \multirow{4}{*}{$\begin{array}{l}\text { Upper- } \\
\text { intermediate }\end{array}$} & Elementary & .18833 & .09127 & .199 & -.0671 & .4438 \\
\hline & & Pre-intermediate & .12000 & .09127 & .565 & -.1355 & .3755 \\
\hline & & Intermediate & .03500 & .09127 & .980 & -.2205 & .2905 \\
\hline & & Intermediate & .03500 & .08492 & .975 & -.2444 & .3144 \\
\hline
\end{tabular}




\section{Appendix 6 One-way ANOVA test on linguistic complexity in science-related and non-science texts}

\begin{tabular}{|c|c|c|c|c|c|c|c|c|c|}
\hline \multicolumn{10}{|c|}{ Descriptive statistics } \\
\hline & & \multirow[t]{2}{*}{$\mathbf{N}$} & \multirow[t]{2}{*}{ Mean } & \multirow[t]{2}{*}{$\begin{array}{c}\text { Std. } \\
\text { Deviation }\end{array}$} & \multirow[t]{2}{*}{$\begin{array}{l}\text { Std. } \\
\text { Error }\end{array}$} & \multicolumn{2}{|c|}{$\begin{array}{l}\text { 95\% Confidence Interval for } \\
\text { Mean }\end{array}$} & \multirow[t]{2}{*}{ Minimum } & \multirow[t]{2}{*}{ Maximum } \\
\hline & & & & & & Lower Bound & Upper Bound & & \\
\hline \multirow[t]{3}{*}{ Ure's lexical density } & Science & 12 & .4725 & .02768 & .00799 & .4549 & .4901 & .41 & .50 \\
\hline & Non-science & 12 & .4642 & .03872 & .01118 & .4396 & .4888 & .37 & .51 \\
\hline & Total & 24 & .4683 & .03319 & .00677 & .4543 & .4823 & .37 & .51 \\
\hline \multirow[t]{3}{*}{ Halliday's lexical density } & Science & 12 & 4.5483 & .75953 & .21926 & 4.0658 & 5.0309 & 3.48 & 5.48 \\
\hline & Non-science & 12 & 4.7633 & .87306 & .25203 & 4.2086 & 5.3181 & 3.54 & 6.57 \\
\hline & Total & 24 & 4.6558 & .80778 & .16489 & 4.3147 & 4.9969 & 3.48 & 6.57 \\
\hline \multirow[t]{3}{*}{ Grammatical intricacy } & Science & 12 & 1.7858 & .33030 & .09535 & 1.5760 & 1.9957 & 1.27 & 2.58 \\
\hline & Non-science & 12 & 1.6408 & .28647 & .08270 & 1.4588 & 1.8228 & 1.20 & 2.08 \\
\hline & Total & 24 & 1.7133 & .31130 & .06354 & 1.5819 & 1.8448 & 1.20 & 2.58 \\
\hline \multirow{2}{*}{ Nominalisation } & Non-science & 12 & .6075 & .35602 & .10277 & .3813 & .8337 & .15 & 1.23 \\
\hline & Total & 24 & .5750 & .30668 & .06260 & .4455 & .7045 & .14 & 1.23 \\
\hline \multirow[t]{3}{*}{ Grammatical metaphor } & Science & 12 & .2242 & .14100 & .04070 & .1346 & .3138 & .04 & .52 \\
\hline & Non-science & 12 & .2842 & .18812 & .05431 & .1646 & .4037 & .04 & .59 \\
\hline & Total & 24 & .2542 & .16545 & .03377 & .1843 & .3240 & .04 & .59 \\
\hline
\end{tabular}




\begin{tabular}{|c|c|c|c|c|c|c|}
\hline \multicolumn{7}{|c|}{ ANOVA } \\
\hline & & $\begin{array}{l}\text { Sum of } \\
\text { Squares }\end{array}$ & $d f$ & $\begin{array}{l}\text { Mean } \\
\text { Square }\end{array}$ & $\mathrm{F}$ & Sig. \\
\hline \multirow[t]{3}{*}{ Ure's lexical density } & Between Groups & .000 & 1 & .000 & .368 & .550 \\
\hline & Within Groups & .025 & 22 & .001 & & \\
\hline & Total & .025 & 23 & & & \\
\hline \multirow[t]{3}{*}{ Halliday's lexical density } & Between Groups & .277 & 1 & .277 & .414 & .526 \\
\hline & Within Groups & 14.730 & 22 & .670 & & \\
\hline & Total & 15.008 & 23 & & & \\
\hline \multirow[t]{3}{*}{ Grammatical intricacy } & Between Groups & .126 & 1 & .126 & 1.320 & .263 \\
\hline & Within Groups & 2.103 & 22 & .096 & & \\
\hline & Total & 2.229 & 23 & & & \\
\hline \multirow[t]{3}{*}{ Nominalisation } & Between Groups & .025 & 1 & .025 & .261 & .615 \\
\hline & Within Groups & 2.138 & 22 & .097 & & \\
\hline & Total & 2.163 & 23 & & & \\
\hline \multirow[t]{3}{*}{ Grammatical metaphor } & Between Groups & .022 & 1 & .022 & .782 & .386 \\
\hline & Within Groups & .608 & 22 & .028 & & \\
\hline & Total & .630 & 23 & & & \\
\hline
\end{tabular}




\section{Appendix 7 Pearson correlations test}

\begin{tabular}{|c|c|c|c|c|c|c|}
\hline & & $\begin{array}{l}\text { Ure's lexical } \\
\text { density }\end{array}$ & $\begin{array}{c}\text { Halliday's lexical } \\
\text { density }\end{array}$ & $\begin{array}{c}\text { Grammatical } \\
\text { intricacy }\end{array}$ & Nominalisation & $\begin{array}{c}\text { Grammatical } \\
\text { metaphor }\end{array}$ \\
\hline \multirow[t]{3}{*}{ Ure's lexical density } & Pearson Correlation & 1 & $.489^{*}$ & -.260 & .129 & .112 \\
\hline & Sig. (2-tailed) & & .015 & .221 & .548 & .602 \\
\hline & $\mathrm{N}$ & 24 & 24 & 24 & 24 & 24 \\
\hline \multirow[t]{3}{*}{ Halliday's lexical density } & Pearson Correlation & $.489^{*}$ & 1 & $-.465^{*}$ & $.740^{* *}$ & $.615^{* *}$ \\
\hline & Sig. (2-tailed) & .015 & & .022 & .000 & .001 \\
\hline & $\mathrm{N}$ & 24 & 24 & 24 & 24 & 24 \\
\hline \multirow[t]{3}{*}{ Grammatical intricacy } & Pearson Correlation & -.260 & $-.465^{*}$ & 1 & -.236 & -.298 \\
\hline & Sig. (2-tailed) & .221 & .022 & & .267 & .157 \\
\hline & $\mathrm{N}$ & 24 & 24 & 24 & 24 & 24 \\
\hline \multirow[t]{3}{*}{ Nominalisation } & Pearson Correlation & .129 & $.740^{* *}$ & -.236 & 1 & $.796^{* *}$ \\
\hline & Sig. (2-tailed) & .548 & .000 & .267 & & .000 \\
\hline & $\mathrm{N}$ & 24 & 24 & 24 & 24 & 24 \\
\hline \multirow[t]{3}{*}{ Grammatical metaphor } & Pearson Correlation & .112 & $.615^{* *}$ & -.298 & $.796^{* *}$ & 1 \\
\hline & Sig. (2-tailed) & .602 & .001 & .157 & .000 & \\
\hline & $\mathrm{N}$ & 24 & 24 & 24 & 24 & 24 \\
\hline
\end{tabular}




\section{Appendix 8 Components of a multiple Theme}

\begin{tabular}{|c|c|c|c|}
\hline Metafunction & Component of Theme & Type & Typical words \\
\hline \multirow{19}{*}{ Textual } & Continuative & & yes, no, well, oh, now, okay \\
\hline & \multirow{2}{*}{$\begin{array}{l}\text { Conjunction } \\
\text { (structural Theme) }\end{array}$} & structural conjunction & and, or, but, so, because, while, when, after, before, if, since, that, whether \\
\hline & & conjunctive preposition & instead of, on, after, before, because of, despite \\
\hline & \multirow[t]{2}{*}{ Wh-relative } & Definite & which, who, that, whose, when, where (why, how), \\
\hline & & Indefinite & whatever, whichever, whoever, whosever, whenever, however \\
\hline & \multirow[t]{14}{*}{ Conjunctive Adjunct } & Appositive & that is, in other words, for instance, \\
\hline & & Corrective & rather, at least, to be precise \\
\hline & & Dismissive & in any case, anyway, leaving that aside \\
\hline & & Summative & briefly, to sum up, in conclusion \\
\hline & & Verificative & actually, in fact, as a matter of fact \\
\hline & & Additive & also, moreover, in addition, besides \\
\hline & & Adversative & on the other hand, however, conversely \\
\hline & & Variative & instead, alternatively \\
\hline & & Temporal & meanwhile, before that, later on, next, soon, finally \\
\hline & & Comparative & likewise, in the same way \\
\hline & & Causal & therefore, for this reason, as a result, with this in mind \\
\hline & & Conditional & in that case, under the circumstances, otherwise \\
\hline & & Concessive & nevertheless, despite that \\
\hline & & Respective & in this respect, as far as that's concerned \\
\hline
\end{tabular}




\begin{tabular}{|c|c|c|c|}
\hline Metafunction & Component of Theme & Type & Typical words \\
\hline \multirow{16}{*}{ Interpersonal } & \multirow[t]{14}{*}{ Modal Adjunct } & Probability & probably, possibly, certainly, perhaps, maybe \\
\hline & & Usuality & usually, sometimes, always, never, often, seldom \\
\hline & & Typicality & occasionally, generally, regularly, for the most part \\
\hline & & Obviousness & of course, surely, obviously, clearly \\
\hline & & Opinion & in my opinion, personally, to mind my \\
\hline & & Admission & frankly, to be honest, to tell you the truth \\
\hline & & Persuasion & honestly, really, believe me, seriously \\
\hline & & Entreaty & Please, kindly \\
\hline & & Presumption & evidently, apparently, no doubt, presumably \\
\hline & & Desirability & (un)fortunately, to my delight/distress, regrettably, hopefully \\
\hline & & Reservation & at first, tentatively, provisionally, looking back on it \\
\hline & & Validation & broadly speaking, in general, on the whole, strictly speaking, in principle \\
\hline & & Evaluation & (un)wisely, understandably, mistakenly, foolishly \\
\hline & & Prediction & to my surprise, surprisingly, as expected, by chance \\
\hline & Vocative & $\begin{array}{l}\text { Nominal group (proper } \\
\text { tittle, position) }\end{array}$ & Mr Wolf, Dr David \\
\hline & $\begin{array}{l}\text { Finite (operator) in yes/no } \\
\text { interrogative }\end{array}$ & Auxiliary verbs & $\begin{array}{l}\text { do, does, did, is, am, are, have, has, had, will, would, can could, may, might, } \\
\text { must, should, shall, ought }\end{array}$ \\
\hline
\end{tabular}




\section{Appendix 9 The $3 \times 3$ toolkit}

\begin{tabular}{|c|c|c|c|}
\hline Metafunctions & $\begin{array}{l}\text { Social activity: Genre \& Register } \\
\text { (whole text) }\end{array}$ & $\begin{array}{l}\text { Discourse semantics } \\
\text { (phase) }\end{array}$ & $\begin{array}{l}\text { Grammar and expression } \\
\text { (clauses and sentences) }\end{array}$ \\
\hline $\begin{array}{l}\text { Ideational } \\
\text { meanings }\end{array}$ & $\begin{array}{l}\text { - Do the beginning, middle, } \\
\text { stages of texts build knowledge } \\
\text { relevant to discipline specific } \\
\text { topics and purposes? } \\
\text { - Does the language construct the } \\
\text { technical, specialised and formal } \\
\text { knowledge of the discipline area } \\
\text { (field)? }\end{array}$ & $\begin{array}{l}\text { - Are topics defined and classified according to } \\
\text { discipline-specific criteria? } \\
\text { - Is information related in logical relationships } \\
\text { (e.g., time, cause, consequences, comparison)? } \\
\text { - Are tables, diagrams, lists, formulae, examples } \\
\text { and quotes logically integrated with verbal text } \\
\text { (e.g., to extend, report, specific or qualify } \\
\text { points)? } \\
\text { - Is information extended across phases (e.g., in } \\
\text { terms of general/specific; point/elaboration; } \\
\text { evidence/interpretation; claim/evaluation)? }\end{array}$ & $\begin{array}{l}\text { - Do elements within noun groups effectively } \\
\text { describe and clarify specialised terms (e.g., } \\
\text { classifying adjectives, defining clauses)? } \\
\text { - Do verb groups express processes relevant to the } \\
\text { genre (e.g., defining, classifying, cause and effect, } \\
\text { reporting?) } \\
\text { - Are circumstances (e.g., prepositional phrases) } \\
\text { used to specify location of time, place, etc. where } \\
\text { necessary? } \\
\text { - Is tense consistent with genre and expressed } \\
\text { through logically structured verbal elements? } \\
\text { - Are nouns typically generalised and determined } \\
\text { correctly in terms of mass/count, singular/plural, } \\
\text { generic/specific? } \\
\text { - Is vocabulary discipline specific and formal (e.g., } \\
\text { no contractions or phrasal verbs? }\end{array}$ \\
\hline
\end{tabular}




\begin{tabular}{|c|c|c|c|}
\hline Metafunctions & $\begin{array}{l}\text { Social activity: Genre } \& \text { Register } \\
\text { (whole text) }\end{array}$ & $\begin{array}{l}\text { Discourse semantics } \\
\text { (phase) }\end{array}$ & $\begin{array}{l}\text { Grammar and expression } \\
\text { (clauses and sentences) }\end{array}$ \\
\hline $\begin{array}{l}\text { Interpersonal } \\
\text { meanings }\end{array}$ & $\begin{array}{l}\text { - Do texts convince the reader by } \\
\text { moving points or positions } \\
\text { forward across stages (e.g., by } \\
\text { amplifying, justifying, reinforcing, } \\
\text { and acknowledge experts in the } \\
\text { field)? } \\
\text { - Does the language present } \\
\text { points and arguments in } \\
\text { authoritative, impersonal and } \\
\text { objective ways (tenor)? }\end{array}$ & $\begin{array}{l}\text { - Does the interaction with the reader focus on } \\
\text { giving information (i.e., no questions or } \\
\text { commands)? } \\
\text { - Is the subject matter evaluated according to } \\
\text { institutional values (e.g. relevance, validity, } \\
\text { significance)? } \\
\text { - Are grading resources used to imply evaluation? } \\
\text { - Do patterns of evaluation develop the writers' } \\
\text { stances within and across phases? } \\
\text { - Are authoritative resources used to support } \\
\text { points? } \\
\text { - Does the writer include and control the voices } \\
\text { of external sources to develop points and guide } \\
\text { the reader forwards a preferred position? }\end{array}$ & $\begin{array}{l}\text { - Do Mood choices realise information giving } \\
\text { function (i.e., subject ^ finite)? } \\
\text { - Do Subjects and verbs agree in number? } \\
\text { - Are evaluations often achieved infusing lexical } \\
\text { items with degrees of intensity and attitude? } \\
\text { - Are interpersonal objective metaphors used to } \\
\text { negotiate opinions and recommendations (e.g., "It } \\
\text { is clear that" or "There is a need for..." rather "I } \\
\text { think" or "you should")? } \\
\text { - Is source material incorporated into text through } \\
\text { correctly formed quotes, paraphrasing and } \\
\text { summarising? } \\
\text { - Are conjunctions and continuatives used to } \\
\text { monitor and adjust reader expectations? } \\
\text { - Are sources cited correctly (e.g. using projection) } \\
\text { and referenced according to discipline } \\
\text { specifications (e.g., LMA?) }\end{array}$ \\
\hline $\begin{array}{l}\text { Textual } \\
\text { meanings }\end{array}$ & $\begin{array}{l}\text { - In the content previewed in the } \\
\text { beginning stage (introduction) } \\
\text { and reviewed in the end stage } \\
\text { (i.e., conclusion)? } \\
\text { - Are global headings and }\end{array}$ & $\begin{array}{l}\text { - Are ideas developed within phases (e.g., } \\
\text { paragraph) with topic and summary sentences } \\
\text { used to predict and summarise? } \\
\text { - Does information flow logically from sentence } \\
\text { to sentence across phases? }\end{array}$ & $\begin{array}{l}\text { - Do choice of unmarked Theme sustain orientation } \\
\text { to the topic, selection of marked Theme marks } \\
\text { shifts in orientation? } \\
\text { - Is grammatical metaphor used to rework } \\
\text { processes, qualities and logical relations as }\end{array}$ \\
\hline
\end{tabular}




\begin{tabular}{|c|c|c|c|}
\hline Metafunctions & $\begin{array}{l}\text { Social activity: Genre } \& \text { Register } \\
\text { (whole text) }\end{array}$ & $\begin{array}{c}\text { Discourse semantics } \\
\text { (phase) }\end{array}$ & $\begin{array}{l}\text { Grammar and expression } \\
\text { (clauses and sentences) }\end{array}$ \\
\hline & $\begin{array}{l}\text { abstracts used to signal layout of } \\
\text { longer texts? } \\
\text { - Does the language construct } \\
\text { coherent, signposted and } \\
\text { abstract texts (mode)? }\end{array}$ & $\begin{array}{l}\text { - Are entities and parts of text tracked through } \\
\text { cohesive resources (e.g., reference, institution } \\
\text { and repetition) } \\
\text { - Are internal conjunctions used to organise text? } \\
\text { - Does information flow from more dense } \\
\text { abstract terms in topic sentences to expanded } \\
\text { concrete terms in subsequent sentences? }\end{array}$ & $\begin{array}{l}\text { abstract entities and relationships (e.g., use } \\
\text { nominalisation to express processes as nouns } \\
\text { rather than verbs)? } \\
\text { - Is active and passive voice used to adjust } \\
\text { information focus and Theme? } \\
\text { - Are articles and pronouns used to keep track of } \\
\text { participants? } \\
\text { - Do spelling, punctuation, bullets, paragraphing } \\
\text { and layout assist information structure? } \\
\text { - Are abstract nouns used to generalise and track } \\
\text { ideas? }\end{array}$ \\
\hline
\end{tabular}

